JOSÉ CARLOS VAZ

\title{
MANUTENÇÃO DE SISTEMAS PRODUTIVOS: UM ESTUDO SOBRE A GESTÃO DA DISPONIBILIDADE DE EQUIPAMENTOS
}

Dissertação apresentada à Escola Politécnica da Universidade de São Paulo para obtenção do título de Mestre em Engenharia 
JOSÉ CARLOS VAZ

\section{MANUTENÇÃO DE SISTEMAS PRODUTIVOS: UM ESTUDO SOBRE A GESTÃO DA DISPONIBILIDADE DE EQUIPAMENTOS}

Dissertação apresentada à Escola Politécnica da Universidade de São Paulo para obtenção do título de Mestre em Engenharia

Área de Concentração:

Engenharia de Produção

Orientador:

Prof. Dr. Dario Ikuo Miyake 


\section{FICHA CATALOGRÁFICA}

\section{Vaz, José Carlos}

Manutenção de sistemas produtivos: um estudo sobre a gestão da disponibilidade de equipamentos. São Paulo, 2003. 203p.

Dissertação (Mestrado) - Escola Politécnica da Universidade de São Paulo. Departamento de Engenharia de Produção.

1. Gestão 2. Manutenção 3. Disponibilidade I. Universidade de São Paulo. Escola Politécnica. Departamento de Engenharia de Produção II.t 


\section{DEDICATÓRIA}

Aos meus familiares e amigos, pelo estímulo ao aperfeiçoamento de meus conhecimentos. 


\section{AGRADECIMENTOS}

Ao Prof. Dr. Dario Ikuo Miyake pelo apoio e orientação, sempre oportuna e segura, para a elaboração deste trabalho.

Ao Prof. Dr. Nilton Nunes Toledo, pelo incentivo para o início deste trabalho.

Ao Eng. Luiz G. G. Zanetti, pelo estímulo dado durante o decorrer do projeto.

Aos Professores do Departamento de Produção, pela colaboração sempre presente.

Aos representantes das empresas pesquisadas, que tornaram possível o estudo de campo deste trabalho.

Aos funcionários do Departamento de Produção, sempre prestativos.

A todos que, de alguma forma, deram seu apoio para a realização deste trabalho. 


\section{RESUMO}

Este trabalho traduz um estudo de casos, que procura pesquisar e sistematizar o conhecimento sobre a gestão do estado dos equipamentos para atender às suas funções produtivas, isto é, uma gestão orientada para resultados. A função manutenção tem sido considerada como aquela que agrega conhecimentos e atividades para assegurar a disponibilidade operacional dos sistemas produtivos, dentro de padrões de desempenho antecipadamente especificados, ao menor custo possível e atendendo a requisitos pertinentes de segurança. Nesse contexto, pretendese caracterizar de que modo abordagens ou políticas, adotadas por empresas selecionadas, que requerem o exercício da função manutenção, se vinculam a indicadores de disponibilidade. Ao longo do trabalho, a disponibilidade é tratada como um "indicador de resultado" das atividades de manutenção. Transparece da literatura que a análise da tendência desse indicador deve orientar as tomadas de decisão referentes às ações sobre o equipamento. Desse modo, compete verificar se, e como, é feito o vínculo entre esse indicador e decisões relativas à manutenção, sem perder de vista a produtividade da empresa. Assim, descreve-se o contexto em que se inserem a manutenção e a disponibilidade e são identificados elementos que, interferindo na disponibilidade, permitem desdobrá-la e associá-la a uma estrutura analítica que auxilie o levantamento e encaminhamento de análises sobre os dados obtidos no campo, para melhor percepção do tratamento dado à disponibilidade. Para possibilitar o encaminhamento do estudo de casos e a definição das proposições de pesquisa, a função manutenção é associada a um processo, em que se usa o indicador de disponibilidade como feedback, para a otimização do próprio processo de operação da função manutenção, bem como da especificação dos recursos de entrada desse processo. Três proposições são estruturadas e verificadas em quatro empresas que tipificam dois grupos distintos de operações, focalizando o tratamento dado à disponibilidade, e, no seu âmbito, o tratamento de compromissos de gestão e do estudo do ciclo de vida do equipamento. Para possibilitar uma avaliação objetiva das variáveis das proposições da pesquisa, que são de natureza essencialmente qualitativa, encontrou-se, no Capability Maturity Model (CMM), um modelo conceitual que, por suas características evolutivas, forneceu inspiração para estruturar o necessário instrumento de avaliação. A conclusão da pesquisa revela que as proposições de estudo não se confirmaram de forma plena, apontando sensível diferença de seu atendimento quando se faz a comparação entre os dois grupos de empresas, deixando, assim, um espaço em aberto para novas pesquisas. 


\begin{abstract}
This work is focused on a case study development. It intends to research and systematize knowledge about the state or condition management of equipment in order to fulfill their productive functions. That means that this management is result oriented. When the maintenance function is defined, it has been considered as the one that associates knowledge and activities in order to assure the operational availability of the productive systems. This operational availability has to be conducted within previously specified performance standards, at the lowest cost possible, and according to established safety requirements. Within this context, this research intends to describe how the approaches, or basic strategies, adopted by selected companies, which require the maintenance function, are attached to availability indicators. It is implied by the theory observed in literature, the trend analysis of this indicator should guide the decision making process concerning actions about the equipment. It is important to examine if, and how, the relationship between this indicator and the decisions involving maintenance is performed, without loosing sight of the company productivity. Therefore, it is observed the context where maintenance and availability are present and identify elements that contribute, because of their properties, to the operational availability of the productive equipment. As part of the theoretical framework, elements were identified that, because of their availability interference, allowed to unfold this availability and associate it to an analytical structure. This contributed to the data survey process and proceed to the analysis of the data obtained in the field, in order to improve the perception of the treatment given to availability. In order to allow the case study orientation and the definition of research propositions, the maintenance function is modeled as a process, where the availability indicator is used as feedback for the optimization of the operation process of the maintenance function itself, as well as an input resource specification of this process. Three propositions are studied and observed, in four companies that represent two different operation groups. So, it is possible to study how they treat availability, management trade-offs and the equipment life cycle. It was stated the need to define a structured methodology to make an objective evaluation of the investigated organizations possible, as research propositions, are essentially of qualitative nature. The Capability Maturity Model (CMM), a conceptual model, inspired, due to its up-grading characteristics, to structure the necessary evaluation tool. The research's conclusion appoints that the propositions were not completely confirmed. There is sensible difference between the two groups of organizations. So there is a potential of new researches.
\end{abstract}




\section{SUMÁRIO}

LISTA DE FIGURAS

LISTA DE TABELAS

LISTA DE ABREVIATURAS E SIGLAS

1 - INTRODUÇÃO

1.1 - Apresentação, Objetivos e Estrutura da Dissertação 01

1.1.1 - Apresentação 01

$\begin{array}{ll}1.1 .2 \text { - Objetivos } & 02\end{array}$

1.1.3 - Estrutura da Dissertação 03

1.2 - Relevância, Evolução e Impacto da Manutenção e da Disponibilidade $\quad 04$

1.2.1 - Relevância da Manutenção e da Disponibilidade 06

1.2.2 - Evolução da Manutenção $\quad 09$

1.2.3 - Impacto da Disponibilidade no Resultado da Empresa 10

2 - CONTEXTO DE INSERÇÃO DA MANUTENÇÃO E DA

DISPONIBILIDADE

2.1 - A Empresa vista como Sistema 13

2.2 - As Empresas e as Estratégias Competitivas $\quad 15$

2.3 - Sistemas de Manufatura, Estratégias de Manufatura e Disponibilidade $\quad 16$

2.4 - As Alterações de Estado como razão das atividades de Manutenção 21

2.4.1 - O Equipamento como um Agregado de Componentes 21

2.4.2 - Esforços e Solicitações sobre os Componentes do Equipamento 22

2.4.3 - As Alterações de Estado dos Componentes 23

2.4.4 - O Ciclo de Vida do Equipamento 23

2.4.4.1 - Caracterização de Ciclo de Vida 23

2.4.4.2 - Esforço Integrado para Aprimoramento da Disponibilidade 27

2.4.4.3 - Gestão do Ciclo de Vida 28

2.4.5 - Gestão do Estado dos componentes do Equipamento 31

2.5 - Mensuração e Indicadores de Desempenho 31

2.6 - A Disponibilidade como Contribuinte para a Produtividade 35 
3 - DETALHAMENTO DA DISPONIBILIDADE E DO PROCESSO DE MANUTENÇÃO $\quad \mathbf{3 7}$

3.1 - Levantamento e Análise dos Elementos Componentes da Disponibilidade 37

3.1.1 - Caracterização da Confiabilidade, da Taxa de Falhas e do Tempo Médio entre Falhas (MTBF) 37

3.1.1.1 - Conceitos e Evolução 37

3.1.1.2 - Aplicação das Técnicas de Confiabilidade associadas à Manutenção 38

3.1.1.3 - Critérios de Definição de Confiabilidade $\quad 40$

3.1.1.4 - Critérios de Avaliação de Confiabilidade de Equipamentos 41

3.1.2 - Caracterização da Manutenibilidade e do Tempo Médio de Reparo (MTTR) 42

3.1.2.1 - Desmembramento do Tempo de Reparo 42

3.1.2.2 - Fatores que interferem no Tempo de Reparo 43

3.1.3 - Extensão da Aplicação da Disponibilidade 43

3.1.3.1 - Interpretação da Disponibilidade 45

3.1.3.2 - Disponibilidade no Serviço de Transporte, sobre Trilhos, de Passageiros 46

3.2 -Estrutura Analítica da Disponibilidade $\quad 47$

3.3 - Operações Elementares, Políticas e Abordagens de Gestão da Manutenção 50

3.3.1 - Operações Elementares de Manutenção 51

3.3.2 - Caracterização de Políticas de Manutenção 53

3.3.2.1 - Manutenção Corretiva

3.3.2.1.1 - Manutenção Corretiva não Planejada 56

3.3.2.1.2 - Manutenção Corretiva Planejada 57

3.3.2.2 - Manutenção Preventiva 58

3.3.2.3 - Manutenção Preditiva $\quad 60$

3.3.2.4 - Manutenção Detectiva

3.3.2.5 - Manutenção Planejada 62

3.3.2.6 - Prevenção de Manutenção 62

3.3.2.7 - Política “operar até quebrar” 62

3.3.3 - Gestão do Processo da Manutenção 62

3.3.4 - Técnicas para Melhoria da Disponibilidade $\quad 64$

3.3.4.1 - Técnicas para Melhoria da Confiabilidade 65

3.3.4.2 - Técnicas para Melhoria da Manutenibilidade e do MTTR 66 
3.3.5 - Abordagens de Gestão da Manutenção 67

3.3.5.1 - Manutenção Produtiva $\quad 67$

3.3.5.2 - TPM: Total Productive Maintenance 67

3.3.5.3 - RCM: Reliability Centered Maintenance $\quad 69$

3.4 - Compromissos de Gestão da Manutenção 71

3.4.1 - Compromisso com Custos 72

3.4.2 - Compromisso com Segurança

3.4.3 - Compromisso com o Processo de Produção 78

3.4.4 - Compromisso com Determinações Legais e Normas Técnicas 80

3.4.5 - Compromisso com o Ambiente 80

3.5 - Sistema de Informação

4 - A ESTRUTURA CONCEITUAL DA PESQUISA E AS PROPOSIÇÕES 86

4.1 - Estruturação da Pesquisa e das Proposições 86

4.2 - Proposições da Pesquisa 96

4.2.1 - Proposição P1 96

4.2.2 - Proposição P2 98

$\begin{array}{ll}4.2 .3 \text { - Proposição P3 } & 100\end{array}$

5 - METODOLOGIA DA PESQUISA $\quad 102$

5.1 - Estratégia da Pesquisa 102

5.1.1 - Critérios para a Definição da Abordagem da Pesquisa 102

$\begin{array}{ll}5.1 .2 \text { - Validade e Confiabilidade da Pesquisa } & 104\end{array}$

$\begin{array}{ll}\text { 5.1.2.1 - Validade Construtiva } & 104\end{array}$

5.1.2.2 - Validade Interna 106

5.1.2.3 - Validade Externa 106

5.1.2.4 - Confiabilidade do Estudo 107

$\begin{array}{ll}5.1 .3 \text { - Pesquisa Qualitativa e Pesquisa Quantitativa } & 107\end{array}$

5.1.4 - Definições Operacionais 108

$\begin{array}{ll}\text { 5.1.4.1 - Dados Qualitativos } & 110\end{array}$

5.1.4.2 - Dados Quantitativos 110

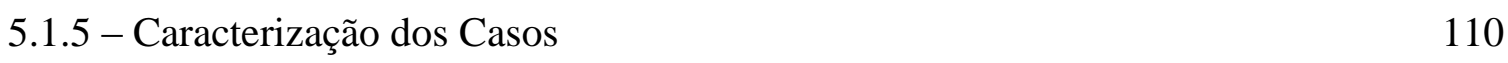

$\begin{array}{ll}\text { 5.1.5.1 - Empresa TPT1 } & 111\end{array}$

$\begin{array}{ll}\text { 5.1.5.2 - Empresa TPT2 } & 113\end{array}$ 
5.1.5.3 - Empresa IPA1

5.1.5.4 - Empresa IPA2

5.1.6 - Procedimentos Analíticos

5.1.7 - Escala de Avaliação das Variáveis da Pesquisa

5.2 - Instrumento de Avaliação das Variáveis

5.2.1 - O Modelo CMM (Modelo de Maturidade da Capacidade)

5.2.2 - Quadro Referencial de Avaliação das Variáveis

\section{6 - PESQUISA DE CAMPO E ANÁLISE dOS CASOS VISANDO À}

\section{VERIFICAÇÃO DAS PROPOSIÇÕES}

6.1 - Agenda das Entrevistas

6.2 - Desenvolvimento das Entrevistas e Coleta de Dados

6.3 - Organização e Análise dos Dados

6.4 - Avaliação das Variáveis da Pesquisa

6.5 - Análise dos Casos e das Proposições

6.5.1 - Análise do Grupo TPT

6.5.2 - Análise do Grupo IPA

6.5.3 - Análise da Proposição P1

6.5.4 - Análise da Proposição P2

6.5.5 - Análise da Proposição P3

7.1 - Implicações e Extensão dos Resultados Obtidos 148

7.2 - Delimitação do Escopo da Pesquisa

7.3 - Revisão Crítica do Estudo

7.4 - Tendências

7.5 - Continuidade da Pesquisa 


\section{LISTA DE FIGURAS}

Figura 1.1 Impacto da Disponibilidade no Lucro $\quad 11$

Figura 2.1 Inserção da Manutenção no Sistema de Manufatura 18

Figura 2.2 Índice do Desempenho Operacional Global 19

Figura 2.3 Aprimoramento e Evolução da Confiabilidade e do MTTR 29

Figura 3.1 Estrutura Analítica da Disponibilidade $\quad 49$

Figura 3.2 Compromisso entre Custo e Níveis de Manutenção Preventiva e $\begin{array}{ll}\text { Corretiva } & 73\end{array}$

Figura 3.3 Informação para Gestão da Manutenção 82

Figura 3.4 Contexto Operacional do Processo de Manutenção 83

$\begin{array}{lll}\text { Figura 4.1 } & \text { Estrutura Conceitual da Pesquisa }\end{array}$

Figura 4.2.a Abrangência da Proposição P1 94

Figura 4.2.b Abrangência da Proposição P2 95

Figura 4.2.c Abrangência da Proposição P3 95

$\begin{array}{lll}\text { Figura 5.1 Níveis de Maturidade do CMM } & 117\end{array}$

Figura 5.2 Quadro Referencial para Avaliação das Variáveis da Pesquisa 120

Figura 6.1 Avaliação das Variáveis de P1 133

Figura 6.2 Médias das Avaliações das Variáveis de P2 para cada $\begin{array}{ll}\text { Compromisso } & 134\end{array}$

Figura 6.3 Avaliação das Variáveis de P3 135 


\section{LISTA DE TABELAS}

Tabela 1.1 Evolução da Manutenção

Tabela 1.2 Impacto da Disponibilidade nos Processos de Manutenção e de Operação

Tabela 2.1 Fatores Intervenientes na Evolução da Taxa de Falhas e do MTTR ao Longo do Ciclo de Vida

Tabela 3.1 Fatores Intervenientes no Tempo de Reparo

Tabela 3.2 Operações Elementares e Políticas de Manutenção 55

Tabela 5.1 Situações Relevantes para Diferentes Estratégias de Pesquisa 102

Tabela 5.2 Táticas do Estudo de Caso para Teste de Qualidade do Projeto de $\begin{array}{ll}\text { Pesquisa } & 105\end{array}$

Tabela 5.3 Características das Empresas Selecionadas para a Pesquisa 112

Tabela 6.1 Avaliação das Variáveis da Proposição P1 129

Tabela 6.2 Avaliação das Variáveis da Proposição P2 130

Tabela 6.2.a Média das Avaliações das Variáveis para cada Compromisso 131

Tabela 6.3 Tabela 6.3 - Avaliação das Variáveis da Proposição P3 132 


\section{LISTA DE ABREVIATURAS E SIGLAS}

AAR

ABNT

AGMA

AIEE

ANSI

ASLE

CMM

CQ

DIN

FMEA

FMECA

FTA

IPA

ISO

$\mathrm{MC}$

MMT

MP

MTBF

MTBM

MTTR

NBR

NEMA

NLGI

PCP

PDCA

PM
American Association of Railroads

Associação Brasileira de Normas Técnicas

American Gear Manufacturers Association

American Institute of Electrical Engineers

American National Standard Institute

American Society of Lubrication Engineers

Capability Maturity Model

Controle de Qualidade

Deutsches Institute Für Normung

Failure Mode and Effect Analysis (Análise do Modo e Efeito de Falhas)

Failure Mode and Effect and Critical Analysis (Análise do Modo, Efeito e Criticidade de Falhas)

Failure Tree Analysis (Análise da Árvore de Falhas)

Indústria de Produtos Alimentícios

International Organization for Standardization

Manutenção Corretiva

Mean Maintenance Time

Manutenção Preventiva

Mean Time Between Failures

Mean Time Between Maintenance

Mean Time To Repair

Norma Brasileira

National Electrical Manufacturers Association

National Lubricating Grease Institute

Planejamento e Controle da Produção

Plan, Do, Check, Act

Prevenção de Manutenção 


$\begin{array}{ll}\text { RCM } & \text { Reliability Centered Maintenance } \\ \text { RMSP } & \text { Região Metropolitana de São Paulo } \\ \text { SAE } & \text { Society of Automotive Engineers } \\ \text { SEI } & \text { Software Engineering Institute } \\ \text { SM } & \text { Sistema de Manufatura } \\ \text { TPM } & \text { Total Productive Maintenance } \\ \text { TPT } & \text { Transporte de Passageiros sobre Trilhos }\end{array}$




\section{1 - INTRODUÇÃO}

\section{1 - Apresentação, Objetivos e Estrutura da Dissertação}

\subsection{1 - Apresentação}

Ao se iniciar a pesquisa para este trabalho, o propósito era estudar as atividades de manutenção visando ao desenvolvimento de uma "engenharia de disponibilidade", meta que no decorrer do tempo se mostrou ambiciosa. Pensava-se em desenvolver, a partir da teoria, uma contribuição direta para disseminação de uma atitude mais pró-ativa, dirigida a resultados, como substituta do termo "manutenção" no cotidiano das empresas. "Manutenção", no entender do autor desta pesquisa, apresenta uma conotação "conservadora". Como se verá, será atingida uma etapa intermediária desse projeto.

Para isso, foi necessário consolidar um significado para a "disponibilidade". A partir da literatura pesquisada, ela se posiciona como um indicador chave da qualidade das operações desenvolvidas no âmbito da função manutenção, aqui considerada como uma "prestadora de serviços" para a função produção.

A busca dessa consolidação firmou-se, particularmente, pelos estudos sobre indicadores de produtividade associados aos sistemas de produção (MUSCAT e FLEURY, 1993), pelos estudos da disponibilidade (ZARIFIAN, 1999), pelos estudos vinculados à organização da operação de serviços (JOHNSTON e CLARK, 2002), e pelos estudos referentes a riscos relacionados com concepção ergonômica do trabalho (KLETZ, 1993). Sendo a disponibilidade um indicador, no contexto da tecnologia da informação (PETINON e SHIMIZU, 2001), firmou-se a necessidade de se caracterizar um Sistema de Informação que o forneça. Aspectos da organização do trabalho (MARX, 1998) também apontam para a necessidade de considerá-la, quando do estabelecimento da organização para a execução de trabalhos referentes à função manutenção.

A pesquisa da literatura teve, então, seu foco dirigido para a disponibilidade, considerando-a como um fator contribuinte para a produtividade. Na pesquisa, apenas uma proposição de delineamento de uma estruturação analítica da 
disponibilidade foi inicialmente observada, apresentando fatores que a influenciam (KELLY, 1980, p.5). Decidiu-se, então, levantar um embasamento teórico da função manutenção e da disponibilidade, de modo a melhor aprofundar-se no desdobramento dos fatores que interferem na disponibilidade, numa abordagem sistêmica que leva em consideração o processo desenvolvido pela função manutenção e seu contexto ambiental.

A pesquisa desse embasamento teórico é complementada com a investigação, na prática, de como esses fatores são efetivamente "trabalhados", de modo particular, no âmbito das tomadas de decisão referentes ao exercício da função manutenção.

A manutenção tem sido entendida como uma função de apoio à função produção. Assim, enquanto a manutenção é uma função no âmbito da empresa, a disponibilidade é um indicador associado aos resultados obtidos por esta função. Coloca-se, então, o desafio de se pesquisar como a compilação, registro, e aplicação de conclusões das análises dessa indicação de resultado contribuirão para a melhor gestão das atividades de manutenção e para a produtividade da empresa.

\subsection{2 - Objetivos}

Em função do exposto, foram estabelecidos os seguintes objetivos para o trabalho de pesquisa:

a) apresentar o direcionamento da teoria da manutenção na bibliografia investigada;

b) estruturar o conhecimento e as tendências de tratamento da disponibilidade na literatura;

c) verificar como o indicador de disponibilidade é aplicado pelas empresas estudadas, nas tomadas de decisão;

d) verificar até que nível o embasamento teórico está sendo aplicado em empresas industriais e/ou de serviços de transporte, com a intenção de identificar:

- posturas de gestão em face dos estágios de ciclo de vida do equipamento;

- operações, políticas e abordagens de gestão adotadas no âmbito da função manutenção;

- tipos de operações de manutenção, diferenciando as de inspeção das de intervenção; 
- funções de apoio (planejamento e controle, engenharia, suprimentos, e qualidade);

- existência de sistema de informação integrando Manutenção, Produção e Suprimentos;

- consideração do contexto ambiental em que está inserido o processo de manutenção.

e) Analisar as empresas estudadas com relação às abordagens de manutenção adotadas, principalmente se dirigidas de modo explícito à disponibilidade;

f) verificar aspectos comuns e diferenciados entre os tratamentos dados pelas empresas para a disponibilidade;

g) apresentar conclusões, em função da comparação entre a teoria e a prática.

Desse modo, a motivação fundamental da pesquisa é verificar como a disponibilidade dos sistemas e equipamentos produtivos é abordada e tratada no âmbito do planejamento e gestão da manutenção das empresas.

Para que esses objetivos sejam atingidos, num primeiro passo, são levantados aspectos, disponíveis na literatura, relacionados com a manutenção e a disponibilidade, e formulada uma estrutura analítica de fatores componentes da disponibilidade no contexto das atividades de manutenção. A partir daí, através de uma estrutura conceitual baseada em mecanismo de controle e de elaboração de proposições a serem verificadas no âmbito de quatro empresas, objetos de estudos, desenvolve-se uma análise crítica de como a disponibilidade é tratada nas tomadas de decisão, procurando, assim, confrontar a relevância que lhe é atribuída na prática com aquela apontada na base teórica levantada.

\subsection{3 - Estrutura da Dissertação}

$\mathrm{O}$ contexto de inserção da disponibilidade é apresentado no Capítulo 2. O tratamento da disponibilidade leva em conta o ambiente de competição em que se inserem as empresas. Apresenta-se também "a máquina". Sem compreendê-la, não será possível uma atuação eficaz da função manutenção. A máquina (equipamento produtivo, ou simplesmente equipamento) é a razão da existência da função manutenção. O conceito de ciclo de vida do equipamento é apresentado neste 
Capítulo. Essas considerações convergem para um estudo da disponibilidade, sob o enfoque de ser ela tanto uma meta como um produto das atividades de manutenção e, também, um contribuinte para a produtividade.

O Capítulo 3 coloca em foco a disponibilidade, apresentando aspectos conceituais levantados na literatura e formas de sua interpretação, encerrando-se com a idealização de um modelo detalhado de estrutura analítica de fatores que nela interferem.

O mesmo Capítulo 3 contempla ainda o embasamento teórico referente às atividades de manutenção, essenciais para se assegurar de nível de disponibilidade adequado. Procura-se situá-las como função, apresentando seus tipos de operações elementares e diferenciando as operações de inspeção das de intervenção. De uma forma compatível com a visão sistêmica da empresa, apresenta-se uma estrutura conceitual do contexto operacional integrado das atividades de Manutenção, Produção e Suprimentos.

No Capítulo 4, são apresentadas a estrutura conceitual da pesquisa e as proposições, objetos de estudo, baseadas em ações e elementos associados a um mecanismo de controle de gestão e aprimoramento do processo de manutenção, utilizando a disponibilidade como indicador de resultado.

O Capítulo 5 indica a metodologia da pesquisa usada para o trabalho, justificando-se a adoção da estratégia de estudo de casos múltiplos e destacando-se a apresentação de um instrumento de avaliação de dados, inspirado na natureza evolutiva do CMM (Capability Maturity Model).

Em seqüência, no Capítulo 6, contempla-se a verificação das proposições de pesquisa e também os quadros para a análise crítica comparativa. Uma análise crítica entre o embasamento teórico e o observado na prática das empresas é conduzida. Finalmente, o Capítulo 7 levanta as implicações para a gestão da manutenção, conclusões e limitações de pesquisa.

\section{2 - Relevância, Evolução e Impacto da Manutenção e da Disponibilidade}

HIPKIN e DE COCK (2000, p.278) apontam que organizações manufatureiras estão sendo pressionadas para dar uma melhor atenção à função manutenção. Para justificar essa afirmação, apontam diversas razões: o acirramento 
da competição que demanda controle rigoroso de custos, com a Manutenção respondendo com uma participação cada vez maior nos custos operacionais; instalações automatizadas que exigem disponibilidade e confiabilidade, da planta e dos equipamentos, mais elevadas; acidentes relacionados com as condições de segurança e com o ambiente que têm sido cada vez mais associados às falhas de equipamentos; e uma reavaliação das práticas de manutenção que tem sido provocada por necessidade de melhor compreensão das falhas de equipamentos.

Os mesmos autores, ainda, afirmam que pressões competitivas obrigaram as organizações de manufatura a pesquisar todos os aprimoramentos possíveis e, assim, continuamente buscar novas intervenções de gestão para aprimorar suas operações. Como a gestão dos ativos físicos, na atualidade, responde por um significativo crescimento na participação dos custos operacionais, mais atenção está sendo dirigida ao campo de estudos da manutenção.

Logo, essas considerações permitem afirmar que as organizações industriais existem em função do lucro, que é obtido por meio da agregação de valor, ao desenvolverem processos de transformação de matérias-primas em produtos acabados e, para isso, se apóiam no uso racional de equipamentos e mão-de-obra.

O lucro pode ser avaliado pela diferença entre a receita da venda de produtos e seus custos de fabricação e comercialização. A rentabilidade é influenciada por muitos fatores, entre os quais podem ser citados a demanda do mercado, o preço do produto, o volume de produção e outros custos relacionados com o investimento, a vida útil e a operação dos equipamentos. A manutenção está correlacionada com a rentabilidade, à medida que influencia na capacidade de produção e no custo operacional dos equipamentos. As atividades de manutenção visam a assegurar o desempenho e a disponibilidade dos equipamentos para a produção, mas, ao mesmo tempo, contribuem para acrescer os custos de fabricação. Portanto, cabe à manutenção industrial, enquanto função organizacional, procurar atingir um equilíbrio entre esses efeitos, maximizando a sua contribuição na rentabilidade da empresa.

A correlação entre os trabalhos de manutenção e a rentabilidade tem se intensificado à medida que as instalações industriais têm se tornado cada vez maiores e mais automatizadas e, conseqüentemente, seus custos de paralisação cada vez mais 
onerosos e a qualidade dos produtos mais dependentes das condições dos processos. Com isso, se por um lado, o sistema e as atividades de manutenção tornaram-se mais críticos à produção, por outro lado, tornaram-se mais sofisticados e caros.

Assim, para melhorar a rentabilidade, economias substanciais podem ser conseguidas através do aperfeiçoamento da gestão da manutenção e de um maior cuidado para com os fatores que, presentes ao longo dos estágios do ciclo de vida dos equipamentos, irão interferir nos resultados operacionais.

Diversos são os problemas que surgem ao longo do ciclo de vida dos equipamentos, demandando a devida atenção por parte dos dirigentes industriais. Muitas empresas falham ao adotar a postura, meramente reativa, de tomar contramedidas conforme problemas relacionados com as condições dos equipamentos emergem com a sua utilização. Um problema tipicamente menosprezado é que, ao se iniciar a utilização operacional de um novo equipamento, não se alcança, de imediato, um regime equilibrado de disponibilidade e produção. A demora para se atingir condições operacionais adequadas pode comprometer, por exemplo, a rentabilidade esperada para um dado produto.

Nesse contexto, a disponibilidade dos equipamentos para a produção é um fator fundamental para o sucesso da empresa. Para que o funcionamento do equipamento, dentro das especificações estabelecidas, seja gerido de modo eficaz é imprescindível investigar o potencial de ocorrência de falhas que podem interferir na sua disponibilidade operacional, da qual depende a produtividade.

\subsection{1 - Relevância da Manutenção e da Disponibilidade}

A preocupação com a gestão da função manutenção é demonstrada por dezenas de publicações, particularmente nas últimas décadas. Uma seleção de conceitos de manutenção comprova a importância dada a essa função, também caracterizando, de forma explícita ou implícita, a relevância da disponibilidade do equipamento.

A disponibilidade pode ser associada a expressões como: "confiabilidade e manutenibilidade", "funcionamento regular", "condições de uso operacional", "atendimento continuado às funções especificadas", "desempenho das funções para as quais o equipamento foi projetado" e "atendimento a um processo de produção ou 
de serviço". Essas expressões estão presentes em conceitos de manutenção, formulados nas últimas três décadas, entre os quais alguns foram selecionados e são apresentados a seguir, na ordem cronológica de sua publicação.

Inicialmente, apresenta-se um termo abrangente para a tecnologia da manutenção, criado na Inglaterra em 1970: Terotecnologia. É “uma combinação, entre outras, de práticas de gestão, de finanças e de engenharia aplicadas a ativos físicos para reduzir os custos ao longo do ciclo de vida econômica; trata da especificação e projeto dirigidos para a confiabilidade e manutenibilidade da planta industrial, de equipamentos, edifícios e estruturas, levando em conta sua instalação, comissionamento, manutenção, modificação e substituição, e o retorno de informação sobre o projeto, o desempenho e custos" (CORDER, 1976, p.2).

Aqui, cabe esclarecer que o termo instalação, além de significar o ato ou efeito de instalar, tem sido usado para indicar o conjunto de equipamentos ou componentes que compõem uma determinada utilidade, como é o caso de instalação elétrica, instalação predial ou instalação hidráulica.

“A manutenção pode ser considerada como uma combinação de ações conduzidas para substituir, reparar, revisar ou modificar componentes ou grupos identificáveis de componentes de uma fábrica de modo que esta opere dentro de uma disponibilidade especificada em um intervalo de tempo também especificado. Em resumo, a função manutenção consiste em controlar a disponibilidade da fábrica" (KELLY, 1980, p.4).

Manutenção "é a função que tem a atribuição de conservar itens ou equipamentos em condições de uso operacional, ou restabelecê-las. Compreende serviços, teste, inspeção, ajustes/alinhamentos, remoções, substituições, reinstalação, pesquisa de falhas, calibragem, verificação de condição, reparo, modificação, revisão geral, reconstrução, e recuperação. Manutenção compreende tanto atividades corretivas como preventivas" (PATTON,1980, p.12).

"Manutenção é a função empresarial que tem como encargo o controle constante das instalações, assim como o conjunto de trabalhos de reparação e revisão necessários para garantir o funcionamento regular e o bom estado de conservação das instalações produtivas, serviços e instrumentação das empresas” (BALDIN, 1982, p.19). 
A manutenção é a "medicina dos equipamentos" (MONCHY, 1989, p.2) e pode-se definir a missão do serviço de manutenção como "a gestão otimizada do parque de equipamentos do complexo de produção" (MONCHY, 1989, p.9). Este mesmo autor, afirma que essa otimização só pode ser alcançada em função de objetivos, que devem ser claramente definidos a partir do conhecimento de três fatores: fator econômico (menores custos de falhas e de produção e economia de energia); fator humano (condições de trabalho, segurança e fatores ambientais); e fator técnico (disponibilidade e durabilidade dos equipamentos).

Outra definição de manutenção é "assegurar que os ativos físicos atendam continuamente às suas funções especificadas" (MOUBRAY, 1992, p.6).

“A manutenção é definida como a combinação de ações técnicas e administrativas, incluindo as de supervisão, destinadas a manter ou recolocar um item em um estado no qual possa desempenhar uma função requerida" (NBR 54621994).

“A função manutenção é definida como uma função estratégica que busca a maior disponibilidade e confiabilidade das instalações através da diminuição de quebras e falhas nos equipamentos e sistemas, otimizando o uso dos recursos disponíveis. O objetivo básico da manutenção é garantir a continuidade operacional da planta, maximizando a disponibilidade e a confiabilidade dos equipamentos e das instalações industriais, ao menor custo possível e preservando a integridade do homem e do meio ambiente. Esta definição genérica tem sido detalhada segundo diferentes enfoques, conforme se trate de uma abordagem mais centrada na questão técnica, gerencial ou econômica da manutenção” (CAVALCANTE, 1998, p.76).

"Manter significa fazer tudo que for preciso para assegurar que um equipamento continue a desempenhar as funções para as quais foi projetado, num nível de desempenho exigido" (XENOS, 1998, p.18).

Mais recentemente, a manutenção foi definida associando-a a sua missão: "garantir a disponibilidade da função dos equipamentos e instalações de modo a atender a um processo de produção ou de serviço, com confiabilidade, segurança, preservação do meio ambiente e custo adequados" (KARDEC e NASCIF, 2001, p.22). Vale destacar que esta definição manifesta de modo claro um avanço na preocupação com o meio ambiente. 
Finalmente, "manutenção é o termo usado para abordar a forma pela qual as organizações tentam evitar as falhas ao cuidar de suas instalações físicas. Ela é uma parte importante da maioria das atividades de produção das organizações, especialmente aquelas cujas instalações físicas têm papel fundamental na produção de seus bens e serviços" (SLACK, 2002, p.643).

Ao se analisar essas definições, de modo geral, pode ser notado que elas apontam alguns fatores condicionantes do exercício das atividades de manutenção, como custos, segurança, o processo de produção e o meio ambiente. Se esses fatores se manifestam, os gestores de manutenção devem, de algum modo, considerá-los em suas tomadas de decisão na forma de compromissos a serem atendidos.

\subsection{2 - Evolução da Manutenção}

A história da manutenção acompanha as evoluções tecnológicas, econômicas e sociais da humanidade. Para uma visão do seu desenvolvimento pode ser tomado como referencial o detalhamento considerando como base a década de 1930, e apresentado na Tabela 1.1.

\begin{tabular}{|c|c|c|}
\hline Primeira Geração & Segunda Geração & Terceira Geração \\
\hline Antes de 1940 & 1940 & Após 1970 \\
\hline \multicolumn{3}{|c|}{ EXPECTATIVA EM RELAÇÃO À MANUTENÇÃO } \\
\hline - Conserto após a falha & 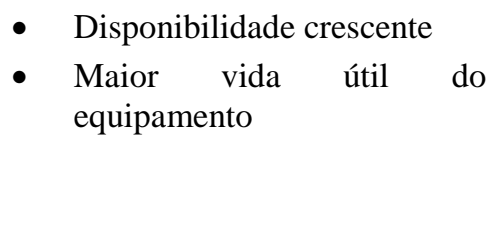 & $\begin{array}{ll}\text { - } & \text { Maior disponibilidade } \\
\text { confiabilidade } \\
\text { - } & \text { Melhor relação custo-benefício } \\
\text { - } & \text { Melhor qualidade dos produtos } \\
\text { - } & \text { Preservação do meio ambiente }\end{array}$ \\
\hline \multicolumn{3}{|c|}{ EVOLUÇÃO DAS TÉCNICAS DE MANUTENÇÃO } \\
\hline - $\quad$ Conserto após a falha & \begin{tabular}{|l} 
- $\begin{array}{l}\text { Computadores grandes e } \\
\text { lentos }\end{array}$ \\
- $\begin{array}{l}\text { Sistemas manuais de } \\
\text { planejamento e controle do } \\
\text { trabalho }\end{array}$ \\
- \\
Monitoração por tempo
\end{tabular} & $\begin{array}{ll}\text { - } & \text { Monitoração de condição } \\
\text { - } & \text { Projetos voltados para } \\
\text { confiabilidade e manutenibilidade } \\
\text { - } \\
\text { - } \text { Análise de risco } \\
\text { rápidos } \\
\text { - Softwares potentes } \\
\text { - Análise do Modo e Efeito de } \\
\text { Falhas (FMEA) } \\
\text { Grupos de } \\
\text { multidisciplinares }\end{array}$ \\
\hline
\end{tabular}

Tabela 1.1 - Evolução da Manutenção (Adaptada de Kardec e Nascif, 2001, p. 8) 


\subsection{3 - Impacto da Disponibilidade nos Resultados da Empresa}

A pertinência da preocupação com a disponibilidade está implícita nos exemplos de TRIOLA (1999, p.13 e p.73) e HUSBAND (1976, p.7), que caracterizam impactos associados à disponibilidade, respectivamente, de natureza operacional (Tabela 1.2) e de ordem econômica (Figura 1.1).

- Impacto no Processo de Manutenção do Equipamento

Um jato de três motores decolou do Aeroporto Internacional de Miami com destino à América do Sul, mas um dos motores falhou logo após a decolagem. Enquanto o avião retornava à pista, os outros dois motores também falharam, mas o piloto conseguiu fazer uma aterrissagem segura. Com três motores independentes, a probabilidade de todos os três falharem simultaneamente é de apenas $0,0001^{3}$, ou seja, uma chance em um trilhão. Constatou-se que, um mesmo mecânico havia trocado o óleo nas três turbinas, colocando incorretamente os anéis de vedação da entrada de óleo. A utilização de três motores distintos independentes tem por objetivo aumentar a segurança, mas a interferência de um único mecânico tornou os motores dependentes. Os processos de manutenção passaram a exigir que os motores fossem vistoriados e ajustados por mecânicos diferentes.

\section{- Impacto no Processo de Operação do Equipamento}

Algumas pessoas costumam desligar o computador logo após o término de determinada tarefa, enquanto outras deixam-no ligado até que não precisem mais utilizá-lo naquele dia. $\mathrm{O}$ painel de circuitos e os chips do computador sofrem com esses ciclos de liga/desliga. Mas o monitor pode se danificar quando a mesma imagem é deixada na tela por períodos de tempo muito longos. $\mathrm{O}$ tempo médio entre falhas $(\mathrm{MTBF}=$ Mean Time Between Failures) para o disco rígido já foi de 500 horas, mas hoje é de cerca de 30.000 horas. Considerando os efeitos danosos dos ciclos on/off sobre o painel de circuitos e os chips do computador, e o grande MTBF para discos rígidos, faz sentido deixar o computador ligado até o fim do dia, desde que a tela do monitor possa ser protegida utilizando-se um programa de descansar a tela. Muitas pessoas utilizam essa estratégia, que se originou em parte de uma análise estatística de eventos passados.

Tabela 1.2 - Impacto da Disponibilidade nos Processos de Manutenção e de Operação (Adaptada de Triola, 1999, p. 13 e p. 73)

Considerando que a concorrência entre empresas tem aumentado no passado recente, e que se acentuam tendências de turbulências de mercado, parece conveniente firmar que o sucesso ou o fracasso, de qualquer empresa, depende da vantagem competitiva que ela apresenta. A empresa deve justificar ao comprador um preço do seu produto através de um custo mais baixo ou de benefícios únicos oferecidos. Assim, “a concorrência está no âmago do sucesso ou fracasso das empresas. Nesse contexto, a empresa precisa encontrar uma estratégia competitiva favorável no campo em que se disputa a concorrência” (PORTER, 1989, p.1). 


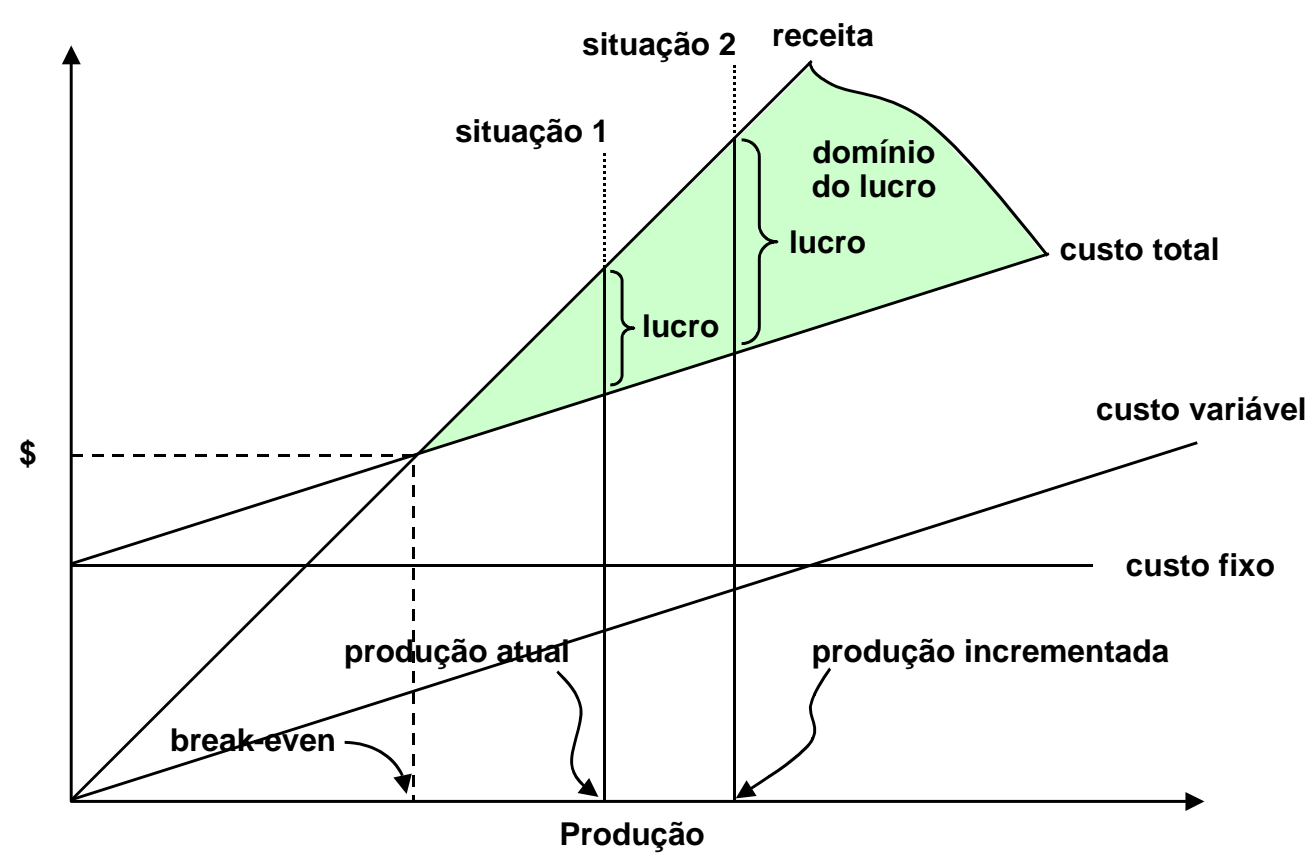

Figura 1.1 - Impacto da Disponibilidade no Lucro (Adaptada de Husband, 1976, p. 7)

Esse autor, permite ainda outras considerações. Embora, uma empresa possa ter inúmeros pontos fortes e pontos fracos, em comparação com seus concorrentes, há dois tipos básicos de vantagem competitiva que uma empresa pode apresentar: baixo custo ou diferenciação.

Para análise das fontes da vantagem competitiva, PORTER (1989, p.31) introduz o conceito de cadeia de valores, desagregando a empresa em dois grupos de atividades de valor: atividades primárias e atividades de apoio. As atividades primárias de valor agrupam cinco categorias genéricas: logística interna, operações, logística externa, marketing e vendas, e serviço.

Esse autor insere as atividades de manutenção de equipamentos na categoria operações, à medida que estão associadas à transformação de insumos no produto final da empresa. Em empresas de serviços, onde operações representa uma categoria vital, a manutenção se insere de modo relevante nas atividades de valor e, portanto, no ambiente de concorrência da empresa.

Visando a investigar o que impulsiona a agenda de melhoria e transformação de uma empresa, num ambiente de competição, HAMEL e PRAHALAD (1997, p.2) 
caracterizam duas posturas. Uma delas, de natureza defensiva, remete-nos à imagem de um engenheiro de manutenção, que dedica energia à manutenção do "passado instalado" na empresa. A segunda, de natureza ofensiva, estes autores associam à atuação de um arquiteto, que desenvolve oportunidades de como competir no futuro.

Chama a atenção, que o texto destes autores, caracterizando o engenheiro de manutenção dentro de uma visão conservadora, reforça um estereótipo conservador do perfil desse profissional.

Contudo, o presente estudo é elaborado dentro de uma expectativa de que o grau de maturidade da função manutenção evolua, de modo que o "engenheiro de manutenção" desenvolva também o perfil de "arquiteto" e impulsionador dessa evolução. 


\section{2-CONTEXTO DE INSERÇÃO DA MANUTENÇÃO E DISPONIBILIDADE}

\section{1 - A Empresa vista como Sistema}

Conforme HARDING (1992, p.24), um sistema é um conjunto de partes inter-relacionadas, as quais, quando ligadas, atuam de acordo com padrões estabelecidos sobre inputs (entradas) no sentido de produzir outputs (saídas). Uma vantagem dessa interpretação é que os sistemas têm a facilidade de serem divididos em subsistemas, sendo cada subsistema relacionado com os outros.

Este autor também destaca que toda empresa deve planejar e controlar suas atividades em relação às atividades dos competidores, ao sistema legal, à comunidade local ou ao sistema social, ao sistema tecnológico para aquele ramo industrial e ao sistema financeiro do país. Ainda, para HARDING (1992, p.26), a empresa:

a) é um sistema;

b) faz parte de um sistema maior (a indústria);

c) está relacionada com muitos outros sistemas; e

d) é composta de certo número de subsistemas, que interagem para constituir um todo dinâmico.

$\mathrm{Na}$ atualidade, em face da competitividade global, o relacionamento da empresa pode extrapolar fronteiras nacionais. Para SLACK (2002, p.32), a função produção na organização representa a reunião de recursos destinados à produção de seus bens e serviços. Ela é responsável por satisfazer às solicitações de consumidores, por meio da produção e entrega de produtos e serviços. Assim, qualquer organização possui uma função produção, por que produz algum tipo de bem e/ou serviço.

No presente estudo, a expressão função manutenção implica a reunião de recursos destinados à assegurar a disponibilidade operacional dos equipamentos e instalações da função produção. Vale destacar que é "nas fronteiras justapostas entre as funções" que ocorre grande parte dos problemas de interesse da administração e, conseqüentemente, as oportunidades de melhorias (SLACK, 2002, p.33). 
Complementando, diversas subdivisões funcionais (gerências, departamentos ou seções), em empresas de manufatura ou serviços, executam atividades de apoio que podem ser consideradas serviços, caracterizando uma relação cliente fornecedor interno. "A boa gestão dessa relação pode contribuir com a quebra de barreiras organizacionais, gerando a integração das diversas funções da empresa e concorrendo para o atendimento de seus objetivos estratégicos" (CORRÊA e CAON, 2002, p.28).

Esses últimos autores se apóiam, particularmente, no exemplo do setor de manutenção, que executa serviços de reparos, avaliações de funcionamento, limpeza e substituições de componentes, entre outros, nos equipamentos utilizados pela área de produção. Interpretando suas palavras, a missão da manutenção é garantir a disponibilidade e o desempenho dos equipamentos e instalações produtivas e seu próprio desempenho pode ser avaliado pela rapidez com que atende às solicitações da área de operações, pela conseqüência ou qualidade na execução de suas atividades e pelos custos que gera para a empresa, em função da disponibilidade dos equipamentos produtivos que assegura. A qualidade dos serviços e bens físicos produzidos, os tempos envolvidos na produção e a confiabilidade desses tempos, entre outros, dependem, em certo grau, do desempenho da função manutenção.

Pois bem, é justamente esse desempenho do setor de manutenção que está no contexto do presente estudo, visto que ele decorre de tomadas de decisão pertinentes ao processo da própria manutenção.

MONCHY (1989, p.10) chama à atenção que, "por maior que seja a importância do serviço de manutenção, ele não é um fim, mas um meio para ajudar a produção". O mesmo autor destaca haver um conflito entre as funções produção e manutenção, requerendo uma coordenação quase permanente entre elas, assim como um conhecimento recíproco dos contratempos, missões e problemas.

Além disso, MONCHY (1989, p.11) previa que "a evolução num futuro próximo tende a uma imbricação das funções. Antes de qualquer coisa, pela própria confusão dos objetivos: gerenciar a produtividade e gerenciar a qualidade. A manutenção diz cada vez mais respeito à qualidade dos produtos, que passa pela qualidade dos equipamentos produtivos". 
A idéia do cliente interno, também é delineada por FLEURY e VARGAS (1983, p.32) que ao analisarem "tarefas que dão ao empregado uma área natural de responsabilidade" levam em conta também "um usuário, alguém dentro da empresa, que vai servir como um cliente".

Assim, para o controle de relacionamento entre funções, vale citar que, quando consideramos o "funcionamento das partes tendo em vista o resultado do todo, verificamos que o adequado entrosamento das partes é tão importante para o todo quanto o bom funcionamento de cada uma. Além disso, o desempenho de um sistema depende também de seu relacionamento com o ambiente - o sistema maior do qual faz parte" (SILVA, 1997, p.28).

\section{2 - As Empresas e as Estratégias Competitivas}

Depois de enfrentar duras batalhas nas várias guerras de produtividade travadas ao longo dos últimos dez anos, grande parte das empresas pode estar satisfeita com o enxugamento de suas operações. E com razão, já que processos foram reformulados, reduziram-se custos indiretos e foram eliminadas atividades supérfluas. Adicione-se, ainda, que "houve incremento na qualidade dos produtos e serviços, pondo fim a erros e informações confusos. Foram também derrubadas as divisões que existiam entre os departamentos de uma mesma organização, permitindo que as pessoas trabalhassem juntas e se comunicassem livremente" (HAMMER, 2002).

Deve-se levar em conta que, a complexidade do equipamento cresceu de modo acelerado. Com o advento do computador e a avançada engenharia de controle, a tecnologia de processos de produção expandiu-se. Como consequiência do custo da fábrica e do equipamento ter crescido de modo significativo, fez-se necessário assegurar a máxima utilização efetiva do sistema produtivo. O padrão de desenvolvimento nas indústrias de capital intensivo deixa pouco, ou nenhum, tempo para reparos essenciais do equipamento, lubrificação e manutenção regular. Muito trabalho desse tipo poderia ser previamente executado durante a noite ou em fins de semana, enquanto o equipamento estivesse parado. "Como as operações contínuas tornam-se uma necessidade, alguma estratégia definitiva precisa ser desenvolvida para se obter a máxima eficiência. Mesmo com um único turno de trabalho, a 
complexidade do moderno equipamento demanda um programa cuidadosamente planejado de manutenção" (HARDING, 1992, p.110).

Ao responder à questão sobre o que se espera de empresas competitivas, SILVA (1997, p.31) considera que "no longo prazo, algumas querem crescer, outras esperam sobreviver ao longo do tempo". Esse mesmo autor acrescenta que o desempenho das empresas, para atingir seus objetivos de longo prazo, depende de uma série de características de atuação, entre as quais inclui a produtividade, intrinsecamente ligada a custos baixos e ao lucro que a empresa irá conseguir de sua operação. Nessa linha de pensamento, CONTADOR (1997, p.49) considera a produtividade como a mais potente arma de competição, lembrando que a redução de custos é o grande motivador da busca de maior produtividade, caracterizando entre os atributos da empresa para a produtividade: insumos e processo com elevada qualidade, estoques reduzidos e rapidez na manufatura. Nesta pesquisa, considera-se esse último atributo se relacionando fortemente com a disponibilidade operacional do sistema produtivo, a qual decorre, como se verá ao longo do trabalho, marcadamente de operações de manutenção.

\section{3 -Sistemas de Manufatura, Estratégias de Manufatura e Disponibilidade}

Nesse contexto, se insere uma das abordagens de gestão da manutenção, a Manutenção Produtiva Total, ou TPM (do inglês Total Productive Maintenance), como exemplo de integração, dando ênfase para a participação efetiva dos operadores da produção e dos demais colaboradores da empresa - abrangendo pessoal técnico e administrativo - cujas atividades seriam, muitas vezes, desenvolvidas em grupos de trabalho, envolvendo a cooperação de outras empresas, inclusive serviços subcontratados e empresas afiliadas. As atividades de TPM não fornecem apenas técnicas de Manutenção Preventiva (MP), mas também encerram uma filosofia de MP e de sua aplicação no aprimoramento dos ambientes de trabalho. As novas atividades de MP envolvem todos os membros da empresa e seu impacto revolucionário começa com mudanças na fábrica, na consciência das pessoas e no ambiente de trabalho, com o propósito de reformular a estrutura da empresa e gerar lucros maiores a partir da análise de indicadores de desempenho. 
"As atividades de TPM devem ser consideradas como um conjunto de atividades de MP direcionadas a cada estágio do ciclo de vida do equipamento. Essas atividades envolvem estágios, tais como estudo do equipamento, decisões sobre especificações e desenho, fabricação, instalação, operações reais, manutenção, atualização e obsolescência" (TAKAHASHI e OSADA, 1993, p.xii).

No mundo contemporâneo, a busca de fontes de vantagens competitivas é essencial, sendo importante evidenciar os atributos competitivos de uma empresa. Enquanto alguns "atributos interessam ao comprador: preço, qualidade do produto e variedade de modelos... outros não, como marketing, produtividade, rapidez de fabricação" (CONTADOR, 1997, p. 39). Ainda segundo este autor, "arma da competição é um meio que a empresa utiliza para alcançar vantagem competitiva em produtividade, qualidade no processo, domínio de tecnologia".

Outro aspecto a ser destacado é que, "da forma como Porter definiu os tipos de atividades que constituem a cadeia de valor, pode-se considerar que, num caso genérico, as atividades primárias de operação representam grande parte dos processos da manufatura. As atividades da manufatura e os recursos por elas utilizados podem ser melhor visualizados definindo uma entidade organizacional que os envolva totalmente" (MIYAKE, 1993, p.19). Essa entidade, chamada de Sistema de Manufatura (SM) é representada na Figura 2.1, em que as atividades de manutenção têm como um dos seus objetivos assegurar a disponibilidade operacional dos equipamentos.

Vale lembrar que, "produtividade é a capacidade de produzir ou o estado em que se dá a produção. A produtividade é medida pela relação entre os resultados da produção efetivada e os recursos produtivos aplicados a ela (ou produção/recursos), como peças/hora-máquina, toneladas produzidas/homem-hora, quilogramas fundidos/quilowatt-hora. A produtividade é medida para cada recurso isoladamente, para ser possível avaliar o comportamento e o desempenho de cada um" (CONTADOR, 1997, p.121). Complementando, também conforme esse autor, “como produtividade é igual a produção/recursos, uma maior produtividade significa que se produz mais, com os mesmos recursos, ou que uma mesma produção é feita com menos recursos. Portanto, em qualquer situação, o custo unitário do produto diminui". 


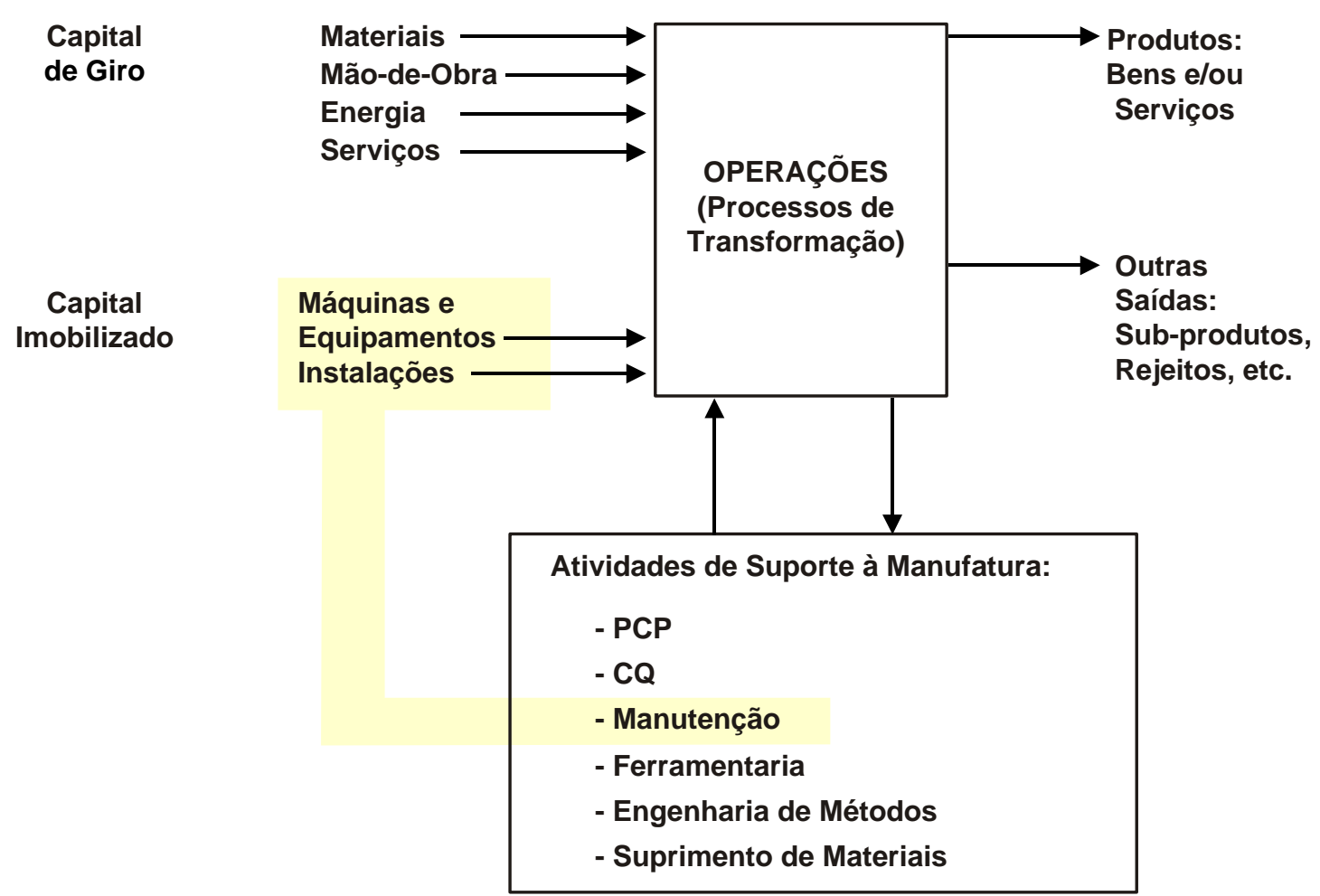

Figura 2.1 - Inserção da Manutenção no Sistema de Manufatura (Adaptada de Miyake, 1993, p. 20)

Entre as "Cinco Metas da TPM" apontadas por SLACK (2002, p.648), há duas que se relacionam de modo mais próximo com as atividades de manutenção e se vinculam com a disponibilidade:

a) Melhorar a eficiência do equipamento: o que demanda examinar como as instalações estão contribuindo para a eficiência da produção, analisando-se todas as perdas que ocorrem. Perda de eficiência pode resultar de perdas por parada, perdas por quedas de velocidade de funcionamento ou perdas por defeitos (Figura 2.2). A eficiência do equipamento é medida por meio do "índice do desempenho operacional global", que resulta do produto: índice do tempo operacional x índice da performance operacional x índice de produtos aprovados. Para melhorar a eficiência do equipamento é preciso que todos os tipos de perdas sejam investigados. Em particular, as perdas por parada compreendem o tempo de parada do equipamento (por causa de quebras e falhas) e o tempo para mudança de linha (em virtude de ajustes ou set-ups). O presente trabalho põe em foco a análise das perdas causadas por paradas em razão de quebras ou falhas, as 
quais se relacionam com a freqüência da ocorrência de falhas e com os tempos requeridos para os reparos.

$\mathrm{O}$ "índice do tempo operacional", um dos principais indicadores da abordagem TPM, conforme MIYAKE (1993, p.97 e p.108) e TAKAHASHI e OSADA (1993, p.52), também tem sido interpretado como uma expressão de disponibilidade, à medida que representa uma indicação do nível geral de utilização do equipamento.

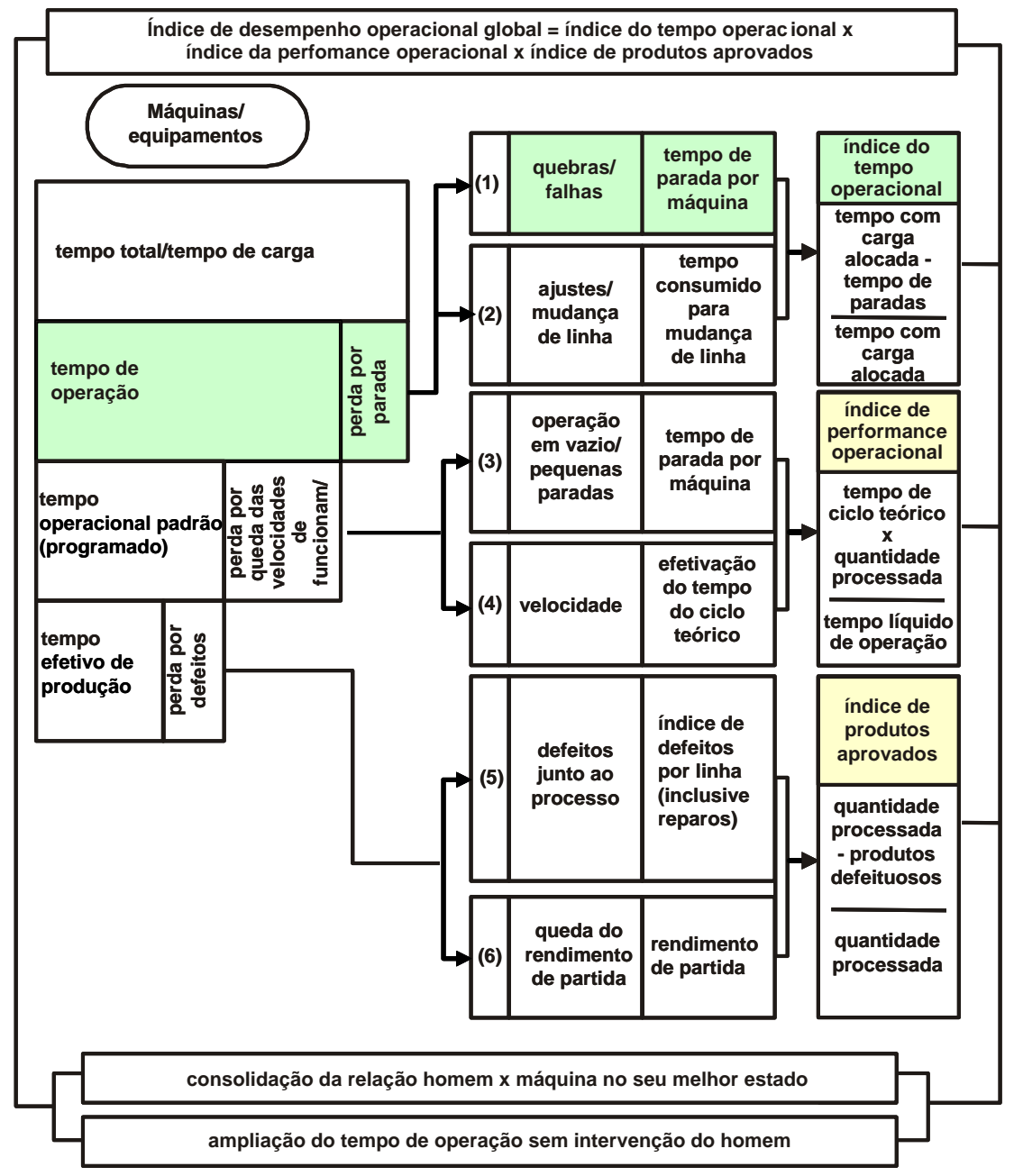

Figura 2.2 - Índice do Desempenho Operacional Global (Adaptada de Nakajima, 1989, p. 25)

b) Administrar os equipamentos desde o início de seu ciclo de vida: esta meta ambiciona evitar totalmente a manutenção através da "Prevenção de Manutenção" (PM). 
"A PM compreende considerar as causas de falha e a manutenibilidade dos equipamentos durante sua etapa de projeto, sua manufatura e sua instalação. Em outras palavras, a PM tenta rastrear todos os problemas potenciais de manutenção até sua causa primeira e depois tenta eliminá-los nesse ponto" (SLACK, 2002, p.649).

Numa primeira abordagem, pode-se afirmar que disponibilidade é o grau em que a produção está pronta para funcionar. "Uma máquina da produção não está disponível se ela acabou de falhar ou está sendo consertada após uma falha" (SLACK, 2002, p.634). A disponibilidade é mensurável no contexto da vida operacional do equipamento.

Há diversas formas para medir a disponibilidade, dependendo das características da operação do equipamento e dos motivos de paradas. Por exemplo, incluindo ou não os tempos relacionados com as manutenções de natureza preventiva ou corretiva. Ainda, de acordo com SLACK (2002, p.634), "quando a disponibilidade está sendo usada como indicador do tempo de operação, excluindo a conseqüência da falha, é calculada" pela fórmula:

\section{Disponibilidade $(\mathrm{D})=\mathrm{MTBF} /(\mathrm{MTBF}+\mathrm{MTTR})$}

onde MTBF, é o Tempo Médio entre Falhas do equipamento e MTTR é o Tempo Médio de Reparo, que é o tempo médio necessário para reparar o equipamento.

O MTBF (ou seu inverso, a Taxa de Falhas) é um indicador da confiabilidade do equipamento, que pode ser definida como a probabilidade de que o equipamento exercerá determinada função, em condições pré-especificadas e durante um período de tempo também pré-determinado.

Já o MTTR, é um indicador da manutenibilidade, que é uma característica do projeto e da instalação do equipamento, correspondendo à probabilidade do restabelecimento da sua condição operacional especificada, em determinado período de tempo, com o uso de recurso também previamente determinado.

A disponibilidade, como um indicador de avaliação do relacionamento entre as funções de manutenção e de produção, requer uma gestão eficaz que aparentemente só será conseguida com ações sobre seus componentes: sobre o 
MTBF ou a Taxa de Falhas (indicadores da Confiabilidade), ou sobre o MTTR (indicador da Manutenibilidade) (MONCHY, 1989, p.108).

\section{4 - As Alterações de Estado como Razão das Atividades de Manutenção}

Inicialmente, convém caracterizar o conceito de falha. Falha é o término da capacidade de um item desempenhar a função requerida. É a diminuição total ou parcial da capacidade de uma peça, componente ou equipamento de desempenhar a sua função durante um período de tempo, quando o item deverá ser reparado ou substituído. A falha leva o item a um estado de indisponibilidade (NBR 5462). Essa definição, considera no seu bojo que a função do equipamento seja perfeitamente especificada.

XENOS (1998, p.68) destaca três categorias de causas possíveis para falhas: falta de resistência (inerente ao equipamento e que resulta de deficiências de qualidade do seu projeto e de outras etapas do seu ciclo de vida), uso inadequado (aplicação de esforços que estão acima da capacidade do equipamento) e manutenção inadequada (ações preventivas, contra a degradação do equipamento, insuficientes ou incorretas).

\subsection{1 - O Equipamento como um Agregado de Componentes}

O conhecimento do equipamento, que usualmente está em poder da função produção, para que esta desenvolva suas atividades, é essencial para o desenrolar eficaz dos trabalhos de manutenção. Entende-se por equipamento, ou máquina, uma unidade complexa, integrando um conjunto de partes, peças ou componentes físicos, e que tem por objetivo desempenhar uma ou mais funções quando solicitado.

O pacote de componentes de um equipamento representa os ingredientes da especificação desse equipamento. Para caracterizar o equipamento, eles necessitam ser conectados de alguma forma para que o relacionamento entre eles seja formalizado. Assim, o equipamento traduz um arranjo que define o relacionamento entre as funções de cada componente, representando um mecanismo que possibilita ao equipamento desempenhar sua função prevista.

Para uma fabricação econômica, é essencial que as peças sejam intercambiáveis. Tal concepção requer necessariamente qualidade de conformidade 
de fabricação das peças. Se as diferentes peças não se ajustam com precisão, a montagem final torna-se impossível e a maior parte da economia visada se perderia. Essas considerações, baseadas em FLEURY e VARGAS (1983, p.27), citando Ford, levam à necessidade duma precisão absoluta de fabricação, "levada a um décimo de milésimo de polegada".

A falta de padronização das peças, situação comum antes da fábrica de Ford, implicava a necessidade de longo tempo para ajuste e encaixe durante a montagem do veículo, que é um equipamento. Além de significar mais tempo de montagem, por causa dos ajustes, a indústria necessitava contratar pessoal qualificado, capaz de realizar delicadas operações nas peças até que encaixassem umas nas outras. Para tornar as peças intercambiáveis, Ford adotou um único "sistema de medida em toda a fábrica, o que foi uma inovação significativa, além de contar com avanços tecnológicos nas máquinas ferramentas, que permitiriam maior precisão de fabricação" (SILVA, 1997, p.19).

No contexto da função manutenção, é exatamente essa possibilidade de intercâmbio de peças e componentes que, também, contribui para tornar exeqüíveis as intervenções de manutenção e, potencialmente, para diminuir a duração dos tempos de reparo do equipamento.

Assim, o suprimento de peças padronizadas e intercambiáveis é que torna possível a execução dos serviços de manutenção, visando à preservação e à disponibilidade dos equipamentos.

\subsection{2 - Esforços e Solicitações sobre os Componentes do Equipamento}

Logo que entram em operação, todos os equipamentos ficam sujeitos a esforços e solicitações que provocam alterações no estado, ou condição, de suas peças ou seus componentes. DRAPINSKI (1973, p.5), ao analisar as falhas de equipamentos e instalações, cita como exemplos típicos de esforços ou solicitações: tração, compressão, flexão, flambagem, torção, cisalhamento, contato (adesão ou abrasão), mudanças de velocidades (contra forças de inércia), forças dinâmicas (inclusive pulsações e vibrações), temperatura, concentrações de tensões devido a transições da estrutura do material, concentrações de tensões devido à forma da peça, e tensões residuais. 
Considerando a dinâmica de utilização do equipamento, decorre que esses esforços e solicitações estão associados ao desenvolvimento do processo de produção da empresa ao usar os equipamentos do sistema produtivo.

\subsection{3 - As Alterações de Estado dos Componentes}

Como conseqüência dos esforços e solicitações, vão ocorrer degradações de estado (MONCHY, 1989, p.79), ou de condição, dos componentes, que, ultrapassando ou atingindo limites considerados como aceitáveis, implicarão na necessidade de intervenções de manutenção, visando ao restabelecimento de condições de pleno desempenho da função estabelecida para o equipamento.

Ainda, conforme DRAPINSKI (1973, p.5), o exame de peças danificadas de muitos equipamentos vai revelar uma variedade de alterações de estado, como: desgaste; corrosão (eletroquímica afetando metais em meio aquoso, química devido ao contato com produtos agressivos, elétrica sob o efeito de correntes parasitas, bacteriana sob o efeito de bactérias aeróbicas ou anaeróbicas, de contato ou frettingcorrosion devido a peças em contato e submetidas a vibrações, e cavitação que se manifesta em peças em contato com zonas de turbulência líquida); quebra ou deformação por impacto, ou estática; quebra ou deformação por calor ou choque térmico; quebra por fadiga; e danos característicos de cada elemento componente do equipamento (como engrenagem, correia, retentor ou pneu).

A análise de tendências de parâmetros representativos do estado dos componentes, passa, então, a ser preocupação fundamental da gestão da manutenção. Essa análise só é possível em situações caracterizadas por alterações que permitam controle, ao longo da vida do equipamento.

\subsection{4 - O Ciclo de Vida do Equipamento}

\subsubsection{1 - Caracterização do Ciclo de Vida}

O ciclo de vida do equipamento é constituído de uma série de estágios, que devidamente analisados ajudam na compreensão do comportamento operacional desse equipamento. O estágio de projeto merece atenção especial. Destaque-se que o nível de manutenção requerido por um equipamento em seu estágio, ou vida, operacional é afetado por fatores presentes em estágios anteriores. 
A etapa de projeto, isto é, a da especificação técnica do equipamento, é fundamental. É nessa etapa que são firmadas características que determinarão a disponibilidade do equipamento.

Para SLACK (2002, p.118), não existe uma definição de projeto reconhecida universalmente; diferentes especialistas usam, às vezes, definições bastante diferentes. Para este autor, projeto é o processo conceitual através do qual algumas exigências funcionais de pessoas, individualmente ou em massa, são satisfeitas pelo uso de um produto ou de um sistema que deriva da tradução física de um conceito.

"Um bom projeto consiste em observar as coisas do dia-a-dia com novos olhos e trabalhá-las de modo que possam funcionar melhor. Consiste em desafiar a tecnologia existente" (SLACK, 2002, p.143). No entender do autor da presente pesquisa, a recomendação de SLACK deve ser observada principalmente pelo pessoal de manutenção, na busca contínua do aprimoramento do projeto do equipamento.

Alternativas devem ser analisadas na etapa de projeto, pois a escolha vai interferir na disponibilidade operacional do equipamento. Como exemplo pode-se citar "tecnologias de pequena escala que podem ser mais robustas". Imagine-se que a escolha seja entre três equipamentos de pequeno porte e dois maiores. "No primeiro caso, se um equipamento quebra, um terço da capacidade é perdida, mas no segundo caso a capacidade é reduzida à metade" (SLACK, 2002, p.266).

$\mathrm{Na}$ fase de projeto, o desenvolvimento de um protótipo, uma unidade piloto, ou uma unidade industrial de demonstração representam subsídio considerável para atender, de modo eficaz, o sistema produtivo.

Visando a delinear um espectro do ciclo de vida do equipamento, foi elaborada, para esta pesquisa, a Tabela 2.1 apontando fatores intervenientes na evolução da Taxa de Falhas e do MTTR, identificando, na primeira coluna, seus sucessivos estágios. Em cada um deverá ser dedicada atenção a fatores que, dependendo de critérios de análise nesses estágios, contribuirão de modo satisfatório, ou não, para a evolução da Taxa de Falhas e do MTTR. Exemplos de fatores com potencial de interferência na Taxa de Falhas são apresentados na coluna central, enquanto que a coluna da direita contempla fatores que poderão influenciar no MTTR. A esses fatores correspondem causas de falhas, decorrentes de controles de 
qualidade inadequados, as quais poderão se manifestar durante a vida operacional do equipamento, degradando sua disponibilidade.

Como parte do espectro do ciclo de vida, o destaque assinalado na Tabela 2.1, integrando os estágios de Operação, Manutenção e Modificações de Projeto, corresponde à vida operacional do equipamento.

\begin{tabular}{|c|c|c|c|}
\hline \multicolumn{2}{|c|}{$\begin{array}{l}\text { Estágio do Ciclo de Vida } \\
\text { do Equipamento }\end{array}$} & $\begin{array}{c}\text { Interferência na Taxa } \\
\text { de Falhas (Confiabilidade) }\end{array}$ & $\begin{array}{l}\text { Interferência no MTTR } \\
\text { (Manutenibilidadł }\end{array}$ \\
\hline \multicolumn{2}{|c|}{ Concepção } & Estágio do avanço tecnológico & Estágio do avanço tecnológico \\
\hline \multicolumn{2}{|c|}{ Projeto } & Especificação de componentes inadequados & $\begin{array}{l}\text { Especificação de componentes de } \\
\text { difícil aquisição }\end{array}$ \\
\hline \multicolumn{2}{|c|}{ Fabricação dos Componentes } & $\begin{array}{l}\text { Utilização de material não conforme com a } \\
\text { especificação de projeto }\end{array}$ & - \\
\hline \multicolumn{2}{|c|}{ Montagem da Máquina } & Tensões e desalinhamentos durante a montagem & - \\
\hline \multicolumn{2}{|c|}{ Teste de Fábrica } & $\begin{array}{l}\text { Procedimentos inadequados e instrumentos não } \\
\text { aferidos }\end{array}$ & - \\
\hline \multicolumn{2}{|c|}{ Embalagem e Transporte } & $\begin{array}{l}\text { Esforços e condições ambientais não previstos em } \\
\text { projeto }\end{array}$ & - \\
\hline \multicolumn{2}{|c|}{ Recebimento e Armazenagem } & $\begin{array}{l}\text { Armazenagem além do tempo de vida de } \\
\text { componentes }\end{array}$ & - \\
\hline \multicolumn{2}{|c|}{ Instalação e Energização } & Desalinhamento e aterramento elétrico deficientes & - \\
\hline \multicolumn{2}{|c|}{ Teste Pré-operacional } & Falta de representatividade do regime operacional & - \\
\hline \multirow{3}{*}{ 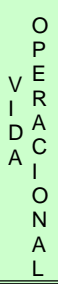 } & Operação & Velocidade acima das especificações de projeto & $\begin{array}{l}\text { Demora na liberação da máquina para } \\
\text { a manutenção }\end{array}$ \\
\hline & Manutenção & $\begin{array}{l}\text { Reparos mal executados/falta de manutenção } \\
\text { preventiva }\end{array}$ & $\begin{array}{l}\text { Falta de planejamento da manutenção } \\
\text { e de suprimento de materiais }\end{array}$ \\
\hline & Modificações de projeto & Alteração da especificação de componentes & $\begin{array}{l}\text { Alteração das condições de acesso. } \\
\text { Especificação de materiais não } \\
\text { compatíveis com o mercado } \\
\text { fornecedor }\end{array}$ \\
\hline \multicolumn{2}{|c|}{ Retirada de Serviço } & - & - \\
\hline
\end{tabular}

\section{Tabela 2.1 - Fatores Intervenientes na Evolução da Taxa de Falhas e do MTTR (Elaborada pelo Autor) ao longo do Ciclo de Vida}

\section{a) O comportamento da Taxa de Falhas}

Os fatores que apresentam potencial de interferir na Taxa de Falhas exigem atenção em quase todas as etapas do ciclo de vida do equipamento, tanto na da vida operacional, como nas anteriores.

Em geral e de uma forma bastante genérica, o comportamento da Taxa de Falhas (inverso do MTBF), indicador da confiabilidade, ao longo da vida operacional do equipamento, tem sua evolução sido representada por um modelo típico, 
designado "curva da banheira", ou "bathtub curve", indicada em um dos quadrantes da Figura 2.3, que será objeto de análise mais adiante.

\section{b) O comportamento do Tempo de Reparo}

Facilidades de reparo dependem muito do partido econômico adotado durante a etapa de projeto do equipamento, já que elas estão relacionadas com o custo, vida útil operacional prevista para o equipamento, e tipo de aplicação. É bom relembrar que, a padronização de peças de reposição, ao permitir que elas sejam intercambiáveis, representa um importante fator interveniente na disponibilidade operacional, e que deverá ser considerado durante o projeto.

Entretanto, estimar a evolução dos tempos de reparo ao longo da vida operacional do equipamento não é uma tarefa simples. Para isso, um caminho visualizado passa por recorrer ao conceito de "curva de aprendizado". A curva de aprendizado leva em conta que o aprimoramento decorre da prática. Assim, um trabalho de manutenção pode sempre ser executado melhor e em menor período de tempo não somente na segunda vez, mas também nas vezes subseqüentes.

Um efeito, registrado e referente a esse conceito (KERZNER, 2001, p.953), ocorreu em 1925, quando, na Wright-Patterson Air Force Base, se verificou que o total de horas requeridas para a montagem da estrutura de um avião diminuía conforme a quantidade de unidades montadas crescia. Além de implicar em menor custo por avião, mais aviões podiam ser produzidos com os mesmos recursos em menor período de tempo.

As curvas de aprendizado indicavam que a quantidade de homens-hora de fabricação (mais especificamente a mão-de-obra direta) diminuía cada vez que a empresa dobrava sua produção. Estudos empíricos desse fenômeno resultaram em três conclusões, ainda segundo KERZNER (2001, p.954):

- O tempo requerido para desempenhar uma tarefa decresce conforme a tarefa é repetida.

- A intensidade de aprimoramento (melhoria) decresce conforme mais unidades são produzidas.

- A taxa de aprimoramento tem suficiente consistência para permitir seu uso como instrumento de predição. 
Com essas considerações, é possível afirmar que a repetição da tarefa aprimora o aprendizado: tempo e custo devem diminuir e supervisão, desperdício e ineficiência podem ser reduzidos ou eliminados, aumentando a produtividade. KERZNER (2001, p.961) ainda afirma que "os efeitos de aprendizagem estendem-se ao pessoal de manutenção". Assim, tomando-se por base essa afirmação, assume-se neste estudo que a evolução dos Tempos de Reparo se assemelha à forma de uma curva de aprendizado, conforme apresentada no quadrante "D" da Figura 2.3.

\subsubsection{2 - Esforço Integrado para Aprimoramento da Disponibilidade}

A melhoria da disponibilidade depende de um conjunto de medidas devidamente integradas, já que o seu indicador depende da evolução da Taxa de Falhas e do MTTR. A Figura 2.3 foi elaborada com o objetivo de apresentar uma visão sistêmica e integrada de ações, ao longo do ciclo de vida, e a evolução dos resultados delas decorrentes.

Os quadrantes "A" e "C" indicam etapas em que as ações para melhorias podem alavancar resultados satisfatórios para a disponibilidade. O quadrante "A" indica etapas do ciclo de vida do equipamento, que requerem atenção para melhorar a confiabilidade. Na verdade, esse quadrante considera, de modo implícito, fatores cujos exemplos foram detalhados na Tabela 2.1.

O quadrante " $\mathrm{C}$ " resume que, basicamente, os aprimoramentos visando ao MTTR devem estar focados em fatores associados às etapas de projeto, e às de operação e manutenção. Esse quadrante, que contempla uma composição do tempo de interrupção da produção, incluindo subsídios para a análise do MTTR, foi inserido na Figura 2.3, apoiando-se em considerações, sobre tempos de reparo, elaboradas por SMITH (1985, p.25). Nessa composição, as características de projeto do equipamento, as atividades de planejamento dos trabalhos de reparo e a gestão de suprimentos de materiais têm papéis relevantes.

Já o quadrante "B" apresenta o modelo típico da evolução da confiabilidade conhecido como "curva da banheira" (KELLY, 1980, p.47; SMITH, 1985, p.22; NAKAJIMA, 1989, p.35), resultante de tomadas de decisão durante os estágios apontados no quadrante "A". LAFRAIA (2001, p.15) chama a atenção para o fato de que "a curva da banheira apresenta, de maneira geral, as fases da vida de um 
componente. Embora ela seja apresentada como genérica, a curva da banheira só é válida para componentes individuais". Esse autor alerta que, nem todos os tipos de componentes/sistemas seguem todas as fases: mortalidade infantil (falhas precoces), vida útil (falhas de natureza aleatória) e desgaste (falhas por desgaste). Ainda, segundo LAFRAIA (2001, p.18), enquanto componentes mecânicos apresentam, normalmente, as três fases, os eletrônicos apresentam falhas aleatórias, lançando-se mão da substituição destes últimos, em situações de "quebra", já que "a Manutenção Preventiva nesse caso é de pouca efetividade". Assim, a representação da evolução da taxa de falhas (inverso do MTBF) que é apresentada no quadrante "B" deve ser observada levando em conta esses aspectos.

Por sua vez, o quadrante "D" apresenta uma proposição conceitual da forma de evolução do MTTR, assumindo a manifestação de melhorias decorrentes de um processo de aprendizagem e da eficaz aplicação de metodologias de aprimoramento das operações de reparo.

\subsubsection{3 - Gestão do Ciclo de Vida}

Das considerações expostas, é possível propor que a busca da produtividade e da redução de custos operacionais, através da disponibilidade operacional do equipamento, requer um tratamento das contribuições para aprimoramento da confiabilidade e do tempo de reparo, ao longo de todo o espectro do ciclo de vida do equipamento, analisando possíveis falhas e atacando de forma antecipada suas causas.

Ainda, é conveniente realçar que é na etapa de projeto (ou seja, elaboração das especificações técnicas do equipamento) que a confiabilidade e a manutenibilidade são analisadas explicitamente, ou não, podendo apontar para uma solução de compromisso que considere o custo inicial do equipamento, o seu desempenho e o seu custo operacional.

Portanto, deve-se considerar etapas anteriores ao início de sua vida operacional, durante as quais há necessidade de atenção para potenciais causas de falhas que irão interferir na vida operacional, na produtividade e nos custos de produção. 


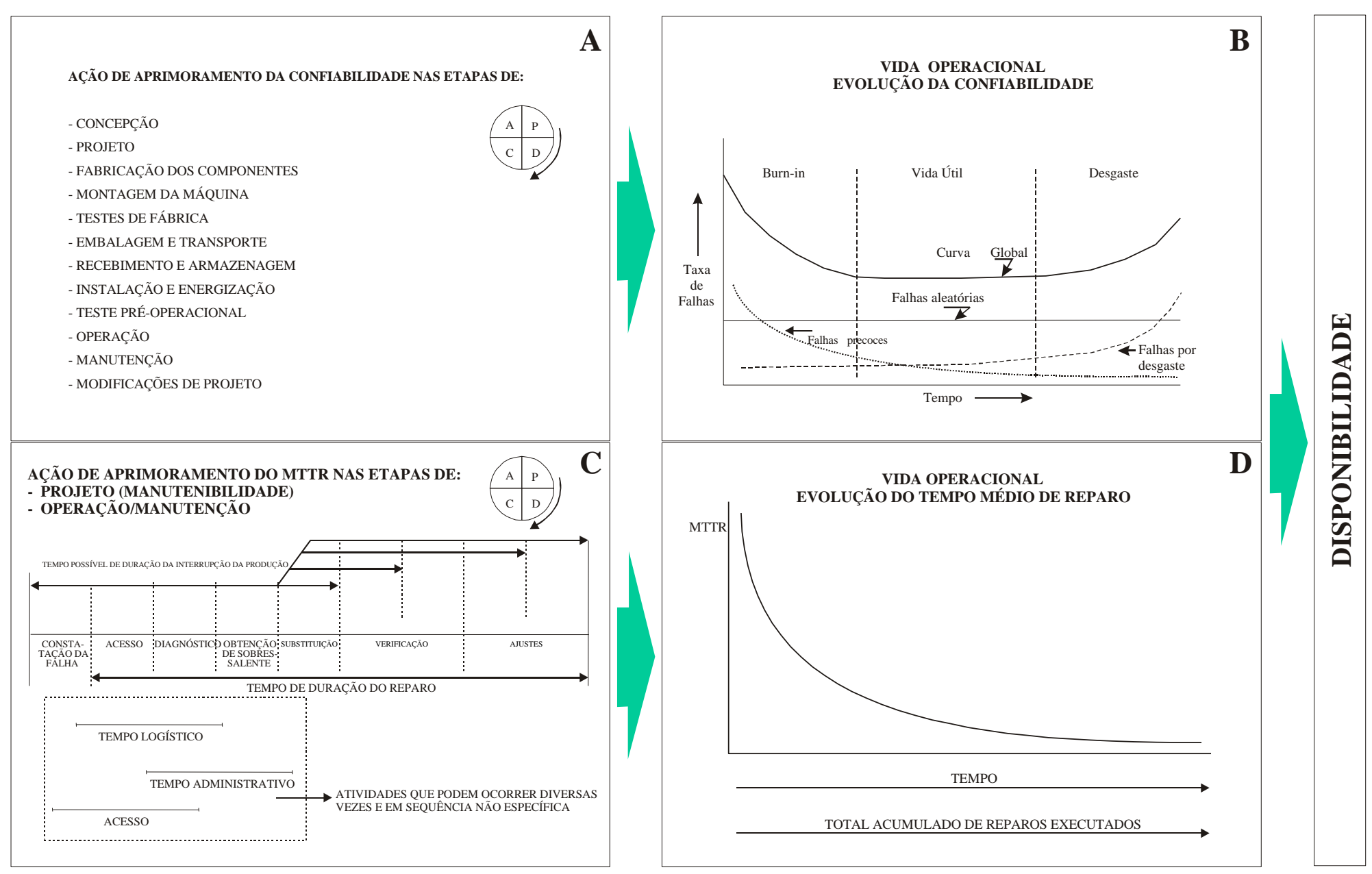

Figura 2.3 - Aprimoramento e Evolução da Confiabilidade e do MTTR (Adaptada de Vaz e Miyake, 2002, p.238) 
Antecipando considerações mais detalhadas sobre técnicas para melhoria de confiabilidade, que serão apresentadas no item 3.3.4 do presente estudo, duas técnicas, FMEA e FTA, citadas de modo bastante presente por diversos autores, como BURGESS (1984, p.238), LAFRAIA (2001, p.123 e p.257) e SLACK (2002, p.637 e p.638), são a seguir introduzidas.

Uma revisão crítica do projeto do equipamento pode ser enriquecida com o uso de metodologias, como a da Análise do Modo e Efeito de Falhas (FMEA, do original em inglês Failure Mode and Effect Analysis). O objetivo dessa metodologia é identificar todos os modos de falha, em potencial, dentro de um projeto de equipamento, todas as probabilidades de falhas catastróficas ou críticas, de tal maneira que elas possam ser eliminadas ou minimizadas através de correções do projeto, em tempo hábil. A FMEA é uma das ferramentas de análise da confiabilidade de projeto.

A Análise da Árvore de Falhas (FTA, Failure Tree Analysis) é outra técnica utilizada no estudo de falhas potenciais, correspondendo a uma análise dedutiva detalhada, que, usualmente, requer considerável volume de informações sobre o sistema produtivo.

Utilizando-se como metodologia de trabalho as ferramentas da Qualidade Total (SLACK, 2002, p.665), pode-se propor um plano de aumento de confiabilidade e diminuição do tempo de reparo: novos instrumentos para localização de falhas, elaboração de procedimentos, melhorias, treinamentos e reciclagens.

Também, a reunião e divulgação de registros, relacionados com a atuação da Manutenção, irá colaborar para a determinação do nível ótimo dessa atuação sobre os sistemas e equipamentos produtivos. Como, na busca do aprimoramento da confiabilidade e da manutenibilidade, a atualização do projeto representa um conceito de melhoramento contínuo (SLACK, 2002, p.605), as informações reunidas deveriam, de modo sistemático, realimentar o fabricante do equipamento e seus usuários, e, em condições ideais, alimentar um banco de dados para serem compartilhadas. É um objetivo ambicioso e as dificuldades envolvidas representam um obstáculo para sua consecução, pois dependem de sistemas de informação e comunicação que representam investimentos expressivos. Além disso, transparece a 
idéia de que as organizações empresariais nem sempre possuem concordância de objetivos, a não ser o próprio lucro em ambiente competitivo.

\subsection{5 - Gestão do Estado dos Componentes do Equipamento}

Conforme LAFRAIA (2001, p.1), o principal objetivo da engenharia é proporcionar meios materiais que maximizem o bem-estar humano. Entretanto, há uma série de restrições de ordem física, econômica ou mesmo social. Para esse autor, essas restrições tornam impraticável a operação, em condições ideais, dos sistemas físicos.

Assim, se situações indesejáveis implicarem em riscos de vidas humanas e/ou prejuízos econômico-financeiros relevantes, devem ser dirigidos esforços para minimizar, ou mesmo evitar, a ocorrência dessas situações.

Nesse contexto, o acompanhamento do estado dos componentes, conforme parâmetros estabelecidos na etapa de projeto, configura-se como essencial para assegurar a disponibilidade do sistema produtivo.

Para o mesmo autor, ainda, "o estudo ou análise de um produto, sistema ou equipamento pode ser efetuado observando as partes ou componentes desse sistema como um todo. Nesse caso, faz-se necessário uma interação entre as diversas partes que o compõem, a fim de demonstrar o seu funcionamento de modo geral".

Do mesmo modo, caracterizando esse processo de interação e inspirando-se em ZARIFIAN (1999, p.19), que, ao analisar o valor de serviço a partir dos recursos, considera o papel fundamental da competência profissional, pode-se extrapolar que “o serviço" de manutenção "é uma organização e uma mobilização, a mais eficiente possível, de recursos para interpretar, compreender e gerar a mudança perseguida nas condições de atividade do destinatário do serviço" de manutenção, no caso a função produção.

\section{5 - Mensuração e Indicadores de Desempenho}

Diversos autores desenvolveram estudos sobre a mensuração de desempenho.’'É impossível saber se uma operação é bem sucedida ou não, se os objetivos de desempenho específicos em relação aos quais seu sucesso é mensurado não estão claramente explicitados” (SLACK, 2002, p.62). 
Outros autores (JOHNSTON e CLARK, 2002, p.376), complementam afirmando que a arte da mensuração do desempenho vem mudando consideravelmente. Sugerem que está se tornando um importante campo de conhecimento, à medida que os gerentes - em particular, os gerentes de operações tentam entender o efeito de suas decisões. Exemplificam afirmando que, antes de tomar uma decisão, precisam saber, com algum grau de certeza, como ela afetará, além de sua operação, seus clientes, funcionários e a situação financeira da organização. Embora ainda haja um longo caminho a percorrer, para esses autores algumas organizações estão começando a entender corretamente esses vínculos e também assegurando que as informações obtidas sobre a administração do desempenho não são apenas coletadas por serem interessantes, mas principalmente para adotarem as ações apropriadas.

Conforme recomendações dos últimos autores, há dois testes úteis de uma mensuração do desempenho: primeiro, qual seu propósito e, segundo, que sistemas estão disponíveis para apoiar ou atingir esse propósito.

A disponibilidade é um resultado, que deve ser medido por meio de um indicador que represente uma mensuração. Assim, nesse ponto, parece ser conveniente lembrar algumas considerações sobre a importância de indicadores. Há quatro propósitos para a adoção da mensuração: comunicação, motivação, controle e melhoria (JOHNSTON e CLARK, 2002, p.376).

- Comunicação: ao mensurar algo, a organização está querendo comunicar que isso é importante; assim, uma medida informa aos funcionários o que a organização espera deles e, de fato, o que pode ser atribuído a eles, como indivíduos ou departamento. É também um meio importante de implementar uma estratégia.

Em relação ao presente estudo, por exemplo, ao mensurar a disponibilidade de um equipamento, a organização está informando que isso é importante, implicando que os gestores e operadores devem esforçar-se para atingir metas ou melhorar resultados obtidos.

- Motivação: uma medida ou conjunto de medidas usadas por uma organização cria hábitos mentais que influenciam o comportamento dos funcionários. 
- Controle: um propósito-chave da mensuração do desempenho é fornecer feedback, isto é, que ação pode ser adotada para manter um processo sob controle. Isso exige um loop de controle completo, com medidas, metas, meio de checagem de desvio, mecanismos de feedback, e meio de adoção da ação apropriada se o processo não estiver atingindo o resultado esperado. $\mathrm{O}$ controle pode ser usado para assegurar um desempenho consistente.

Esse conceito de mecanismo de controle, conforme também apresentado por WILD (1984, p.553), firma-se como a fonte inspiradora para a estrutura conceitual desta pesquisa, na qual o feedback é, essencialmente, estabelecido a partir do indicador de resultado de disponibilidade dos equipamentos.

- Melhoria: as medidas de desempenho fornecem um meio de impulsionar a melhoria. Freqüentemente a simples comunicação de uma medida pode provocar melhorias. A informação sobre o que conduz o processo para uma meta ou para fora dela, pode também ajudar os gestores e as organizações a aprenderem como melhor gerenciar o processo envolvido.

MUSCAT e FLEURY (1993, p.83), ao analisarem, no contexto da relevância de indicadores, a manufatura na estratégia competitiva das empresas, apontam uma série de fatores contribuintes para a intensificação da competição, a saber, a globalização de atividades, a volatilidade dos mercados, a compressão do time-tomarket, a maior proximidade dos clientes e atendimento de suas necessidades, e os custos reduzidos e riscos elevados. Entre esses fatores podem ser destacados três que, de modo mais próximo, se relacionam com as atividades de manutenção: compressão do time-to-market (demandando processos aperfeiçoados, seja de pesquisa e desenvolvimento, de engenharia, de manufatura ou de distribuição), maior proximidade dos clientes e atendimento de suas necessidades (implicando integração de funções dentro da empresa), e custos reduzidos (implicando gestão dos custos de manutenção).

Redes de indicadores podem ser utilizadas como instrumento de monitoramento dos Fatores Críticos de Sucesso referentes a uma certa empresa. Fatores Críticos de Sucesso (FCSs) "são variáveis nas quais a empresa precisa necessariamente ter bom desempenho para dar sustentação à estratégia competitiva. 
Quando se identificam os FCSs estão sendo identificadas as variáveis que devem ser mensuradas e, se possível, aperfeiçoadas, para se atingir os objetivos da empresa, através de sua estratégia competitiva, ou seja, estão identificados os Indicadores de Gestão da empresa" (MUSCAT, FLEURY, 1993, p.83).

“A empresa, ao se posicionar frente à competição, deverá criar mecanismos para saber se está sendo realmente competitiva e para verificar se está aperfeiçoando sua forma de atuação, relativamente às necessidades dos clientes e à operação dos competidores. Em outras palavras, a empresa deverá definir, medir e monitorar indicadores, que serão utilizados na estrutura de ações para melhorar seu desempenho competitivo" (MUSCAT e FLEURY, 1993, p.83), formando uma "Rede de Indicadores", ou seja: uma estrutura de indicadores que serão utilizados na especificação de ações para aprimoramento do desempenho compatíveis com intervenções em cada componente do detalhamento do sistema produtivo da empresa.

Assim, a definição de FCSs referentes a uma certa empresa visa a encaminhar medições de características de produtos ou parâmetros de processos, criados para monitoração da conveniência da adoção de ações gerenciais, isto é, tomadas de decisão relacionadas com as competências da empresa.

É importante que sejam objeto de levantamento, registro das informações que entram no seu cálculo, e de análise sistemática de sua evolução. Os indicadores devem ser analisados tanto de modo agregado, como detalhado. Ações pontuais sobre o processo contribuem para o resultado final. Assim, é imprescindível que fique bem claro que os indicadores representam instrumentos de controle. Portanto, devem estar associados a um mecanismo de feedback de informações. Em resumo, os indicadores representam informações para tomada de decisão.

Também para WILD (1984, p.21), é essencial medir e monitorar desempenhos no âmbito da organização, e, como os sistemas operacionais são os principais componentes de qualquer organização, a medição dos resultados desses sistemas insere-se como aspecto relevante na avaliação de qualquer medição de desempenho global.

Ainda, recorrendo a WILD (1984, p.61), o alto escalão de qualquer organização sempre procura exercer algum controle sobre as partes constituintes da 
organização. Ora, no caso da função manutenção, a disponibilidade é um resultado que permite o exercício desse controle.

WILD (1984, p.559), apontando tarefas de planejamento e controle de operações, inclui para a função manutenção, como tarefa de controle, "checar a eficiência da manutenção por meio do monitoramento da disponibilidade, tempo de paralisação e custos de manutenção da instalação". Destaca, portanto, embora de modo implícito, a importância de indicadores de disponibilidade e de um fator que requer solução de compromisso com a disponibilidade, ou seja, o custo de manutenção.

Caracterizando quão importante é a medição do desempenho organizacional, FRANCISCHINI (2002, p.8) analisa a perspectiva dos processos internos da organização, apontando que devem ser identificados e medidos "os processos internos críticos, nos quais a empresa deve alcançar a excelência para oferecer propostas de valor, capazes de atrair e reter clientes, em segmentos alvo de mercado, e satisfazer às expectativas que os acionistas têm de retornos financeiros".

Em face da relevância da disponibilidade operacional para os retornos financeiros, já caracterizada no item 1.2.3 deste trabalho, a função manutenção pode ser enquadrada entre os processos internos críticos, que devem ser devidamente medidos, gerando indicadores pertinentes e provocando tomadas de decisão para seu aprimoramento.

\section{6 - A Disponibilidade como Contribuinte para a Produtividade}

Um dos contribuintes para diminuir o tempo produtivo é a necessidade de se efetuar intervenções de manutenção no equipamento. Dificuldades técnicas de programação também podem significar adição de perda de tempo produtivo.

CONTADOR (1994, p.217), ao apresentar um "método para rápido aumento da produtividade fabril", fundamenta-o "na redução ou eliminação do tempo inativo do homem, da máquina e do material, que é a grande causa de ineficiência”. Para obtenção desse aumento de produtividade, CONTADOR (1994, p.222) recomenda concentrar-se em uma série de objetos de estudo, entre os quais inclui a "redução da espera da máquina durante as inspeções" e a "redução dos tempos improdutivos acarretados por espera pelo serviço de manutenção". 
Ora, a preocupação com a disponibilidade parece implícita nessas recomendações, vinculando-a com a produtividade final do sistema produtivo da organização.

Vale a pena lembrar que, Produção (ou Operação) corresponde à obtenção de produtos por meio da interação de recursos. A Figura 2.1, já apresentada, indica que os processos de transformação dependem de recursos de entrada, entre os quais se encontram as máquinas ou equipamentos.

Produtividade é um conceito vinculado aos processos de transformação, mas parece não haver um consenso geral sobre o que se entende por esse termo.

A origem do conceito de produtividade está associada ao de Eficiência, que corresponde à relação apresentada a seguir.

$$
\eta=\text { Energia Útil / Energia Fornecida }
$$

Para se caracterizar a Disponibilidade como contribuinte da Produtividade, no âmbito deste estudo, parece pertinente explorar uma das relações apresentadas por FRANCISCHINI (1994, p.12):

\section{Produtividade $\mathrm{P}=$ Valor das Saídas / Custos dos Recursos}

Esse tratamento, devidamente associado ao sistema físico de produção e à Figura 1.1, permite verificar que se assegurando a disponibilidade do equipamento, ou sua elevação, a produção pode ser incrementada, sem necessariamente se elevar custos fixos associados aos recursos físicos. Assim, ao dar sua parcela de contribuição ao denominador da relação acima, a disponibilidade é também um contribuinte em potencial da produtividade.

Em todo caso, ganhos de produtividade resultam em maior folga para investimentos, sendo em geral considerados fundamentais para consecução dos objetivos das empresas (SILVA, 1997, p.31).

Ainda, vale destacar que, o estudo da disponibilidade está associado diretamente à medição do tempo, e que, segundo MARTINS (1999, p.19), o tempo exerce um papel fundamental no modelo de produtividade industrial, e que a partir da apuração do tempo realmente gasto com as tarefas seria possível calcular a produtividade. 


\section{3 -DETALHAMENTO DA DISPONIBILIDADE E DO PROCESSO DE MANUTENÇÃO}

\section{1 - Levantamento e Análise dos Elementos Componentes da Disponibilidade}

Neste ponto, a disponibilidade, que é o foco da pesquisa, é analisada com mais detalhes, à luz dos seus principais fatores componentes. Inicia-se esta análise aprofundando-se o conhecimento referente à confiabilidade. Na seqüência, analisa-se a manutenibilidade. Esses conceitos, já apresentados anteriormente, por ocasião da exposição sobre o contexto da inserção da disponibilidade e da manutenção, são aqui retomados para que se possa encaminhar melhor o entendimento do desdobramento da disponibilidade, representado ao final do Capítulo por meio de uma Estrutura Analítica.

\subsection{1 - Caracterização da Confiabilidade, da Taxa de Falhas e do Tempo Médio Entre Falhas (MTBF)}

\subsubsection{1 - Conceitos e Evolução}

A confiabilidade tem sido definida por diversos autores que, de modo geral, apresentam conceituações semelhantes, incluindo a preocupação com o desempenho da função do equipamento. De modo geral, expressam que a confiabilidade é capacidade de um item desempenhar uma função requerida sob condições especificadas, durante um intervalo de tempo estabelecido. É a probabilidade do equipamento desempenhar uma função requerida, sob determinadas condições, durante um intervalo de tempo estabelecido. "Confiabilidade é a probabilidade de que um componente ou sistema funcionando dentro dos limites especificados de projeto, não falhe durante o período de tempo previsto para a sua vida, dentro das condições de agressividade do meio ambiente" (LAFRAIA, 2001, p.2; KERZNER, 2001, p.1084; KARDEC e NASCIF, 2001, p.96; MONCHY, 1989, p.105).

O MTBF (Tempo Médio entre Falhas) é confirmado na literatura como um indicador de confiabilidade (MONCHY, 1989, p.108).

Assim, a confiabilidade de um componente (ou peça, produto, equipamento ou sistema) diz respeito à probabilidade de que esse componente desempenhe 
corretamente as suas funções, pelo menos por um determinado tempo, dentro de um conjunto de circunstâncias operacionais, chamado de condições normais de operação.

A falha é um estado físico irregular de um sistema que ameace sua operação normal. A anormalidade é entendida como o desvio de algum parâmetro mensurável além dos limites do que o projeto e a experiência consideram aconselhável para uma operação normal. Desse modo, a falha significa a interrupção do desempenho do componente de suas funções habituais. A maneira de falhar depende das características do componente e da operação, podendo variar desde a falha súbita ou instantânea até a falha gradativa, com longo período de maturação até a danificação total do componente em termos de sua função (MOREIRA, 1993, p.235).

A aplicação do termo confiabilidade, no âmbito das atividades de Manutenção, teve origem nas análises de falhas em equipamentos eletrônicos para uso militar, durante a década de 50, nos Estados Unidos (KARDEC e NASCIF, 2001, p.95).

Conforme BALDIN (1982, p.51), o conjunto de estudos que se agrupam sob o título teoria da confiabilidade abrange um conjunto de teorias e métodos matemáticos e estatísticos, procedimentos organizacionais e práticas operacionais que, através do estudo das leis de ocorrência de falhas, se orientam para a resolução dos problemas de previsão, estimativa e otimização da probabilidade de sobrevivência, duração média de vida e da porcentagem de tempo de bom funcionamento do sistema.

As condições normais de operação são muito importantes e indissociáveis do conceito de confiabilidade. As condições normais dizem como o componente deve ser usado, que esforços pode suportar, como deve ser sua manutenção, e assim por diante. Em suma, envolvem um conjunto de instruções de operação, fora das quais a confiabilidade perde o seu sentido (MOREIRA, 1993, p.235).

\subsubsection{2 - Aplicação das Técnicas de Confiabilidade associadas à Manutenção}

Neste ponto, cabe esclarecer os motivos pelos quais a indústria se vê na obrigação de utilizar as técnicas de confiabilidade. Entre os motivos apontados por BALDIN (1982, p.52), destacam-se os seguintes, quando se pensa em sua pertinência com a manutenção: 
a) Tendência de aumento da complexidade dos equipamentos modernos, fato que implica no crescimento da probabilidade de falha, até o ponto em que pode ser impossível colocar em operação o que foi projetado com o máximo zelo.

b) Necessidade de se atingir um compromisso entre três fatores: necessidade de redução de peso e volume dos equipamentos, mantendo a segurança operacional. Nem sempre é possível superdimensionar os componentes de um equipamento para se ter maior confiabilidade, se para isso for exigido um excessivo aumento de peso ou de volume.

c) Necessidade de aumento do tempo de duração de funcionamento do equipamento.

d) Dificuldade de manutenção: uma maior duração do tempo de funcionamento permite maior utilização do equipamento, com as vantagens econômicas correspondentes. Podem surgir dificuldades para se manter as partes menos acessíveis do equipamento, partes que deverão, então, apresentar maior confiabilidade.

e) Tendência de maior emprego de componentes eletrônicos. As técnicas de confiabilidade são bastante utilizadas no campo da eletrônica, seja devido aos equipamentos eletrônicos apresentarem tendência de complexidade, seja por que seus componentes estejam acentuadamente normalizados, o que facilita a coleta de dados sobre seu funcionamento".

f) Necessidade de eliminar o risco de perda de vidas humanas ou, em geral, de perdas significativas.

g) Conseqüências econômicas do inadequado funcionamento de um equipamento que tendem a se tornar mais críticas: seja por que os equipamentos tendem a custar mais caro, seja por que os equipamentos se destinam a maiores volumes de produção.

Entretanto, a confiabilidade tem seu custo. Para elevar o grau de confiabilidade, os estudos têm que ser mais precisos, os projetos mais comprometidos, os experimentos mais rigorosos, as construções mais bem elaboradas, sempre com o emprego de técnicas cada vez mais avançadas. Esse fato deve implicar elevação dos custos associados a essas atividades. 
Por outro lado, no entender de BALDIN (1982, p.53), "quando se aumenta o grau de confiabilidade, os custos inerentes às falhas diminuem, reduzindo, entre outros, além dos custos de atividades diretas de manutenção, os custos de materiais de reposição e os custos decorrentes da falta de produtividade".

Também, conforme esse autor, reafirmando a importância da confiabilidade, verifica-se, em muitos contratos importantes de aquisição de equipamentos, a tendência de ser incluída uma cláusula referente à confiabilidade, "ainda que esteja especificada de forma pouco precisa".

Nesse tipo de contrato, aponta BALDIN (1982, p.54), freqüentemente se exige que o fornecedor demonstre a confiabilidade do equipamento, o que representa uma carga de custos elevada, "até o ponto de implicar ser menos dispendioso projetar o sistema para um grau de confiabilidade mais alto do que o contratado, compensando com uma quantidade menor de provas necessárias de demonstração".

\subsubsection{3 - Critérios de Definição de Confiabilidade}

Também, tomando-se por base BALDIN (1982, p.55), podem ser alinhados os seguintes pressupostos para uma definição de confiabilidade:

a) Prescrição inequívoca do critério que determina se o elemento funciona ou não funciona. Às vezes, esse critério é tão óbvio que a definição do estado não funciona é imediata. Outras vezes, o estado de falha só pode ser caracterizado com o alcance de um limite admissível nas condições do equipamento em foco, além do qual se caracteriza a falha, casos em que se podem identificar estados intermediários entre o de bom funcionamento e o de falha, correspondentes a diferentes níveis de condições funcionais.

b) Estabelecimento preciso das condições ambientais e de utilização, e que se mantenham constantes no período de tempo em consideração. Esse pressuposto coloca em destaque a importância do regime de operação do sistema produtivo.

c) Definição do intervalo de tempo $t$ durante o qual se requer que o elemento funcione.

Desse modo, se fixadas as duas primeiras condições, a confiabilidade de um elemento é função somente do tempo, função cuja forma depende da lei 
probabilística segundo a qual o não funcionamento, ou falha, pode ocorrer ao longo do tempo.

\subsubsection{4 - Critérios de Avaliação de Confiabilidade de Equipamentos}

Se a confiabilidade é um indicador componente da disponibilidade convém considerar como avaliá-la. Ainda, recorrendo a BALDIN (1982, p.55), para avaliar a confiabilidade dos equipamentos podem ser utilizados três procedimentos:

a) Usar a informação procedente do funcionamento de muitos equipamentos iguais, durante um extenso período de tempo e nas mesmas condições de funcionamento. Se os dados são numerosos do ponto de vista estatístico, podem ser utilizados diretamente sem necessidade de elaboração adicional.

b) Usar a informação procedente do funcionamento de alguns equipamentos durante um curto período de tempo. Os dados das provas desse tipo dão uma estimativa do comportamento com certo grau de confiança, isto é, com certa probabilidade de que resulte verdadeira. Os valores obtidos requerem elaboração com procedimentos estatísticos.

c) Usar a confiabilidade conhecida das partes componentes do equipamento para fazer cálculos de previsão da confiabilidade do conjunto. Esse procedimento é útil quando, não se dispondo de dados para um procedimento do primeiro tipo, se deseja uma avaliação da confiabilidade do equipamento antes que se disponha dos resultados de uma amostragem. Nesse caso, "os dados de confiabilidade no nível de componente são mais abundantes e fáceis de se conseguir" (BALDIN, 1982, p.55).

"Observar que a taxa de falhas tem dimensão inversa do tempo, sendo possível interpretar-se como o número de falhas na unidade de tempo, que é a medida da velocidade de aparecimento das falhas" (BALDIN, 1982, p.58).

Ora, todos esses procedimentos dependem de um elemento essencial: o acesso à informação pertinente. Assim, a necessidade de se dispor de um sistema de informação compatível firma-se como indispensável. 


\subsection{2 - Caracterização da Manutenibilidade e do Tempo Médio de Reparo (MTTR)}

O conceito de manutenibilidade também tem sido apresentado por diferentes autores, de modo geral, em paralelo à apresentação do conceito de confiabilidade: "manutenibilidade é a capacidade do produto permanecer ou ser restaurado a um nível de desempenho quando uma manutenção prescrita é executada" (KERZNER, 2001, p.1084).

Manutenibilidade é uma característica de um equipamento ou conjunto de equipamentos. Essa característica é que determina o maior ou menor grau de facilidade para a execução dos serviços de manutenção (KARDEC e NASCIF, 2001, p.89).

Uma outra forma de apresentar a manutenibilidade é considerando a probabilidade que o equipamento tem de ser recolocado em estado de funcionamento após uma falha, dentro de um dado intervalo de tempo. Ela é caracterizada pelo MTTR (MONCHY, 1989, p.109).

Esse autor vincula diretamente a manutenibilidade ao MTTR. "O tempo fora de serviço de uma instalação devido às falhas é o resultado de numerosos fatores concorrentes" (BALDIN, 1982, p.82). Considerou-se o comentário desse autor ao se analisar, particularmente, o quadrante "C" da Figura 2.3.

\subsubsection{1 - Desmembramento do Tempo de Reparo}

Em uma primeira classificação, os tempos de reparo poderiam ser divididos em:

- Tempo consumido no diagnóstico da falha;

- Tempo consumido no reparo da falha; e

- Tempo consumido no controle do reparo.

Tomando-se por base uma proposta de BALDIN (1982, p.82), pode-se encaminhar também um desdobramento dos tempos mais analítico, que leve em conta as operações singulares executadas pela equipe de reparo, e que permitirá investigar melhor os tempos envolvidos: 
a) Preparação: tempo necessário para se dispor instrumentos de controle, ferramentas, manuais de manutenção, assim como os instrumentos necessários para iniciar a operação de localização da falha.

b) Localização da falha: tempo durante o qual se efetuam testes e análises sobre o equipamento para se isolar a causa da falha.

c) Desmontagem: tempo necessário para acessar à parte que falha e decidir o que vai ser feito (reparação ou substituição).

d) Obtenção das peças de reposição e materiais necessários: tempo durante o qual se solicita ao almoxarifado as peças de reposição dos componentes que serão substituídos, e que são administrados pelo setor de suprimentos da empresa.

e) Reparo: tempo durante o qual se repara o defeito sobre o próprio equipamento, retirando, reparando e recolocando a mesma peça, ou removendo-a e substituindo-a por outra de reposição.

f) Ajuste e calibração: tempo durante o qual se efetuam as operações de ajuste e calibração do componente reparado.

g) Montagem: tempo necessário para voltar a montar o equipamento.

h) Comprovação de funcionamento: tempo no qual se certifica que o equipamento reparado funciona corretamente.

i) Limpeza e finalização: tempo requerido para se recolocar o equipamento em serviço, durante o qual a equipe de manutenção retira sobras de material e efetua a limpeza final.

\subsubsection{2 - Fatores que Interferem no Tempo de Reparo}

Evidentemente, há numerosos fatores que influem na duração total do reparo. Alguns deles são fatores próprios do projeto, outros de natureza organizacional, outros correspondem à prática operativa. Fatores apontados por BALDIN (1982, p.83) e por KARDEC e NASCIF (2001, p.89), subsidiaram a composição da Tabela

\section{1 .}

\subsection{3 - Extensão da Aplicação da Disponibilidade}

Em função de ser a disponibilidade o conceito chave do presente estudo, o seu tratamento é retomado apresentando-se algumas definições e considerações 
complementares, e, particularmente, procurando estendê-la, além do setor de manufatura, para o serviço de transportes, sobre trilhos, de passageiros.

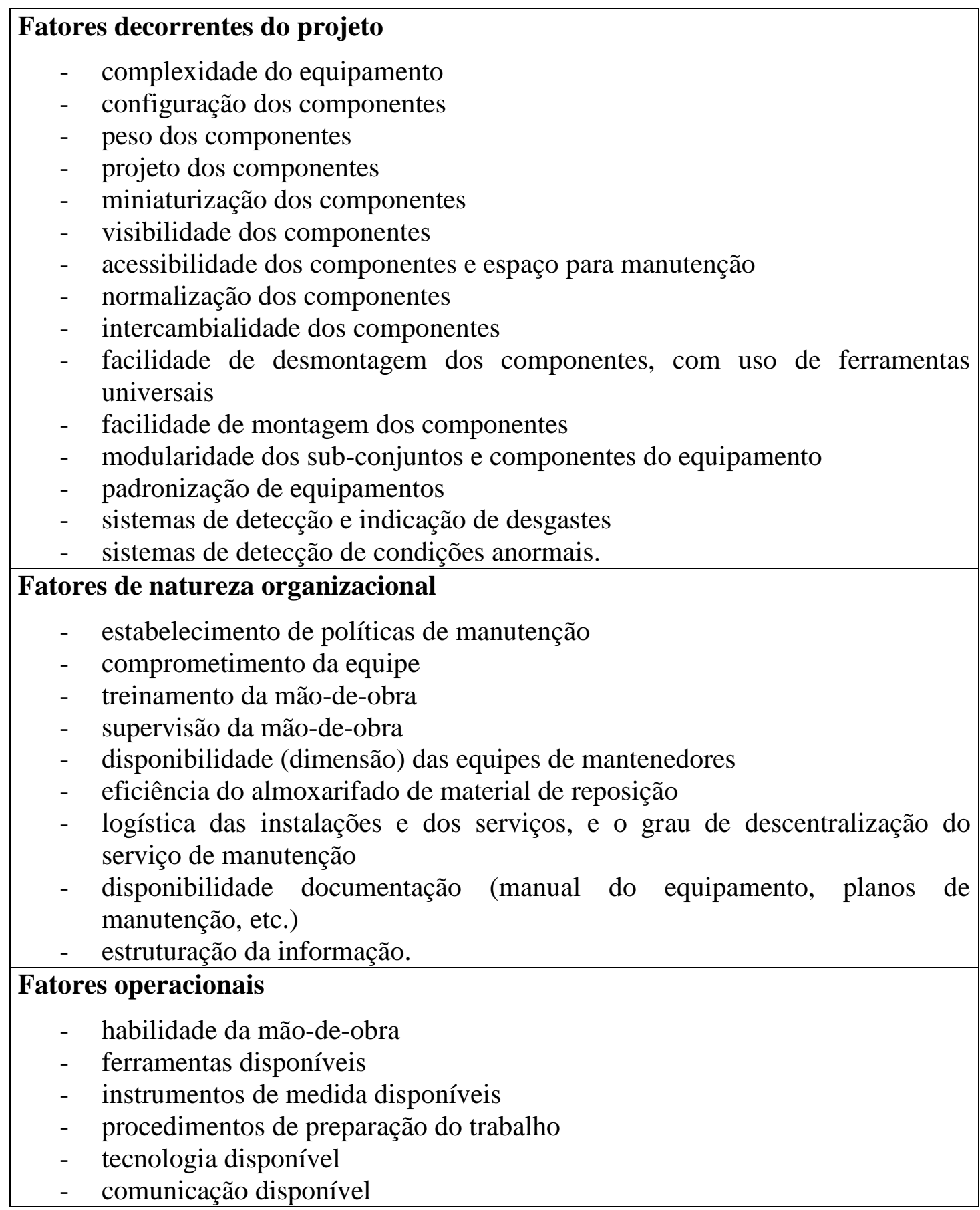

Tabela 3.1 - Fatores Intervenientes no Tempo de Reparo (Adaptada de Baldin, 1982, p. 83; Kardec e Nascif, 2001, p. 89) 


\subsubsection{1 - Interpretação da Disponibilidade}

A fórmula clássica da disponibilidade, introduzida no item 2.3 deste estudo, é, ora, reapresentada:

$$
\mathrm{D}=\mathrm{MTBF} /(\mathrm{MTBF}+\mathrm{MTTR})
$$

Ela tem, conforme MONCHY (1989, p.163), no MTBF a representação da confiabilidade e no MTTR a da manutenibilidade, e que já foram objeto de considerações anteriores (itens 2.4.4.1, 3.1.1 e 3.1.2).

"A disponibilidade é a probabilidade de bom funcionamento de um dispositivo no instante $t$ " (MONCHY, 1989, p.166).

Disponibilidade é a "capacidade de um item estar em condições de executar uma certa função em um dado instante ou durante um intervalo de tempo determinado, levando-se em conta os aspectos combinados de sua confiabilidade, manutenibilidade e suporte de manutenção, supondo que os recursos externos requeridos estejam assegurados" (NBR 5462, 1994, p.2). Ainda, conforme a NBR 5462, o termo "disponibilidade" é usado como uma medida do "desempenho de disponibilidade".

A disponibilidade pode ser definida de várias formas, dentro da conceituação básica da fórmula acima, que supõe basicamente apenas duas condições para o equipamento, isto é, operando normalmente ou paralisado, nessa última situação sendo submetido a reparo. Entretanto, existe no cotidiano das organizações um amplo complexo de situações intermediárias. De modo geral, o ajuste da fórmula para levar em conta esse efeito não altera sua conceituação básica. Exemplo de uma aplicação mais abrangente é apresentado por MONCHY (1989, p.168):

$$
\mathrm{D}=(\mathrm{MTBM} / \mathrm{MTBM}+\mathrm{MMT}), \text { onde }
$$

MTBM = Mean Time Between Maintenance (Tempo Médio entre Intervenções de Manutenção)

MMT = Mean Maintenance Time (Tempo Médio da duração das Intervenções Preventivas e Corretivas)

Outras variações da fórmula da disponibilidade são apresentadas por MONCHY (1989, p.168), SMITH (1985, p.26) e KELLY (1980, p.4), além da interpretação do "índice do tempo operacional", no contexto da abordagem TPM, 
conforme exposto no item 2.3 deste trabalho. Convém destacar que o "tempo total" (ou "tempo de carga") da Figura 2.2, na forma originalmente apresentada por NAKAJIMA (1989, P.25), foi obtido a partir de um tempo total mais abrangente, do qual já foram deduzidos tempos de paradas programadas (como os destinados a intervenções preventivas). Assim, o "índice do tempo operacional" dispensa tempos referentes a essas paradas programadas.

\subsubsection{2 -Disponibilidade no Serviço de Transporte, sobre Trilhos, de Passageiros}

$\mathrm{Na}$ explanação sobre "Valor, Organização e Competência na Produção de Serviço", ZARIFIAN (1999, p.1) procura "exprimir uma nova maneira de ver e avaliar a produção em qualquer setor". Ao propor "uma definição do valor do serviço", o autor utiliza uma dupla abordagem: uma a partir de resultados ("o serviço é uma transformação nas condições de atividade do destinatário, cujos resultados são considerados válidos por este último") e outra a partir dos recursos (“o serviço é a organização e a mobilização de recursos visando interpretar, compreender e produzir a transformação citada acima").

Há quatro tipos de avaliação de serviço (serviço no singular, conforme ZARIFIAN) a partir dos resultados: de utilidade, de justiça, de solidariedade e de estética. Ainda, ZARIFIAN (1999, p.9-10) insiste "no fato de que a verdadeira utilidade consiste na transformação das condições de atividade do destinatário de um serviço". Nesse contexto, esse autor toma o exemplo do "transporte, por metrô, de passageiros que se dirigem aos seus locais de trabalho" e propõe dizer que "a produção do serviço consiste na transformação das condições de atividade desses passageiros, isto é, no resultado útil que é chegar a seu trabalho na hora certa”, sendo "uma das qualidades mais importantes do metrô ... sua confiabilidade em termos do fluxo de trens e da duração do trajeto".

As considerações acima, no entender do autor da presente dissertação, convergem para o foco da pesquisa: o conceito de disponibilidade. ZARIFIAN (1999, p.34) considera o caso de empresas que utilizam uma infra-estrutura de rede "altamente integrada e, devido a isso, muito sensível a qualquer incidente", podendo paralisar, no caso do metrô, "a rede de linhas e todo o sistema de circulação de trens nas linhas". O "conceito fundamental que permite perceber qual é o desempenho 
esperado dessa infra-estrutura" é a "disponibilidade". Continuando a citar ZARIFIAN (1999, p.35-36), “disponibilidade é a capacidade da rede ... estar permanentemente em situação de ser usada, nas condições de funcionamento esperadas. A confiabilidade é uma condição da disponibilidade”. Este mesmo autor precisa melhor o conceito de disponibilidade, “em princípio clássico em manutenção. A disponibilidade não é valorizada em si mesma, como um recurso implantado nos equipamentos que constituem a rede. A origem de sua valorização está inteiramente ligada à garantia da execução do serviço. Haverá falta de disponibilidade quando a prestação do serviço é interrompida, ou perturbada e, por conseguinte, a geração do serviço, que depende dessa prestação, não é mais assegurada de maneira válida (deteriorando os critérios de avaliação dos resultados esperados)".

No entender de ZARIFIAN (1999, p.35), "o critério de disponibilidade da rede não é, basicamente, um critério de manutenção, mas um critério de serviço".

É importante citar que, ZARIFIAN (1999, p.35) avança na análise da disponibilidade e propõe um conceito que permita percebê-la e determiná-la: o conceito de incidente, que tem o sentido de prejudicar a produção do serviço, e, em função disso, vai mobilizar o "profissionalismo dos funcionários" da organização para o restabelecimento da prestação do serviço, e, no caso de um sistema como o do metrô, compreendendo que os problemas de sua eficiência dependem não apenas da confiabilidade intrínseca dos equipamentos, "mas de todo o sistema de informação incorporado, que informa e controla permanentemente o estado da disponibilidade". A produção e interpretação das informações pelos profissionais envolvidos passam a ser cruciais para o tratamento a ser dado no caso de incidente e a conseqüente mobilização de recursos.

\section{2 - Estrutura Analítica da Disponibilidade}

Aumentar a disponibilidade parece ser um objetivo clássico dos serviços de manutenção. Isso implica o crescimento da confiabilidade dos equipamentos e a diminuição das durações das intervenções de manutenção (MONCHY, 1989, p.109).

SLACK (2002, p.74) interpreta confiabilidade como "fazer as coisas em tempo para os consumidores receberem seus bens ou serviços prometidos", 
relacionando-a diretamente com um resultado a ser atingido: a disponibilidade operacional de equipamentos.

Tanto MONCHY como SLACK permitem confirmar o delineamento do desdobramento da disponibilidade em fatores contribuintes associados à confiabilidade e os associados aos tempos de reparo.

Para SILVA (1997, p.25), a forma de pensar da "era da máquina" envolve a doutrina do reducionismo ("todos os objetos e todos os fenômenos - assim como suas propriedades e também nossas experiências e conhecimento a respeito deles são compostos de elementos menores"), o pensamento analítico ("para se entender ou explicar alguma coisa, esta deve ser dividida em partes menores, que uma vez entendidas, tornam possível o entendimento do todo") e a análise ("para solucionar problemas é preciso subdividi-lo em problemas menores, que recebem soluções particulares").

A "era da máquina" é marcada pelo conceito do mecanicismo, onde um problema pode ser analisado e resolvido pela identificação, separação e estudo de seus elementos principais. Desse modo, torna-se possível descobrir quais são os elementos dos mecanismos, e as relações de causa e efeito entre eles, que compõem a máquina (MARTINS, 1999, p.21).

Assim, em função dessa forma de pensar, e considerando-se o exposto neste Capítulo, é apresentada a Figura 3.1, traduzindo o esforço de desdobramento da disponibilidade, levando-se em conta, particularmente, a inserção da confiabilidade e da manutenibilidade do equipamento (KELLY, 1980, p.5), e dos tempos de paralisação dos equipamentos (BALDIN, 1982, p.84).

A manutenção pode ser considerada como uma combinação de operações (que serão mais detalhadas no item 3.3 deste estudo) conduzidas para controlar a disponibilidade dos equipamentos do sistema produtivo (KELLY, 1980, p.4). A disponibilidade é influenciada por meio de paralisações que requeiram a ação da equipe de manutenção. A Figura 3.1 apresenta fatores que afetam as paralisações e aponta sua correlação com a disponibilidade, entre os quais se encontram a confiabilidade e a manutenibilidade, que são características incorporadas ao equipamento na fase de projeto. 


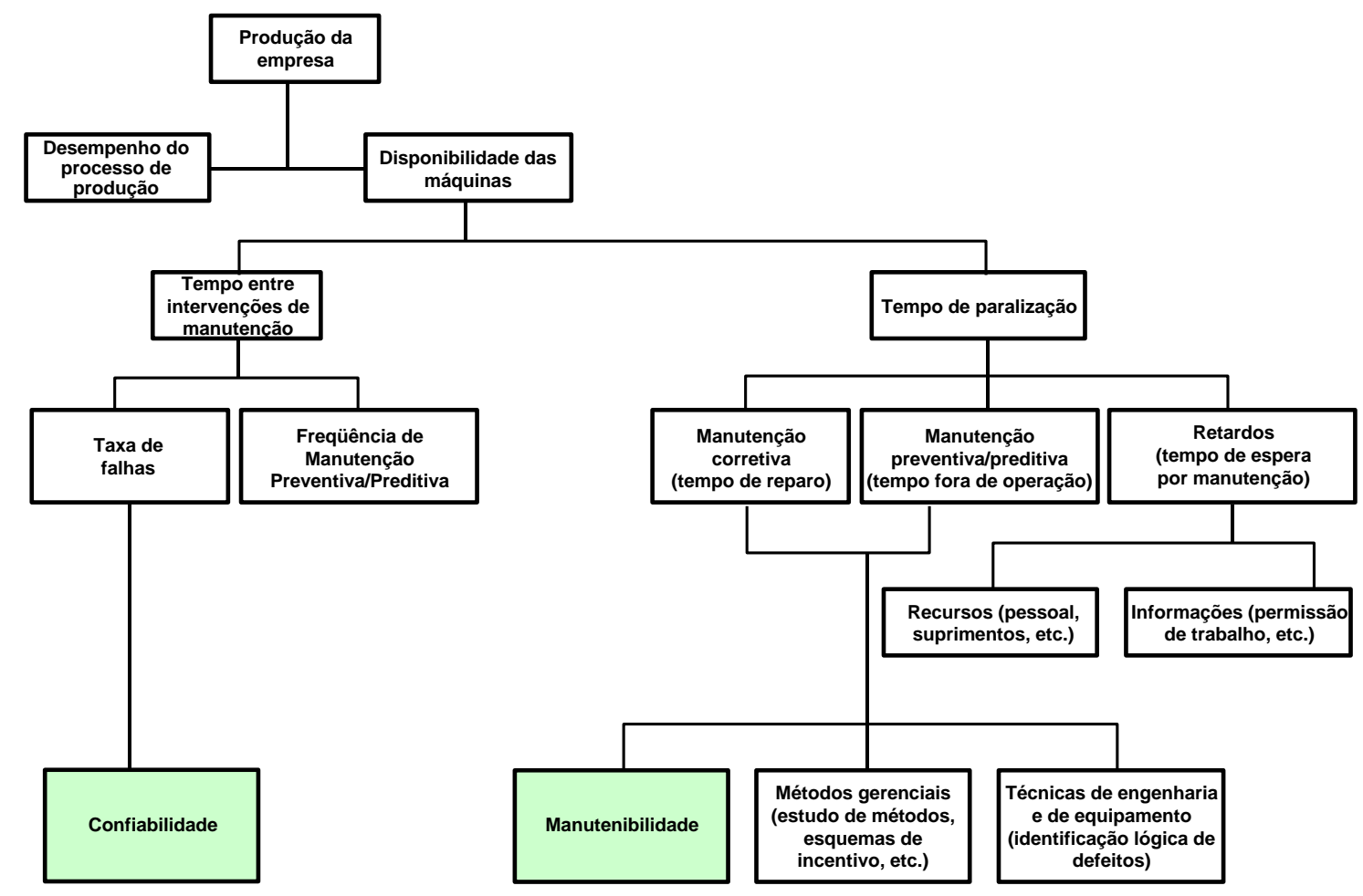

Figura 3.1 - Estrutura Analítica da Disponibilidade (Adaptada de Kelly, 1980, p. 5 e de Baldin, 1982, p. 84)

As causas intrínsecas de confiabilidade ou manutenibilidade insatisfatórias, só poderão ser reduzidas por alterações de especificações de projeto, nem sempre ao alcance direto dos gestores da manutenção. A função manutenção interfere na disponibilidade, de forma mais direta, por meio de políticas de Manutenção Preventiva (MP) e da Manutenção Corretiva (MC). Em seqüência, no item 3.3, mostra-se que a MP pode ser conduzida tomando por base intervalos prédeterminados e/ou condições pré-estabelecidas de funcionamento (KELLY, 1980, p.6). Neste último caso, quando há o monitoramento de condição do equipamento, alguns autores sugerem um conceito derivado da MP, denominado Manutenção Preditiva. A MP pode determinar que, para sua execução, o equipamento seja colocado fora de operação, interferindo na disponibilidade.

Já, a política de MC corresponde à atuação sobre o equipamento após a ocorrência de falha, ou quando fica abaixo de uma condição aceitável estando este em operação (KELLY, 1980, p.6), também interferindo na disponibilidade, em função de paralisação do equipamento para reparo. 
Assim, o tempo de paralisação decorre não só do tempo de atuação sobre o equipamento, mas também de atrasos devido à falta de recursos, de informação, e de técnicas e de métodos engenharia adequados.

\section{3 - Operações Elementares, Políticas e Abordagens de Gestão da Manutenção}

Como ponto de partida para as próximas considerações, entende-se o conceito de serviço (no singular), expresso por ZARIFIAN (1999, p.4), como capaz de englobar os serviços desenvolvidos pela função manutenção. Este autor, ao procurar uma definição geral para o "valor do serviço", aponta que foram herdadas da administração concreta de empresas duas abordagens importantes:

- A do valor-trabalho, desenvolvida com o estabelecimento do taylorismo: "a administração das empresas vai ser exercida tomando como modelo, prioritariamente, a diminuição do tempo de trabalho por unidade de mercadoria, o que redunda em um duplo ganho - um ganho de competitividade em face dos concorrentes (diminuição dos custos) e um ganho de rentabilidade em face dos empregados (elevação da taxa de lucro mesmo quando a média absoluta dos salários aumenta)".

- A do valor-desempenho, proposta mais recentemente, sob forte influência do modelo industrial japonês, sob a forma de um conjunto de desempenhos (custo, qualidade, variedade, inovação), a partir dos quais poderão ser pesquisadas formas dinâmicas de tomadas de decisão.

No contexto desta pesquisa, parece ser válido destacar a observação de ZARIFIAN (1999, p.4) de "que a introdução da noção de valor-desempenho constitui a oportunidade para a introdução do cliente como referência principal do complexo de desempenhos". Assim, o cliente passa a ser a referência principal na avaliação de desempenhos.

Interpretando CORRÊA e CAON (2002, p.29), é possível considerar a função produção como um cliente, interno à empresa, da função manutenção, despontando o indicador de disponibilidade como um avaliador de desempenho desse relacionamento. Manifesta-se, assim, uma possibilidade de avaliação de como o 
"produto" do serviço função manutenção é recebido pela função produção e da qualidade desse serviço.

Ainda, recorrendo a ZARIFIAN (1999, p.6), este autor ao analisar "o valor de serviço a partir dos resultados", procurando precisar o objeto de avaliação, aponta que não é em relação a um estado ou a uma condição de um objeto, mas a uma atividade que se pode julgar os resultados produzidos pelo serviço. Assim, deduz-se que, quando a falha de um equipamento é tratada e eliminada, ocorre uma transformação nas condições de atividade da função produção. Parafraseando ZARIFIAN (1999, p.7), já que a transformação se dá nas condições de atividade da função produção, o intermediário (reparo do equipamento) não é senão um meio para a realização do serviço, não sendo ele o serviço. O serviço prestado não é o reparo do equipamento, é a sua disponibilidade recobrada. "O serviço é o efeito, o resultado, nas condições de exercício da atividade”. (ZARIFIAN, 1999, p.8).

Para os fins da presente pesquisa, entende-se que esse "intermediário", caracterizado por ZARIFIAN, corresponde no cotidiano das empresas, às operações desempenhadas no âmbito da função manutenção para assegurar a disponibilidade do equipamento para a função produção.

\subsection{1 - Operações Elementares de Manutenção}

De início, vale lembrar que a manutenção como função (significando a parte da organização que produz os serviços para assegurar a disponibilidade dos equipamentos) se diferencia da manutenção como processo (significando qualquer transformação de recursos de input para gerar a disponibilidade dos equipamentos para o cliente interno produção (SLACK, 2002, p.44).

Ao abordarem-se as atividades de manutenção é necessário considerá-las como agrupadas em dois blocos: aquelas que são executadas diretamente sobre os equipamentos e aquelas que correspondem a estudos, planejamento, programações, definições de estratégias e políticas de atuação para execução do primeiro bloco. Enquanto as primeiras são executadas ao nível de "chão de fábrica", as últimas são desenvolvidas ao nível de escritório, de um escalão decisório, em princípio concatenadas com as estratégias empresariais. Na verdade, a efetividade dessa concatenação faz parte das preocupações da presente pesquisa. 
"Qualquer operação produz bens ou serviços, ou um misto dos dois, e faz isso por um processo de transformação. Por transformação" entende-se "o uso de recursos para mudar o estado ou condição de algo para produzir outputs" (SLACK, 2002, p.36). Assim, os inputs para o processo de transformação, no âmbito da função manutenção, são:

- os recursos transformados - os que são tratados, transformados ou convertidos de alguma forma (materiais, informações e, como recurso dominante, os equipamentos objeto de manutenção).

- recursos de transformação - instalações e funcionários de manutenção, que agem sobre os recursos transformados.

A caracterização de operações de manutenção que serão adjetivadas como elementares, no âmbito deste trabalho, representa um primeiro passo para a construção da Tabela 3.2, onde se procura associá-las às políticas de manutenção, as quais serão caracterizadas no item 3.3.2. Diversos textos se preocupam com as operações de manutenção, apresentando-as de forma dissertativa e com terminologia nem sempre coincidente. Assim, julgamos conveniente estabelecer uma estrutura que possa caracterizá-las melhor, tendo como ponto de partida as operações de manutenção levantadas por LIMA (1992, p.10). Essas operações, que ocorrem ao nível do equipamento produtivo, serão as aqui consideradas como "operações elementares de manutenção":

- Conservação: cuidados sistemáticos sobre componentes de equipamentos e sistemas, com o propósito de os manter em bom estado. Incluem: lubrificação, calibração, ajuste, limpeza, substituição.

- Teste: Verificação de desempenho de equipamentos e componentes de sistemas.

- Inspeção: exames programados ou não, de equipamentos e componentes utilizando critérios e procedimentos prescritos.

- Restauração: ações programadas para aumentar a vida de equipamentos e componentes, visando a atender aos padrões específicos de renovação e modernização.

- Reparo: o processo de retornar um item a uma condição especificada, incluindo, localização da falha, aprovisionamento de material, correção, ajuste e teste. 
Essas operações elementares de manutenção podem ser desenvolvidas em conjunto, ou individualmente, no dia-a-dia da manutenção. Na verdade, ao se considerar que a "manutenção é a medicina dos equipamentos" (MONCHY, 1987, p.2), pode-se reunir essas operações elementares em dois grupos básicos, fazendo uma analogia com as atividades médicas:

- Acompanhamento, inspeções e testes, que não implicam alteração do estado dos componentes dos equipamentos, e

- Intervenções (conservação, restauração e reparo), que implicam alteração de estado do equipamento ou de seus componentes.

Um conjunto de operações elementares, citado na literatura (TAKAHASHI e OSADA, 1993, p.122; XENOS, 1998, p.275), corresponde à prática básica identificada por $\mathbf{5 S}$, que é considerada na manutenção moderna. Essa prática, originária do Japão, é aplicada como base para o desenvolvimento de Sistemas da Qualidade. Deriva das iniciais das cinco palavras que definem suas principais dimensões: Seiri (Organização), Seiton (Ordem), Seiso (Limpeza), Seiketsu (Asseio) e Shitsuke (Disciplina) (KARDEC e NASCIF, 2001, p.174).

\subsection{2 - Caracterização de Políticas de Manutenção}

A gestão da função manutenção envolve um volume relativamente considerável de decisões em tempos relativamente curtos. Em função disso, é vital que se tenha um conjunto de princípios gerais que possa orientar a tomada de decisão em direção a objetivos estabelecidos, sendo um desses a disponibilidade.

Procurando caracterizar um conceito para "política de manutenção", encontra-se em LIMA (1992, p.7), uma proposição que permite o balizamento de uma definição: "a distribuição de recursos (homens, materiais e capital) entre os tipos alternativos de ações de manutenção que estão disponíveis para o administrador". Complementando, "os diversos tipos de manutenção podem também ser considerados como políticas de manutenção, desde que a sua aplicação seja o resultado de uma definição gerencial ou política global da instalação, baseada em dados técnicos e econômicos" (KARDEC e NASCIF, 2001, p.36). 
Assim, tomando por base considerações de KELLY (1980, p.72), BALDIN (1982, p.91), KARDEC e NASCIF (2001, p.36), e LIMA (1992, p.7), estrutura-se, em seqüência, uma relação de possíveis políticas para o exercício da manutenção, as quais, por sua vez, serão exercidas através das operações elementares de manutenção, que representam a ação sobre o equipamento. A Tabela 3.2, associando as operações elementares e as políticas de manutenção, representa o resultado de um esforço para resumir conceitos que, de modo geral, apresentam-se de forma esparsa na literatura revisada, e com terminologia nem sempre coincidente.

Segundo KARDEC e NASCIF (2001, p.38), “a análise conjunta, levando em conta outros fatores, definirá a melhor política". Esses "outros fatores”, embora não citados de modo explícito por esses autores, estão, de algum modo, associados a compromissos, com os quais a gestão da manutenção, na busca da disponibilidade, irá se defrontar. Esses compromissos surgem como um tema atraente para uma investigação e serão objeto de considerações mais aprofundadas no item 3.4 do presente trabalho.

\subsubsection{1 - Manutenção Corretiva}

Essa política corresponde a realizar a operação de intervenção de manutenção após a ocorrência da falha (SLACK, 2002, p.645; HIPKIN e DE COCK, 2000, p.278; MONCHY, 1989, p.37).

Outra interpretação é considerar a Manutenção Corretiva como "a atuação para a correção da falha ou do desempenho menor que o esperado" (KARDEC e NASCIF, 2001, p.36).

Ao atuar em um equipamento que apresenta um defeito ou um desempenho diferente do esperado, faz-se Manutenção Corretiva. Assim, a Manutenção Corretiva não é, necessariamente, uma manutenção de emergência (KARDEC e NASCIF, 2001, p.36).

Convém observar que existem duas condições específicas que levam à Manutenção Corretiva: desempenho deficiente apontado pelo acompanhamento das variáveis operacionais e a ocorrência da falha. Desse modo, a ação principal na Manutenção Corretiva é corrigir ou restaurar as condições de funcionamento do equipamento ou sistema. 


\begin{tabular}{|c|c|c|c|}
\hline & OPERAÇÕES ELEMENTARES & \multirow{2}{*}{\multicolumn{2}{|c|}{ POLÍTICAS }} \\
\hline \multirow[t]{2}{*}{$\begin{array}{l}\text { ACOMPANHAMENTO, } \\
\text { INSPEÇÕES E TESTES }\end{array}$} & INTERVENÇÕES & & \\
\hline & $\begin{array}{l}\text { 1. INTERVENÇÃO CORRETIVA: Intervenção de manutenção após a falha ou } \\
\text { um desempenho menor que o esperado. }\end{array}$ & \multicolumn{2}{|c|}{$\begin{array}{l}\text { MANUTENÇÃO } \\
\text { CORRETIVA }\end{array}$} \\
\hline \multirow{2}{*}{$\begin{array}{l}\text { VISITAS SISTEMÁTICAS } \\
\text { ACOMPANHAMENTO } \\
\text { INSPEÇÕES E } \\
\text { TESTES }\end{array}$} & $\begin{array}{l}\text { 2. INTERVENÇÃO PREVENTIVA: Intervenção da manutenção para reduzir ou } \\
\text { evitar a ocorrência de falhas ou evitar queda do desempenho, obedecendo a } \\
\text { um programa baseado ou intervalos pré-definidos (tempo, produção, } \\
\text { quilometragem). }\end{array}$ & $\begin{array}{l}\text { MANUTENÇÃO } \\
\text { PREVENTIVA }\end{array}$ & \multirow{5}{*}{ 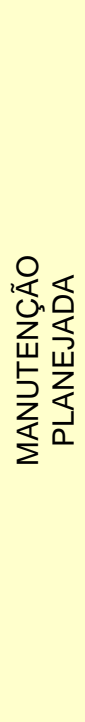 } \\
\hline & $\begin{array}{l}\text { 3. INTERVENÇÃO BASEADA NA CONDIÇÃO: Intervenção realizada com } \\
\text { base em alterações de parâmetros de "condição" ou "desempenho". } \\
\text { 3.1 Intervenção realizada na ocasião da detecção da alteração de parâmetros } \\
\text { de "condição" ou "desempenho". } \\
\text { 3.2 Intervenção decorrente da análise de tendência de parâmetros de } \\
\text { "condição" ou "desempenho". }\end{array}$ & $\begin{array}{l}\text { MANUTENÇÃO } \\
\text { PREDITIVA }\end{array}$ & \\
\hline $\begin{array}{l}\text { ACOMPANHAMENTO } \\
\text { INSPEÇÕES E TESTES }\end{array}$ & $\begin{array}{l}\text { 4. PARADA DE MANUTENÇÃO/REVISÃO GERAL: Intervenção adicional } \\
\text { visando restaurar e/ou melhorar as condições de equipamentos e instalações, } \\
\text { estruturada a partir dos dados da produção, inspeções, manutenção e } \\
\text { inspeção de equipamentos. }\end{array}$ & $\begin{array}{l}\text { MANUTENÇÃO } \\
\text { PREVENTIVA }\end{array}$ & \\
\hline $\begin{array}{l}\text { INSPEÇÕES } \\
\text { E TESTES }\end{array}$ & $\begin{array}{l}\text { 5. INTERVENÇÃO DE OPORTUNIDADE: Intervenção adicional efetuada } \\
\text { sobre o equipamento aproveitando-se qualquer ocasião associada a alguma } \\
\text { intervenção planejada ou não. }\end{array}$ & $\begin{array}{l}\text { MANUTENÇÃO } \\
\text { PREVENTIVA }\end{array}$ & \\
\hline \multirow[t]{4}{*}{$\begin{array}{l}\text { INSPEÇÕES } \\
\text { E TESTES }\end{array}$} & 6. Intervenção decorrente de verificações funcionais & $\begin{array}{l}\text { MANUTENÇÃO } \\
\text { DETECTIVA }\end{array}$ & \\
\hline & $\begin{array}{l}\text { 7. INTERVENÇÃO PARA MELHORIA DA DISPONIBILIDADE } \\
\text { 7.1 Melhoria da Confiabilidade } \\
\text { 7.1.1 Decorrente da Análise do Modo e Efeito de Falha (FMEA) } \\
\text { 7.1.2 Decorrente da Análise das Causas-raízes da Falha (RCFA) } \\
\text { 7.1.3 Análise de Falhas já ocorridas: Método da análise e Solução de } \\
\text { Problemas da Gestão pela Qualidade Total. } \\
\text { 7.2 Melhoria da Manutenibilidade }\end{array}$ & \multicolumn{2}{|c|}{$\begin{array}{l}\text { ENGENHARIA DE } \\
\text { MANUTENÇÃO }\end{array}$} \\
\hline & 8. EVITAR INTERVENÇÃO & \multicolumn{2}{|c|}{$\begin{array}{l}\text { PREVENÇÃO DE } \\
\text { MANUTENÇÃO }\end{array}$} \\
\hline & $\begin{array}{l}\text { 9. INTERVENÇÃO APÓS A QUEBRA: decorrente de uma política explícita de } \\
\text { "operar até quebrar" }\end{array}$ & \multicolumn{2}{|c|}{$\begin{array}{l}\text { OPERAR ATÉ } \\
\text { QUEBRAR }\end{array}$} \\
\hline
\end{tabular}

Tabela 3.2 - Operações Elementares e Políticas de Manutenção (Elaborada pelo Autor) 
A Manutenção Corretiva pode ser dividida em duas classes: Manutenção Corretiva não Planejada e Manutenção Corretiva Planejada.

\subsubsection{1 - Manutenção Corretiva não Planejada}

Manutenção Corretiva não Planejada implica na correção da falha sem qualquer programação prévia. Caracteriza-se pela atuação da equipe de manutenção em fato já ocorrido, seja esse uma falha, ou um desempenho menor que o esperado.

Normalmente, a Manutenção Corretiva não Planejada implica em custos elevados, pois a quebra inesperada pode acarretar perdas de produção, perda de qualidade do produto e elevados custos indiretos de manutenção.

Além disso, quebras aleatórias podem provocar consequiências graves para o equipamento. Em plantas industriais de processo contínuo (como petróleo, petroquímico, e cimento) estão presentes elevadas pressões, temperaturas e vazões, com considerável quantidade de energia desenvolvida no processo. Interromper processos dessa natureza, de forma abrupta, para reparar um determinado equipamento pode comprometer a qualidade de outros, que operam adequadamente, levando-os a colapsos ou a uma redução da campanha de produção da planta. Um exemplo típico é o surgimento de vibrações em equipamentos de grande porte que apresentavam funcionamento suave antes da ocorrência de uma intervenção (KARDEC e NASCIF, 2001, p.37).

Pode-se deduzir que, quando uma empresa tem a maior parte de sua Manutenção Corretiva na classe não planejada, a equipe de manutenção é comandada pelos equipamentos.

Ainda, no que diz respeito aos serviços de emergência, SLACK (2002, p.73) afirma que, de todas as operações que necessitam dar uma resposta rápida às demandas da função produção, poucas necessitam mais rapidez do que os serviços de emergência, delineando um desdobramento do tempo de resposta em três elementos: o tempo para a manutenção caracterizar o evento, o tempo de deslocamento da equipe e o tempo para tratar o equipamento de modo adequado.

\section{Manutenção Corretiva Paliativa}

Esse enfoque de manutenção corretiva é apresentado por MONCHY (1989, p.37): é a ação de tirar um equipamento do estado de pane, isto é, de recolocá-lo em 
estado de funcionamento in situ, às vezes sem mesmo interromper o funcionamento do conjunto em que está inserido. Tem um caráter provisório.

\section{Manutenção Corretiva Curativa}

O mesmo autor também apresenta esse outro enfoque, quando os reparos (consertos), feitos in situ, ou na oficina central, por vezes após a retirada do estado de pane, têm um caráter definitivo.

\subsubsection{2 - Manutenção Corretiva Planejada}

De modo diferente da Manutenção Corretiva não Planejada, a Manutenção Corretiva Planejada é a correção do desempenho menor que o esperado, ou da falha, em decorrência de uma tomada de decisão gerencial, isto é, pela atuação em função de acompanhamento preditivo ou pela decisão de operar até a quebra (KARDEC e NASCIF, 2001, p.38). A descrição desses autores revela uma superposição de conceitos com a Manutenção Preditiva, que será exposta no item 3.3.2.3.

Para isso, é essencial dispor de informação confiável, obtida por meio de acompanhamento do estado do equipamento.

A adoção de uma política de Manutenção Corretiva Planejada requer considerar uma série de fatores:

- compatibilização da necessidade da intervenção com os interesses da produção.

- aspectos relacionados com a segurança - a falha não provoca nenhuma situação de risco para o pessoal ou para a instalação.

- planejamento adequado dos serviços de manutenção.

- garantia da existência de sobressalentes, equipamentos e ferramental.

- presença de recursos humanos e da tecnologia necessária para a execução dos serviços.

No entender de KARDEC e NASCIF (2001, p.39), quanto maiores forem as implicações da falha na segurança pessoal e operacional, no seu custo intrínseco, nos compromissos de entrega da produção, mais marcantes serão as condições de adoção da política de Manutenção Corretiva Planejada. Essa afirmação se soma às contribuições para a preocupação com compromissos, que conforme já apontado, serão detalhadas no item 3.4 deste estudo. 


\subsubsection{2 - Manutenção Preventiva}

Como a política de Manutenção Corretiva implica em perturbações para a disponibilidade do sistema produtivo, o desenvolvimento da Manutenção Preventiva (limpeza, lubrificação, substituição e verificação, em intervalos pré-planejados) visa a eliminar ou reduzir as probabilidades de falhas das instalações (SLACK, 2002, p.645).

Manutenção Preventiva é a "manutenção efetuada com a intenção de reduzir a probabilidade de falha de um bem ou a degradação do serviço prestado" (MONCHY, 1989, p.39). Essa definição tem implícito em seus objetivos assegurar a confiabilidade de um equipamento, reduzindo falhas em serviço e melhorando a disponibilidade operacional.

Portanto, constitui-se em um serviço programado, que envolve a observação sistemática de rotinas, não só pela função produção como pela própria função que executa o serviço de manutenção. Inclui conservação, inspeção e testes para corrigir pequenos e incipientes funcionamentos insatisfatórios, que reduzem a eficiência de sistemas/componentes (LIMA, 1992, p.4).

Muitas empresas, segundo BALDIN (1982, p.91), adotam a intervenção por substituição do componente. A substituição preventiva, definida por esse autor, é a "troca de um componente de um equipamento por outro novo, baseando-se no fato de que o original funcionou por um determinado número de horas, ainda que de forma perfeita".

O método da substituição é aceitável para aumentar a disponibilidade dos equipamentos, mas BALDIN (1982, p.92) aponta que ele só é economicamente válido quando a taxa de falha do componente é crescente, e o custo total da intervenção de emergência (custo de parada do equipamento, mais o custo da peça ou de sobressalentes, mais o custo da mão-de-obra), ao ocorrer a falha, é superior ao custo total da intervenção (substituição) preventiva.

Inversamente à política de Manutenção Corretiva, a Manutenção Preventiva procura evitar a ocorrência de falhas, ou seja, procura prevenir. Em determinados setores, como na aviação, a adoção de Manutenção Preventiva é imperativa para determinados sistemas ou componentes, pois o fator segurança se sobrepõe aos demais (KARDEC e NASCIF, 2001, p.39). 
Como, nem sempre, os fabricantes dos equipamentos fornecem dados precisos para orientar os planos de Manutenção Preventiva, além das condições operacionais e ambientais influírem de modo significativo na expectativa de degradação dos equipamentos, a definição de periodicidade e substituição para cada instalação pode tomar como base o histórico de plantas similares, operando em condições também similares (KARDEC e NASCIF, 2001, p.40).

Contudo, ao longo da vida útil do equipamento não pode ser descartada a eventual ocorrência de "falha entre duas intervenções preventivas, o que, obviamente, implicará uma ação corretiva" (KARDEC e NASCIF, 2001, p.40).

Entretanto, ainda para estes autores (KARDEC e NASCIF, 2001, p.41), há fatores que devem ser levados em consideração para adoção de uma política de Manutenção Preventiva, que mais uma vez, de modo implícito, tangenciam a necessidade de se levar em conta compromissos de gestão. Entre eles, os autores destacam:

- inviabilidade da Manutenção Preditiva (que será abordada no item 3.3.2.3),

- requisitos de segurança pessoal ou da instalação que tornam impositiva a intervenção, normalmente para substituição de componentes,

- aproveitamento da oportunidade de interrupção em equipamentos críticos de difícil liberação operacional,

- riscos de agressão ao meio ambiente, e

- presença de sistemas complexos e/ou de operação contínua.

Se, por um lado, a Manutenção Preventiva proporciona um conhecimento prévio das ações de manutenção, pode por outro lado provocar a retirada do equipamento ou sistema de operação para execução dos serviços programados, ocasionando queda da disponibilidade. Assim, prováveis questionamentos à política de Manutenção Preventiva podem ser apresentados pelos operadores de sistemas produtivos, em função do processo de produção.

Nesse contexto, KARDEC e NASCIF (2001, p.41) apontam também riscos da Manutenção Preventiva introduzir defeitos devido a falha humana, falta de qualidade dos sobressalentes, introdução de contaminação, danos durante paradas e partidas, e falhas das próprias instruções de manutenção. 
Ainda, pode ser considerada nesse contexto preventivo a chamada "manutenção de oportunidade", que corresponde a "intervenções adicionais", aproveitando-se qualquer ocasião associada a alguma intervenção que já esteja sendo executada.

\subsubsection{3 - Manutenção Preditiva}

A Manutenção Preditiva, também entendida como manutenção sob condição ou manutenção com base no estado do equipamento, refere-se a ações que predizem a falha (HIPKIN e DE COCK, 2000, p.278); visa a realizar manutenção somente quando as instalações dela precisarem. Pode incluir a monitoração contínua da condição do equipamento. Os resultados dessa monitoração seriam, então, a base para decidir se o equipamento deve ser parado e peças substituídas (SLACK, 2002, p.645); é a atuação realizada com base em monitoração de parâmetro de condição ou desempenho, exigindo acompanhamento sistemático do equipamento (KARDEC e NASCIF, 2001, p41).

Para BALDIN (1982, p.293), o que distingue esse modo de praticar manutenção é a estreita subordinação das intervenções ao resultado de inspeções. Como exemplos de parâmetros a inspecionar, mais comuns, BALDIN (1982, p.296) indica:

a) nível de vibração

b) espessura de materiais

c) grau de impureza metálicas em lubrificantes.

A adoção desse tipo de política requer um eficaz sistema de informação sobre o estado dos equipamentos. A validade do processo se baseia fundamentalmente na validade da informação, na freqüência de inspeções que devem ter caráter sistemático e num elevado grau de confiabilidade dos diagnósticos (BALDIN, 1982, p.227).

O objetivo da Manutenção Preditiva é prevenir falhas nos equipamentos ou sistemas através de acompanhamento de parâmetros, de modo geral, permitindo a operação contínua do equipamento pelo maior tempo possível. Na realidade, a Manutenção Preditiva associa-se a predizer as condições dos equipamentos, ou seja, 
a Manutenção Preditiva privilegia a disponibilidade à medida que minimiza a intervenção nos equipamentos ou sistemas principalmente quando eles são necessários sob o ponto de vista operacional (KARDEC e NASCIF, 2001, p.42).

Assim, quando o grau de degradação se aproxima ou atinge o limite previamente estabelecido, é executada a intervenção, em função de um acompanhamento sistemático. Normalmente, esse tipo de acompanhamento permite a preparação prévia do serviço, além de compatibilizar a atuação da Manutenção com estratégias relacionadas com a Produção.

Em resumo, as condições básicas (KARDEC e NASCIF, 2001, p.42) para adotar a Manutenção Preditiva requerem que:

- o equipamento/sistema permita algum tipo de monitoramento/medição;

- o equipamento, sistema ou instalação mereça essa política de manutenção em função dos custos envolvidos;

- as falhas sejam oriundas de causas que possam ser monitoradas e ter sua evolução acompanhada;

- seja estabelecido um programa sistematizado de acompanhamento, análise e diagnóstico.

\subsubsection{4 - Manutenção Detectiva}

Manutenção Detectiva (Detective Maintenance) corresponde a verificações funcionais, freqüentemente de sistemas de proteção, para verificar se eles encontramse efetivamente ativos (HIPKIN e DE COCK, 2000, p.278).

A Manutenção Detectiva começou a ser citada na literatura a partir da década de 90. Essa denominação deriva do termo detectar e tem sido adotada para indicar atuação efetuada em sistemas de proteção buscando detectar falhas desses sistemas, chamadas de ocultas, e que não são perceptíveis de imediato ao pessoal de operação e manutenção (KARDEC e NASCIF, 2001, p.44).

Em sistemas automatizados, a identificação de falhas ocultas é primordial para garantir a confiabilidade. Nesses sistemas complexos essas ações só devem ser levadas a efeito por pessoal devidamente treinado e habilitado, da área de manutenção em conjunto com o pessoal da operação. Especialistas fazem verificações no sistema, sem tirá-lo de operação, com habilidade para detectar essas 
falhas ocultas, e preferencialmente corrigir a situação, mantendo o sistema operando (KARDEC e NASCIF, 2001, p. 44 e p.46).

\subsubsection{5 - Manutenção Planejada}

Manutenção Planejada é uma forma genérica de expressar a abrangência das políticas Preventiva, Preditiva e Detectiva. Particularmente, HIPKIN e DE COCK (1999, p.278) utilizam a expressão Manutenção Pró-ativa para designar o conjunto de políticas de Manutenção Preventiva e Manutenção Preditiva.

\subsubsection{6 - Prevenção de Manutenção}

Como parte do quadro conceitual da Tabela 3.2, vale destacar esse enfoque, já apresentado no item 2.3, tendo por referência NAKAJIMA (1989, p.14), TAKAHASHI e OSADA (1993, p.274) e SLACK (2002, p.648), pois parece pertinente considerá-lo como uma política de manutenção, exatamente pelo seu propósito de evitar a execução de operações de manutenção.

\subsubsection{7 - Política "operar até quebrar"}

Essa política decorre de uma decisão gerencial que, de modo explícito, estabelece que não se toma qualquer ação pré-determinada para evitar a falha, ou a quebra do equipamento ou de seus componentes (KELLY, 1980, p.75). Pode-se deduzir que essa decisão busca um compromisso com custos envolvidos. Contudo, as falhas, nessas condições, não podem envolver aspectos de segurança nem ser freqüentes, casos em que se requer verificações regulares do estado das instalações.

Entretanto, mesmo que a decisão gerencial seja de deixar o equipamento funcionar até a quebra, algum planejamento pode ser feito para quando a falha ocorrer. Por exemplo, substituir o equipamento por outro idêntico, ter um "kit" para reparo rápido, ou preparar o posto de trabalho com dispositivos e facilidades para a equipe de manutenção.

\subsection{3 - Gestão do Processo de Manutenção}

Os gestores da manutenção devem se preocupar com a especificação das políticas e operações de manutenção e seu aprimoramento, em função da 
monitoração de resultados obtidos. Métodos apropriados devem ser usados para se assegurar o atendimento, pela função manutenção, de requisitos de desempenho, de confiabilidade, de custos e de segurança, enquanto fornecedora de serviços à função produção.

Em BURGESS (1984, p.7) encontram-se alguns elementos da função engenharia, na busca da excelência. No entender deste pesquisador esses elementos podem aqui ser, e são, ajustados à gestão do processo de manutenção:

- Impulsionar direção e ação: a gestão da manutenção deve converter políticas em direção e ação. Essa gestão deve impulsionar a liderança para que programas de manutenção funcionem. Sem os necessários recursos para o emprego de métodos e procedimentos aplicáveis "qualquer programa não passa de uma fantasia".

- Dar suporte ao treinamento: o desenvolvimento de novos métodos implica em treinamento do pessoal envolvido para sua adoção. E aqui, também se inserem duas questões-chave apontadas por BURGESS (1984, p.7): o como se quer que o trabalho seja executado e o por que é importante atuar segundo determinado procedimento. Responder a estas duas questões é essencial para se atingir resultados especificados.

- Monitorar e avaliar resultados: a gestão da manutenção deve periodicamente monitorar o seu progresso e avaliar resultados. Nessa recomendação, insere-se a disponibilidade como um resultado que deve ser avaliado.

- Perseguir a busca da excelência: a gestão da manutenção deve estar ativamente envolvida com o aprimoramento integrado da qualidade, por meio de um processo contínuo.

Já, interpretando KARDEC e NASCIF (2001, p.46), a gestão da manutenção compreende "deixar de ficar consertando de forma constante", para procurar as causas básicas de falhas, modificar situações permanentes de mau desempenho, deixar de conviver com problemas crônicos, melhorar padrões e procedimentos, desenvolver a manutenibilidade, dar feedback à função projeto e interferir tecnicamente no suprimento de materiais.

Em qualquer sistema produtivo, sempre haverá lugar para as diferentes políticas e operações de manutenção (KARDEC e NASCIF, 2001, p.53). O 
predomínio de uma, ou outra, deriva de uma decisão gerencial que deve considerar fatores como:

a) Importância do equipamento do ponto de vista operacional, de segurança pessoal, de segurança da instalação (dos equipamentos do sistema produtivo), e do meio ambiente.

b) Custos envolvidos no processo, no reparo/substituição e nas conseqüências da falha.

c) Oportunidade que se manifesta para a execução do serviço de manutenção.

d) Capacidade de adequação do equipamento/instalação favorecer a aplicação de determinada política ou operação de manutenção.

Concluindo, o desenvolvimento da gestão da manutenção nas organizações produtivas deve se concentrar no desenvolvimento de técnicas e métodos de gerenciamento que enfatizem a definição de procedimentos pré-estabelecidos e que promovam a diminuição da probabilidade de falhas, antecipando-se a sua ocorrência. Essa gestão deve aprimorar métodos estatísticos para cálculo e determinação da disponibilidade e confiabilidade dos equipamentos, aperfeiçoar "os equipamentos e tecnologias para inspeção, detecção e monitoramento das condições operacionais dos equipamentos (como líquido penetrante, ressonância magnética, análise de vibração, ferrografia e termografia), além de ampliar as capacidades de gerenciamento para o planejamento e programação das atividades de manutenção de acordo com cronogramas pré-definidos" (CAVALCANTE, 1998, p.77).

\subsection{4 - Técnicas para Melhoria da Disponibilidade}

Como parte da função gestão do processo de manutenção, na busca de excelência, os tomadores de decisão devem se munir da adoção de técnicas para a melhoria da disponibilidade, através da melhoria da confiabilidade e da manutenibilidade. $\mathrm{Na}$ busca do aprimoramento da disponibilidade, essas técnicas devem ser consideradas. Uma pesquisa da literatura aponta algumas delas. 


\subsubsection{1 - Técnicas para Melhoria da Confiabilidade}

A disponibilidade pode ser aprimorada através da confiabilidade. BURGESS (1984, p.238) sugere uma série de técnicas para essa finalidade:

- Análise de Pareto: é a representação gráfica do arranjo de problemas na ordem decrescente de sua frequiência de ocorrência ou de seu impacto. Esse diagrama é particularmente útil por ocasião da apresentação de dados para a definição de prioridades por parte dos gestores da manutenção.

- Diagrama de causa e efeito: é uma ferramenta para a solução de problemas que apresenta graficamente os componentes lógicos de um problema. Embora o diagrama possa não resolver o problema de modo direto, ele representa um estímulo para se encaminhar para uma solução.

- Análise de falhas decorrentes de testes de materiais: o avanço tecnológico e o uso de laboratórios especializados de testes de materiais permitem caminhar no aperfeiçoamento da confiabilidade.

- Monitoração da alteração de projetos: procedimento que deve ser adotado para acompanhar a implementação de alteração de projeto visando a solucionar uma condição de falha ou um problema de campo recorrente.

- Simplicidade do projeto: a complexidade proporciona maiores oportunidades para a diminuição de confiabilidade.

- Redundância: é a presença de mais de um meio para o desempenho de uma determinada função. Um exemplo corresponde ao caso de equipamentos de bombeamento de líquidos reservas em operações de processo contínuo.

- Uso de peças de confiabilidade comprovada: isso requer histórico, portanto, informação, para verificação de peças que apresentaram taxas de falhas zero ou de pequena monta.

- Uso de métodos de projeto de sucesso comprovado.

- Análise e Revisão criteriosas de projetos.

- Análise do Modo e Efeito de Falhas (FMEA): método de análise de produto (equipamento) ou processo, usado para identificar os possíveis modos de falha e determinar seu efeito sobre os respectivos desempenhos. Para que se calcule o risco (probabilidade de falha $\mathrm{X}$ severidade dos efeitos $\mathrm{X}$ probabilidade de detecção da falha), e se hierarquizem os modos de falha, investigam-se: 
- os modos potenciais de falha,

- os efeitos e os danos causados pela falha,

- a severidade do efeito,

- o mecanismo ou causa de falha,

- a probabilidade da ocorrência da falha,

- a possibilidade de detectar a falha antes de o efeito gerar suas conseqüências, e

- meios para eliminar ou ao menos reduzir o efeito da falha.

- Análise do Modo, Efeito e Criticidade de Falhas (FMECA): do inglês Failure Mode and Effect and Critical Analysis, é um método de análise que, partindo do FMEA, considera que determinados componentes são especialmente críticos para a operação do equipamento de que fazem parte.

- Modelagem da Confiabilidade.

- Análise de Tempo de Falha (Weibull Analysis): técnica que modela tempos de falha segundo algumas das distribuições estatísticas.

- Análise da Árvore de Falhas (FTA): estrutura as falhas de modo hierárquico, considerando que uma falha primária, ou evento de topo, podem ser causados por diversas falhas secundárias, que por sua vez são conseqüência de possíveis falhas terciárias, e assim por diante, até que se atinja o último nível significativo de falha. A cada modo de falha é associada uma probabilidade, geralmente obtida em base empírica.

\subsubsection{2 - Técnicas para a Melhoria da Manutenibilidade e do MTTR}

Quando se pesquisa a manutenibilidade, verifica-se que as recomendações para o seu tratamento estão bastante associadas à fase de projeto do equipamento.

Quanto ao MTTR, MONCHY (1989, p.219) e MIYAKE (1993, p.103), apontam para seu aprimoramento o desenvolvimento de estudos de tempos e métodos. Para isso podem ser aplicadas técnicas associadas a cronometragem, observações de campo, estimativas e registros documentais ou em vídeo. Estas considerações podem ser estendidas para todos os tempos de paralisação dos equipamentos, incluindo os referentes às políticas de Manutenção Preventiva. 


\subsection{5 - Abordagens de Gestão da Manutenção}

Há várias abordagens de gestão apontadas na literatura, para gerenciar a aplicação das políticas de manutenção e execução de operações elementares junto ao equipamento. Dentre elas, destacam-se a Manutenção Produtiva, a TPM e a RCM.

\subsubsection{1 - Manutenção Produtiva}

É uma abordagem de gestão da manutenção, que reconhece a importância da confiabilidade, manutenção e eficiência econômica nos projetos de sistemas produtivos (TAKAHASHI e OSADA, 1993, p.43; SLACK, 2002, p.648).

\subsubsection{2 - TPM: Total Productive Maintenance}

Algumas considerações, complementares às apresentadas no item 2.3 deste trabalho, são encaminhadas visando a caracterizar a TPM no contexto das abordagens de gestão da manutenção.

TPM é definida como, a Manutenção Produtiva realizada por todos os empregados através de atividades de pequenos grupos, onde Manutenção Produtiva corresponde ao conceituado no item 3.3.5.1 (SLACK, 2002, p.648). A TPM reúne funções e responsabilidades, através da implantação da manutenção autônoma integrando atividades de manutenção às atividades de operação por meio da capacitação, treinamento e envolvimento dos operadores para a realização de trabalhos da manutenção de rotina, redefinição de padrões de operação e de manutenção, utilização dos sentidos humanos no monitoramento de condições operacionais, e participação em análises e soluções de problemas (NAKAJIMA, 1989, p.85 ; TAKAHASHI e OSADA, 1993, p.7; MIYAKE, 1993, p.97).

Conforme CAVALCANTE (1998, p.7), Nakajima (1989) apresenta TPM, ou estilo japonês de manutenção, como um meio de garantir altos padrões de desempenho e confiabilidade para os sistemas produtivos "capazes de responder às exigências de competitividade das empresas que competem em mercados com demanda altamente variáveis".

Para SLACK (2002, p.489), a TPM visa a eliminar a variabilidade em processos de produção, decorrente do efeito de "quebras não planejadas", o que pode ser alcançado por meio do envolvimento de todos os funcionários, na busca de 
aprimoramentos na manutenção. Os donos de processos são incentivados a assumir a responsabilidade por suas máquinas, ou equipamentos, incluindo a execução de atividades rotineiras de manutenção e de reparos de pouca complexidade. Fazendo isso, os especialistas em manutenção podem, então, ser liberados para desenvolver qualificações de ordem superior, tendo em vista aprimorar o processo de manutenção.

Todavia, a caracterização do operador do equipamento como responsável pela supervisão e execução da manutenção de nível de menor complexidade, implica uma formação específica e que ele aceite tal responsabilidade (MONCHY, 1989, p.48).

Ainda a TPM implica o estabelecimento de um plano de manutenção, contemplando o ciclo de vida do equipamento por meio da eliminação das chamadas "seis grandes perdas": falha do equipamento, set-up e ajustes, ociosidade e pequenas paradas, redução de velocidade, deficiências de processo e queda de rendimento (HIPKIN e DE COCK, 2000, p.278). Inclui a Prevenção de Manutenção (PM), que pressupõe um projeto maitenance-free, Manutenção Preventiva (MP) e aprimoramento da manutenibilidade. Pequenas paradas são reduzidas pela lubrificação, limpeza, ajustes de desempenho e inspeções que são feitas pelos operadores, com a equipe de manutenção desempenhando inspeções periódicas e reparos preventivos de maior complexidade (HIPKIN e DE COCK, 2000, p.290).

NAKAJIMA (1989, p.12) sintetiza, em cinco características essenciais, a abordagem TPM:

1) maximizar a eficiência do equipamento;

2) desenvolvimento de Manutenção Produtiva prevendo a vida do equipamento;

3) envolvimento multidisciplinar na TPM (Engenharia, Projeto, Produção e Manutenção);

4) envolvimento participativo de todos os empregados;

5) promoção da TPM por meio de gestão da motivação (atividades de pequenos grupos).

A primeira é alcançada pela completa eliminação de falhas, defeitos e outros fenômenos negativos (o que é, na verdade, cerne da filosofia japonesa de zero defeitos). Destaca-se, assim, que a fusão da manutenção tradicional e das funções de produção, representa a aceitação de que se pode esperar dos operadores a execução 
de tarefas simples de manutenção. O desempenho operacional global, que inclui o desempenho econômico, é alcançado pela minimização dos custos de conservação e pela manutenção de condições ótimas do equipamento, ao longo da vida do equipamento por meio da minimização dos custos do ciclo de vida (HIPKIN e DE COCK, 2000, p.289).

De algum modo o modelo TPM sugere compatibilidade com teorias relacionadas com o enriquecimento de cargos, conforme apresentado por FLEURY e VARGAS (1983, p.32) ao descrever, entre os métodos para alcançar o enriquecimento, o da ampliação vertical: "é o caso em que se atribuem tarefas de diferentes naturezas para um cargo; por exemplo, um operador de torno seria também responsabilizado pela inspeção do produto e pela manutenção da máquina”.

Complementando, CAVALCANTE (1998, p.68) fornece subsídios para se afirmar que, na abordagem TPM, está implícita a integração de atividades de manutenção às de produção para:

- a realização da manutenção de rotina, com destaque para as atividades de limpeza, lubrificação, inspeção geral e ajustes;

- a redefinição de padrões de operação e manutenção dos equipamentos através das atividades de pequenos grupos;

- a utilização dos 5 sentidos do ser humano no monitoramento das condições operacionais do equipamento;

- a participação na análise e solução de problemas detectados e para a incorporação de melhorias voltadas para a eliminação das seis grandes perdas no(s) equipamento(s) sob sua responsabilidade.

Pondo termo a essas considerações sobre TPM, vale salientar a afirmação de MIYAKE (1993, p.97) de que um objetivo intrínseco da abordagem TPM é a maximização da disponibilidade dos equipamentos produtivos.

\subsubsection{3 - RCM: Reliability Centered Maintenance}

A abordagem RCM corresponde a "um processo usado para determinar o que deve ser feito para assegurar que qualquer ativo físico continue a fazer o que seus usuários querem que ele faça no seu contexto operacional” (MOUBRAY, 2003, p.7). 
A RCM, proveniente da indústria de aviação civil, é uma abordagem estruturada para determinar os requisitos de manutenção dos ativos físicos em seu contexto operacional. Estabelece os requisitos funcionais e os padrões de desempenho desejados para o sistema produtivo e seus equipamentos. Relacionandoos com o projeto e com parâmetros da confiabilidade inerente, características de falha funcional são determinadas e, para cada uma dessas, uma análise do modo e efeito de falhas (FMEA) é elaborada. As consequiências de cada falha se enquadram em uma das quatro categorias: conseqüências ambientais e de segurança (dano para o ser humano ou ruptura de algum regulamento ou padrão ambiental conhecido), consequiências operacionais (efeito adverso na capacidade operacional), conseqüências não operacionais (sem efeito adverso direto na segurança, no meio ambiente ou na capacidade operacional), ou conseqüências de falhas ocultas (associadas a dispositivos cuja função é assegurar que as conseqüências da falha de uma função original serão menos sérias do que seriam se elas não tivessem proteção) (HIPKIN e DE COCK, 1999, p.289; MOUBRAY, 2003, p.94-111).

Seguindo um processo de lógica de decisão, uma intervenção pró-ativa, baseada em restauração planejada, descarte planejado e manutenção sob condição (compreendendo o que tradicionalmente é conhecido como Manutenção Preditiva e Preventiva) é considerada, tratando as falhas de acordo com critérios de estrita aplicabilidade e desempenho desejado. Se os critérios para as tarefas pró-ativas não são atendidos, devem ser encaminhadas ações de default (que tratam do estado da falha e são escolhidas quando não é possível identificar uma tarefa pró-ativa efetiva) incluindo pesquisa de falha (para conseqüências ocultas), de possíveis alterações de projeto do equipamento, ou modificações nos procedimentos de operação, de manutenção, e treinamento ou manutenção não programada (HIPKIN e DE COCK, 2000, p.289; MOUBRAY, 2003, p.129).

Em síntese, "RCM é uma metodologia na qual a funcionalidade do equipamento, através da análise do modo e efeito de falha, e avaliação das consequiências da falha, é usada para determinar as adequadas tarefas de manutenção e os intervalos nos quais elas devem ser desenvolvidas" (HIPKIN e DE COCK, 2000, p.278). 


\section{4 - Compromissos de Gestão da Manutenção}

No item 2.1, deste estudo, a empresa foi apresentada como um sistema e que se relaciona com outros sistemas, ou seja, com seu ambiente.

Conforme SLACK (2002, p.47), o ambiente turbulento em que a maioria das organizações atua, faz com que suas funções tenham que se ajustar continuamente à conjuntura vigente. As operações da empresa são vulneráveis às incertezas e requisitos do ambiente em que a empresa está inserida. Também, o sistema de manutenção não funciona no vazio, isoladamente. Ele sofre influências, de dentro e de fora da empresa, que podem afetar seu desempenho.

No caso de influências originadas no interior da empresa, o sistema de manutenção encontra-se na esfera de influência de outras áreas funcionais, como produção, projeto, suprimentos e finanças. Esta última é responsável por assegurar que a empresa opere sob uma base eficaz de custo, e geralmente com lucro.

Vários fatores exercem influência externa sobre a empresa, como um todo e sobre o sistema de manutenção em particular. O ambiente, normas técnicas emitidas por entidades externas e determinações legais são alguns desses fatores.

Desse modo, a gestão da manutenção e da disponibilidade deve levar em conta uma série de fatores que extrapolam as características físicas inerentes dos equipamentos. Os gestores da manutenção, quando tomam decisões na direção do objetivo disponibilidade, devem considerar soluções de compromissos com outros objetivos, ou mesmo determinações, da empresa, ou do ambiente em que esta se insere.

Convém observar que a preocupação com compromissos é manifestada por autores como SILVEIRA e SLACK (2001, p.949), quando afirmam que o conceito de compromisso (trade-off) está, cada vez mais, tornando-se importante para as estratégias de operação.

De modo geral, fatores geradores de compromissos estão presentes nos textos da literatura pesquisada sobre a gestão da manutenção, mas sem transparecer um seu tratamento sistematizado. Assim, mostra-se conveniente pinçar da literatura alguns desses fatores (custos, segurança, processo de produção, normas técnicas, determinações legais e meio ambiente) e tecer algumas considerações a seu respeito. 


\subsection{1 - Compromisso com Custos}

O desenvolvimento da função manutenção implica na geração de custos. Assim, é necessário encontrar uma solução de compromisso entre a disponibilidade almejada e os custos envolvidos para sua consecução. SLACK (2002, p.81) afirma que "o custo baixo é um objetivo universalmente atraente", apontando que entre os custos de instalações, tecnologia e equipamentos estão os de conservação, manutenção e os de substituição de equipamentos de produção.

O ciclo de vida do equipamento compreende estágios que foram apresentados na Tabela 2.1. O custo total do equipamento ao longo desses estágios constitui o custo do ciclo de vida, ou seja, é o custo total previsto e gerado durante todo o ciclo de vida do equipamento.

XENOS (1998, p.161) divide o custo do ciclo de vida em duas categorias: custo de aquisição (compreendendo desde os custos de projeto e fabricação até os de instalação e teste pré-operacional) e custo de utilização (custos de operação e manutenção). Se o equipamento está instalado e em operação é sobre esses últimos custos que os gestores de manutenção têm condições de interferir.

MONCHY (1989, p.185) e KARDEC e NASCIF (2001, p.60) mostram a incompatibilidade entre os objetivos de se assegurar a disponibilidade operacional máxima e o custo total (custo de manutenção mais custo de perda de produção) mínimo. Já, a Figura 3.2 indica a necessidade de um compromisso entre níveis de MP, de MC e um custo total mínimo de manutenção.

É importante distinguir claramente os custos de manutenção dos investimentos com a compra de equipamentos novos ou com a expansão de instalações existentes. Os custos de manutenção dos equipamentos representam uma parcela dos custos de produção da organização. Para manter os equipamentos, é preciso utilizar peças de reposição, materiais de consumo, energia, pessoal de gestão e de campo, serviços subcontratados, dentre outros recursos. 


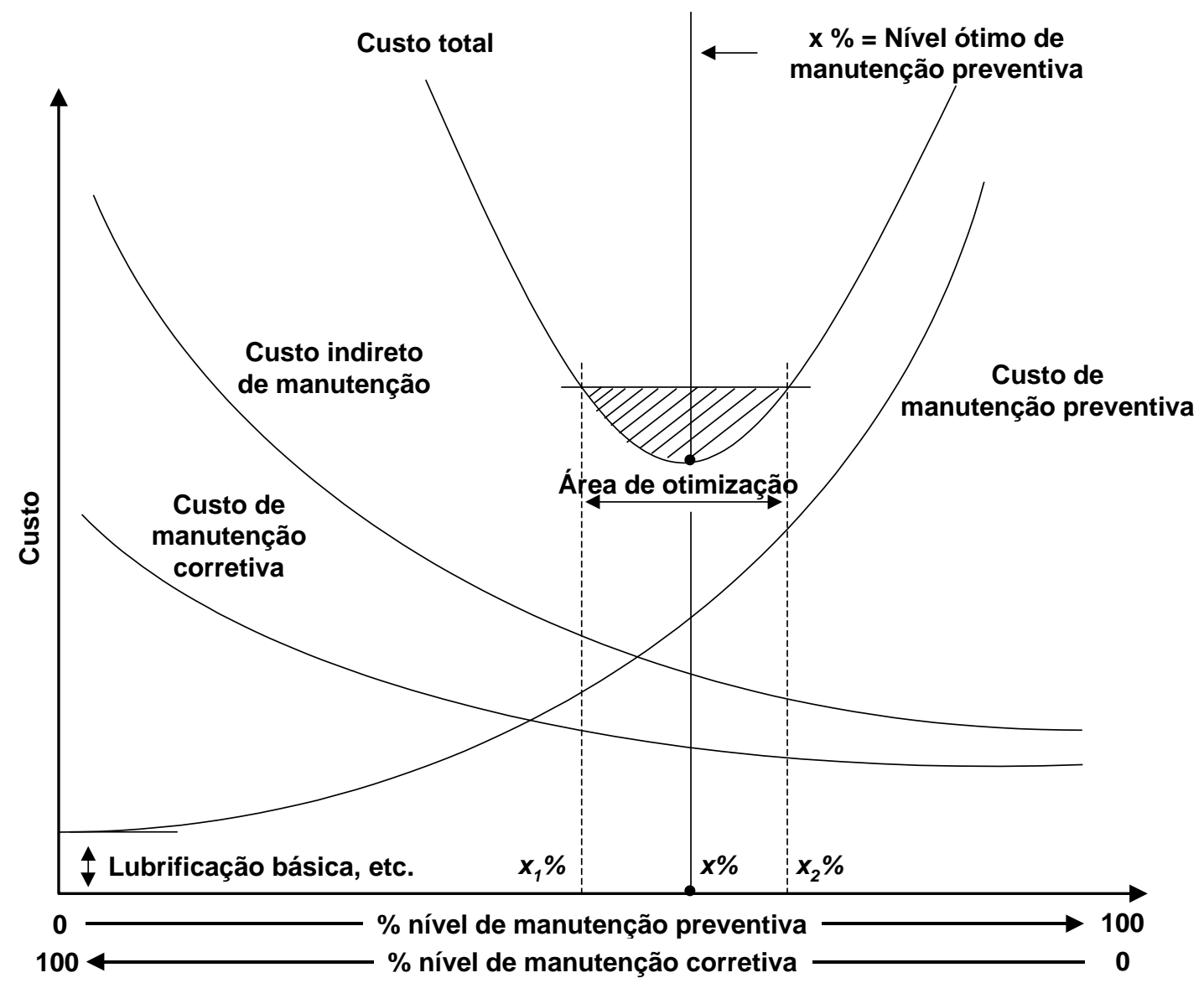

Figura 3.2 - Compromisso entre Custo e Níveis de Manutenção Preventiva e Corretiva (Adaptada de Husband, 1976, p. 36)

Se a manutenção não é eficiente na gestão de falhas dos equipamentos, as metas de lucro da organização poderão ficar comprometidas. No âmbito da função manutenção, uma meta de custo de manutenção serve de guia para a elaboração do orçamento anual da manutenção dos equipamentos (XENOS, 1998, p.220).

Entretanto, os custos de manutenção dependem também do regime de produção. Variações da produção têm consequiências diretas nas necessidades de manutenção dos equipamentos. Em muitos casos, quanto maior a utilização dos equipamentos, mais acelerada será sua degradação, e isto exigirá uma manutenção mais intensiva (XENOS, 1998, p. 223).

As ponderações elaboradas por KELLY (1980, p.8), MONCHY (1989, p.236-248), (MOREIRA, 1993, p.464) e XENOS (1998, p.231), relacionadas com os 
custos de manutenção, confirmam o "objetivo universalmente atraente do custo baixo" e permitem consolidar um conjunto de recomendações para alcançá-lo:

- Praticar a Prevenção de Manutenção: o equipamento tem uma confiabilidade intrínseca, que não pode ser melhorada pelas operações de manutenção, mas somente com a introdução de alterações no seu projeto. Equipamento com baixa confiabilidade intrínseca significa um desafio para a gestão da manutenção, em face da tendência de custos de manutenção mais elevados. Assim, é essencial avaliar o projeto sob o ponto de vista do custo de manutenção e da produtividade, minimizando o custo ao longo do ciclo de vida do equipamento. Entretanto, medidas para se introduzir melhorias, visando a aumentar a confiabilidade intrínseca do projeto original do equipamento, deverão ser objeto de análises contínuas.

- Aprimorar continuamente os equipamentos e os processos de manutenção: esse é um objetivo essencial da gestão da manutenção. O exercício do princípio de melhoria contínua sobre os equipamentos deve provocar aumento de sua confiabilidade intrínseca para evitar a ocorrência ou reincidência de falhas. Essa melhoria pode implicar também na redução do volume de ações preventivas necessárias, reduzindo sua freqüência, e, portanto o custo.

A análise do processo de manutenção também poderá revelar oportunidades para introduzir melhorias e racionalizar tempos de inspeções, intervenções e reparos. O ganho decorrente dessas melhorias implica no aumento da produtividade, como resultado da redução do tempo de interrupção de operação dos equipamentos.

- Rever as condições de operação dos equipamentos: a falta de observação dos procedimentos operacionais dos equipamentos, pelos operadores, pode acelerar a deterioração e causar falhas prematuras. Os procedimentos operacionais devem ser adequados, os operadores devidamente treinados e problemas comportamentais, indutores de erros de operação, minimizados. Ainda, é fundamental respeitar as limitações físicas dos equipamentos, evitando ultrapassar seus fatores de segurança definidos no estágio de projeto. 
Quanto ao meio ambiente, antecipando considerações do item 3.4.5, ele deve ser previsto por ocasião da especificação das condições operacionais do equipamento. Contaminação por poeira, gases corrosivos, vibração intensa, choques de temperatura e exposição a condições atmosféricas desfavoráveis devem ser evitados. Para isso, pode ser necessário eliminar estas causas de falhas na sua origem, ou modificar o projeto do equipamento para aumentar sua resistência.

- Promover uma maior cooperação entre as equipes de manutenção e produção: essa recomendação, fortemente relacionada com a abordagem TPM, implica em reconhecer que um espírito de cooperação entre essas duas áreas contribui de forma significativa para melhorar o desempenho da própria manutenção e aumentar a produtividade.

O reconhecimento desse potencial de contribuição implica estabelecer uma divisão de trabalho, entre as duas equipes, que esteja adaptada à realidade da empresa e que permita aos operadores, devidamente treinados, realizarem algumas tarefas rotineiras e prognosticar anomalias nos equipamentos, relatando-as, de modo expedito, para os especialistas das equipes de manutenção.

- Avaliar a possibilidade de substituir equipamento antigo por outro mais novo: em muitos casos, o equipamento antigo torna-se de difícil manutenção, pois a obtenção de peças de reposição tende a ficar mais onerosa. Também, o custo de manutenção desse equipamento tende a aumentar em função do seu grau de deterioração. Assim, é necessário avaliar as vantagens econômicas e técnicas de se comprar novo equipamento, provavelmente de mais recente geração, para substituir o existente.

- Padronizar os equipamentos, seus componentes e peças: uma outra forma de diminuir custos de manutenção, é padronizar a configuração dos equipamentos. Uma grande variedade de modelos e tipos de equipamentos diferentes cria dificuldades de obtenção de peças de reposição e treinamento do pessoal, além de aumentar o número de diferentes ferramentas, instalações, padrões e procedimentos para a execução da manutenção. Isso torna a gestão da manutenção mais complexa, dificultando o aprimoramento de sua eficiência. 
- Considerar a possibilidade de terceirizar serviços de manutenção: a terceirização de serviços pode ser uma solução para reduzir os custos fixos de manutenção. $O$ custo de alguns serviços de manutenção pode ser muito menor dependendo de quem os executa. As diferenças estão principalmente nos custos fixos com a mão-de-obra e materiais em estoque.

Entretanto, para que a terceirização não tenha um efeito contrário, aumentando os custos ao invés de reduzi-los, é necessário selecionar com cuidado a empresa contratada, garantindo que todos os serviços contratados sejam realizados, o que demanda a clara definição do escopo da terceirização num contrato formal. Ainda, a empresa contratante deve efetuar uma auditoria periódica, através de um sistema formal de avaliação da qualidade dos serviços da contratada.

- Assegurar a qualidade de peças e materiais adquiridos: a qualidade das peças e materiais usados pela manutenção deve ser comprovada, para evitar a redução da confiabilidade intrínseca dos equipamentos. A compra de peças de qualidade deficiente, aparentemente de menor custo no ato da compra, pode implicar em custos mais elevados no longo prazo. Assim, é essencial que se leve em conta também o "ciclo de vida das peças". Em outras palavras, entre duas peças de mesma qualidade, recomenda-se optar pela mais barata; entre duas peças com preços diferentes, recomenda-se avaliar a relação custo/benefício, em função da qualidade que está sendo adquirida.

- Evitar estoques excessivos de peças e materiais: entende-se por estoque quaisquer quantidades de bens físicos que sejam conservados, de forma improdutiva, por algum intervalo de tempo, aí se incluindo componentes para a manutenção dos equipamentos produtivos. Os estoques protegem contra incertezas. Essas incertezas dizem respeito ao momento em que se necessita de um determinado item. Contudo, deve-se levar em conta a afirmação de MARTINS e ALT (2001, p.141) de que “estoque custa dinheiro". Comprovando, podem ser citados os custos associados ao capital investido diretamente no estoque, aluguel da área de estocagem, equipamentos de estocagem, perdas no estoque, materiais de estoque que não são mais utilizados devido à obsolescência, furtos e roubos e gestão do estoque. 
- Reduzir as Falhas nos Equipamentos: isso requer sistematizar o tratamento de falhas, visando a identificar ou elaborar estratégias para evitar sua reincidência, reduzindo assim o trabalho imprevisível e que não agrega valor. Paralelamente, a colocação em prática de ações preventivas através da elaboração de um plano de manutenção, pode reduzir as falhas, mas essa decisão pode ser tomada levando em conta o compromisso com a minimização de custos, traduzido na Figura 3.2.

- Modularização do Equipamento: corresponde ao agrupamento de componentes de um equipamento, formando entidades funcionalmente diferenciadas, visando a facilitar sua integral identificação, remoção e substituição (PATTON, 1980, p.14). O custo da modularização deve ser analisado em função da rapidez com que um módulo pode ser tratado, assegurando à produção, de modo expedito, a disponibilidade do equipamento em que o módulo está inserido. Essas análises exigem, de modo bastante acentuado, atenção no estágio de projeto.

\subsection{2 - Compromisso com Segurança}

A busca da disponibilidade, aos custos mais baixos, não deve prejudicar a segurança do equipamento e do pessoal envolvido. A segurança, no âmbito da manutenção, está associada à eliminação de condições de risco que podem provocar algum tipo de dano ou lesão, implicando em proteções contra falhas, quebras e acidentes (PATTON, 1980, p.160). Este autor caracteriza a segurança como de suprema importância, ao apresentar suas conclusões da utilização da abordagem RCM (PATTON, 1980, p.209).

Já, KARDEC e NASCIF (2001, p.214), ao tratar da questão da segurança, abordam de modo detalhado apenas aspectos de segurança pessoal, considerando a segurança operacional como implícita no tratamento da confiabilidade dos equipamentos.

KLETZ (1993, p.1) ilustra uma série de acidentes que ocorreram porque o equipamento não estava adequadamente preparado para a manutenção, ou porque a manutenção adequada não foi executada. O título do próprio livro de KLETZ (O que houve de errado) parece pretender representar um alerta para a questão da segurança no âmbito da manutenção. O exemplo do impacto da disponibilidade no processo de 
manutenção, apresentado na Tabela 1.2, confirma que o tratamento da questão da segurança apresenta contornos bastante amplos.

\subsection{3 - Compromisso com o Processo de Produção}

Em um artigo, publicado pela Harvard Business Review em 1984, Lynn Shostack argumenta que, embora os serviços possam falhar por incompetência humana, a causa principal das falhas encontra-se numa ausência de métodos sistemáticos para o projeto e controle dos serviços (MOREIRA, 1993, p.244). Assim, o processo de produção contribui com falhas que exigem a atuação da manutenção.

Logo, se caracteriza a necessidade de reconhecimento dos processos, para se identificar as atividades mais suscetíveis a falhas, e a natureza provável dessas. Isso permitirá traçar antecipadamente cursos de ação, tanto para prevenir como para corrigir falhas. Se analisadas já na fase de projeto, pode-se reduzir de modo significativo suas conseqüências.

O planejamento do arranjo físico implica em tomar decisões sobre a forma como serão dispostos os centros de trabalho da instalação. Esses centros de trabalho podem representar qualquer coisa que ocupe espaço: um departamento, uma sala, uma pessoa ou grupo de pessoas, equipamentos, bancadas e estações de trabalho. Em todo o planejamento de arranjo físico, irá existir sempre uma preocupação básica: tornar mais fácil e suave o movimento do trabalho através do sistema, quer esse movimento se refira ao fluxo de pessoas ou de materiais (MOREIRA, 1993, p.259).

Já, SLACK (2002, p.216) estende a preocupação com o arranjo físico à manutenção: "antes de considerar os vários métodos usados no projeto detalhado de arranjo físico, é útil definir quais são os objetivos dessa atividade. De certa forma, os objetivos dependerão de circunstâncias específicas, mas há alguns objetivos que são relevantes para todas as operações", entre eles "coordenação gerencial" (supervisão e coordenação devem ser facilitadas pela localização da mão-de-obra e dispositivos de comunicação) e "acesso" (todos os equipamentos e suas instalações devem estar acessíveis para permitir adequada limpeza e manutenção). Esses dois objetivos irão interferir nos tempos de reparo e, em conseqüência, na disponibilidade.

Também, este pesquisador julga poder incluir, no âmbito do processo de produção, as considerações de ZARIFIAN (1999, p.20), de que "a competência 
humana, profissional, se revela, desde o início, decisiva na eficiência de uma produção de serviço, pois é preciso interpretar e compreender as expectativas do cliente usuário" - no caso da manutenção é a função produção - "quanto aos resultados a serem gerados". Assim, desde o início, também, é preciso conhecer a atividade do destinatário Produção, para a Manutenção atuar com pertinência sobre os seus equipamentos.

Há casos em que a base produtiva da empresa é constituída por uma rede altamente integrada e muito sensível a qualquer incidente, que pode paralisá-la. Esse é o caso do Metrô de Paris, que ZARIFIAN (1999, p.34) apresenta como exemplo, contemplando sua rede de linhas e todo o sistema de circulação de trens nessas linhas. Um aspecto relevante apontado por ZARIFIAN (1999, p.34) é o de que "cada vez mais, esta rede é dupla: a rede física de apoio é duplicada por uma rede de informação que garante, em tempo real, o controle e o comando da rede física ... Ela produz informação ... e, simultaneamente, faz o comando da rede física".

ZARIFIAN (1999, p.34) aponta exatamente a disponibilidade como conceito fundamental para perceber qual é o desempenho esperado dessa infra-estrutura. Para esse autor "disponibilidade é a capacidade da rede (e quando ela é muito integrada, de seus diferentes nós e terminais) de estar permanentemente em situação de ser usada, nas condições de funcionamento esperadas. A confiabilidade é uma condição da disponibilidade". "A disponibilidade não é valorizada em si mesma, como um recurso implantado nos equipamentos que constituem a rede. A origem de sua valorização está inteiramente ligada à garantia da execução do serviço" atendendo aos usuários de um sistema tipo metrô.

Nesse contexto, parece oportuno relembrar o conceito de incidente, apresentado por ZARIFIAN (1999, p.35), que, potencial, virtual ou real, condiciona a garantia da disponibilidade.

Finalizando, um layout funcional, devidamente ajustado à produção deve permitir margem de segurança adequada para o sistema produtivo, quando ocorrem quebras de equipamento. Equipamentos semelhantes devem ser dispostos de modo que uma simples quebra não paralise todo o processo (HARDING, 1992, p.76). 


\subsection{4 - Compromisso com Determinações Legais e Normas Técnicas}

Por ocasião da revisão da literatura não se encontrou um tratamento sistematizado sobre as determinações legais associadas às atividades de manutenção. Entretanto, algumas citações foram coletadas.

Há inspeções e intervenções de caráter obrigatório (caso de equipamentos como caldeiras, elevadores e equipamentos de ar condicionado). Uma referência a portarias governamentais do Ministério do Trabalho diretamente pertinentes à manutenção, é apresentada por KARMAN (1994, p.158), que cita a "NR-10 Instalações e Serviços em Eletricidade / Portaria n $12 / 83$ " e a "NR-13 Caldeiras e Recipientes sob Pressão / Portaria $\mathrm{n}^{\circ}$ 02/84". Esta última, por exemplo, determina que "as caldeiras serão, obrigatoriamente, submetidas a uma inspeção de segurança", pelo menos uma vez por ano. A Portaria 3.523/GM, do Ministério da Saúde, é outro exemplo levantado e aprova o Regulamento Técnico pertinente à "manutenção do estado de integridade e eficiência de todos os componentes dos sistemas de climatização".

Quanto a Normas Técnicas, MILASCH (1984, p.352), ao abordar a manutenção de transformadores em líquido isolante, cita ABNT, AIEE e NEMA; KARMAN (1994, p 158) cita a "NBR-5674 Manutenção de Edificações"; e DRAPINSKI (1973, p.215-225) cita ASLE, ISO, SAE, DIN, AGMA, ABNT e NLGI.

\subsection{5 - Compromisso com o Ambiente}

No item 3.4.1, em que se aborda a revisão das condições de operação do equipamento, já foi manifestada a preocupação com o ambiente, que é aqui retomada. As empresas, independentemente do seu campo de ação, têm que lidar com pressões ambientais, sendo que a exposição ao risco ambiental varia, de forma ampla, nos vários ramos dos sistemas produtivos. Disposições governamentais e maior sensibilização da comunidade colaboram nesse sentido.

Assim, os temas de proteção ambiental tornam-se cada vez mais importantes (SLACK, 2002, p.125). Em muitos países desenvolvidos, a legislação estabeleceu restrições ao uso de materiais tóxicos e o lançamento de efluentes. A maior parte dessas restrições e o próprio meio ambiente afetam as operações de processos da 
organização, abrangendo uma vasta gama de questões, inclusive aquelas com implicações estratégicas e competitivas (NBR ISO 14001: 1996).

Assim, parece ser possível deduzir que a manutenção deve estar atenta não só aos impactos sobre o ambiente, mas, de modo mais amplo, aos impactos que, em sentido inverso, decorrem do ambiente em que o sistema produtivo se insere e que interferem nas políticas e operações de manutenção.

\section{5 - Sistema de Informação}

Uma maneira de examinar a evolução da função manutenção é considerar os fluxos de informação, que são necessários ao planejamento e ao controle eficaz da manutenção e, também, examinar o conjunto de decisões tomadas, que são prérequisitos das operações de manutenção. A análise dos movimentos de informação é essencial para qualquer análise de sistemas para processamento de dados. O processamento e comparação de informações são extremamente úteis para a manutenção. Isto depende de que elas sejam precisas, e de processamento e comunicação ágeis.

Todo problema de decisão envolve o julgamento sobre um conjunto conhecido de alternativas. Supõe-se que a decisão deva ser tomada no presente, mas os seus efeitos far-se-ão sentir ao longo do tempo. A informação disponível é freqüentemente constituída de dados de diversos graus de precisão: "alguns são conhecidos com certeza, outros são estimados com certo cuidado e, finalmente, poderão existir dados cuja precisão deixa muito a desejar. São cercados de incertezas e se referem normalmente a eventos de um período futuro, sobre os quais o tomador de decisão tem pouca ou nenhuma influência” (MOREIRA, 1993, p.129).

Para harmonizar todos os processos que interagem na manutenção, é fundamental a existência de um Sistema de Controle da Manutenção. Ele deve permitir, identificar claramente: que serviços serão feitos; quando os serviços serão feitos; que recursos serão necessários para a execução dos serviços; quanto tempo será gasto em cada serviço; qual será o custo de cada serviço, o custo por unidade e o custo global; que materiais serão aplicados; e que instrumentos, dispositivos e ferramentas serão necessários. 
A tendência atual é de que, toda a empresa esteja interligada e os dados de um departamento sejam facilmente acessados por qualquer dos outros departamentos. "A grande maioria dos dados da organização deve ser de domínio público - dentro da empresa - e estar disponível para consulta através da rede de computadores" (KARDEC e NASCIF, 2001, p.79).

As Figuras 3.3 e 3.4 ilustram, respectivamente, esquemas representativos das informações para a gestão da manutenção e do contexto operacional do processo de manutenção.

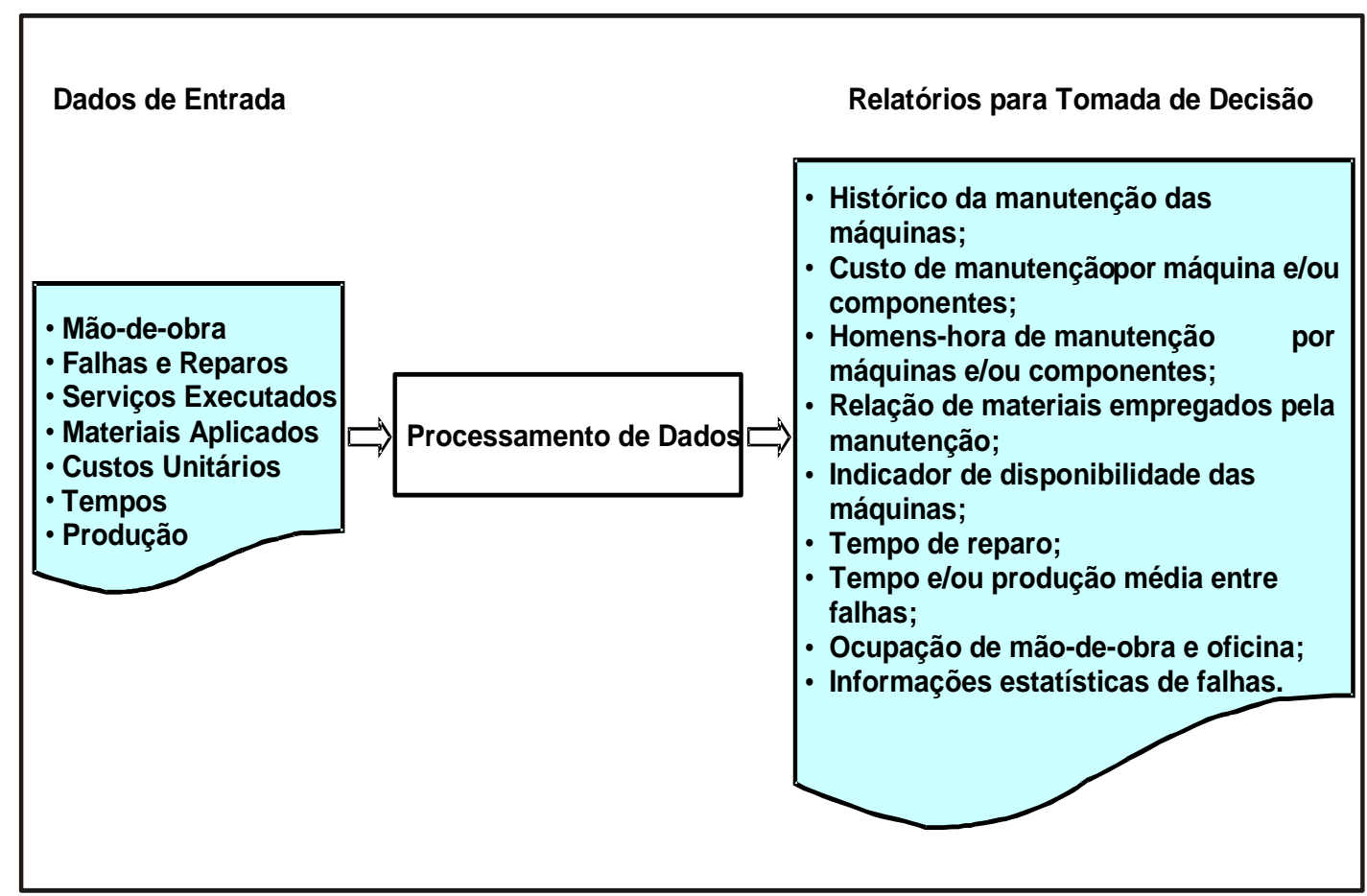

Figura 3.3 - Informação para Gestão da Manutenção (Adaptada de Kelly, 1980, p. 11)

Recorrendo-se a SLACK (2002, p.43), encontra-se uma possibilidade de confirmação do relacionamento proposto na Figura 3.4, referente ao contexto operacional de manutenção. Considerando que a operação global de uma organização pode ser denominada macrooperação, e que seus departamentos podem ser denominados microoperações, com inputs-transformação-output, cria-se o conceito de hierarquia de operações, com duas implicações importantes: "uma diz respeito à ligação das microoperações para formar os relacionamentos dos consumidores e dos 
fornecedores internos. A outra se preocupa com a forma de vermos todas as partes da organização como operações que requerem administração de produção".

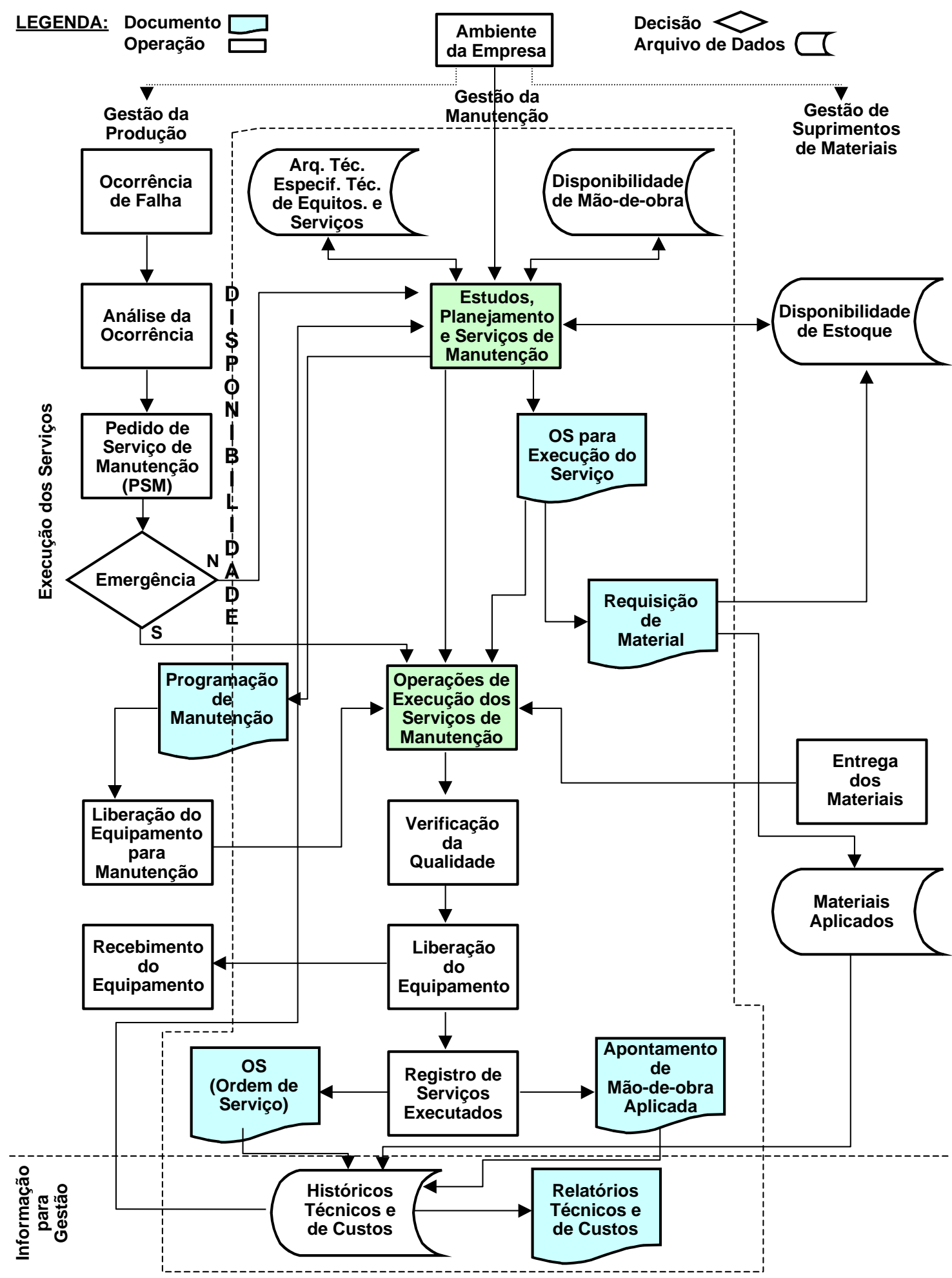

Figura 3.4 - Contexto Operacional do Processo de Manutenção (Adaptada de Vaz, 1997, p.406) 
Ainda, para SLACK (2002, p.44), “as expressões consumidor e fornecedor interno podem ser usadas para descrever aqueles que recebem outputs e fornecem inputs a qualquer micro-operação. Sem dúvida, esses consumidores e fornecedores internos são outras micro-operações. Assim, podemos modelar qualquer função produção como uma rede de micro-operações que estão engajadas em transformar materiais, informações ou consumidores (isto é, funcionários), cada micro-operação sendo, ao mesmo tempo, uma fornecedora interna de bens e serviços e uma consumidora interna de bens e serviços de outras micro-operações".

No presente estudo, considera-se a função manutenção como fornecedor da função produção da empresa. Nesse contexto, a disponibilidade é um indicador do desempenho do relacionamento entre as duas funções.

Naturalmente, cada parte da empresa deve desempenhar papéis claramente definidos para que a empresa possa competir com sucesso.

SLACK (2002, p.64) aponta que três "papéis parecem ser particularmente importantes para a função produção", no que diz respeito à estratégia empresarial: como apoio, como implementadora e como impulsionadora. Pois bem, a função manutenção também deverá estar afinada com esses papéis da função produção para o atendimento das estratégias empresariais. A propósito, entre as estratégias que influenciam o aperfeiçoamento do desempenho da produção e aproximam-se das metas estratégicas da organização, SLACK (2002, p.102) aponta a estratégia de prevenção e recuperação de falhas, que "influencia a forma como a Produção procura prevenir falhas e interrupções em suas atividades e a forma como reage quando ocorrem falhas".

No contexto da organização, a função suprimento de materiais atua como fornecedor interno relevante da função manutenção, o que permite ajustar, também para esse relacionamento, as considerações acima, baseadas em SLACK.

Pois bem, toda essa esfera de relacionamentos deve ser levada em conta para a estruturação de um sistema de informação de gestão da manutenção, para o qual LIMA (1992, p.33) indica quatro estágios de evolução: 
1 etapa: Sistema de Controle Manual - utilização de formulários e mapas, preenchidos manualmente para planejamento, controle e análise de manutenções preventivas e corretivas.

$2^{\mathrm{a}}$ etapa: Sistema de Controle Semi-automatizado - é aquele em que as manutenções são parcialmente controladas com a adoção de algum sistema computadorizado.

$3^{\mathrm{a}}$ etapa: Sistema de Controle Automatizado - a informação relativa às manutenções preventivas e corretivas é transferida para o sistema computadorizado, obtendo-se gráficos, listas, etc.

4 etapa: Sistema de Controle por microcomputador - a informação sobre a manutenção em geral é obtida com o uso de micro computador acoplado ao computador central da empresa (o "mainframe"), de forma a se ter dados de outras funções.

BALDIN (1982, p.177), sugeria um sistema de informações integrado, para a manutenção, relacionando diversas funções (gestão de estoques, planejamento de intervenções, controle de gestão, etc.). Hoje, a evolução tecnológica permite delinear uma etapa mais avançada, utilizando-se redes internas e integradas de informações dentro da empresa. "A tecnologia de banco de dados e de redes (englobando microcomputadores e terminais) permitiu tal integração. $O$ barateamento dos mainframes viabilizou a centralização de uma série de informações e aplicações de interesse geral das empresas" (LAURINDO, 2002, p.31). 


\section{4 - A ESTRUTURA CONCEITUAL DA PESQUISA E AS PROPOSIÇÕES}

Na luta pela sobrevivência no mercado, "as empresas estão constantemente buscando intervir para aprimorar suas operações" (HIPKIN e DE COCK, 2000, p.277). Embora, nesse contexto de competitividade, a literatura seja rica em apontar a importância da disponibilidade operacional de equipamentos como fundamental para a produção da empresa, não se observou a aplicação de uma metodologia para um tratamento que seja explicitamente a ela dirigido. Há, sim, uma riqueza evidente de literatura referente à aplicação de tecnologias de manutenção dirigidas ao equipamento.

Assim, o presente trabalho também representa um esforço de caracterização de um instrumental, que permita verificar aspectos do tratamento da disponibilidade em tomadas de decisão pertinentes à gestão da manutenção de equipamentos de sistemas produtivos.

\section{1 - Estruturação da Pesquisa e das Proposições}

Procurando ser coerente com os objetivos iniciais, convém relembrar que a motivação da pesquisa, em que se insere este estudo, é verificar como a disponibilidade dos equipamentos produtivos é abordada e tratada, no âmbito da gestão da manutenção das empresas.

A função manutenção, dentro da organização, deve ser administrada. Isso significa que deve ter suas atividades planejadas e controladas. Assim o controle de gestão da manutenção corresponde a um processo através do qual se assegura que suas atividades, efetivamente, estarão de acordo com as atividades planejadas, para atender aos resultados também antecipadamente estabelecidos.

A literatura sobre os processos de tomadas de decisão, que representam condição necessária para a implantação de otimizações na organização, é muito rica (MOREIRA, 1993, p.25-146; STONER, 1982, p.108-125; PATTON, 1980, p.100106; SHIMIZU, 2001, p.21-293; GRAY e LARSON, 2002, p.278-283), confirmando a posição de destaque desses processos no cotidiano das organizações. Assim, as tomadas de decisão pelos gerentes, particularmente as que se referem às atividades de manutenção, também fazem parte da dinâmica operacional das organizações. 
Segundo o autor da presente pesquisa, nesse contexto se insere um dos produtos da função manutenção, ou seja, equipamentos produtivos disponíveis para o processamento da função produção, com a qualidade deste produto avaliada por meio de um indicador, que muitas vezes é chamado apenas de disponibilidade.

A conceituação da disponibilidade como um indicador de resultado, pelo destaque que lhe é dado na literatura, leva a presumir que ele seja utilizado para o aprimoramento do processo que o produz. Assim, sendo a manutenção este processo, parece conveniente explorar alguns aspectos referentes a sua gestão em função, particularmente, dos resultados apurados de disponibilidade operacional dos equipamentos produtivos.

Para enfrentar o desafio dessa exploração, torna-se necessário dispor de um modelo conceitual, amparando a formulação e o tratamento de conceitos pertinentes. A inspiração para essa formulação e tratamento foi encontrada nos modelos clássicos de mecanismo de sistemas de controle e de processos de transformação, conforme apresentado por WILD (1984, p.62 e p.553) e STONER (1985, p.402-411), e no modelo geral de administração da Produção apresentado por SLACK (2002, p.58).

Desse modo, esse mecanismo de controle e aprimoramento, devidamente ajustado ao processo de manutenção, permitiu elaborar a estrutura conceitual para a pesquisa. Esse mecanismo de controle não pode prescindir de um indicador de resultado ou de comportamento do processo. No caso do presente estudo, considerase a disponibilidade como indicador do processo de manutenção.

STONER (1982, p.401) fornece uma definição que chama a atenção para os elementos essenciais do processo de controle: o controle administrativo é um esforço sistemático de se estabelecer padrões de desempenho com objetivos de planejamento, projetar sistemas de feedback de informações, comparar o desempenho efetivo com testes padrões pré-determinados, determinar se existem desvios e medir sua importância e, ainda, tomar qualquer medida necessária para garantir que todos os recursos estejam sendo usados, da maneira mais eficaz e eficiente possível, para a consecução dos objetivos da empresa.

Ainda, STONER (1985, p.405) descreve um método de projeto de processo de controle contemplando cinco passos, que serão considerados à luz dos objetivos da presente pesquisa. 
1. Definir os resultados desejados: os resultados, que se deseja obter, segundo este autor, devem ser definidos o mais especificamente possível. Os resultados desejados, também, devem estar associados a responsáveis por sua consecução.

Ora, entende-se que, no caso do presente estudo, o foco na disponibilidade operacional do sistema produtivo define um resultado desejado. Quanto aos responsáveis pela sua consecução, eles são os recursos humanos intervenientes no processo de manutenção.

2. Estabelecer indicadores que prevejam os resultados: segundo o mesmo autor, STONER (1985, p.406), esse direcionamento permite que os administradores corrijam os desvios antes que uma série de atividades seja completada. Os desvios identificados pelo controle têm que ser, portanto, indicadores de resultado, isto é, têm que indicar aos gestores se é preciso ou não tomar medidas corretivas. Em outras palavras, este autor traduz o mesmo pensamento de MUSCAT e FLEURY (1993, p.85) quanto ao uso de indicadores na especificação de ações de aprimoramento de cada componente do sistema produtivo da empresa, conforme exposto no item 2.5 deste estudo.

No presente trabalho, esse indicador de resultados corresponde ao indicador de disponibilidade, que pressupõe um processo de sua mensuração. Uma vez dispondo de indicadores mensurados, eles poderão facilitar estimativas de disponibilidade futuras.

3. Estabelecer padrões dos indicadores e dos resultados: sem padrões estabelecidos para os indicadores, os gestores podem ter uma reação exagerada diante de pequenos desvios, ou deixar de reagir quando os desvios forem significativos.

STONER (1985, p.406) estabelece que os padrões têm que ser apropriados às suas circunstâncias. No caso do indicador de disponibilidade de equipamentos do sistema produtivo, os padrões de disponibilidade, e mesmo seus componentes, confiabilidade e MTTR, devem ser inicialmente estabelecidos por ocasião da especificação técnica, ou seja, do projeto dos equipamentos. 
Entretanto, os padrões dos indicadores de disponibilidade devem ser flexíveis para poderem se ajustar a eventuais mudanças de condição de uso do equipamento.

Essa flexibilidade de ajuste lembra a necessidade de se estabelecerem compromissos, conforme já apresentado no item 3.4 deste estudo.

4. Estabelecer a rede de informação e de feedback: isto é, devem ser estabelecidos os meios para se levantar informação sobre os indicadores e compará-los com os padrões. STONER (1985, p.406) afirma que a rede de informação que interessa, deve fornecê-la aos tomadores de decisão em tempo hábil para se agir.

No presente estudo, considera-se a necessidade de um sistema de informação adequado à operacionalização da manutenção, a responsável pelo resultado de disponibilidade, aquele que, de modo ideal, seja integrado à função produção e ao sistema de suprimento da manutenção.

5. Avaliar as informações e tomar as providências corretivas: corresponde a tomar decisão em função dos indicadores de disponibilidade, devidamente confrontados com seus padrões estabelecidos antecipadamente. Mais uma vez, a informação é relevante, pois é em função de sua avaliação sobre um desvio que a decisão é tomada.

Em função desses passos propostos por STONER, procurou-se representar, de forma esquemática, a estrutura conceitual para a pesquisa. Como já citado anteriormente, o modelo foi inspirado em WILD (1984, p.62), através de seus esquemas representativos dos tipos básicos de controle. Adotando-se uma visão sistêmica (item 2.1 deste trabalho), foi desenvolvida a estrutura conceitual da pesquisa, representada na Figura 4.1.

Assim, os conceitos fundamentais, necessários para o desenvolvimento da pesquisa, levando em conta o contexto e o aprimoramento do processo de manutenção, foram levantados a partir de ampla revisão da literatura, tendo como enfoque a disponibilidade operacional dos equipamentos dos sistemas produtivos. A estrutura conceitual, que serve de base para o estudo, foi construída contemplando ações que se manifestam ao nível operacional da manutenção, ou seja, de "chão de 
fábrica", e ações que se manifestam ao nível de gestão das operações de manutenção. Essas ações interferem no resultado "disponibilidade".

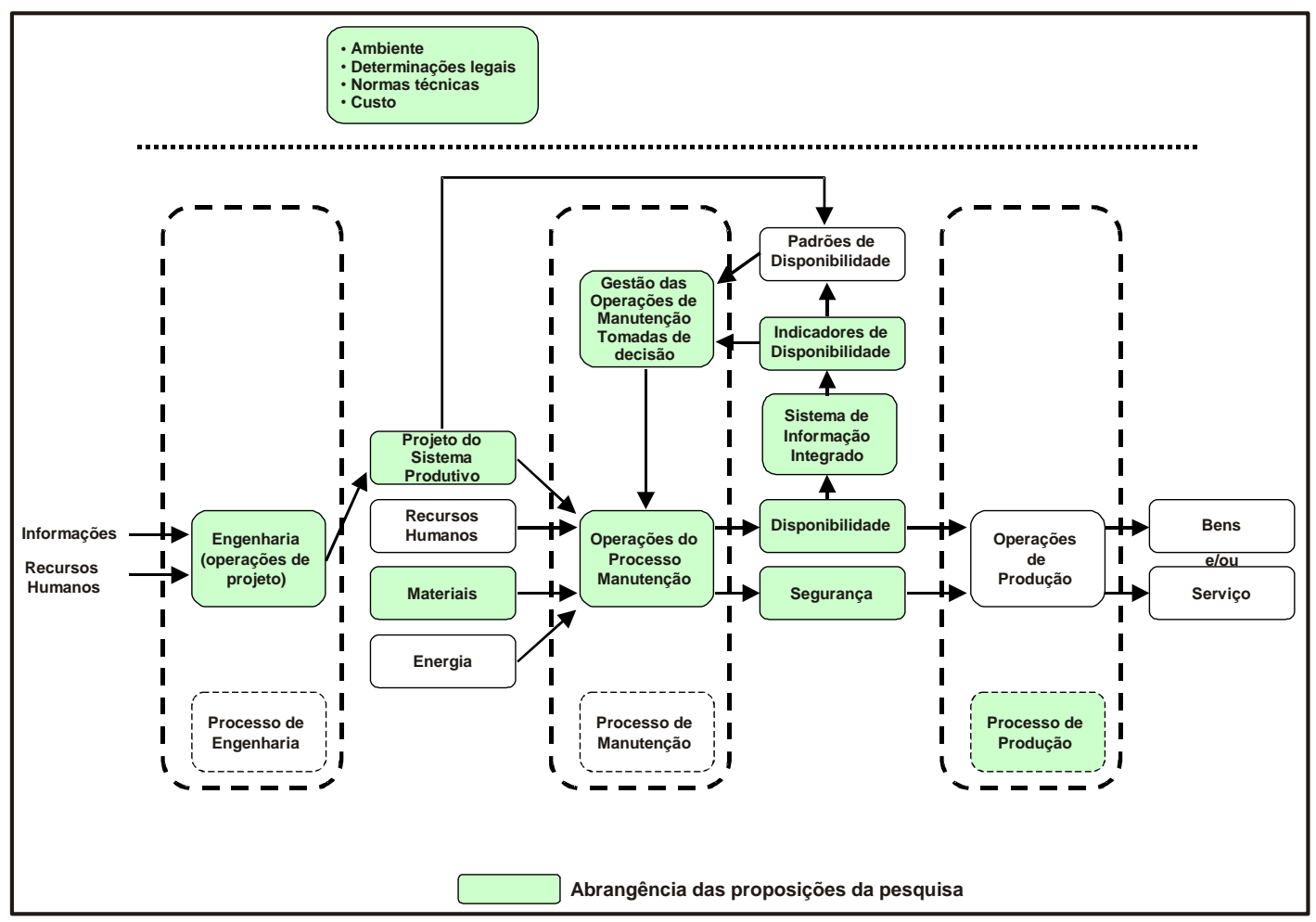

Figura 4.1 - Estrutura Conceitual da Pesquisa (Elaborada pelo Autor)

Neste trabalho, a função manutenção é considerada como um processo em que se usa o indicador de disponibilidade como feedback para a otimização do próprio processo de operação da função manutenção, bem como da especificação dos recursos de entrada desse processo. Sendo um indicador, ele só tem sentido se for efetivamente analisado, seja num único ponto ou por meio de análise de sua tendência. Assim, admitir-se-á que, num estágio mais evoluído de tomadas de decisão, haja padrões que expressem a disponibilidade requerida. Tais padrões são fundamentais para fins de comparação, avaliação e controle, pois a simples disposição de um indicador seria ineficaz.

A estrutura conceitual, representada na Figura 4.1, foi elaborada para firmar o embasamento para a pesquisa e orientar a expressão de três proposições a serem verificadas. A estrutura conceitual tem como foco central o processo de manutenção, "fornecedor do produto disponibilidade" ao processo de produção que é seu cliente 
(item 2.3 deste estudo). Por sua vez, o processo de manutenção depende de um fornecedor relevante, que é o processo de engenharia, que, com suas operações de projeto, provoca o início e o delineamento do ciclo de vida dos equipamentos do sistema produtivo. Vale destacar, também, que esses equipamentos, especificados mediante seu projeto e submetidos às operações elementares de manutenção, estão inseridos no processo de produção, para o qual a disponibilidade dos primeiros é essencial.

$\mathrm{Na}$ estrutura desenvolvida, são apresentados três dos processos que ocorrem dentro da organização: processo de engenharia, processo de manutenção e processo de produção. A princípio, o mecanismo de controle ocorre em função da obtenção de indicadores de disponibilidade e sua confrontação com padrões estabelecidos no âmbito do processo de engenharia.

A aplicação de um sistema de processos em uma organização, junto com a identificação, interações desses processos e sua gestão, pode ser considerada como "abordagem de processo". Uma vantagem desse tipo de abordagem é o controle que ela permite sobre a ligação entre os processos individuais dentro do sistema de processos, bem como sua combinação e interação (NBR ISO 9001 : 2000).

Uma visão sistêmica requer que seja dada atenção ao ambiente. Conforme exposto no item 2.1, a empresa está sendo considerada como um sistema. A visão da administração, baseada em sistemas, procura ver a organização como um processo unificado, voltado para um fim, formado por partes inter-relacionadas. STONER (1985, p.35), tomando como referência as discussões conceituais de Bertalanffy, afirma que a visão de sistemas para os administradores considera a organização como um todo e como parte do meio exterior mais amplo. Ainda, a atividade de qualquer parte de uma organização afeta a atividade de todas as outras partes.

Essa visão sistêmica configura-se como aparente alternativa à visão mecanicista, que não proporciona encaminhamento de solução para determinados problemas. O conceito fundamental desse pensamento sistêmico é que, qualquer problema está inserido num sistema mais amplo (síntese) e é composto de subsistemas (análise), que interagem entre si e atingem objetivos (MARTINS, 1999, p.21). 
Também é STONER (1985, p 36) quem afirma que um sistema que interage com seu ambiente é considerado aberto e que todas as organizações interagem com seu ambiente, variando o grau de interação.

Assim, dessas considerações transparece que uma abordagem sistêmica torna mais abrangente e integrada a compreensão das organizações, pois conduz uma visão do todo para o detalhe, relacionando de modo mais categórico componentes do sistema com os resultados dele pretendidos. Também, podem ser identificadas as necessidades de melhorias, pois o desmembramento do todo para o detalhe aponta para problemas de integração.

Mais ainda, permite objetividade de análise de operações da empresa, levando em conta sua natureza, à medida que orienta a análise do todo para o detalhe, identificando de modo mais preciso os focos de necessidades de controle, à medida que estabelece uma relação mais coerente entre resultados, entradas e os processos operacionais.

Em trabalho recente, SILVEIRA e SLACK (2001, p.949) informam que o conceito de compromisso (trade-off) se torna cada vez mais relevante para as estratégias de operação, representando a base para conceituar os processos de aprimoramento, afirmando que esse conceito aplicado à manufatura representa um dos paradigmas de gestão de operações, cuja importância mais se tem destacado nos últimos anos. Estes autores levantaram proposições de que os compromissos em manufatura realmente existem e que esses compromissos ocorrem principalmente entre objetivos concorrentes, embora existam outros tipos de compromissos.

Assim, idealizou-se a gestão do processo de manutenção e do resultado obtido, a disponibilidade, requerendo considerar alguns compromissos, também representados na estrutura conceitual da pesquisa: ambiente, determinações legais, normas técnicas, custos, segurança e processo de produção.

Embora contemplando outros fatores, na Figura 4.1 procurou-se limitar a abrangência das proposições da pesquisa em face das restrições decorrentes dos recursos disponíveis para um estudo como este.

As proposições P1, P2 e P3 visam a explorar alguns processos que não foram observados de forma evidente na literatura revisada: 
- a aplicação do desdobramento do indicador de disponibilidade, particularmente procurando verificar o tratamento dado ao MTTR, ou ao tempo de paralisação do equipamento;

- a sistematização do tratamento de compromissos no âmbito da definição de políticas de manutenção; e

- o tratamento dado ao estudo do ciclo de vida do equipamento, no âmbito das decisões pertinentes à manutenção e à disponibilidade .

A abrangência de cada uma das proposições, em relação à estrutura conceitual da pesquisa, tem sua representação nas Figuras 4.2.a, 4.2.b e 4.2.c, respectivamente, a fim de subsidiar a justificativa da elaboração de cada uma delas.

Embora o processo de manutenção dependa de outros insumos, o presente estudo se limita a levar em conta apenas o projeto do sistema produtivo (que incorpora os equipamentos produtivos, com suas características físicas inerentes, e que serão submetidos a operações de manutenção) e materiais (que, oriundos do processo de suprimento da empresa, são indispensáveis para o exercício das operações elementares de manutenção). O estudo, também, se restringe quanto aos "produtos do processo de manutenção" considerando os produtos disponibilidade (foco da pesquisa) e segurança. Este último é também considerado como um dos compromissos com os quais os gestores da manutenção deverão lidar na busca da disponibilidade.

A Figura 4.1 indica um conjunto de conexões de conceitos que podem sugerir diversas proposições. Para as conexões associadas às proposições em teste, conceitos são apresentados como condição necessária para outros. Isto é, a condição representada pelo conceito independente deve estar presente, mas pode não ser suficiente para a condição representada pelo conceito dependente ocorrer.

Associadas a essa estrutura conceitual, são formuladas as três proposições que direcionarão o estudo empírico para uma avaliação do tratamento de gestão que, na prática, as organizações dão ao processo de manutenção, em função de tomadas de decisão pertinentes à disponibilidade dos equipamentos produtivos, ao estabelecimento de compromissos ao encaminhar decisões no âmbito da manutenção, e ao delineamento do ciclo de vida do equipamento: 
P1 - O desdobramento do indicador de disponibilidade em indicadores parciais, obtidos através de um sistema integrado de informação (manutenção, produção e suprimentos), facilita a gestão das operações de manutenção.

P2 - A adequada definição das políticas e operações de manutenção requer considerar, de modo sistematizado, compromissos com o ambiente, determinações legais, normas técnicas, custos, segurança e processo de produção.

P3 - As empresas consideram relevante, para a obtenção da disponibilidade, levar em conta, por ocasião de projetos de novos sistemas produtivos ou de projetos de renovação, ampliação ou substituição, o estudo perspectivo do ciclo de vida do equipamento.

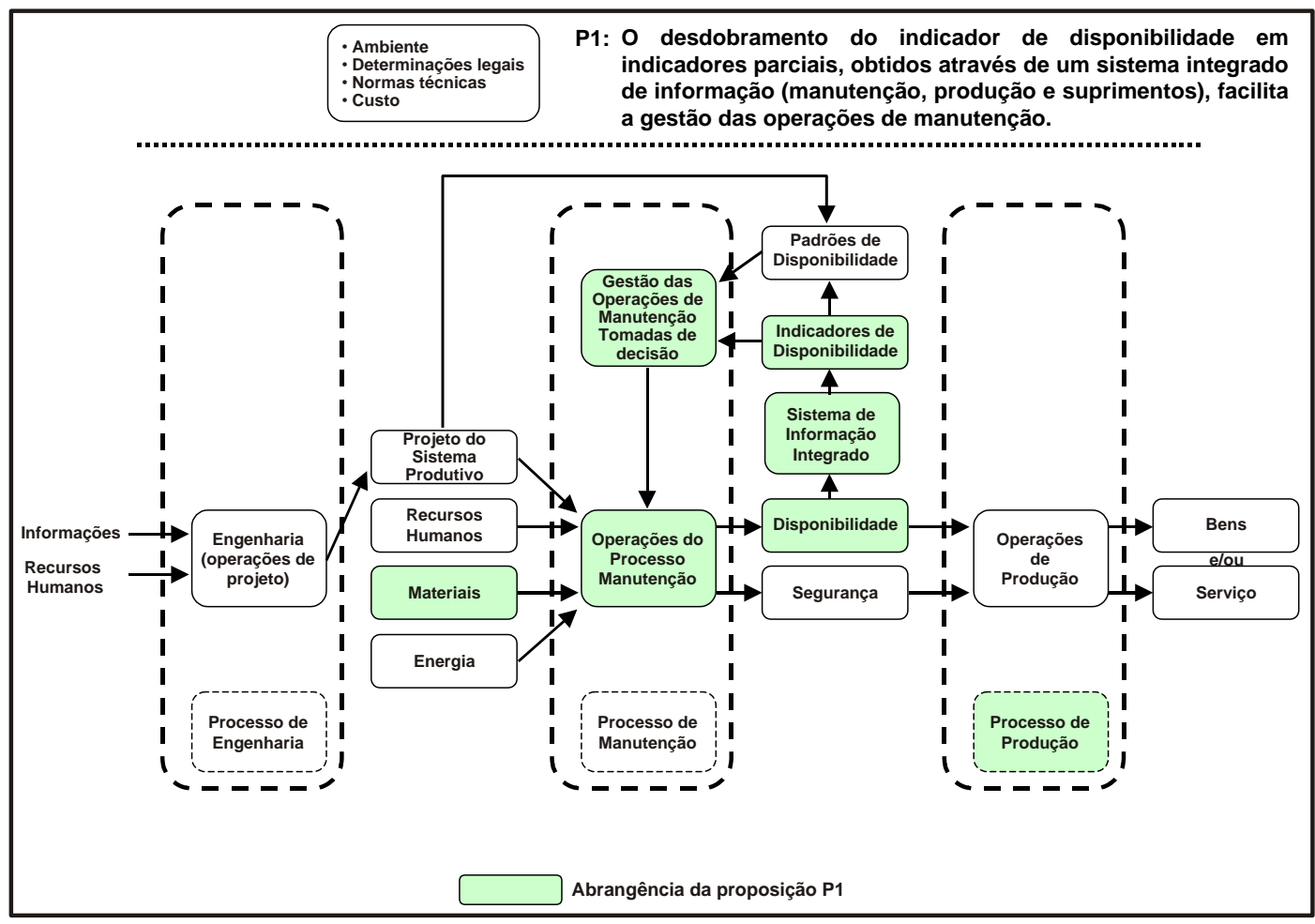

Figura 4.2.a - Abrangência da Proposição P1 


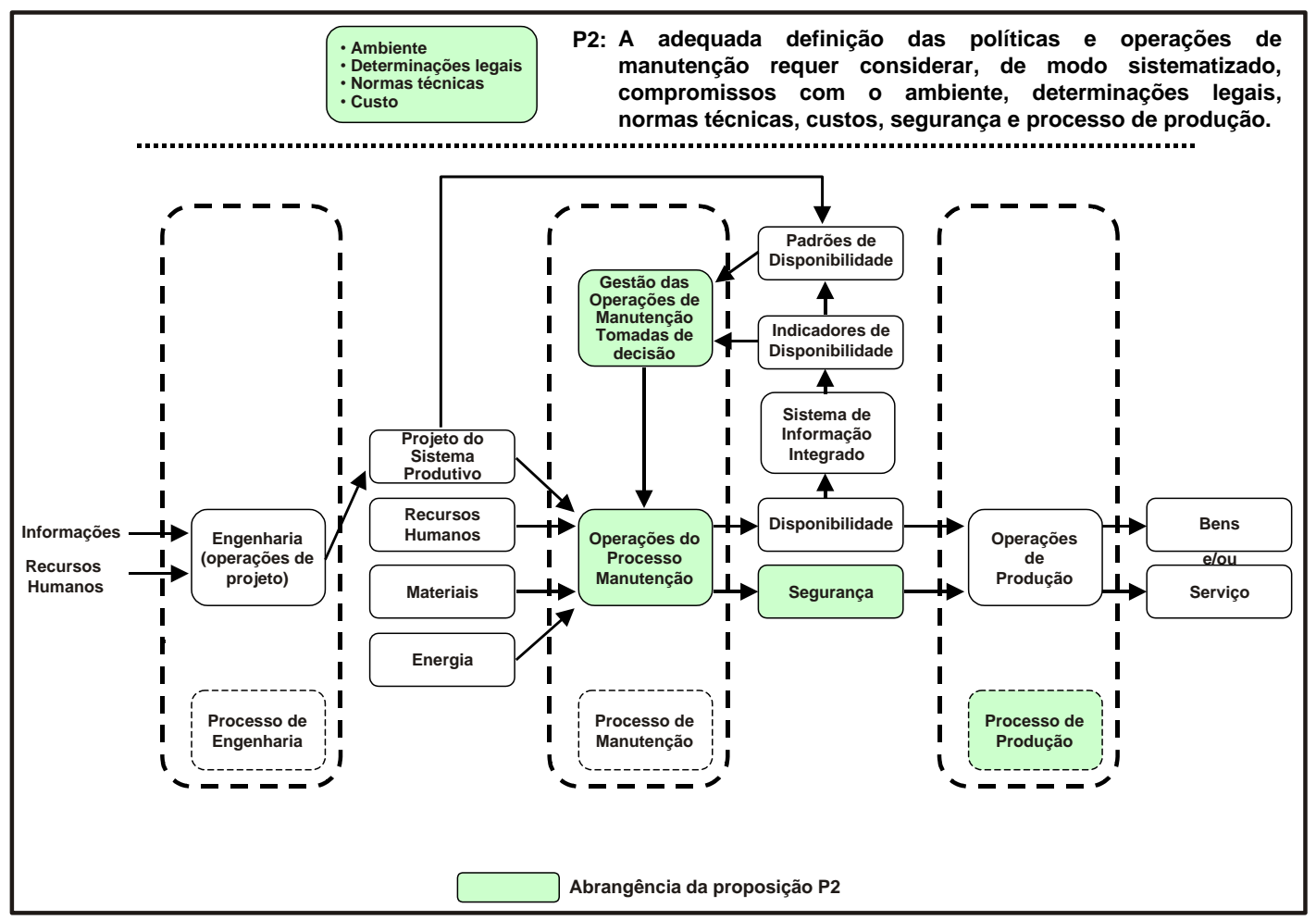

Figura 4.2.b - Abrangência da Proposição P2

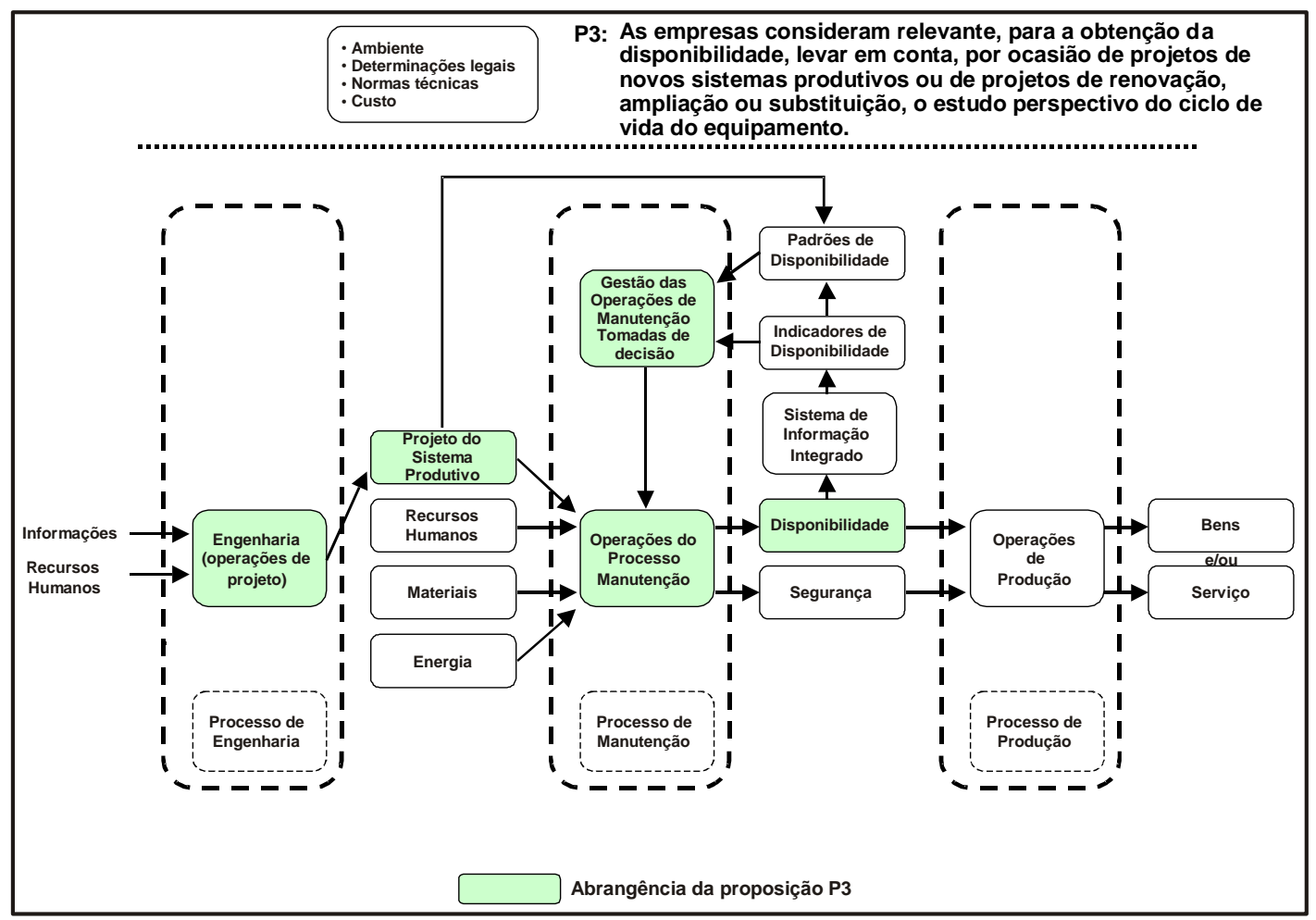

Figura 4.2.c - Abrangência da Proposição P3

(Elaboradas pelo Autor) 
A Figura 4.1 indica somente os fatores relevantes para esta pesquisa, não se estendendo além de considerar a aplicação da disponibilidade, como um indicador de resultado dos serviços executados pela função manutenção para atender à função produção e encaminhar tomadas de decisão adequadas. Considera-se, portanto, a disponibilidade, como um instrumento de medida (quantificada pelo indicador de disponibilidade) que possibilita parte do controle para o aprimoramento da produtividade na organização.

Entretanto, não se considera diretamente o desempenho do processo de produção, nem do processo de engenharia, embora algumas considerações de compromisso, sugeridas pela literatura revisada, possam interferir nesses desempenhos.

Conforme já observado, elevado número de publicações aponta a relevância da gestão da função manutenção e da disponibilidade para a produtividade. Assim, foi assumido como princípio que o aprimoramento das funções manutenção e produção conduzem ao aprimoramento do desempenho econômico da organização. Mas, como o desempenho econômico decorre de uma grande variedade de fatores operacionais e não operacionais, qualquer tentativa para se tirar conclusões de sua vinculação com o processo de manutenção extrapola o escopo do presente estudo.

\section{2 - Proposições da Pesquisa}

\subsection{1 - Proposição P1}

O desdobramento do indicador de disponibilidade em indicadores parciais, obtidos através de um sistema integrado de informação (manutenção, produção e suprimentos) facilita a gestão das operações de manutenção.

A literatura sobre planejamento e gestão da manutenção, de um modo geral, aborda a disponibilidade desdobrando-a em dois fatores componentes diretos: o MTBF e o MTTR. Esse desdobramento é adotado tanto quando a disponibilidade é tratada do ponto de vista de vista de gestão (KARDEC e NASCIF, 2001, p.103) como quando é considerada sob o enfoque estatístico (LAFRAIA, 2001, p.199). Assim, na estruturação do conceito de disponibilidade estes dois fatores componentes têm sido regularmente considerados. 
Entretanto, na busca do aprimoramento da disponibilidade não parece ser conveniente, na prática, limitar-se de modo estreito ao MTTR, pois se deve lembrar que há uma gama mais abrangente de tempos de paralisação decorrentes também de intervenções de natureza preventiva.

Uma preocupação, presente ao longo deste trabalho, focaliza o desdobramento da disponibilidade para efeito de tomadas de decisão relativas à gestão de operações de manutenção. Observa-se, na literatura levantada, um direcionamento bastante forte em apontar a disponibilidade como um resultado relevante, mas não foi encontrado nenhum estudo particular, mais aprofundado, de como tratá-la operacionalmente.

Desse modo, relembrando SILVA (1997, p.25), este autor afirma que "para se entender ou explicar alguma coisa, esta deve ser dividida em partes menores; que uma vez entendidas, tornam possível o entendimento do todo" e que "para solucionar problemas é preciso subdividi-lo em problemas menores, que recebem soluções particulares". Assim, julga-se poder aplicar essas recomendações ao estudo da disponibilidade, por meio de um desdobramento.

Ora, esse desdobramento extrapola a função manutenção, já que a própria disponibilidade é um resultado que pode estar sendo mensurado pela função produção, e o MTTR tem contribuintes, como o fornecimento de sobressalentes em tempo hábil, que dizem respeito às atividades de suprimento de materiais para a manutenção.

Assim, essa extrapolação, de modo ajustado a uma visão sistêmica, leva à necessidade de que informação fluindo da Manutenção, da Produção e de Suprimentos seja devidamente considerada. De alguma forma, essa informação decorre da existência de algum sistema que permite sua fluência, sistema este que pode integrar, ou não, as funções produção, manutenção, suprimentos ou outras funções empresariais.

Segundo STONER (1985, p.109), "as decisões descrevem o processo através do qual se escolhe um caminho como solução de um problema específico" e "a solução de problemas refere-se ao conjunto amplo de atividades envolvidas na descoberta e implantação de uma ação, direcionada para corrigir uma situação insatisfatória". 
Assim, espera-se que a solução de problemas referentes à gestão das operações de manutenção seja facilitada usando informação sobre a disponibilidade, fluindo das áreas de Produção, Manutenção e Suprimentos de materiais.

Entretanto, compete verificar, na prática, as limitações das tomadas de decisão de gestão, em função da informação sobre a disponibilidade. Em particular, verificando como é tratado o MTTR, ou os tempos de intervenção de manutenção.

Desse modo, para a verificação da Proposição P1 é considerada a presença de quatro variáveis, que constando do quadro referencial para avaliação de dados da pesquisa (Figura 5.2), são detalhadas a seguir.

Para que haja um indicador de disponibilidade, pressupõe-se que haja algum sistema de informação (variável 1.1) que o forneça, e que esse sistema, no contexto operacional do processo de manutenção (Figura 3.4), integre informação das áreas de suprimento sobre materiais aplicados nas operações elementares de manutenção, e informação da produção, como tempos de paralisação de equipamentos produtivos ou volumes de produção.

Do mesmo modo, entende-se que, no âmbito da Proposição P1 haja um processo de averiguação da disponibilidade (variável 1.2), sem o que a proposição se torna nula.

A constatação da existência de um desdobramento do indicador de disponibilidade (variável 1.3) é considerada como um indício de que há um tratamento de gestão, que visa a compreendê-lo e administrá-lo mais detalhadamente.

Finalmente, evidências de tomadas de decisão (variável 1.4), no âmbito das políticas e operações de manutenção, em função da disponibilidade, colaboram para a confirmação da proposição nos casos em estudo.

\subsection{2 - Proposição P2}

A adequada definição das políticas e operações de manutenção requer considerar, de modo sistematizado, compromissos com o ambiente, determinações legais, normas técnicas, custos, segurança e o processo de produção.

Conforme SILVEIRA e SLACK (2001, p.949), o conceito de compromisso está cada vez mais se tornando relevante para as estratégias de operações. Eles devem ser analisados em função da importância do impacto que provocam nas 
operações. As tomadas de decisão devem ocorrer considerando objetivos múltiplos e concorrentes entre si.

Embora a literatura pesquisada sobre gestão da manutenção não tenha apresentado, de modo explícito e sistematizado, o conceito de compromisso, transparece uma preocupação implícita, quando, ainda que de modo esparso, apresenta recomendações ou preocupações em relação a alguns fatores restritivos das atividades de operação de manutenção.

Os mesmos autores, SILVEIRA e SLACK (2001, p.949), também afirmam que compromissos estão presentes de modo perceptível, portanto, existem e representam um conceito central na abordagem gerencial dos processos de aprimoramento. Estes autores, em suas conclusões, apontam para a importância de se identificar quais são os compromissos relevantes para cada operação específica.

Assim, para o desafio da definição das políticas de manutenção, parece ser importante primeiro caracterizar alguns compromissos e, depois, verificar a sistematização do tratamento que eles têm merecido dos gestores de manutenção. Desse modo, espera-se melhor compreender esse "pacote" de compromissos da gestão da manutenção na busca da disponibilidade.

Conforme já exposto no item 2.1, em que se considera a empresa como sistema, e no item 4.1, em que se considera esse sistema ser aberto e, portanto, interagindo com o seu ambiente, torna-se interessante melhor compreender como os compromissos são considerados na definição de políticas e abordagens de manutenção apresentadas nos itens 3.3.2 e 3.3.5.

Neste trabalho de pesquisa, estão sendo considerados fatores do ambiente em que se insere o processo de manutenção, determinações legais, normas técnicas, custos, segurança e o próprio processo de produção, já considerados no item 3.4 do presente trabalho.

A Proposição P2 procura explorar o eventual tratamento sistematizado dado a compromissos, no âmbito da gestão da manutenção. Não se afirma que esses são os únicos compromissos. Entretanto, evidências da literatura de restrições a tomadas de decisão, sobre as políticas de manutenção, conduziram à seleção desses seis compromissos para uma incursão exploratória do tratamento a eles dedicado. 
Assim, foram caracterizadas duas variáveis para a verificação da Proposição e que fazem parte do quadro referencial constante da Figura 5.2. A Proposição procura confirmar se há definição de políticas de manutenção em função de um tratamento estruturado dos compromissos.

Se há esse tratamento, compete verificar qual é o estágio de sistematização (variável 2.1), devidamente representado por algum critério que venha a se apresentar de modo explícito na oportunidade de investigação de campo, e se há evidência de definição de políticas e operações de manutenção em função dos compromissos (variável 2.2), de modo a confirmar, ou não, a Proposição P2.

\subsection{3 - Proposição P3}

As empresas consideram relevante para a obtenção da disponibilidade, levar em conta, por ocasião de projetos de novos sistemas produtivos ou de projetos de renovação, ampliação ou substituição, o estudo perspectivo do ciclo de vida do equipamento.

Ao longo da vida operacional das empresas, os sistemas produtivos estão sujeitos à sua implantação original, renovação, ampliação ou substituição. Cada uma dessas situações representa a incorporação de equipamentos ou componentes ao patrimônio físico da organização. Assim, esses equipamentos têm seu ciclo de vida em andamento, ou estão dando início a ele.

De modo geral, o ciclo de vida dos equipamentos é exposto na literatura enfocando uma preocupação com custos, que é fundamental.

Entretanto, chama a atenção a recomendação de TAKAHASHI e OSADA (1993, p.254) para a importância de se criarem as "bases necessárias para desenvolver know-how interno e mobilizar as pessoas em relação à engenharia do equipamento", o que deve refletir-se "nas atividades de manutenção preventiva, tendo como principal objetivo a criação de um equipamento orientado para o usuário, que satisfaça e se adapte especificamente a cada ambiente de trabalho". Outrossim, nesta pesquisa entende-se que essa orientação para o usuário deve levar em conta uma de suas expectativas, que é a da disponibilidade operacional do equipamento para produção. 
Ainda, TAKAHASHI e OSADA (1993, p.248) afirmam que o termo "ciclo de vida do equipamento" é usado casualmente referindo-se "especificamente a problemas dos novos equipamentos ou equipamentos em época de inspeção e renovação - tendo, esses dois estágios, vida útil limitada. Raramente, discute-se o equipamento no contexto do seu ciclo de vida".

Assim, a proposição tem por objetivo verificar qual é o tratamento dado ao relacionamento entre o estudo perspectivo do ciclo de vida e a disponibilidade, que é um resultado de interesse do usuário Produção.

O estudo perspectivo do ciclo de vida deve considerar seus estágios e respectivos fatores intervenientes na evolução da disponibilidade, conforme exposto no item 2.4.4 e, particularmente, representado na Tabela $\mathbf{2 . 1}$

Do exposto na literatura, compete verificar se o ciclo de vida é tratado nas organizações, e como. Para isso, a Proposição P3 lastreia-se em duas variáveis, que também constam do quadro referencial da Figura 5.2.

A primeira diz respeito à forma de tratamento, sob um ponto de vista perspectivo, que é dado por ocasião do estágio de projeto de novos sistemas produtivos (variável 3.1) à obtenção futura da disponibilidade operacional dos equipamentos. A segunda está associada ao estágio de vida operacional e procura firmar evidências de que há considerações sobre a disponibilidade por ocasião de projetos de renovação, de ampliação ou substituição (variável 3.2).

Assim, a primeira variável pressupõe que vai se considerar a disponibilidade por ocasião de um novo projeto, e a segunda pressupõe que a disponibilidade é considerada por ocasião de projetos de renovação, ampliação ou substituição. 


\section{5 - METODOLOGIA DA PESQUISA}

\section{1 - Estratégia da Pesquisa}

\subsection{1 - Critérios para Definição da Abordagem da Pesquisa}

O presente estudo tem como base uma abordagem empírica de pesquisa, entre aquelas propostas na literatura. Em particular, adota-se a estratégia de pesquisa de estudo de caso para a verificação de proposições associadas ao embasamento teórico.

As principais estratégias de pesquisa, conforme exposto por BRYMAN (1995, p.29) são a pesquisa experimental, a pesquisa de avaliação, a pesquisa-ação e o estudo de caso. De modo geral, a pesquisa experimental e a pesquisa de avaliação estão associadas à abordagem quantitativa, enquanto a pesquisa-ação e o estudo de caso, à abordagem qualitativa. Porém, em uma pesquisa-ação ou em um estudo de caso podem ser empregados dados quantitativos; igualmente, em uma pesquisa experimental ou em uma pesquisa de avaliação podem ser aplicadas informações qualitativas.

Também YIN (2001, p.24), conforme a Tabela 5.1, descreve estratégias de pesquisa, isto é, experimento, levantamento, análise de arquivos, pesquisa histórica e estudo de caso. Assim, o exposto por este autor parece sugerir que a estratégia adequada para uma pesquisa depende de três condições, a saber, da forma de questão de pesquisa proposta, da extensão do controle que se tem sobre eventos comportamentais e do grau de enfoque em acontecimentos históricos em oposição a acontecimentos contemporâneos.

\begin{tabular}{|l|l|c|c|}
\hline \multicolumn{1}{|c|}{ Estratégia } & \multicolumn{1}{|c|}{$\begin{array}{c}\text { Forma da questão de } \\
\text { pesquisa }\end{array}$} & $\begin{array}{c}\text { Exige controle sobre } \\
\text { eventos } \\
\text { comportamentais? }\end{array}$ & $\begin{array}{c}\text { Focaliza } \\
\text { acontecimentos } \\
\text { contemporâneos? }\end{array}$ \\
\hline Experimento & Como, por que & Sim & Sim \\
\hline Levantamento & $\begin{array}{l}\text { Quem, o que, onde, } \\
\text { quantos, quanto }\end{array}$ & Não & Sim/Não \\
\hline Análise de arquivos & $\begin{array}{l}\text { Quem, o que, onde, } \\
\text { quantos, quanto }\end{array}$ & Não & Não \\
\hline Pesquisa histórica & Como, por que & Não & Sim \\
\hline Estudo de caso & Como, por que & \\
\hline
\end{tabular}

Tabela 5.1 - Situações Relevantes para Diferentes Estratégias de Pesquisa (Transcrita de Yin, 2001, p. 24) 
Desse modo, a estratégia de estudo de caso transparece como a apropriada para este estudo, pois uma questão explanatória foi colocada (como, por que), a pesquisa não tem controle sobre os eventos comportamentais, e o foco corresponde a eventos contemporâneos. Também, a opção pelo estudo de caso permite a realização de estudos mais detalhados, com base nos quais haja possibilidade de se trabalhar com diversos aspectos que compõem o processo de manutenção.

O estudo de caso aprecia análises minuciosas de um ou de poucos casos, interpretando sob a perspectiva dos integrantes (e não do pesquisador) as relações entre os indivíduos pesquisados e o ambiente, assim como as relações concernentes aos indivíduos entre si.

MC LACHLIN (1997, p.274) cita que outros autores também delinearam razões fundamentais para o uso do método de estudo de caso em gestão de operações.

Assim, a pesquisa referente ao presente trabalho prevê a utilização da estratégia de estudo de caso, acompanhada de um quadro teórico resultante de uma ampla revisão bibliográfica sobre as operações de manutenção, a gestão do processo de manutenção, o indicador de disponibilidade e o ciclo de vida dos equipamentos produtivos.

Este estudo de caso prevê a realização de entrevistas semi-estruturadas e a observação direta pelo pesquisador em quatro empresas, com essas entrevistas feitas com gerentes, ou gestores, vinculados à função manutenção.

Para a orientação das entrevistas foi elaborado um roteiro, constante do Anexo A, baseado nas variáveis contempladas na Figura 5.2. Essa figura será analisada no item 5.2.2 do presente trabalho, contendo os tópicos mais relevantes a serem abordados.

Ainda, o trabalho de pesquisa requer considerar, para sua legitimidade, uma abordagem devidamente estruturada e que leve em conta: adequação aos conceitos revisados a partir do levantamento bibliográfico, adequação aos objetivos da pesquisa, e a validade e a confiabilidade da abordagem. 


\section{Adequação aos Conceitos Revisados}

Os objetivos da execução dos serviços de manutenção e os parâmetros associados à disponibilidade apresentam relações abrangentes e que podem resultar em interpretações diversificadas por parte de gerentes de produção e gerentes de manutenção. Isto requer o acompanhamento do pesquisador durante a coleta de dados visando a elucidar os conceitos da pesquisa e, assim, assegurar consistência e compreensão do universo em análise, o que implica a escolha de método focalizando uma abordagem perceptiva.

\section{Adequação aos Objetivos da Pesquisa}

Uma característica implícita da pesquisa é que não se sabe de antemão quais resultados serão obtidos. O estabelecimento das relações causais entre variáveis é condição essencial para a pesquisa. Logo, o método de pesquisa deve propiciar a elaboração de conceitos e indicadores de evidências associados às proposições apresentadas, contemplando relações de causa e efeito.

\subsection{2 - Validade e Confiabilidade da Pesquisa}

YIN (2001, p.55) descreve táticas do estudo de caso associadas a quatro testes lógicos para se julgar a qualidade do projeto de pesquisa (Tabela 5.2): (1) validade construtiva (do conceito), (2) validade interna, (3) validade externa, e (4) confiabilidade. A elaboração de um projeto criterioso de pesquisa, coleta de dados e análise de dados, deve colaborar para um rigor que desafia críticas, algumas válidas, que têm sido feitas às abordagens baseadas na estratégia do estudo de caso.

Em seqüência, cada um desses testes é definido, juntamente com recomendações desse autor para se lidar com a estratégia de pesquisa de estudo de caso.

\subsubsection{1 - Validade Construtiva}

A validade construtiva está associada à extensão em que se estabelece um conjunto suficientemente operacional de medidas corretas para os conceitos que estão sendo estudados e de que não sejam utilizados julgamentos subjetivos para se coletar os dados (YIN, 2001, p.56). O mesmo autor, YIN (2001, p.56), aponta 
também a relevância da "especificação prévia dos eventos operacionais significantes".

\begin{tabular}{|c|c|c|}
\hline Testes & Tática do estudo de caso & $\begin{array}{l}\text { Fase da pesquisa na qual a tática } \\
\text { deve ser aplicada }\end{array}$ \\
\hline Validade construtiva & $\begin{array}{l}\text { - Utiliza fontes múltiplas de } \\
\text { evidências } \\
\text { - } \begin{array}{l}\text { Estabelece encadeamento de } \\
\text { evidências }\end{array} \\
\text { - O rascunho do relatório do estudo } \\
\text { de caso é revisado por } \\
\text { informante-chave }\end{array}$ & $\begin{array}{l}\text { Coleta de dados } \\
\text { Coleta de dados } \\
\text { Composição }\end{array}$ \\
\hline Validade interna & $\begin{array}{ll}\text { - } & \text { Faz adequação ao padrão } \\
\text { - } & \text { Faz construção da explanação } \\
\text { - } & \text { Faz análises de séries temporais }\end{array}$ & $\begin{array}{l}\text { Análise de dados } \\
\text { Análise de dados } \\
\text { Análise de dados }\end{array}$ \\
\hline Validade externa & $\begin{array}{l}\text { - Utiliza lógica de replicação em } \\
\text { estudos de casos múltiplos }\end{array}$ & Projeto de pesquisa \\
\hline Confiabilidade & $\begin{array}{l}\text { - Utiliza protocolo de estudo de } \\
\text { caso } \\
\text { - } \begin{array}{l}\text { Desenvolve banco de dados para } \\
\text { o estudo de caso }\end{array}\end{array}$ & $\begin{array}{l}\text { Coleta de dados } \\
\text { Coleta de dados }\end{array}$ \\
\hline
\end{tabular}

Tabela 5.2 - Táticas do Estudo de Caso para Teste de Qualidade do Projeto de Pesquisa

(Transcrita de Yin, 2001, p. 55)

A primeira das três táticas de YIN (2001, p.55) para assegurar a validade construtiva é usar fontes múltiplas de evidência. Informações compartilhadas de múltiplas fontes de evidência ajudam a convergir conceitualmente, incentivando "linhas convergentes de investigação". Para o presente estudo, as fontes previstas de evidência incluem dados de entrevistas, questionário para a obtenção de dados, relatórios de empresas (quando disponíveis), e observações do pesquisador.

A segunda tática para assegurar a validade construtiva (assim como elevar a confiabilidade) é estabelecer um encadeamento de evidências. Em outras palavras, deve-se proceder como se um observador externo possa seguir a derivação da evidência. Consiste em "permitir que um observador externo possa perceber que qualquer evidência proveniente de questões iniciais da pesquisa leve às conclusões finais do estudo de caso" (YIN, 2001, p.126). Para o presente estudo, o 
encadeamento de evidências pode também ser seguido, conforme requerido, a partir dos dados brutos, ainda sem tratamento, e por meio de resumos e conclusões.

A terceira tática é a revisão por informantes-chave da minuta do estudo de caso para verificar se há um consenso acurado. Esta tática, devido às dificuldades de acesso aos informantes, não é prevista para o presente estudo.

\subsubsection{2 - Validade Interna}

A validade interna está associada à extensão em que se pode estabelecer uma relação causal, pela qual se mostra que certas condições conduzem a outras condições, descartando falsas relações (YIN, 2001, p.57). É “a validade aproximada com a qual se infere que a relação entre duas variáveis é causal ou que a ausência de relação implica ausência de causa" (McLACHLIN, 1997, p.276).

YIN (2001, p.58) afirma que "a preocupação com a validade interna, para a pesquisa de estudo de caso, pode ser estendida ao problema mais amplo de se fazer inferências". Ainda, conforme YIN (2001, p.58), “o pesquisador inferirá que um evento em particular foi o resultado de alguma ocorrência anterior, com base em evidências obtidas de entrevistas e documentação coletadas como parte do estudo de caso".

\subsubsection{3 - Validade Externa}

A validade externa refere-se ao campo para o qual as descobertas do estudo ou supostas relações causais podem ser generalizadas além do estudo de caso imediato (YIN, 2001, p.58).

O problema da validade externa tem sido uma grande barreira na elaboração de estudos de caso, de acordo com críticos da abordagem do método do estudo de caso. Entretanto, conforme destacado por YIN (2001, p38):

"Um erro fatal que se comete ao se realizar estudos de caso é conceber a generalização estatística como o método de se generalizar os resultados do caso. Isto ocorre por que casos não são unidades de amostragem e não devem ser escolhidos por essa razão". 
Tendo ainda como referência o mesmo autor, YIN (2001, p.43), pesquisas do tipo levantamento se apóiam em generalização estatística, enquanto estudos de caso (como também experimentos) se apóiam em generalização analítica.

Assim, com pesquisa de caso, a generalização é de cada caso para uma mais ampla teoria (generalização analítica), não de amostras para populações (generalização estatística). E é possível com generalização analítica generalizar a partir de um único caso, embora tal generalização não seja automática.

No presente estudo, a quantidade de casos pesquisados limita a generalização, mas a análise de dados obtidos deve encaminhar uma maior abrangência teórica.

\subsubsection{4 - Confiabilidade do Estudo}

Confiabilidade do estudo é a extensão na qual as operações de um estudo podem ser repetidas, com os mesmos resultados (YIN, 2001, p.60). Isso significa que, se for feita uma posterior investigação para conduzir o mesmo estudo de caso, seguindo exatamente os mesmos procedimentos, os mesmos resultados devem ser obtidos. YIN (2001, p.54) recomenda duas táticas para assegurar a confiabilidade em estudos de caso.

A primeira tática é usar um protocolo do estudo de caso como diretriz da pesquisa.

A segunda tática é manter um banco de dados do estudo de caso, com anotações, arquivo de dados, respostas a questionários, documentos, registros organizados e resumos intermediários.

A maneira geral de se aproximar do problema da confiabilidade é tornar as etapas do processo o mais operacionais possível e conduzir a pesquisa de forma que um auditor possa repetir os procedimentos e chegar aos mesmos resultados (YIN, 2001, p.60).

Para esta pesquisa, o planejamento de sua operacionalização e o do registro de dados visa a assegurar a confiabilidade do estudo.

\subsection{3 - Pesquisa Qualitativa e Pesquisa Quantitativa}

BRYMAN (1989, p.175) aponta duas abordagens para a pesquisa: qualitativa e quantitativa. 
YIN (1989) categoriza questões de pesquisa do tipo: "quem", "o que", “onde", "como" e "por que". Esse autor relaciona os problemas de pesquisa do tipo "como" e "por que" ao caráter exploratório, mais próximo de uma abordagem qualitativa, enquanto que "o que", "quem" e "onde" implicam tratamento quantitativo visando a discriminar a incidência do fenômeno estudado.

A abordagem qualitativa permite viabilizar o primeiro reconhecimento do objeto e, eventualmente, instrumentaliza uma posterior abordagem alternativa (PEREIRA, 2001, p.22).

Assim, uma abordagem qualitativa requer considerar os seguintes aspectos (BRYMAN, 1989):

a) maior proximidade do pesquisador às circunstâncias nas quais a empresa está inserida, procurando aprofundar-se no contexto da organização (abordagem perceptiva). Recomenda-se administrar essa proximidade, a fim de evitar um nível de interferências prejudiciais ao escopo da pesquisa;

b) menor rigidez na estruturação da pesquisa, redundando, inicialmente, em proposições menos robustas e conferindo à pesquisa maior flexibilidade quanto ao re-direcionamento dos eventos (caráter exploratório);

c) seqüência dos eventos ao longo da pesquisa, minimizando as dificuldades em reproduzir as etapas da pesquisa;

d) utilização de mais de uma fonte de dados dentro do universo restrito de pesquisa. O pesquisador qualitativo deve atentar para a validade construtiva da pesquisa, identificando as fontes que evidenciam medidas operacionais e julgamentos objetivos.

\subsection{4 - Definições Operacionais}

Para cada variável de pesquisa associada às proposições, foram aplicadas as evidências disponíveis. A ênfase foi em evidências qualitativas, principalmente a partir de entrevistas com gerentes, ou gestores, vinculados à função manutenção.

YIN (2001, p.107) propõe seis origens distintas para a coleta de evidências durante a condução de estudos de caso, e para as quais se dirigiram os esforços da presente pesquisa: 
a) documentação: variedade de documentos. Em estudo de caso, a importância da documentação está em corroborar e incrementar evidências oriundas de outras fontes.

No presente estudo, quando disponíveis, são analisados relatórios fornecidos pelas empresas visitadas.

b) registros em arquivo: condições ou especificações em que sucede o processo de manutenção. As informações obtidas podem ser tanto de natureza qualitativa como quantitativa.

c) entrevistas devidamente agendadas: investigação baseada na percepção dos "tomadores de decisão".

No presente estudo, as entrevistas são orientadas por um roteiro contendo os tópicos mais importantes a serem abordados, tomando por base os quesitos contemplados na Figura 5.2 (item 5.2.2). Em face da dimensão da organização focalizada, podem ser realizadas uma ou mais entrevistas. Desse modo, é possível verificar diferentes visões do processo de manutenção, dentro de uma mesma empresa.

Embora um roteiro, constante do Anexo A e baseado nas variáveis da Figura 5.2, seja adotado, procura-se não prejudicar a flexibilidade para fornecimento de informações que possam aprofundar conhecimentos pertinentes ao objeto da pesquisa.

d) observação direta: oportunidade de examinar alguns comportamentos proeminentes ou condições de restrição. Formalmente, um protocolo de observação ou instrumento de pesquisa pode ser desenvolvido para focalizar o processo de coleta de dados nos assuntos relevantes à pesquisa.

e) observação participante: observação na qual o pesquisador assume posturas pertinentes à observância ativa, participando dos eventos (foco de estudo) que estão sendo estudados.

No presente estudo, não foi prevista a participação do pesquisador de eventos de manutenção, prevendo-se apenas a coleta de dados a partir de entrevistas, de observações e de relatórios eventualmente fornecidos pelas organizações. 
f) artefatos físicos ou culturais: artifícios tecnológicos, ferramental ou instrumentação, ou algumas outras evidencias físicas, como hardware do sistema de informações, estrutura de distribuição da informação.

\subsubsection{1 - Dados Qualitativos}

Como há numerosos depoimentos na forma qualitativa que podem servir como indicadores para uma dada proposição, é inviável delinear um conjunto definitivo de respostas para servir como uma definição operacional. Esta é uma forte razão pela qual a metodologia do estudo de caso é escolhida. Mais, cada depoimento exige julgamento, no seu contexto, para determinar a extensão na qual ele pode ser considerado evidência para a hipótese em questão. Para auxiliar nesta tarefa, é relevante detalhar um plano de balizamento de respostas potencialmente representativas para cada proposição. Esse plano representa um guia para o tipo de evidência que pode conduzir a aceitação de cada proposição. Esse balizamento está implícito na Figura 5.2, que será objeto de considerações específicas mais adiante.

\subsubsection{2 - Dados Quantitativos}

A pesquisa não prevê obtenção de dados de natureza quantitativa.

\subsection{5 - Caracterização dos Casos}

Embora não haja nenhuma quantidade ideal de casos, quatro a dez casos representam uma quantidade aceitável (McLACHLIN, 1997, p.277). Para este estudo de casos, quatro empresas foram escolhidas, representando dois tipos específicos de sistemas produtivos: transporte de passageiros sobre trilhos e produtos alimentícios. Os sistemas e instalações pertencem a duas empresas de transporte de passageiros sobre trilhos e duas empresas da indústria de alimentação, naturalmente, todas, por premissa, demandando serviços de manutenção de seus sistemas produtivos.

A escolha das organizações pesquisadas se fundamenta nos potenciais de contribuição de cada uma para a estruturação do tratamento da manutenção e da disponibilidade. Em face da exigüidade de recursos de pesquisa, a quantidade de empresas pesquisadas é limitada às quatro empresas citadas, procurando-se verificar a possibilidade de generalização da aplicabilidade das proposições testadas. 
A adequada configuração das políticas de manutenção e das práticas de gestão requer a consideração do contexto em que a empresa se insere. Assim, uma primeira caracterização das empresas objeto de pesquisa torna-se essencial.

As empresas escolhidas para a pesquisa (Tabela 5.3) representam os setores de transporte de passageiros sobre trilhos e de processamento de alimentos. Há razões para a escolha de duas empresas representando cada setor. Conta-se com a oportunidade de se comparar empresas de um mesmo setor e de setores diferenciados, avaliando-se eventuais aspectos comuns e diferenciados entre elas. As empresas encontram-se todas localizadas na área da Grande São Paulo e são de capital nacional.

\subsubsection{1 - Empresa TPT1}

É uma empresa de capital misto, que tem por objetivo o planejamento, a construção, a implantação, a operação e a manutenção do sistema de transporte público metroviário na Região Metropolitana de São Paulo (RMSP), tendo iniciado sua operação comercial em 1974. Opera, hoje, aproximadamente $50 \mathrm{~km}$ de linhas, contabilizando da ordem de 2 milhões de entradas de passageiros, diariamente, no sistema.

Possui equipamentos de natureza fixa (como instalações prediais, equipamentos do sistema de eletrificação e equipamentos do sistema de sinalização e controle de trens) e equipamentos móveis (o material rodante, ou seja, o trem). O intervalo entre passagens de trens é muito importante para o desempenho operacional, é valorizado pelo usuário e diretamente percebido como indicador da qualidade do serviço de transporte. Esse intervalo, embora dependa de uma série de fatores, é fortemente condicionado pela disponibilidade do próprio trem e dos sistemas operacionais auxiliares, como sinalização e alimentação elétrica.

No contexto dessa organização, e conforme caracterizado por ZARIFIAN (item 3.3, deste estudo), o cliente do sistema de manutenção é o sistema de operação e o serviço fornecido pela manutenção é a disponibilidade operacional dos sistemas e equipamentos para o transporte do público. 


\begin{tabular}{|c|c|c|}
\hline ELEMENTO & EMPRESAS TPT1 e TPT2 & EMPRESAS IPA 1 e IPA 2 \\
\hline Disponibilidade do sistema produtivo & $\begin{array}{l}\text { Requerem elevada disponibilidade em função da } \\
\text { pressão direta da demanda pelo público usuário }\end{array}$ & $\begin{array}{l}\text { Requer disponibilidade de equipamentos produtivos } \\
\text { em função de um programa de produção }\end{array}$ \\
\hline Distribuição dos equipamentos produtivos & $\begin{array}{l}\text { Distribuídos em extensa área geográfica na região } \\
\text { metropolitana de São Paulo }\end{array}$ & Centralizados em ambiente fechado \\
\hline Origem do investimento & Público & Privado \\
\hline Variação da demanda de produção & Picos diários de demanda, em horários de "rush" & Picos em função de sazonabilidade \\
\hline Interferência do cliente no sistema produtivo & $\begin{array}{l}\text { O cliente (usuário) participa do processo de } \\
\text { produção, como passageiro }\end{array}$ & $\begin{array}{l}\text { O cliente não tem contato físico com o sistema } \\
\text { produtivo }\end{array}$ \\
\hline Controle do sistema produtivo & $\begin{array}{l}\text { Controle através de sistema de hardwares e } \\
\text { softwares que conduzem a informação para um } \\
\text { centro de controle operacional }\end{array}$ & A fábrica permite supervisão direta e local \\
\hline Segurança do cliente & $\begin{array}{l}\text { Depende fortemente do comportamento do sistema } \\
\text { produtivo }\end{array}$ & $\begin{array}{l}\text { O cliente não tem contato físico com o sistema } \\
\text { produtivo }\end{array}$ \\
\hline Aplicação da abordagem TPM & $\begin{array}{l}\text { A produção de serviços se concentra no usuário: } \\
\text { baixo potencial de aplicaçãa da abordagem TPM }\end{array}$ & $\begin{array}{l}\text { Equipamentos de produção centralizados: Elevado } \\
\text { potencial de aplicação de TPM }\end{array}$ \\
\hline $\begin{array}{l}\text { Percepção da disponibilidade e do equipamento pelo } \\
\text { cliente }\end{array}$ & $\begin{array}{l}\text { Percepção direta, pois o cliente entra no sistema } \\
\text { produtivo }\end{array}$ & $\begin{array}{l}\text { O cliente não toma conhecimento de problemas } \\
\text { associados à disponibilidade }\end{array}$ \\
\hline Estabilidade da demanda pelo cliente no curto prazo & Razoavelmente estável & Na dependência de condições do mercado \\
\hline Fins lucrativos & Não & Sim \\
\hline Produto final & Serviços de transporte & Produtos alimentícios \\
\hline Investimento & Intensidade elevada & Moderados, quando comparados com TPT1 e TPT2 \\
\hline Disposição do equipamento & $\begin{array}{l}\text { Sistemas fixos e móveis (caso do trem, que } \\
\text { representa da ordem de } 50 \% \text { do investimento) }\end{array}$ & Essencialmente fixos dentro de área "intra muros" \\
\hline Estocagem do produto & $\begin{array}{l}\text { Sem possibilidade de "estocar o serviço de } \\
\text { transporte" }\end{array}$ & $\begin{array}{l}\text { O produto pode ser estocado, inclusive com } \\
\text { produção antecipada }\end{array}$ \\
\hline
\end{tabular}

Tabela 5.3 - Características das Empresas Selecionadas para a Pesquisa

(Elaborada pelo Autor) 


\subsubsection{2 - Empresa TPT2}

De modo semelhante à empresa TPT1, a empresa TPT2, também, atua no segmento de prestação de serviços de transporte de pessoas na RMSP, principal pólo de desenvolvimento do País com população de 16 milhões de habitantes, respondendo por $16 \%$ do PIB nacional.

A malha de trilhos da TPT2 é composta de 6 linhas, $270 \mathrm{~km}$ de vias, 92 estações, atendendo 22 municípios na RMSP. A média de passageiros transportados por dia útil é de cerca de 1 milhão.

Os equipamentos e sistemas operacionais da TPT2 não são homogêneos, em razão de características particulares de sua formação. Entre os anos de 1994 e 1996, a TPT2, criada por Lei Estadual em 1992, integrou os sistemas de transporte metropolitano de duas outras organizações existentes até aquela data, recebendo equipamentos de diversas gerações tecnológicas.

A TPT2 é um sistema de transporte de passageiros de grande capacidade e importância, e, em termos mundiais, sua extensão e seu volume de passageiros transportados comparam-se ao porte de outros sistemas, de mesma natureza, que operam em regiões metropolitanas como México e Madri.

O valor total de instalação dos sistemas operacionais, excetuando-se edificações e obra de arte, é estimado em cerca de US\$ 2.700 milhões. O custo anual de manutenção dos sistemas operacionais é estimado em mais de US\$100 milhões.

Considerações sobre a importância da disponibilidade, semelhantes às efetuadas para a TPT1, podem ser repetidas para este caso. Particularmente, nesta empresa identificou-se a oportunidade de realização de duas entrevistas, uma dirigida à manutenção de sistemas fixos, e outra dirigida à manutenção do equipamento móvel que é designado como material rodante.

\subsubsection{3 - Empresa IPA1}

A empresa está estabelecida na Grande São Paulo, há quase cem anos, e conta com capital de origem nacional. É líder de mercado no País, no segmento em que atua, sendo uma das mais importantes fábricas de vinagre da América Latina. Apresenta uma linha diversificada de produtos (molhos para saladas, balsâmicos, azeite, agrin, sabores, temperos, ketchup, mostarda, óleo comestível, azeitonas, 
palmitos e cogumelos), de fabricação própria, ou de terceiros utilizando sua marca, que é tradicional.

Possui uma área de instalação de quase $50.000 \mathrm{~m}^{2}$, onde seus vinagres são armazenados e maturados em barris de madeira e tanques de inox.

Trata-se de empresa que expressa enorme preocupação com a lucratividade, com o aprimoramento de processos, com a produtividade e com o ambiente.

\subsubsection{4 - Empresa IPA2}

Esta empresa também fabrica produtos alimentícios, embora de natureza diversa da IPA1. Enquanto a IPA1 possui sua produção centralizada em uma única planta, localizada em município da Grande São Paulo, a IPA2 distribui o processo de sua produção em três unidades localizadas na Grande São Paulo, e uma no sul de Minas Gerais.

É uma empresa nacional que produz panetones, colombas, bolos, torradas, wafers e biscoitos. Assim, alguns de seus produtos têm características nitidamente sazonais.

A empresa tem uma história de mais de sessenta anos, tendo crescido incorporando outras marcas tradicionais no mercado acompanhadas de suas unidades de produção. Assim, suas instalações representam uma diversificação de origens. Grande parte do equipamento é importada.

\subsection{6 - Procedimentos Analíticos}

"A análise de dados" consiste "em examinar, categorizar, classificar em tabelas ou, do contrário, recombinar as evidências tendo em vista proposições iniciais de um estudo". (YIN, 2001, p.131).

O processo para redução e disposição dos dados requer considerações para as quais McLACHLIN (1997, p.278) lembra que há três fluxos concorrentes de atividades: redução dos dados, disposição de dados, e retirada/verificação de conclusões. Resumidamente, para cada local visitado, os dados brutos, originalmente agrupados por informante, devem ser registrados em forma escrita, codificados e agrupados conforme cada proposição, com a informação condensada disposta em um 
resumo para cada organização. Finalmente, o quadro sumário de cada organização deve conduzir um cruzamento de informações conforme cada proposição em teste.

\subsection{7 - Escala de Avaliação das Variáveis da Pesquisa}

No âmbito do presente estudo, desponta a necessidade de se dispor de uma escala que permita avaliar as variáveis que dizem respeito a cada uma das proposições. Para conceber uma escala de medida para um fenômeno qualitativo, o pesquisador deve considerar o referencial teórico relativo à mensuração de eventos qualitativos e às características de seu objeto de estudo. A representação numérica deve sugerir o que sejam as manifestações esperadas desse objeto, segundo o universo de conhecimentos disponíveis sobre ele (PEREIRA, 2001, p.64).

Para verificar cada uma das proposições, procurou-se associar a grandeza de cada variável pertinente à evidência, ou não, de algumas condições, enquadrando-a em uma escala de classificação: incipiente (nível 1), regular (nível 2), médio (nível 3), elevado (nível 4) e pleno (nível 5), e conforme um instrumento de avaliação descrito em sequiência.

\section{2 - Instrumento de Avaliação das Variáveis}

Esta pesquisa se apóia na metodologia de estudo de casos múltiplos e, nesta etapa de planejamento do trabalho de campo, constata-se a necessidade de se definir uma metodologia estruturada para possibilitar avaliar objetivamente as proposições da pesquisa, que são de natureza essencialmente qualitativa. Para isso, foi possível encontrar na escala evolutiva do Capability Maturity Model (CMM) a inspiração para a elaboração de um quadro referencial de avaliação. O Capability Maturity Model (CMM) fornece um modelo conceitual que considera a capacidade de uma dada organização em planejar e realizar determinados processos como uma decorrência de uma trajetória evolutiva. A criação de um quadro referencial visa a restringir interpretações subjetivas ad hoc, e proporcionar avaliações balizadas de modo mais consistente. 


\subsection{1 - O modelo CMM (Modelo de Maturidade da Capacidade)}

Segundo PESSÔA et al (1997, p.2) e TOLEDO et al (2002, p.5), o modelo CMM em sua forma original teria sido desenvolvido pelo Software Engineering Institute (SEI), ligado à Universidade Carnegie Mellon, e o desenvolvimento desse modelo foi financiado pelo Departamento de Defesa do governo norte-americano (DoD), com o objetivo de se estabelecer um padrão de qualidade para os softwares desenvolvidos para as Forças Armadas. Para estes autores, o foco do CMM seria o desenvolvimento de grandes projetos militares e, para sua aplicação em projetos menores e em outras áreas, seria necessário um trabalho cuidadoso de interpretação e adequação à realidade da organização. Tal adequação foi prevista na própria concepção deste modelo.

Ao se pesquisar junto ao SEI (2002), verifica-se que o objetivo de um CMM integrado é proporcionar orientação para aprimorar os processos da organização e sua capacidade para administrar o desenvolvimento, a aquisição e a manutenção de produtos e serviços. Ainda, o SEI (2002) credita a autores como Crosby (1979), Deming (1986), Juran (1988), e Humphrey (1989), os fundamentos básicos e conceituais que inspiraram o desenvolvimento do CMM.

Humphrey e seus parceiros da IBM desenvolveram os conceitos básicos do CMM, ao verificar que a qualidade de sistemas aplicativos estava relacionada diretamente com a qualidade do processo adotado para desenvolvê-los. Para aprimorar o processo, Humphrey idealizou implantar o ciclo PDCA de desenvolvimento contínuo, conforme enfatizado por Deming. Entretanto, os ganhos não se mostraram satisfatórios. Humphrey verificou, então, que, para obter sucesso, era preciso remover impedimentos que prejudicavam o aprimoramento contínuo. Para isso desenvolveu um referencial de maturidade caracterizando o processo evolutivo em cinco níveis, para as organizações incrementarem suas capacidades de processo (GARTNER, 2001).

PESSÔA et al (1997, p.2) observam que o modelo CMM foi baseado nos conceitos de qualidade total estabelecidos por Crosby e salientam que este autor, em Quality is Free, estabelece que a implantação de sistemas de qualidade em empresas segue um amadurecimento gradativo, em patamares que o autor denominou incerteza, despertar, esclarecimento, sabedoria, e certeza. 
Já, "no modelo CMM foram criados níveis de maturidade referentes à maturidade que a organização possui para desenvolver software: inicial, repetitivo, definido, gerenciado e otimizado" (PESSÔA et al, 1997, p.2). A Figura 5.1 mostra o relacionamento entre esses níveis sugerindo que uma organização vai galgando-os em direção ao topo dessa escala de maturidade, à medida que acumula, através de um processo de aprendizagem, um conjunto de competências que a habilitam a assegurar as capacidades de planejamento e gerenciamento de processos referentes aos níveis anteriores de capacidade.

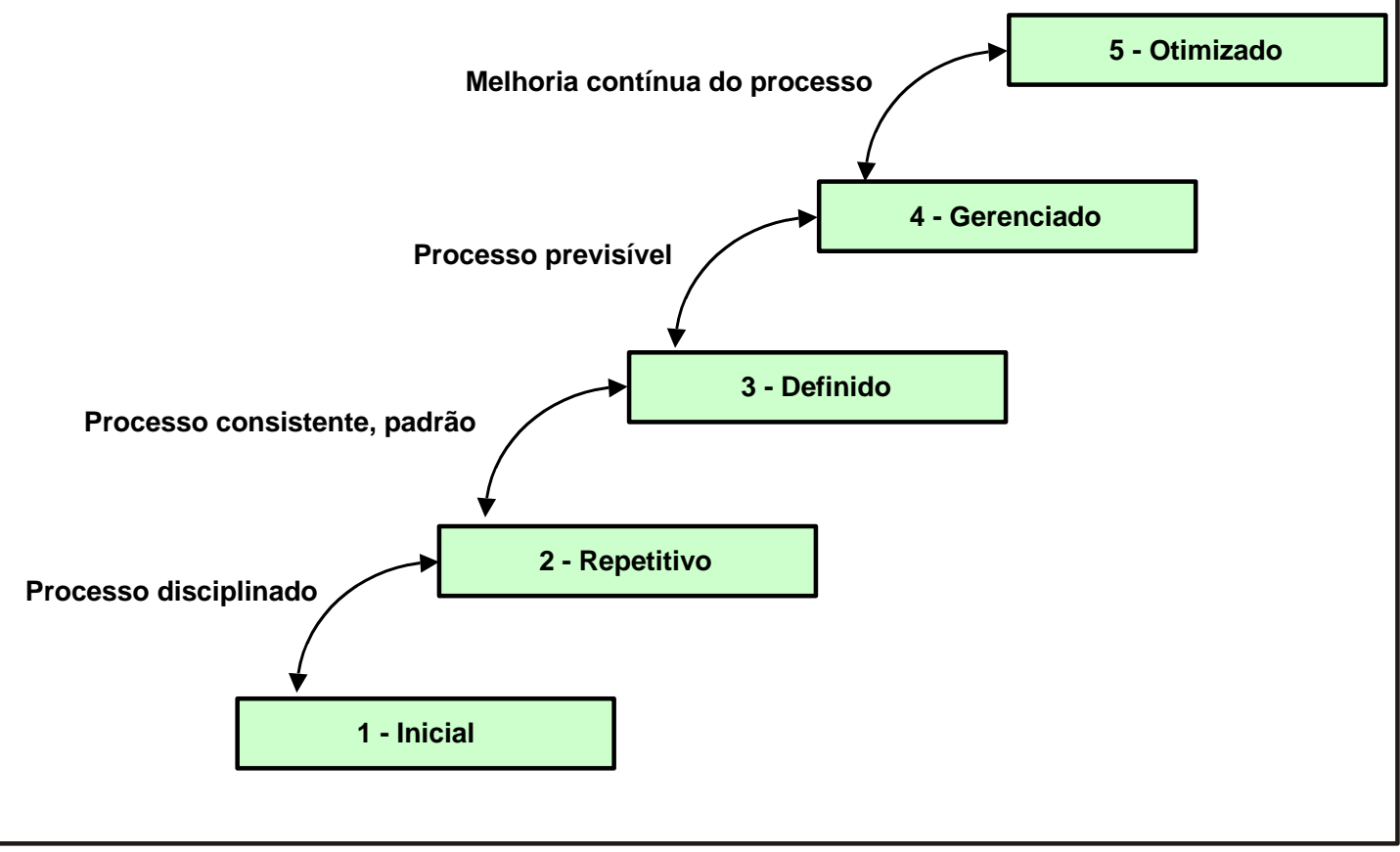

Figura 5.1 - Níveis de Maturidade do CMM (Transcrita de Pessôa et al, 1997, p. 2)

Uma variação desse modelo foi adotada por PENNYPACKER e GRANT (2003, p.4-11) num "estudo empírico desenvolvido para avaliar necessidades de benchmarks de indústrias que podem ser usadas para uma empresa moderna determinar em que posição ela se situa relativamente a organizações que praticam a gestão de projetos em contexto industrial restrito ou abrangente". Estes autores, no estudo em que procuram caracterizar o benchmarking em gestão por projetos, afirmam que “a implementação e institucionalização da gestão por projetos em uma 
organização é um processo evolutivo". Com base em tal premissa, balizam seu estudo de benchmarking adotando um modelo ajustado denominado de PM Solutions Project Management Maturity Model.

O PM Solutions Project Management Maturity Model é baseado em uma estrutura bidimensional. A primeira dimensão reflete o nível de maturidade. A segunda dimensão compreende quesitos-chave para a avaliação em foco. Esse modelo é baseado no CMM do SEI e tem encontrado ampla aceitação como um padrão para o processo de modelagem e avaliação da maturidade organizacional no gerenciamento de processo em diversas áreas (PENNYPACKER e GRANT, 2003, p.6).

Encontra-se, também na literatura, uma proposta de modelo semelhante apresentada por KERZNER (2001, p.1045-1050), denominado de Project Management Maturity Model (PMMM), que este autor propõe como instrumento de análise básico para se atingir resultados de excelência na área de gestão de projetos. $\mathrm{Na}$ concepção deste autor, são também sugeridos cinco níveis evolutivos para representar o estágio de maturidade em que uma dada organização pode ser enquadrada, quais sejam: linguagem compartilhada, processos compartilhados, unicidade metodológica, benchmarking e aprimoramento contínuo.

"Atualmente, organizações em diversas áreas industriais utilizam alguma forma de modelo de maturidade para avaliar o progresso na implementação de best practices" (GRAY e LARSON, 2002, p.14). Um exemplo dessa utilização pode ser encontrado no estudo de ROSENTHAL e VIGELAND (1996, p.5-11), em que um modelo de maturidade é aplicado para avaliação de processos de projeto de produtos em organizações da indústria eletrônica, com o objetivo de aprimorar a qualidade e a produtividade e otimizar custos.

No âmbito nacional, TOLEDO et al (2002) apresentam uma aplicação, em um estudo de caso de uma empresa do ramo de engenharia da construção, de avaliação de grau de maturidade em função de uma escala evolutiva.

Existem, portanto, evidências da difusão de modelos inspirados no CMM, da diversificação de sua aplicação e de seu potencial de contribuição para o aprimoramento de processos. A caracterização de uma escala de patamares, ou níveis, que permita o enquadramento do estágio de evolução em que se encontram os 
processos de uma organização sob avaliação, parece firmar-se como um referencial metodológico.

Para o caso do presente estudo, o instrumental do CMM foi simplificado e adaptado, considerando de modo geral uma escala que leva em conta graus intermediários de avaliação (regular, médio e elevado) dentro de um espectro que vai desde o nível incipiente (em que as variáveis praticamente não apresentam evidências de formalidade ou tratamento na empresa) até o nível pleno (geralmente caracterizado por evidências de integração na empresa, de confrontação com padrões, e de buscas de aprimoramento e atualizações).

Neste trabalho, uma coleta de dados, em entrevistas, na forma qualitativa serve como elemento para a verificação de cada proposição. Contudo, cada depoimento de entrevistado exige um julgamento, no seu contexto, da extensão na qual pode ser considerado como evidência para a proposição em questão. Nessa tarefa, as escalas constituídas de estágios evolutivos subsidiam o enquadramento das variáveis de cada organização para a verificação das proposições de pesquisa.

\subsection{2 - Quadro Referencial de Avaliação das Variáveis}

Assim, em precedência à realização da pesquisa de campo foi desenvolvida uma ferramenta de pesquisa lastreada em um caráter evolutivo. No modelo CMM, as organizações são classificadas em cinco níveis distintos, cada um com suas características próprias. Começa pelo nível das organizações mais imaturas (nível 1), em que não há nenhuma metodologia implementada e tudo ocorre de forma incipiente. O topo é o nível das organizações mais maduras, em que cada detalhe de desenvolvimento do processo está definido, quantificado e monitorado (nível 5). Entre estes extremos, encontram-se os níveis 2, 3 e 4, que representam estágios intermediários.

Para a verificação das três proposições de pesquisa, são considerados níveis representativos da evolução das variáveis representativas. O referencial apresentado na Figura 5.2 indica para as proposições P1, P2 e P3, respectivamente 4, 2 e 2 variáveis específicas, formando um conjunto de 8 aspectos que direcionarão a investigação das organizações objeto de estudo. No caso particular das duas variáveis 
da proposição P2, elas serão aplicadas para verificação do tratamento dado, nas empresas, para cada um dos seis compromissos incluídos neste estudo.

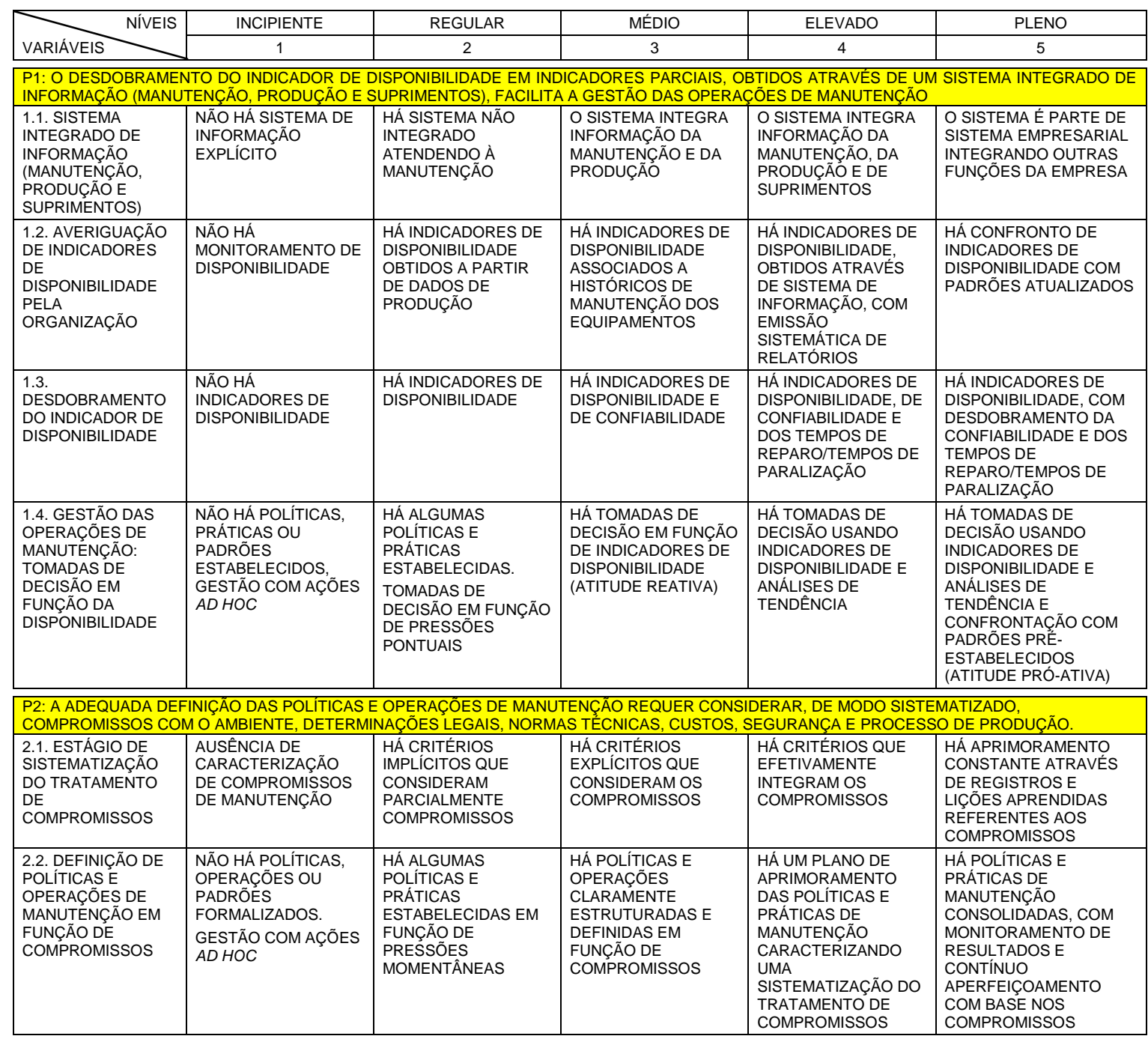

P3: AS EMPRESAS CONSIDERAM RELEVANTE, PARA A OBTENÇÃO DA DISPONIBILIDADE, LEVAR EM CONTA, POR OCASIÃO DE PROJETOS DE NOVOS SISTEMAS PRODUT
VIDA DO EQUIPAMENTO

\begin{tabular}{|c|c|c|c|c|c|}
\hline $\begin{array}{l}\text { 3.1. ESTUDO } \\
\text { PERSPECTIVO DO } \\
\text { CICLO DE VIDA NO } \\
\text { ESTÁGIO DE } \\
\text { PROJETO DE } \\
\text { NOVOS SISTEMAS } \\
\text { PRODUTIVOS }\end{array}$ & $\begin{array}{l}\text { NÃO HÁ CRITÉRIOS } \\
\text { DEFINIDOS PARA } \\
\text { ANÁLISE DO CICLO } \\
\text { DE VIDA }\end{array}$ & $\begin{array}{l}\text { HÁ PREOCUPAÇÃO } \\
\text { IMEDIATA COM O } \\
\text { VALOR DO } \\
\text { INVESTIMENTO }\end{array}$ & $\begin{array}{l}\text { HÁ PREOCUPAÇÃO } \\
\text { COM INVESTIMENTO } \\
\text { E CUSTOS } \\
\text { OPERACIONAIS }\end{array}$ & $\begin{array}{l}\text { HÁ PREOCUPAÇÃO } \\
\text { COM INVESTIMENTO, } \\
\text { CUSTOS, E } \\
\text { DISPONIBILIDADE }\end{array}$ & $\begin{array}{l}\text { HÁ ANÁLISE DE CUSTOS } \\
\text { E DE DESEMPENHO, } \\
\text { CONSIDERANDO DE } \\
\text { MODO INTEGRAL AS } \\
\text { ETAPAS DO CICLO DE } \\
\text { VIDA. HÁ } \\
\text { ESPECIFICAÇÃO } \\
\text { ANTECIPADA DE } \\
\text { PADRÕES DE } \\
\text { DISPONIBILIDADE, } \\
\text { CONFIABILIDADE E } \\
\text { MANUTENIBILIDADE, } \\
\text { POR OCASIÃO DO } \\
\text { PROJETO }\end{array}$ \\
\hline $\begin{array}{l}3.2 \text {. } \\
\text { CONSIDERAÇÃO DA } \\
\text { DISPONIBILIDADE } \\
\text { POR OCASIÃO DE } \\
\text { PROJETO DE } \\
\text { RENOVAÇÃO, } \\
\text { AMPLIAÇÂO OU } \\
\text { SUBSTITUIÇÃO }\end{array}$ & $\begin{array}{l}\text { NÃO HÁ } \\
\text { MONITORAMENTO DA } \\
\text { DISPONIBILIDADE }\end{array}$ & $\begin{array}{l}\text { HÁ INDICADORES DE } \\
\text { DISPONIBILIDADE } \\
\text { MAS NÃO SÃO } \\
\text { UTILIZADOS }\end{array}$ & $\begin{array}{l}\text { CARACTERIZA-SE O } \\
\text { ESTÁGIO DO CICLO } \\
\text { DE VIDA E LEVA-SE } \\
\text { EM CONTA } \\
\text { RESULTADOS DE } \\
\text { DISPONIBILIDADE } \\
\text { OBTIDOS }\end{array}$ & $\begin{array}{l}\text { LEVA-SE EM CONTA } \\
\text { RESULTADOS DE } \\
\text { DISPONIBILIDADE, } \\
\text { CONFIABILIDADE E } \\
\text { MTTR/TEMPOS DE } \\
\text { PARALIZAÇÃO } \\
\text { OBTIDOS }\end{array}$ & $\begin{array}{l}\text { HÁ ATUALIZAÇÃO DE } \\
\text { PROJETOS. } \\
\text { HÁ CONFRONTO DE } \\
\text { DESEMPENHO } \\
\text { OPERACIONAL COM } \\
\text { PADRÕES DE PROJETO }\end{array}$ \\
\hline
\end{tabular}

Figura 5.2 - Quadro Referencial para Avaliação das Variáveis da Pesquisa (Adaptada de Vaz e Miyake, 2003) 
Segundo GRAY e LARSON (2002, p.14), há várias versões do modelo de maturidade. Embora a aplicação do CMM tenha sido concebida e desenvolvida a partir das necessidades da área de sistemas de informação, as diretrizes e a abordagem características do CMM têm sido difundidas e apropriadas em outras esferas organizacionais. Tendo em vista tal flexibilidade, é feita a presente incursão, adotando-se fundamentos evolutivos no âmbito da avaliação das proposições desta pesquisa.

$\mathrm{Na}$ revisão bibliográfica realizada, não foi identificado nenhum trabalho propondo estabelecer tal ponte entre o modelo CMM e a avaliação da função manutenção. Na Figura 5.2, são, então, estabelecidos os cinco níveis ou patamares, que representam o estágio de evolução em que uma organização se encontra em relação a 8 variáveis específicas. Para o propósito de desenvolvimento deste estudo são, então, definidos os seguintes níveis para a avaliação das variáveis: incipiente, regular, médio, elevado e pleno. É importante firmar que, ao serem descritas as evidências de cada nível, para cada uma das variáveis, procurou-se expressá-las caminhando de sua ausência ou presença reduzida (nível incipiente, ou 1) até o topo da escala, em que comparecem evidências de sua completeza ou de tomadas de decisão visando a aprimoramentos (nível pleno, ou 5).

A princípio, pretende-se que o nível de enquadramento em relação a cada variável constitua uma métrica, que possibilite aos gestores de manutenção identificar eventuais lacunas, carências, inconsistências e, assim, estabelecer prioridades em termos de desenvolvimento e delinear ações de melhoria ou reforço para gerenciar a condução da organização rumo a estágios superiores para cada variável avaliada.

A aplicação de um modelo indicando patamares representativos do estágio de um processo, além da clara compreensão do modelo, requer um conhecimento profundo do processo e das variáveis analisadas para garantir o sucesso da aplicação desse instrumento. Esse aspecto representa o maior desafio para a descrição de níveis de uma escala evolutiva associada a cada quesito objeto de avaliação. Certamente, o exercício de análises periódicas para a avaliação do progresso em relação a cada quesito ou processo, no âmbito do planejamento e da gestão da manutenção, deve 
propiciar um maior domínio de seu conhecimento e maior sucesso nas tomadas de decisão subseqüentes.

O quadro referencial da Figura 5.2 representa uma matriz em que duas dimensões são consideradas: as variáveis representativas de cada proposição e os níveis para enquadramento da avaliação de cada variável. A escala é constituída de cinco níveis de enquadramento das variáveis.

Para as descrições dos estados, associados a cada variável, que permitam o seu enquadramento em um determinado nível, adotou-se critério baseado na premissa de que cada variável possa apresentar uma evolução positiva gradativa. Assim, o nível 1 (incipiente) inicia a escalada e significa que as variáveis praticamente não apresentam evidências de sua presença ou tratamento. Já no nível 2 (regular) procura-se representar situações em que há evidências de que, mesmo ainda que de modo precário ou implícito, a variável é objeto de tratamento na organização. A evolução segue, passando pelos níveis 3 (médio) e 4 (elevado), até chegar ao nível 5 (pleno), em que há evidências de domínio da variável, ou de mecanismos de aprendizado e confronto com padrões pré-estabelecidos.

Assim, a matriz contempla quarenta descrições, cinco para cada uma das variáveis representativas das proposições.

A experiência da aplicação desse instrumento de avaliação, por ocasião da execução da pesquisa de campo, tem também como objetivo contribuir para a eventual construção futura de um roteiro mais abrangente para o trabalho de diagnóstico da situação do planejamento e gestão da função manutenção nas empresas. A indicação do nível de variáveis do processo global de manutenção, de uma forma consistente, possibilitaria orientar tomadas de decisão mais eficazes para o desenvolvimento das capacitações de manutenção.

Embora essa abordagem abra oportunidades de aperfeiçoamento pertinentes à manutenção, a evolução para níveis superiores, dentro das escalas propostas de amadurecimento, representa um progresso que vai depender da transposição de obstáculos como resistência à mudança por parte de recursos humanos da organização, bem como de restrições de natureza tecnológica, financeira e temporal. 
Encerrando, à medida que se procura seguir a recomendação de YIN para se assegurar a confiabilidade da pesquisa em abordagens de estudos de casos, não é possível afirmar que um outro avaliador inevitavelmente atribuirá o mesmo grau (1 a 5) para cada variável. Entretanto, um outro pesquisador, seguindo exatamente os mesmos procedimentos e conduzindo o mesmo estudo de caso novamente, deve chegar às mesmas avaliações de incipiente, regular, médio, elevado ou pleno. 


\section{6 - PESQUISA DE CAMPO E ANÁlise DOS CASOS VISANDO À VERIFICAÇÃO DAS PROPOSIÇÕES}

\section{1 - Agenda das Entrevistas}

Procurou-se agendar as entrevistas com o máximo de antecipação, de modo a ajustá-las às conveniências dos entrevistados, que foram informados dos objetivos por telefone, fax ou e-mail. Houve cuidado em se entrevistar representantes das empresas, que atuando em escalão gerencial, tivessem uma visão abrangente da manutenção de seus equipamentos e sistemas produtivos. Apesar dessa antecipação, das cinco entrevistas apenas duas ocorreram no horário programado. Embora todos os entrevistados tenham sido receptivos, as entrevistas desenvolveram-se sob forte pressão do tempo, durando aproximadamente uma hora, sendo que duas foram realizadas fora do horário normal de trabalho.

Assim, houve adiamentos de entrevistas, alterações de horário e local, isso ocorrendo até mesmo no dia e horário programados. Essas alterações antecipavam as pressões que iriam ser observadas por ocasião das visitas.

\section{2 - Desenvolvimento das Entrevistas e Coleta de Dados}

As visitas ao campo e as entrevistas foram balizadas pela metodologia descrita no Capítulo 5. O roteiro da entrevista, constante do Anexo A deste estudo, foi preparado e efetivamente utilizado em cinco oportunidades, já que em uma das quatro empresas pesquisadas, na TPT2, ocorreram duas entrevistas (TPT2A, com enfoque mais dirigido ao material rodante, e TPT2B, com enfoque mais dirigido aos equipamentos fixos instalados ao longo das linhas operacionais), procurando identificar eventuais visões diferentes de tratamento das variáveis da pesquisa dentro de uma mesma empresa.

Alguns conceitos exigiram troca de esclarecimentos durante as entrevistas. Particularmente, variáveis que se referem à Proposição P2 (associadas a compromissos) e à Proposição P3 (relacionadas com o ciclo de vida). Os dados pertinentes à Proposição P1 foram coletados com maior fluidez, parecendo que suas variáveis estavam mais próximas do cotidiano da Manutenção. Afinal, a proposição P1 está mais próxima de resultados desejados, e não de eventuais condicionantes desses resultados, como compromissos ou estágio do ciclo de vida. 
O entendimento do termo "ambiente" pelos entrevistados se mostrou bastante elástico. Houve situação em que ele foi associado a "clima de trabalho", sendo relacionado com aspectos comportamentais, como os de entrosamento entre as equipes de manutenção e as de operação ou produção. Entretanto, essa conotação comportamental não é objeto específico do propósito desta pesquisa.

No decorrer de três entrevistas, foi confirmada a sugestão de que "a manutenção é a medicina dos equipamentos", conforme expresso no item 3.3.1 deste estudo. Solicitações que chegavam aos entrevistados, durante as entrevistas, indicavam que a manutenção abrange, entre suas atividades e de modo visível, as de "pronto socorro".

A entrevista com o Gerente da Manutenção da empresa IPA2 foi interrompida, devido a uma solicitação de seu Diretor Industrial, para que fossem dados esclarecimentos pelo profissional sobre equipamentos que devem ser utilizados para a produção de um dos produtos sazonais da empresa, ou seja, o panetone. Todavia, a entrevista foi reiniciada após trinta minutos.

A coleta de dados foi basicamente derivada dos relatos dos entrevistados, os quais sempre que possível foram complementados com evidências observadas pelo entrevistador. Não houve possibilidade de comprovação física das afirmações dos entrevistados. As empresas do grupo TPT forneceram alguns relatórios, cuja leitura também proporcionou subsídios para as análises posteriores. Essa informação complementar foi incorporada ao Anexo B deste estudo, em que se apontam os dados coletados nas entrevistas nessas empresas. As empresas do grupo IPA, não proporcionaram essa facilidade, caracterizando uma distribuição mais modesta de informação impressa ao pesquisador. O porte das empresas do grupo TPT, a origem de seu capital e a necessidade de uma prestação de contas de seu desempenho às autoridades e ao público parecem ser determinante na emissão desses relatórios, que acabam por conter também informações sobre a atuação da Manutenção da empresa.

Por ocasião do planejamento da pesquisa, já havia sido estabelecido que as entrevistas não seriam gravadas, procurando-se evitar eventuais constrangimentos, tanto do entrevistado, como do entrevistador. O clima de espontaneidade se confirmou durante as entrevistas. Pediu-se, entretanto, anuência para que o entrevistador efetuasse anotações. Em particular, no caso das empresas do grupo 
IPA, que estão sujeitas a uma concorrência de mercado mais acirrada, foi acordado um tratamento confidencial quanto à identificação de suas marcas.

Durante a entrevista, o roteiro previamente preparado foi utilizado para balizar as informações que se desejava obter, já que muitas vezes o entusiasmo do entrevistado por determinado tópico, dispondo-se de um segmento de tempo relativamente curto, poderia apressar a finalização da entrevista, tornando a obtenção de dados insatisfatória.

O entrevistador procurou obter, do entrevistado, evidências que permitissem avaliar o estágio da organização em relação a cada uma das variáveis. Para isto, foi utilizado o Roteiro (Anexo A) para balizamento da entrevista. Na ocasião da entrevista, o pesquisador tinha em suas mãos, como apoio, também o quadro referencial da Figura 5.2.

O roteiro e o quadro referencial foram utilizados apenas para orientação do pesquisador, por ocasião da entrevista, porém sem apresentá-los ao entrevistado, e sem formular as questões de forma direta. A entrevista foi conduzida de forma coloquial, de modo que o diálogo possibilitasse obtenção de informação precisa e objetiva da realidade da organização, visando a inibir eventuais vieses do entrevistado ou do entrevistador.

\section{3 - Organização e Análise dos Dados}

Mesmo com o uso do roteiro de entrevista, as respostas dos entrevistados não apresentavam, necessariamente, uma correspondência biunívoca com as variáveis objeto do questionamento. Assim, como primeiro passo, as anotações foram feitas sem a possibilidade de conexão rigorosa e imediata da informação com variáveis e proposições de pesquisa, já no ato da entrevista. As anotações consideradas relevantes foram feitas conforme o entrevistado apresentava suas considerações.

Mais tarde, os dados anotados em cada entrevista foram compilados e enquadrados em "pacotes" correspondentes às proposições e variáveis de estudo. Quando foram fornecidos relatórios, informações pertinentes deles extraídas foram também compiladas e reunidas com as obtidas nas entrevistas. Essa atividade de organização dos dados deu, então, origem ao Anexo B deste estudo, onde os dados coletados referentes ao estudo estão agrupados por caso. 
Os dados referentes aos compromissos (Proposição P2) apresentaram uma sensível dificuldade para sua organização. De modo geral, os entrevistados apresentaram exemplos de compromissos, e não a comprovação de que há um tratamento sistematizado e específico para eles. A exceção foi em relação a custos, para o qual todas as empresas indicaram um tratamento bastante sistematizado, certamente em decorrência do controle exercido pelas áreas financeiras das empresas sobre cada orçamento da Manutenção. Procurando melhor interpretar a abrangência do entendimento do termo compromisso e, se possível, auxiliar na avaliação das variáveis da Proposição P2, foi elaborada uma tabela, constante do Anexo C, mostrando exemplos de compromissos mencionados por ocasião das entrevistas.

Os dados das entrevistas foram analisados procurando associá-los às proposições e variáveis de pesquisa. Como os dados, muitas vezes, estavam associados a mais de uma variável, esse fato teve que ser interpretado e considerado para o posterior enquadramento da variável na escala de avaliação.

Conforme previsto no item 5.2.2 deste estudo, na forma proposta na metodologia da pesquisa, procurou-se enquadrar, em função dos dados obtidos, as variáveis estudadas nos patamares da escala evolutiva de cinco níveis do quadro referencial de avaliação (Figura 5.2).

\section{4 - Avaliação das Variáveis da Pesquisa}

Em função da análise dos dados obtidos nas entrevistas, foi arbitrado pelo pesquisador o enquadramento de cada variável num dos níveis da escala de 1 (incipiente) a 5 (pleno). Essa atividade exigiu um primeiro esforço que se traduziu no Anexo D, procurando identificar a descrição do nível da variável que melhor representasse a situação encontrada nas empresas.

$\mathrm{O}$ resultado desse enquadramento originou as pontuações que se encontram indicadas nas Tabelas 6.1, 6.2 e 6.3. A Tabela 6.2 apresenta uma configuração especial à medida que se procurou apresentar uma visão do tratamento dado a cada um dos seis compromissos estudados. A Tabela 6.2.a, complementando a Tabela 6.2, foi elaborada com o objetivo de permitir uma visão do tratamento do conjunto de compromissos em cada caso. 
Os resultados das tabelas foram traduzidos em uma série de gráficos (Figuras 6.1, 6.2 e 6.3), visando a sintetizar as análises e permitir uma visualização mais rápida do conjunto dos resultados obtidos. A Figura 6.2 foi construída a partir das médias indicadas na Tabela 6.2.a.

\section{5 - Análise dos Casos e das Proposições}

As tabelas obtidas representam matrizes com duas dimensões básicas: os casos estudados e as variáveis objeto de avaliação. Assim, em função dessas matrizes, há duas opções imediatas para a estruturação da análise. Como do ponto de vista do pesquisador interessa a verificação das proposições, parece recomendável para atingir esse objetivo que o primeiro passo seja dado considerando cada um dos casos.

Conforme a Tabela 5.3, há características comuns às empresas do grupo TPT. As do grupo IPA também apresentam características semelhantes entre si. Assim, parece interessante e mais diligente tratar cada grupo já analisando seus eventuais confrontos ou semelhanças internos, para depois encaminhar as análises mais gerais referentes às proposições.

As Tabelas 6.1, 6.2 e 6.3 estão compatibilizadas com essa orientação e permitem interpretar avaliações por caso, por grupos e da média geral. Na outra dimensão da matriz, estão presentes avaliações para as variáveis e para as proposições. Vale destacar que as médias calculadas são aritméticas, sem levar em conta eventuais critérios de ponderação sobre as variáveis.

\subsection{1 - Análise do Grupo TPT}

Todos os três entrevistados nas empresas do grupo TPT indicaram a existência de sistemas de informação para atender à Manutenção, Produção e Suprimentos. Não há uma integração completa que permita um imediato cruzamento de dados entre os sistemas de cada função. Em uma das empresas, transparece que, além de razões apontadas e associadas à falta de recursos para investimento em um sistema de informação de mais elevado nível de integração, pesam também razões de poder e prestígio sobre o domínio da informação, principalmente sobre o processo de suprimentos, que inclui entre suas atividades as relacionadas com compras de materiais. 


\begin{tabular}{|c|c|c|c|c|c|c|c|c|}
\hline \multirow{2}{*}{ VARIÁVEIS } & \multicolumn{3}{|c|}{ GRUPO TPT } & \multicolumn{2}{|c|}{ GRUPO IPA } & \multicolumn{3}{|c|}{ MÉDIA DA VARIÁVEL } \\
\hline & TPT 1 & TPT 2A & TPT 2B & IPA 1 & IPA 2 & GRUPO TPT & GRUPO IPA & GERAL \\
\hline \multicolumn{9}{|c|}{$\begin{array}{l}\text { P1: O DESDOBRAMENTO DO INDICADOR DE DISPONIBILIDADE EM INDICADORES PARCIAIS, OBTIDOS ATRAVÉS DE UM SISTEMA INTEGRADO DE INFORMAÇÃ } \\
\text { (MANUTENÇÃO, PRODUÇÃO E SUPRIMENTOS) FACILITA A GESTÃO DAS OPERAÇÕES DE MANUTENÇÃO }\end{array}$} \\
\hline $\begin{array}{l}1.1 . \quad \text { SISTEMA } \\
\text { INTEGRADO DE } \\
\text { INFORMAÇÃO } \\
\text { (MANUTENÇÃO, } \\
\text { PRODUÇÃO E } \\
\text { SUPRIMENTOS) }\end{array}$ & 3 & 3 & 3 & 2 & 2 & 3 & 2 & 2,6 \\
\hline $\begin{array}{l}1.2 . \\
\text { AVERIGUAÇÃO } \\
\text { DE INDICADORES } \\
\text { DE } \\
\text { DISPONIBILIDADE } \\
\text { PELA } \\
\text { ORGANIZAÇÃO } \\
\end{array}$ & 5 & 4 & 4 & 2 & 2 & 4,33 & 2 & 3,4 \\
\hline $\begin{array}{l}1.3 . \\
\text { DESDOBRAMENT } \\
\text { O DO INDICADOR } \\
\text { DE } \\
\text { DISPONIBILIDADE }\end{array}$ & 5 & 3 & 4 & 2 & 2 & 4,00 & 2 & 3,2 \\
\hline $\begin{array}{lr}\text { 1.4. GESTÃO } & \text { DAS } \\
\text { OPERAÇÕES } & \text { DE } \\
\text { MANUTENÇÃO: } \\
\text { TOMADAS } & \text { DE } \\
\text { DECISÃO } & \text { EM } \\
\text { FUNÇÃO } & \text { DA } \\
\text { DISPONIBILIDADE } \\
\end{array}$ & 5 & 3 & 3 & 3 & 2 & 3,67 & 2,5 & 3,2 \\
\hline $\begin{array}{lr}\text { MÉDIA } & \text { DA } \\
\text { PROPOSIÇÃO } & \text { P1 } \\
\text { NO CASO } & \\
\end{array}$ & 4,5 & 3,25 & 3,5 & 2,25 & 2 & 3,75 & 2,12 & 3,1 \\
\hline
\end{tabular}

Tabela 6.1 - Avaliação das Variáveis da Proposição P1

(Elaborada pelo Autor) 


\begin{tabular}{|c|c|c|c|c|c|c|c|c|}
\hline \multirow{2}{*}{$\overbrace{\text { VARIÁVEIS }}^{\text {CASOS }}$} & \multicolumn{3}{|c|}{ GRUPO TPT } & \multicolumn{2}{|c|}{ GRUPO IPA } & \multicolumn{3}{|c|}{ MÉDIA DA VARIÁVEL } \\
\hline & TPT 1 & TPT 2A & TPT 2B & IPA 1 & IPA 2 & GRUPO TPT & GRUPO IPA & GERAL \\
\hline \multicolumn{9}{|c|}{$\begin{array}{l}\text { P2: A ADEQUADA DEFINIÇÃO DAS POLITICAS E OPERAÇÕES DE MANUTENÇÃO REQUER CONSIDERAR, DE MODO SISTEMATIZADO, COMPROMISSOS COM O } \\
\text { AMBIENTE, DETERMINAÇÕES LEGAIS, NORMAS TÉCNICAS, CUSTOS, SEGURANÇA E PROCESSO DE PRODUÇÃO. }\end{array}$} \\
\hline $\begin{array}{l}\text { 2.1. ESTÁGIO DE } \\
\text { SISTEMATIZAÇÃO } \\
\text { DO TRATAMENTO } \\
\text { DE } \\
\text { COMPROMISSOS }\end{array}$ & - & - & - & - & - & - & - & - \\
\hline AMBIENTE & 3 & 3 & 3 & 2 & 2 & 3 & 2 & 2,6 \\
\hline $\begin{array}{l}\text { DETERMINAÇÕES } \\
\text { LEGAIS }\end{array}$ & 2 & 2 & 2 & 2 & 2 & 2 & 2 & 2 \\
\hline NORMAS TÉCNICAS & 2 & 2 & 2 & 2 & 2 & 2 & 2 & 2 \\
\hline CUSTO & 5 & 5 & 5 & 5 & 5 & 5 & 5 & 5 \\
\hline SEGURANÇA & 5 & 5 & 5 & 2 & 2 & 5 & 2 & 3,8 \\
\hline \begin{tabular}{|l|l|} 
PROCESSO DE \\
PRODUÇÃO
\end{tabular} & 3 & 3 & 3 & 2 & 2 & 3,0 & 2 & 2,6 \\
\hline $\begin{array}{lll}\text { MÉDIA } & \text { DA } \\
\text { VARIÁVEL } 2.1 & \text { NO } \\
\text { CASO } & & \\
\end{array}$ & 3,3 & 3,3 & 3,3 & 2,5 & 2,5 & 3,3 & 2,5 & 3 \\
\hline $\begin{array}{lr}2.2 \text { DEFINIÇÃO } & \text { DE } \\
\text { POLÍTICAS } & \text { E } \\
\text { OPERAÇÕES } & \text { DE } \\
\text { MANUTENÇÃO } & \text { EM } \\
\text { FUNÇÃOO } & \text { DE } \\
\text { COMPROMISSOS }\end{array}$ & - & - & - & - & - & - & - & - \\
\hline AMBIENTE & 3 & 3 & 3 & 2 & 2 & 3 & 2 & 2,6 \\
\hline $\begin{array}{l}\text { DETERMINAÇÕES } \\
\text { LEGAIS }\end{array}$ & 2 & 2 & 2 & 2 & 2 & 2 & 2 & 2 \\
\hline NORMAS TÉCNICAS & 2 & 2 & 2 & 2 & 2 & 2 & 2 & 2 \\
\hline CUSTO & 5 & 3 & 3 & 3 & 3 & 3,6 & 3 & 3,4 \\
\hline SEGURANÇA & 5 & 4 & 4 & 2 & 2 & 4,3 & 2 & 3,4 \\
\hline $\begin{array}{ll}\text { PROCESSO DE } \\
\text { PRODUÇÃO }\end{array}$ & 3 & 3 & 3 & 2 & 2 & 4,3 & 2 & 2,6 \\
\hline \begin{tabular}{|lll} 
MÉDIA & & DA \\
VARIÁVEL & 2.2 & NO \\
CASO & & \\
\end{tabular} & 3,3 & 2,8 & 2,8 & 2,2 & 2,2 & 3,2 & 2,2 & 2,7 \\
\hline $\begin{array}{|ll|}\text { MÉDIA } & \text { DA } \\
\text { PROPOSIÇÃO } & \text { P2 } \\
\text { NO CASO } & \\
\end{array}$ & 3,3 & 3,0 & 3,0 & 2,3 & 2,3 & 3,27 & 2,5 & 2,9 \\
\hline
\end{tabular}

Tabela 6.2 - Avaliação das Variáveis da Proposição P2

(Elaborada pelo Autor) 


\begin{tabular}{|c|c|c|c|c|}
\hline \multirow{2}{*}{ CASO } & \multirow{2}{*}{ COMPROMISSOS } & \multicolumn{2}{|c|}{$\begin{array}{c}\text { AVALIAÇÃO DAS } \\
\text { VARIÁVEIS }\end{array}$} & \multirow[t]{2}{*}{ MÉDIA } \\
\hline & & 2.1 & 2.2 & \\
\hline \multirow{6}{*}{ TPT 1} & 1. AMBIENTE & 3 & 3 & 3 \\
\hline & 2. DETERM. LEGAIS & 2 & 2 & 2 \\
\hline & 3. NORMAS TÉCNICAS & 2 & 2 & 2 \\
\hline & 4. CUSTO & 5 & 5 & 5 \\
\hline & 5. SEGURANÇA & 5 & 5 & 5 \\
\hline & 6. PROCESSO DE PRODUÇÃO & 3 & 3 & 3 \\
\hline \multirow{6}{*}{ TPT 2A } & 1. AMBIENTE & 3 & 3 & 3 \\
\hline & 2. DETERM. LEGAIS & 2 & 2 & 2 \\
\hline & 3. NORMAS TÉCNICAS & 2 & 2 & 2 \\
\hline & 4. CUSTO & 5 & 3 & 4 \\
\hline & 5. SEGURANÇA & 5 & 4 & 4,5 \\
\hline & 6. PROCESSO DE PRODUÇÃO & 3 & 3 & 3 \\
\hline \multirow{6}{*}{ TPT 2B } & 1. AMBIENTE & 3 & 3 & 3 \\
\hline & 2. DETERM. LEGAIS & 2 & 2 & 2 \\
\hline & 3. NORMAS TÉCNICAS & 2 & 2 & 2 \\
\hline & 4. CUSTO & 5 & 3 & 4 \\
\hline & 5. SEGURANÇA & 5 & 4 & 4,5 \\
\hline & 6. PROCESSO DE PRODUÇÃO & 3 & 3 & 3 \\
\hline \multirow{6}{*}{ IPA 1} & 1. AMBIENTE & 2 & 2 & 2 \\
\hline & 2. DETERM. LEGAIS & 2 & 2 & 2 \\
\hline & 3. NORMAS TÉCNICAS & 2 & 2 & 2 \\
\hline & 4. CUSTO & 5 & 3 & 4 \\
\hline & 5. SEGURANÇA & 2 & 2 & 2 \\
\hline & 6. PROCESSO DE PRODUÇÃO & 2 & 2 & 2 \\
\hline \multirow{6}{*}{ IPA 2} & 1. AMBIENTE & 2 & 2 & 2 \\
\hline & 2. DETERM. LEGAIS & 2 & 2 & 2 \\
\hline & 3. NORMAS TÉCNICAS & 2 & 2 & 2 \\
\hline & 4. CUSTO & 5 & 3 & 4 \\
\hline & 5. SEGURANÇA & 2 & 2 & 2 \\
\hline & 6. PROCESSO DE PRODUÇÃO & 2 & 2 & 2 \\
\hline
\end{tabular}

Tabela 6.2a - Média das Avaliações das Variáveis para cada Compromisso (Elaborada pelo Autor) 


\begin{tabular}{|c|c|c|c|c|c|c|c|c|}
\hline \multirow{2}{*}{ VARIÁVEIS } & \multicolumn{3}{|c|}{ GRUPO TPT } & \multicolumn{2}{|c|}{ GRUPO IPA } & \multicolumn{3}{|c|}{ MÉDIA DA VARIÁVEL } \\
\hline & TPT 1 & TPT 2A & TPT 2B & IPA 1 & IPA 2 & GRUPO TPT & GRUPO IPA & GERAL \\
\hline \multicolumn{9}{|c|}{$\begin{array}{l}\text { P3: AS EMPRESAS CONSIDERAM RELEVANTE, PARA A OBTENÇÃO DA DISPONIBILIDADE, LEVAR EM CONTA, POR OCASIÃO DO PROJETO DE NOVOS SISTEMA } \\
\text { PRODUTIVOS (RENOVAÇÃO, AMPLIAÇÃO OU SUBSTITUIÇÃO), O ESTUDO PERSPECTIVO DO CICLO DE VIDA DO EQUIPAMENTO. }\end{array}$} \\
\hline $\begin{array}{ll}3.1 . & \text { ESTUDO } \\
\text { PERSPECTIVO } \\
\text { DO CICLO } & \text { DE } \\
\text { VIDA } & \text { NO } \\
\text { ESTÁGIO } & \text { DE } \\
\text { PROJETO } & \text { DE } \\
\text { NOVOS } & \\
\text { SISTEMAS } & \\
\text { PRODUTIVOS } & \end{array}$ & 5 & 5 & 5 & 3 & 3 & 5 & 3 & 4,2 \\
\hline $\begin{array}{l}3.2 . \\
\text { CONSIDERAÇÃO } \\
\text { DA } \\
\text { DISPONIBILIDADE } \\
\text { POR OCASIÃO DE } \\
\text { PROJETO DE } \\
\text { RENOVAÇÃO, } \\
\text { AMPLIAÇÃO OU } \\
\text { SUBSTITUICCÃO }\end{array}$ & 5 & 3 & 3 & 2 & 2 & 3,67 & 2 & 3 \\
\hline $\begin{array}{ll}\text { MÉDIA } & \text { DA } \\
\text { PROPOSIÇÃO } & \text { P3 } \\
\text { NO CASO } & \end{array}$ & 5 & 4 & 4 & 2,5 & 2,5 & 4,33 & 2,5 & 3,6 \\
\hline
\end{tabular}

Tabela 6.3 - Avaliação das Variáveis da Proposição P3

(Elaborada pelo Autor) 
P1: O DESDOBRAMENTO DO INDICADOR DE DISPONIBILIDADE EM INDICADORES PARCIAIS, OBTIDOS ATRAVÉS DE UM SISTEMA INTEGRADO DE INFORMAÇÃO (MANUTENÇÃO, PRODUÇÃO E SUPRIMENTOS) FACILITA A GESTÃO DAS OPERAÇÕES DE MANUTENÇÃO.

\begin{tabular}{|c|}
\hline 1.1 SISTEMA \\
INTEGRADO DE \\
INFORMAÇÃO \\
(MANUTENÇÃO, \\
PRODUÇÃO E \\
SUPRIMENTOS) \\
\hline 1.2 AVERIGUAÇÃO \\
DE INDICADORES \\
DE DISPONIBILIDADE \\
PELA ORGANIZAÇÃO \\
\hline 1.3 DESDOBRAMENTO \\
DO INDICADOR DE \\
DISPONIBILIDADE \\
\hline 1.4 GESTÃO DE \\
OPERAÇÕES DE \\
MANUTENÇÃO: \\
TOMADAS DE \\
DECISÃO EM \\
FUNÇÃO DA \\
DISPONIBILIDADE
\end{tabular}

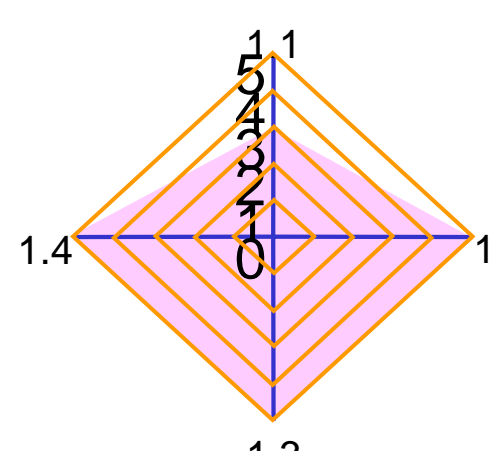

1.3

TPT 1

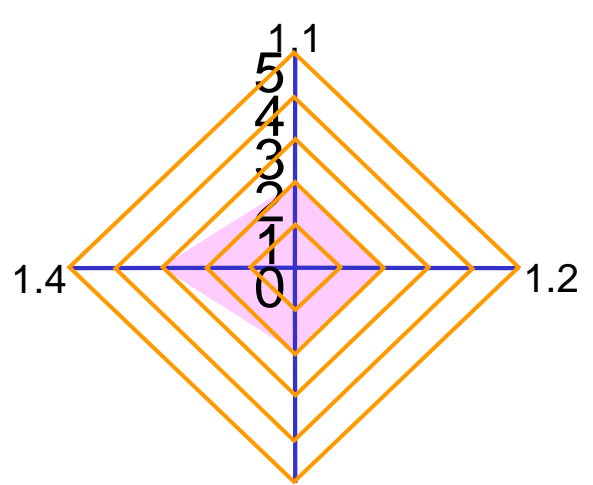

1.3

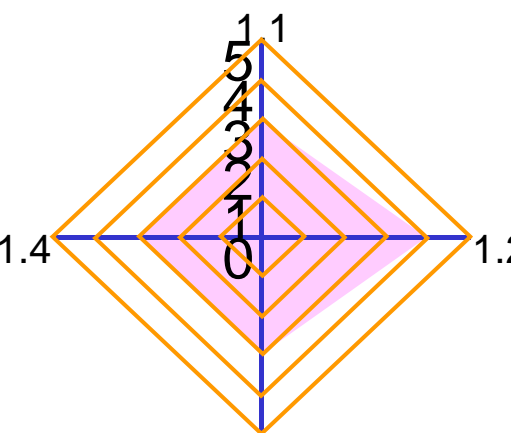

TPT 2 A

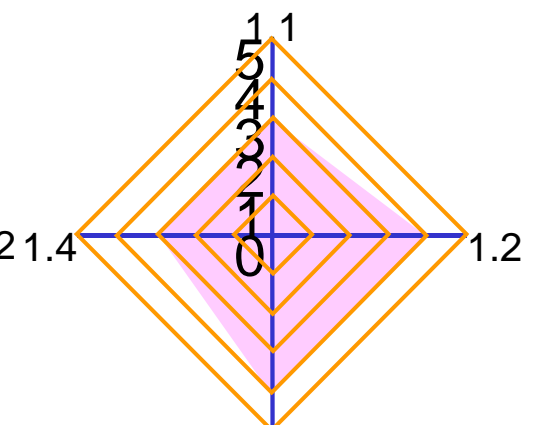

TPT' 2 B

IPA 1

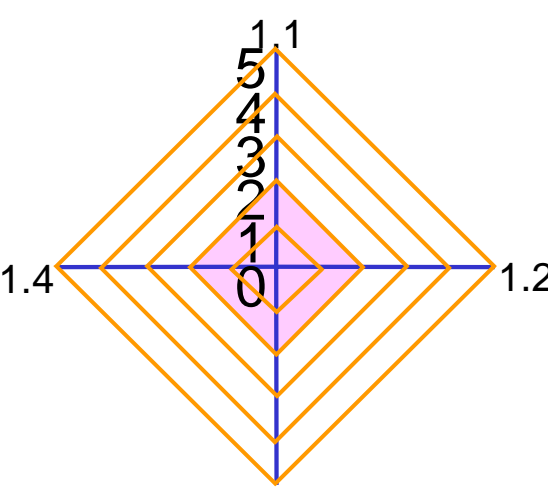

1.3

Figura 6.1 - Avaliação das Variáveis de P1 (Elaborada pelo Autor) 
P2 A ADEQUADA DEFINIÇÃO DAS POLÍTICAS E OPERAÇÕES DE MANUTENÇÃO REQUER CONSIDERAR, DE MODO SISTEMÁTICO, COMPROMISSOS COM O AMBIENTE, DETERMINAÇÕES LEGAIS, NORMAS TÉCNICAS, CUSTOS, SEGURANÇA E PROCESSOS DE PRODUÇÃO.

\begin{tabular}{|l|}
\hline 2.1 ESTÁGIO DE \\
SISTEMATIZAÇÃO \\
DO TRATAMENTO \\
DE COMPROMISSOS \\
\hline 2.2 DEFINIÇÃO DE \\
POLÍTICAS \\
E OPERAÇÕES \\
DE \\
MANUTENÇÃO EM \\
FUNÇÃO DE \\
COMPROMISSOS \\
\hline 1. AMBIENTE \\
2. DETERMINAÇÕES \\
LEGAIS \\
3. NORMAS TÉCNICAS \\
4. CUSTOS \\
5. SEGURANÇA \\
6. PROCESSOS DE \\
PRODUÇÃO
\end{tabular}
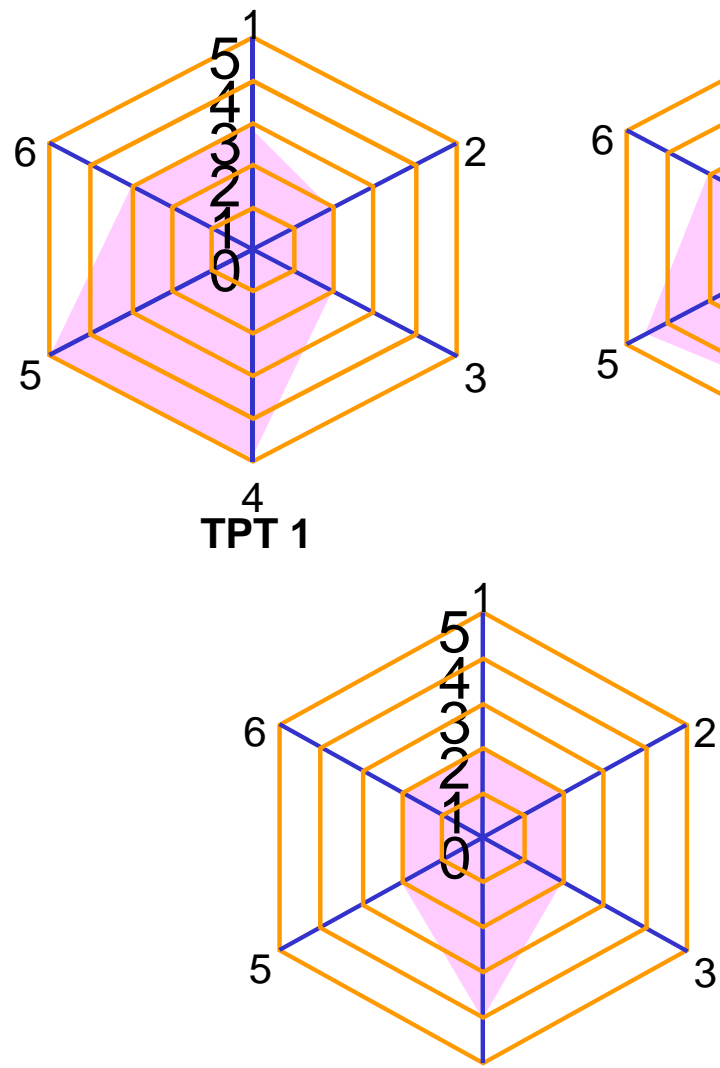

IPA 1

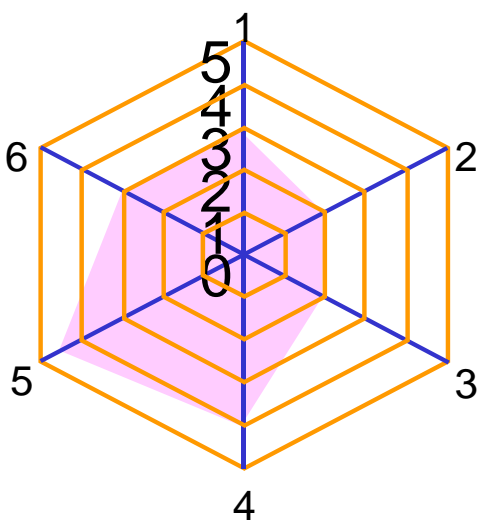

TPT 2 A

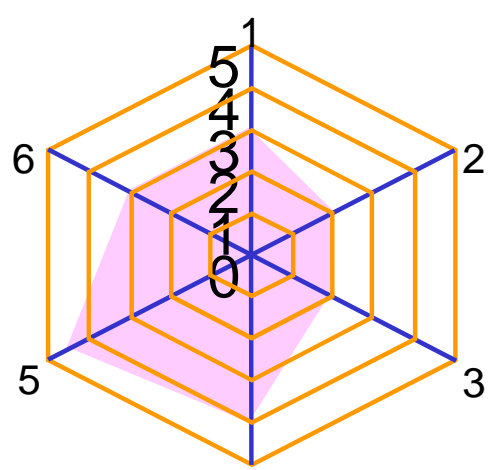

4

TPT 2 B

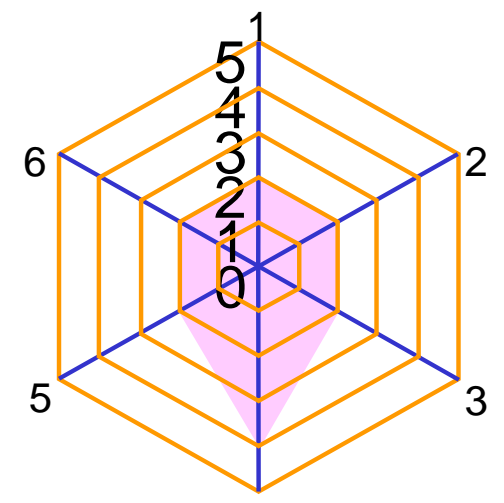

4

IPA 2

Figura 6.2 - Médias das Avaliações das Variáveis de P2 para cada Compromisso (Elaborada pelo Autor) 
P3: AS EMPRESAS CONSIDERAM RELEVANTE, PARA A OBTENÇÃO DA DISPONIBILIDADE, LEVAR EM CONTA POR OCASIÃO DE PROJETO DE NOVOS SISTEMAS PRODUTIVOS OU DE PROJETOS DE RENOVAÇÃO, AMPLIAÇÃO OU SUBSTITUIÇÃO, O ESTUDO PERSPECTIVO DO CICLO DE VIDA DO EQUIPAMENTO.

\begin{tabular}{|c|}
\hline 3.1 ESTUDO \\
PERSPECTIVO DO \\
CICLO DE VIDA NO \\
ESTÁGIO DE PROJETO \\
DE NOVOS \\
SISTEMAS \\
PRODUTIVOS \\
\hline 3.2 CONSIDERAÇÃO \\
DA DISPONIBILIDADE \\
POR OCASIÃO DE \\
PROJETO DE \\
RENOVAÇÃO, \\
AMPLIAÇÃO OU \\
SUBSTITUIÇÃO \\
\hline
\end{tabular}

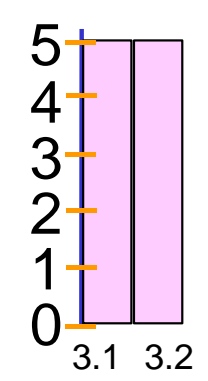

TPT 1

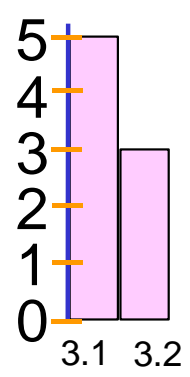

TPT 2 A

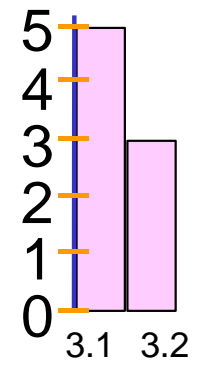

TPT 2 B
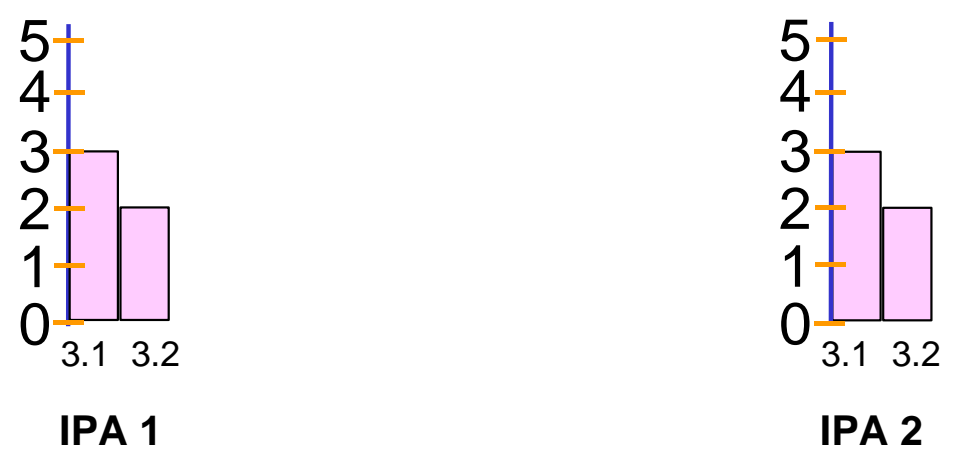

IPA 2

Figura 6.3 - Avaliação das Variáveis de P3 (Elaborada pelo Autor) 
Conforme a Tabela 6.1, a Proposição P1 apresenta elevado nível de confirmação na empresa TPT1. A TPT2A e a TPT2B representam duas visões de uma mesma empresa TPT2, na qual se verifica um elevado grau de homogeneidade quanto às avaliações, mas com uma diferença que chama a atenção. $O$ desdobramento do indicador de disponibilidade é mais acentuado na TPT2B. Isso se deve ao fato de que a TPT2B apresentou evidências de considerar, além da confiabilidade, um grau de preocupação maior com os tempos de reparo e seus componentes.

$\mathrm{O}$ fato de a TPT2B requerer o deslocamento de suas equipes, que mantêm os sistemas fixos, ao longo de dezenas de quilômetros de linhas, parece ser uma razão para esse tipo de controle mais detalhado. Assim, a gestão dos tempos associados aos reparos externos pode decorrer de um propósito que extrapola a necessidade de controle e aprimoramento dos serviços de manutenção, à medida que também se exerce controle sobre a movimentação da equipe, a quilometragem rodada, homenshora aplicados e respectivos custos.

De modo geral, a disponibilidade confirma-se como essencial no grupo TPT, onde o componente confiabilidade é tratado com muito mais ênfase do que os tempos associados aos reparos. A propósito, isso vai se traduzir em marcante diferença quando se compara o grupo TPT com o grupo IPA, no qual prepondera a preocupação com os tempos de "parada da máquina" (que embute os tempos de reparo) sobre o tratamento da confiabilidade. No caso do grupo TPT a disponibilidade e a confiabilidade são percebidas pelo usuário dos sistemas, enquanto que os tempos de reparo são de menor visibilidade. Além disso, nas empresas TPT, a confiabilidade tem forte conotação com a segurança, um dos compromissos considerado na Proposição P2.

No grupo TPT as empresas tomam decisões em função da disponibilidade, mas a TPT1 manifesta um nível mais elevado na escala de avaliação ao apresentar evidente determinação com referência à definição e constância no estabelecimento prévio de padrões que devem ser alcançados.

No que diz respeito à Proposição $\mathrm{P} 2$, associada a compromissos, todo o grupo TPT apresenta cuidados especiais ao tratar aspectos relacionados com a segurança e as empresas possuem comissões internas específicas para este assunto. O custo 
também possui tratamento sistematizado, embora essas empresas não tenham o lucro entre seus objetivos. Os recursos financeiros dependem de fontes governamentais, já que a tarifa não cobre custos de investimento. Procura-se um equilíbrio quanto aos custos operacionais.

Quando se apresenta o termo segurança, o foco dirige-se ao usuário do sistema operacional. Afinal, cada trem pode estar transportando centenas de passageiros.

No grupo TPT, a preocupação com o ambiente é bastante abrangente. Isso decorre da própria extensão da rede de linhas, que no caso da TPT2 cruza diversos municípios. A TPT1 tem suas linhas totalmente confinadas, o que não ocorre na TPT2, onde furtos de cabos elétricos são notáveis e acabam interferindo na disponibilidade do sistema operacional. A disponibilidade de equipamentos também é influenciada por atos de vandalismo externo, que podem exigir a retirada de equipamentos de operação para tratamento e recuperação. Esse é um tipo de problema que parece não afligir as empresas do grupo IPA, que não manifestaram preocupação com esse tipo de acontecimento.

Em essência, a Proposição P2 visava a verificar a forma do tratamento dado aos compromissos, se ele é devidamente estruturado e sistematizado. No grupo TPT apresentaram-se evidências de que isso ocorre de modo categórico para segurança e custos. A colocação dos compromissos nessa ordem é proposital, tentando-se traduzir o clima de preocupação com segurança, com foco no usuário, manifestado pelos entrevistados. As empresas manifestaram preocupação com custos, em função da tarifa cobrada, lembrando que enfrentam concorrência de outros meios de transporte público.

Apurar um tratamento estruturado para as determinações legais e normas técnicas que interferem, ou podem interferir, nas atividades de manutenção se mostrou uma tarefa mais desafiadora. Ao se questionar sobre estes compromissos, as respostas manifestam alguns exemplos e não evidências de um tratamento estruturado.

As interferências com o processo de operação apresentam um tratamento de algum modo sistematizado, já que são tratadas em reuniões periódicas realizadas entre os gestores da Manutenção e os da Operação, principalmente tratando de 
aspectos relacionados com condições de acesso da Manutenção aos equipamentos, acesso que depende de autorização da área de operação do sistema.

A Proposição P3 tem evidências mais representativas quando se trata de novos projetos, à medida que as empresas já estão antecipando nas especificações técnicas, para a aquisição de novos sistemas, valores esperados para disponibilidade, confiabilidade e tempos de reparo para o estágio operacional. Essa preocupação ficou demonstrada na TPT1, onde se evidenciou o cuidado em se formular, já no projeto, um tratamento de modularização de sistemas e equipamentos, visando a assegurar, no futuro, suas disponibilidades operacionais.

A empresa TPT1 apontou, no contexto do compromisso com custos, que está desenvolvendo estudos para introdução da abordagem RCM. Na verdade, essa empresa foi a única que citou esse tipo de abordagem. Espera, com isso, reduzir custos, dedicando maior atenção a operações de manutenção sobre componentes e equipamentos que efetivamente as requerem.

Como exemplo de tratamento de projeto em função da disponibilidade, na TPT1 modificações do projeto de trens em operação, com a incorporação de características modulares, redundaram no aumento de disponibilidade e em menores investimentos na compra de equipamentos novos para atender à demanda do sistema operacional.

\subsection{2 - Análise do Grupo IPA}

Este grupo, quando comparado com o TPT, apresenta evidências de equipes bem enxutas de manutenção e com forte predomínio da Produção. A Manutenção parece estar acentuadamente dirigida para os aspectos relacionados com as tecnologias de preservação do equipamento. Um exemplo de distanciamento da função manutenção de tomadas de decisão sobre os equipamentos foi apresentado na IPA2, onde a compra de novos equipamentos é decidida pela área de marketing da empresa.

Não se configura a utilização de sistemas computadorizados de informação mais avançados, mesmo no âmbito da Manutenção. De modo geral, a informação é originada a partir de relatórios da produção, os quais indicam registros sobre 
interrupções de operação de equipamentos produtivos ou perdas de produção delas decorrentes.

Nesse grupo, a Proposição P1 não se confirma plenamente. Sobressai-se a preocupação com os tempos de parada. De modo mais contundente, se fala em “interrupção da produção". O tempo de parada é considerado um indicador de disponibilidade. Isso, em princípio, deveria conduzir a um estudo mais aprofundado do tempo de reparo. Pode-se dizer que a disponibilidade, nessas empresas, é medida em função do tempo que a Manutenção leva para restabelecer as condições operacionais do equipamento. Mesmo assim, não se evidencia um tratamento sistematizado de tempos e métodos. O restabelecimento depende diretamente das habilidades técnicas dos mantenedores. A visão da Manutenção está dirigida, de modo mais direto, às tecnologias de manutenção dos equipamentos.

Nesse contexto, a IPA2 está implantando um projeto piloto da abordagem TPM, na sua mais nova planta, contando com instalações mais modernas. Essa medida pode representar um avanço na pesquisa de tempos de reparo, uma forma de pró-atividade ao se avaliar "eficiências", e não apenas apresentar a aparente postura heróica de "consertar a máquina". Na IPA1 não ficou evidenciada qualquer intenção de adoção de alguma abordagem mais avançada, como TPM ou RCM. Transparece que a cultura dessa empresa não viabiliza, no momento, a introdução de novas abordagens para gestão da manutenção.

Um aspecto que diferencia o grupo IPA do TPT é que a confiabilidade e os tempos de reparo dos equipamentos produtivos (chamados de operacionais pelos profissionais do grupo TPT), nos casos do primeiro grupo, não apresentam visibilidade aos clientes das empresas. Assim, a Manutenção sofre pressões diretas de ordem exclusivamente interna às empresas.

Quanto à Proposição P2, nessas empresas os compromissos estão associados de forma categórica a custos, mais especificamente à sua sobrevivência no mercado. Quando se abordam custos, os entrevistados destacam de imediato a parcela de contribuição da manutenção para que a empresa sobreviva num mercado competitivo. O compromisso com custos é tão acentuado que pode ser avaliado já na portaria da IPA1, onde um quadro, expressando a missão da empresa, exibe as palavras "lucratividade" no texto referente à visão da empresa, "produtividade e 
lucratividade" na política da qualidade, e "rentabilidade" incluída entre os valores da organização. A propósito, compromissos com o "meio ambiente" e com um “ambiente saudável” também são contemplados entre seus valores.

Custo prepondera, chegando o orçamento a ser considerado como "Bíblia" na IPA1, embora a IPA2 manifeste certa flexibilidade quanto a eventuais desvios do planejamento na execução do orçamento da Manutenção.

Essas empresas, de capital nacional, estão inseridas num mercado interno competitivo. A concorrência é forte, tanto com multinacionais instaladas no país como com empresas de menor porte. Outro fator de concorrência é representado pela entrada de produtos importados.

Ao contrário do grupo TPT, no grupo IPA o termo ambiente não sugere uma preocupação direta com o cliente. Relaciona-se a problemas de ordem mais próxima às instalações, como o do tratamento de efluentes. A expressão "ambiente saudável", contemplada como um dos valores da IPA1, permite um amplo campo de interpretações e não fica definida de modo preciso.

Determinações legais e normas técnicas, embora citadas como relevantes, não apresentam um tratamento sistematizado. Não há listas nem arquivos de imediato acesso que permitam caracterizar esses compromissos.

A visão de segurança é bastante doméstica e relacionada com os funcionários e com o equipamento e, também, no âmbito da Manutenção, não apresenta um tratamento sistematizado.

Há uma preocupação acentuada com eventuais interferências da manutenção com a qualidade do produto, que é alimentício. Nas duas empresas IPA houve manifestação de necessidade de cuidados quanto à limpeza e de coincidente atenção para se evitar eventuais quedas de grãos de solda nos equipamentos produtivos. Chama a atenção que mesmo com a elevada preocupação com qualidade e limpeza, não foi apresentada qualquer evidência de um procedimento explícito, apontando uma diretriz que, antecipadamente, determine os cuidados da Manutenção em relação ao processo de produção.

Uma visão mais direcionada para a Produção, foi citada na IPA2. Para garantir a qualidade dos produtos há procedimentos, técnicas e regulamentos específicos para o setor de produção de alimentos. A Produção segue uma 
metodologia denominada HACCP (Hazard Analysis and Critical Control Points), além do cumprimento de portarias governamentais específicas.

O grupo IPA não demonstra um tratamento para o ciclo de vida dos equipamentos, conforme o recomendado na literatura. Entretanto, a afirmação do gerente entrevistado na IPA2, de que "o retorno do investimento deve ocorrer em um ano, no máximo dois", caracteriza uma preocupação implícita, embora não detalhada, com o ciclo de vida.

\subsection{3 - Análise da Proposição P1}

$O$ desdobramento do indicador de disponibilidade em indicadores parciais, obtidos através de um sistema integrado de informação (manutenção, produção e suprimentos), facilita a gestão das operações de manutenção.

No que diz respeito a um Sistema de Informação, nenhuma empresa apresenta uma plena e explícita integração de processamento de dados entre a Manutenção e as outras funções da empresa. As empresas do grupo IPA foram as que demonstraram caracterizar a menor integração, fato decorrente da notável carência de um sistema de informação, mesmo que no contexto exclusivo da gestão da manutenção. Provavelmente, as organizações TPT, pelo seu porte, e pela visibilidade que o usuário tem da confiabilidade e da segurança do regime operacional, necessitam de maior e mais ágil domínio sobre a informação que possibilite por exemplo o rastreamento do histórico do equipamento. No caso das empresas IPA, o montante do investimento em tais sistemas tem sido alegado como restrição para implantação de sistemas computadorizados mais elaborados.

Embora nenhum caso atenda plenamente à Proposição P1, é evidente o distanciamento entre as empresas do grupo TPT e as do grupo IPA. De qualquer forma, delineia-se um potencial para um avanço no aprimoramento da obtenção da informação e para o tratamento da disponibilidade: no grupo IPA, aprimorando a obtenção de indicadores de confiabilidade e, tanto no TPT como no IPA, aprimorando a gestão dos tempos de paralisação dos equipamentos. Embora no grupo IPA não se tenha apresentado o tratamento da confiabilidade, este dado não apresentaria dificuldade de sua obtenção pelo menos numa primeira aproximação, 
podendo ser derivado da medida de intervalos entre interrupções de produção. Há uma possibilidade de se usar um conceito que está potencialmente disponível. $\mathrm{Na}$ verdade, parece haver um desconhecimento do próprio conceito.

De modo geral, as empresas estudadas têm um potencial de aprimoramento para melhor dominarem a estruturação da disponibilidade.

Quanto à aplicação de indicadores de disponibilidade, de alguma forma, todas as empresas se preocupam com alguma indicação da disponibilidade. Contudo, as do grupo IPA não medem seus indicadores de disponibilidade na forma clássica proposta na literatura (itens 2.3 do presente estudo), já que consideram como “disponibilidade" o apontamento direto "das horas de parada de produção do equipamento". Entretanto, as empresas do grupo TPT apresentaram evidências de preocupação em adotar a fórmula clássica $\mathrm{D}=(\mathrm{MTBF} / \mathrm{MTBF}+\mathrm{MTTR})$, e também de uma riqueza maior de interpretações da disponibilidade (como disponibilidade em instante relevante para a operação, quando se mede a relação entre a quantidade de trens disponíveis para operação sobre a quantidade programada, e a "disponibilidade patrimonial", isto é, traduzindo uma relação entre a quantidade de trens disponíveis para a operação e a quantidade de trens existentes no parque, incluindo as que estão em operação, manutenção e as paralisadas por algum outro motivo, eventualmente em decorrência de algum acidente). Apenas na TPT1, foi encontrada evidência efetiva de estabelecimento explícito de padrões de disponibilidade a serem perseguidos pela gestão da manutenção.

No caso do desdobramento de indicadores de disponibilidade, as empresas do grupo IPA não apresentaram evidências de utilização do potencial desse instrumental de análise. Já as do grupo TPT o fazem, tanto considerando a confiabilidade, como o tempo de reparo. Há uma predominância de preocupação com a confiabilidade (que está associada à segurança) sobre a preocupação com os tempos de reparo (que está associada mais diretamente a custos). Cabe relembrar que na empresa TPT2, onde foram realizadas duas entrevistas, observou-se uma diferenciação de tratamento dado aos tempos de reparo, entre o setor de material rodante (TPT2A), setor em que o equipamento vem até a oficina de manutenção, e o setor de sistemas fixos (TPT2B) espalhados ao longo de dezenas de quilômetros, que exige que a equipe de manutenção vá até o equipamento. 
No setor TPT2A, não há evidências de aplicação de ferramental de tempos e métodos, não sendo os tempos de paralisação devidamente tratados. No caso TPT2B, observou-se um maior apuro no desdobramento desse tempo. Entretanto, isso pode não decorrer, diretamente, de um objetivo de aprimoramento dos métodos de manutenção, mas, sim, das necessidades de controle da movimentação externa das equipes envolvidas na execução dos trabalhos.

Com exceção da TPT1, nota-se nas empresas uma atitude bastante reativa no que diz respeito à gestão da manutenção em função da disponibilidade. Esse fato é mais marcante nas empresas do grupo IPA, com foco nos tempos de paralisação do equipamento produtivo. Na TPT1, a aplicação efetiva de políticas de manutenção preditiva, estudos de implantação da abordagem RCM e análises de tendências parecem evidenciar uma atitude mais pró-ativa, inclusive com a confrontação de resultados obtidos com padrões previamente estabelecidos.

Assim, de modo geral e conforme a Tabela 6.1, não se confirma na sua plenitude a proposição P1 no âmbito das organizações estudadas, embora se apresente um estágio mais elevado de suas variáveis na empresas do grupo TPT, provavelmente devido ao porte da organização e à visibilidade imediata pelo cliente da disponibilidade e da segurança operacionais do sistema produtivo. Essa constatação mostra que há a possibilidade de avanços para melhor domínio e aprimoramento do tratamento da disponibilidade.

\subsection{4 - Análise da Proposição P2}

A adequada definição das políticas e operações de manutenção requer considerar, de modo sistematizado, compromissos com o ambiente, determinações legais, normas técnicas, custos, segurança e processo de produção.

Esta proposição tinha por objetivo verificar como compromissos de gestão da manutenção são tratados nas organizações pesquisadas. A presença deles se confirma, e eles apresentam diferenças no grau de estruturação e sistematização desse tratamento.

Conforme exposto no item 3.4 deste estudo, "o ambiente turbulento em que a maioria das organizações atua, faz com que suas funções tenham que se ajustar 
continuamente à cultura vigente" (SLACK, 2002, p.47). Assim, espera-se também que a Manutenção nas empresas esteja preparada para efetuar seus ajustes conjunturais, que se traduzem na necessidade de atendimento de compromissos.

A pesquisa de campo confirma a existência desses compromissos no âmbito da gestão da manutenção. O compromisso em relação a custo é o que é tratado com melhor estruturação, e, desse modo, corrobora a expressão de SLACK (2002, p.81) de que "o custo baixo é um objetivo universalmente atraente". O orçamento, previamente preparado pelas empresas, é um forte balizador do tratamento de custos, e com o qual os gestores de manutenção buscam conformidade.

O tratamento dos compromissos de segurança firmou-se num nível mais elevado de estruturação nas empresas que apresentam contato direto mais intenso com o usuário, diferenciando-se de modo acentuado das empresas que não têm esse contato.

Os processos de produção e o ambiente (este último mesmo que dentro de um amplo campo conceitual) se firmam como compromissos de manutenção, mas com um tratamento estruturado menor do que o dado a custos e segurança.

Os compromissos com determinações legais e com normas técnicas, que no primeiro caso são obrigatórios, parecem exigir um melhor tratamento. $\mathrm{O}$ fato de eles serem lembrados ocasionalmente, dependendo de pressões pontuais, é sintomático de seu estágio de baixa sistematização.

Assim, a proposição P2 é verificada como parcialmente atendida, apontando também empresas nos mais diversos níveis, e que há um potencial de aprimoramento do tratamento de compromissos no âmbito da gestão da manutenção.

\subsection{5 - Análise da Proposição P3}

As empresas consideram relevante para a obtenção da disponibilidade, levar em conta, por ocasião de projetos de novos sistemas produtivos ou de projetos de renovação, ampliação ou substituição, o estudo perspectivo do ciclo de vida do equipamento.

A Proposição P3 também não permite uma confirmação geral de nível pleno de enquadramento de suas variáveis para todas as empresas. Aqui, mais uma vez se distanciaram os dois grupos de empresas pesquisados. No grupo TPT, a TPT1 
apresenta evidências de enquadrar as variáveis no nível pleno, tanto para novos equipamentos, como para a renovação ou substituição de equipamentos.

Entretanto, as do grupo IPA, que, num primeiro entender do pesquisador, deveriam permitir o enquadramento das variáveis em um nível mais elevado, já que vivem num mercado altamente competitivo, não o fizeram. As empresas do grupo TPT, por suas dimensões e preocupação com segurança, dispõem de uma estrutura de engenharia de manutenção não existente nas empresas do grupo IPA. Essa engenharia, associada a investimentos intensivos, pode representar um condicionante dos estudos pertinentes ao ciclo de vida.

Assim, nas empresas do grupo IPA o estudo perspectivo do ciclo de vida dos equipamentos, na forma delineada na literatura, não se evidenciou fazer parte do cotidiano das tomadas de decisão sobre a disponibilidade.

Todavia, vale destacar que, particularmente na TPT1, constatou-se que há equipamentos, como o material rodante, sendo utilizados há quase quatro décadas, e que se encontram em condições operacionais satisfatórias. Isso evidencia um tratamento sólido do ciclo de vida do equipamento pela Manutenção, preservando sua disponibilidade.

Assim, a proposição P3 também não é atendida na sua plenitude. Essa constatação aponta para um potencial a galgar na escala referencial por parte de algumas organizações. 


\section{7 - CONCLUSÃO}

Ao concluir este estudo, o pesquisador entende que os objetivos do trabalho foram atingidos à medida que se levantou o direcionamento da teoria da manutenção e se verificou o tratamento dado ao indicador disponibilidade na prática. A necessidade de se considerar compromissos de gestão da manutenção ampliou a perspectiva do estudo.

A elaboração de um instrumento referencial para amparar a pesquisa de campo e a sua utilização para verificação das proposições colaboraram para melhor atingir os objetivos propostos.

O presente trabalho procurou, a partir da análise de quatro empresas, uma delas dando origem a dois casos, apresentar e discutir elementos associados à disponibilidade de equipamentos de sistemas produtivos, no âmbito da gestão do processo de manutenção. Três proposições, centradas no indicador de disponibilidade, em compromissos de gestão e no ciclo de vida do equipamento, serviram de base para a pesquisa de campo.

Por se tratar de poucos casos, boa parte dos aspectos observados pode não ser generalizável. Entretanto, as observações e conclusões podem ser encaradas como recomendações e pontos de alerta em processos de gestão de operações de manutenção.

Assim, o estudo, que ora se encerra, mostrou dois grupos de organizações distanciados entre si no que se refere ao atendimento das proposições de pesquisa, que se vinculavam essencialmente à gestão do processo de manutenção e de um produto desse processo, a disponibilidade. Ficou constatado, para os casos estudados, que um grupo de empresas apresenta visível contraste com outro grupo, quando se trata de utilização de técnicas e instrumentos de gestão da disponibilidade, de sistematização do tratamento de compromissos e de tomadas de decisão em função do ciclo de vida.

A disponibilidade dos equipamentos caracterizou-se como um resultado desejável em todos os casos examinados. Ela pode ser tratada tanto na forma mais simples, a partir da mensuração dos tempos de interrupção da produção, ou na forma mais elaborada, em que é desdobrada em indicadores parciais de confiabilidade, de tempos de reparo e de tempos de paralisação do equipamento produtivo para 
intervenções de caráter preventivo. Assim, a disponibilidade, como resultado das atividades de manutenção, é um indicador presente nessas organizações estudadas, sempre visando a atender aos processos de produção ou de operação dos sistemas produtivos.

No contexto da gestão da manutenção, que gera a disponibilidade, também se configurou que se levam em conta relações de compromissos, algumas de forma mais sistematizada que outras. Foram coletados exemplos que confirmam a presença dos compromissos considerados na pesquisa.

Não há uniformidade no tratamento de compromissos. Custo manifesta-se como o compromisso de tratamento mais sistematizado. Sua relevância é observada tanto em textos da literatura pesquisada como nas empresas investigadas. Certamente, o tratamento dado a custos decorre de um critério de sistematização universal, que se traduz no orçamento empresarial, que é preparado e controlado pelas áreas financeiras. Outra razão, fundamental no contexto desta pesquisa, está associada à competitividade. Esse aspecto é relevante tanto para as empresas industriais de alimentos como para as de transporte. Nas primeiras, os gestores de manutenção alegaram a concorrência de outros fabricantes, e nas de transporte citaram meios alternativos de transporte.

Compromissos com a segurança ficaram caracterizados de forma destacada nas empresas de transporte de passageiros, nas quais o cliente usuário participa do processo produtivo. Nessas empresas estão presentes Comissões Permanentes de Segurança, com participantes da Manutenção, da Operação e do Projeto, o que indica um tratamento bastante estruturado de problemas relacionados à segurança.

Assim, compromissos se firmam presentes no cotidiano das atividades de manutenção, mas sem uma apresentação e tratamento de forma consolidada.

Ainda, o tratamento perspectivo do ciclo de vida, levando em conta a disponibilidade por ocasião do projeto tem grau de tratamento variável, nem sempre considerando padrões de disponibilidade ou o seu desdobramento. As empresas de transporte, em que os investimentos são intensivos, indicam um tratamento mais próximo ao indicado na literatura. Essas empresas chegam a estabelecer requisitos de MTBF e MTTR em especificações contratuais de projeto para aquisição de equipamentos. 
A pressão por resultados, já normalmente exercida sobre o pessoal de manutenção, parece se acentuar, particularmente em função de um dos compromissos de gestão da manutenção, incluído nesta pesquisa, isto é, minimização de custos. No passado recente, conforme o gerente entrevistado da IPA2, "o compromisso era com a qualidade, hoje é com custos". Desse modo, ele expressava preocupação com aspectos de competitividade, com a elevação de preços da matériaprima, e com a queda de vendas, decorrente de diminuição do poder aquisitivo do consumidor.

O fato de uma empresa estar mais avançada no que diz respeito à adoção de abordagens e políticas de manutenção é promissor, pois ela pode fornecer metas de benchmark para outras organizações. Há uma possibilidade de aprimoramento. Como foram pesquisadas empresas de portes diferenciados, qualquer conclusão mais detalhada só pode ser encaminhada se considerada a devida escala de grandeza.

Pode-se, com algum cuidado, confirmar que em algumas situações se manifestou o perfil do profissional de manutenção que tende a ter uma postura mais defensiva, dedicando energia à manutenção do "passado instalado" na empresa. Entretanto, a postura de natureza ofensiva também foi observada, quando foram apresentadas evidências de implantação de abordagens atualizadas de gestão.

Os resultados distanciados entre os dois grupos de empresas analisados também levam à reflexão sobre o potencial existente para o avanço da postura dos gestores de manutenção, com visão de futuro, aprimorando a contribuição da função manutenção para a empresa enfrentar a concorrência. Assim, espera-se romper com as imagens marcadamente conservadoras, tanto da função manutenção em si, como de seus gestores.

Ainda, a preocupação demonstrada por gestores de manutenção com custos, por ocasião da coleta de dados da pesquisa, e com a concorrência, é, de alguma forma, um forte indício da inserção dessa função na cadeia de valor da empresa.

\section{1 - Implicações e Extensão dos Resultados Obtidos}

Os resultados obtidos traduzem a interpretação de visões obtidas em cada uma das entrevistas efetuadas. Conforme observado, com entrevistados de diferentes setores de uma mesma empresa foram obtidos alguns dados, que podem encaminhar 
diferentes conclusões. Assim, conclusões específicas não podem ser estendidas, sem um cuidado especial, a outras áreas funcionais de uma mesma empresa, e muito menos para uma generalização abrangendo um universo contemplando outras empresas.

Todavia, os resultados obtidos firmaram uma escala de posições, caminhando do nível incipiente para o nível pleno de enquadramento das variáveis e do atendimento das proposições de pesquisa. Como as variáveis representam, de algum modo, micro-processos dentro das empresas, essa escala demonstra que há um potencial de elevação dos níveis de enquadramento das variáveis e aprimoramento na busca da disponibilidade e da produtividade.

Ainda, embora o foco do estudo tenha sido a disponibilidade, é importante um retorno à Figura 2.2 como advertência para se evitar que esse foco leve a desconsiderar outros fatores, que, em conjunto, contribuem para o desempenho operacional global da organização.

\section{2 - Delimitação do Escopo da Pesquisa}

Em função da complexidade e abrangência do tema, alguns elementos não foram mais profundamente abordados, o que pode ser exemplificado com a incursão exploratória no estudo de compromissos de gestão da manutenção, que ficou limitada a seis deles, selecionados a partir de observação da literatura.

A pesquisa se restringiu a considerar processos de manutenção em andamento dentro de duas organizações prestadoras de serviços de transporte público e de duas do setor de manufatura, representando um momento de cada uma delas. Nesse contexto é que foram realizadas as entrevistas. Entretanto, deve ser lembrado que os resultados encontrados podem decorrer também da concepção, da época, da forma de implantação e de como se consolidou o processo de manutenção.

A gama de tipos de empresas existentes é enorme, e, certamente, todas requerem serviços de manutenção, nem que seja para uma simples troca de lâmpadas. A manutenção transparece como uma função universalmente necessária. Contudo, observe-se que neste estudo apenas dois tipos de empresas foram pesquisados, limitando-se uma eventual generalização das avaliações. 


\section{3 - Revisão Crítica do Estudo}

Este estudo não teve a pretensão de ser completo e definitivo. Ele envolveu uma pesquisa bibliográfica e uma de campo, para se identificar a relevância da disponibilidade e os fatores que para ela contribuem.

Vale destacar que o quadro referencial de avaliação, com a escala em níveis evolutivos, embora sujeita a aprimoramento, efetivamente proporcionou condições de conforto para o pesquisador atuar de modo mais objetivo para avaliação e enquadramento das variáveis pesquisadas.

\section{4 - Tendências}

Algumas tendências podem ser identificadas, e que certamente terão influência na gestão da manutenção e da disponibilidade dos equipamentos, no futuro. Entre elas podem ser apontadas:

- expansão do uso de monitoramento on line, informando de modo mais expedito dados da condição de equipamentos;

- tendência de as equipes de manutenção e as de produção se imbricarem;

- uso de instrumental tecnologicamente mais avançado: coletores portáteis de dados e consultas on line, de sistemas consolidando integração da informação no âmbito da própria manutenção e com outras funções da empresa;

- uso do conceito de projeto modular de equipamentos e sistemas produtivos, permitindo a rápida substituição, pela equipe de manutenção, de módulos funcionais procurando otimizar a disponibilidade do equipamento em que se inserem;

- uso de equipamentos e sistemas inteligentes para autocorreção de problemas;

- diagnóstico e instrução para reparo emitidos de modo automático pelo sistema;

- a tendência de contratação de serviços terceirizados de manutenção, que exige esforço de elaboração de especificações técnicas detalhadas, incluindo os resultados de disponibilidade esperados.

\section{5 - Continuidade da Pesquisa}

Finalizando, o autor da pesquisa acredita que ela pode ser enriquecida através da sua continuidade, havendo um potencial de estudos para: 
- aprofundamento do conhecimento das relações entre indicadores de disponibilidade e os de produtividade da empresa;

- estudo da correlação entre a disponibilidade e a modularidade de equipamentos;

- estudo da correlação da disponibilidade de equipamentos do sistema produtivo com os fatores críticos de sucesso da organização;

- estudo aprofundando-se nas razões da aparente falta de aplicação do "ferramental da engenharia de produção" no âmbito das operações de manutenção, principalmente sobre os tempos de reparo e de paralisação dos equipamentos produtivos;

- desenvolvimento de uma metodologia de concepção e implantação de sistemas de manutenção dentro de uma visão de gestão de projetos;

- aprofundamento de estudos para identificação e tratamento estruturado de compromissos da gestão da manutenção, pois eles demonstram um potencial de "agregar valor" a uma função que é vista normalmente como um centro de custos indesejável dentro da empresa.

- desenvolvimento e aprimoramento de uma escala evolutiva que, nos moldes do CMM, permita conduzir avaliações sobre o grau de maturidade da gestão do processo de manutenção de sistemas produtivos. Um instrumento desse tipo permitirá uma avaliação construtiva dos procedimentos e sistemas organizacionais de manutenção.

Essa última proposição de continuidade de pesquisa requer mais detalhes. Um instrumento que permita análise crítica do processo de manutenção, baseado numa escala de níveis de avaliação, produzirá uma imagem mais clara da situação em cada organização, a partir de comparações com as melhores práticas, que, em princípio, estariam no nível 5 da escala. Como conseqüência, indicará os caminhos de um processo de melhoria contínua das atividades de manutenção. Naturalmente, um instrumento de avaliação desse tipo abrangerá dimensões muito mais amplas do que a modesta incursão desta pesquisa, em que se estabeleceu apenas um quadro referencial de apoio. Assim, um instrumental de avaliação como esse deveria abranger dimensões associadas à responsabilidade da gestão da manutenção, métodos e procedimentos adotados, e gerenciamento de recursos humanos e materiais. 
- Anexo A: Planejamento e Roteiro das Entrevistas

- Anexo B: Dados coletados na Entrevistas

- Anexo C: Compilação de Exemplos de Compromissos apontados nas Entrevistas

- Anexo D: Enquadramento dos Casos no Quadro Referencial de Avaliação das Variáveis 


\section{Anexo A: Planejamento e Roteiro das Entrevistas}

\section{Identificação das Empresas}

- Seleção de quatro empresas para o estudo de casos: duas da área de transporte de passageiros sobre trilhos e duas do setor industrial produtor de alimentos.

\section{Identificação dos Contatos}

- Através de indicações preliminares de pessoas do relacionamento do entrevistador.

- Identificação de profissionais nas empresas, de preferência do escalão de gestão, que tenham suas atividades relacionadas com a gestão da manutenção e/ou de produção/operação.

- Em face da dimensão da empresa e de sua área de manutenção, procurar se possível não se fixar em um único profissional, o que pode implicar mais do que uma entrevista.

3. Definição de Datas e Horários

- Agendar com cada profissional, datas e horários.

4. Duração das Entrevistas

- Estabelecer, em princípio, um limite máximo de duas horas. Se o entrevistado apresentar a disposição de continuidade da entrevista, mesmo que seja por meio de outro profissional da empresa, a oportunidade deve ser aproveitada para enriquecimento das observações pertinentes à pesquisa.

5. Épocas dos Fatos

- Considerar evidências do passado recente e do presente que, de alguma forma, sejam pertinentes às variáveis investigadas.

6. Registros das Entrevistas

- Mediante anotações pelo entrevistador, sem uso de gravador, visando evitar eventuais constrangimentos por parte do entrevistado.

- As anotações deverão, preferencialmente, seguir o roteiro de entrevista e serão efetuadas no ato da entrevista para posterior organização da informação obtida. 
7. Roteiro da Entrevista

- O entrevistador procurará obter, do entrevistado, evidências que permitam avaliar o estágio da organização em relação a cada uma das variáveis, para tanto se balizando também pelo conteúdo da Figura 5.2.

- O roteiro será utilizado apenas para orientação do pesquisador, por ocasião da entrevista, porém sem apresentá-lo ao entrevistado, e sem formular as questões de forma direta. A entrevista deve ser conduzida de forma coloquial, de modo que o diálogo possibilite obtenção de informação precisa e objetiva da realidade da organização, visando a inibir eventuais vieses do entrevistado ou do entrevistador.

- O roteiro previsto para as entrevistas encontra-se detalhado mais adiante.

8. Análise Documental Complementar

- Averiguar com o entrevistado sobre a possibilidade de fornecimento de documentação ou relatórios que possam enriquecer os dados obtidos durante a entrevista.

9. Início da Entrevista

- Apresentação ao entrevistado dos objetivos da visita. 


\title{
ROTEIRO DA ENTREVISTA
}

\author{
Empresa: \\ Setor / Área / Departamento: \\ Entrevistado(s): \\ Função / Cargo:
}

P1: O desdobramento do indicador global de disponibilidade em indicadores parciais, obtidos através de um sistema integrado de informações (manutenção, produção e suprimentos) facilita a gestão das operações de manutenção

\subsection{Sistema integrado de informação (manutenção, produção e suprimentos)}

Quais são as informações que são consideradas relevantes no âmbito das atividades de manutenção?

Como são coletadas, processadas e apresentadas as informações pertinentes à manutenção?

Há um sistema que integre informações de manutenção? Quais são as suas principais características? Qual é o nível de integração?

O sistema é parte de um sistema empresarial?

\subsection{Averiguação de indicadores de disponibilidade pela organização}

Há levantamento e aplicação de indicadores de disponibilidade?

Como são obtidos? Obtidos através de fontes da manutenção ou diretamente através de fontes da produção?

São associados a históricos de manutenção de equipamentos produtivos?

Há emissão sistemática de relatórios que apontem os indicadores de disponibilidade?

Há confronto com padrões atualizados de disponibilidade? Quais são esses padrões?

\subsection{Desdobramento do indicador de disponibilidade}

Se há indicador(es) de disponibilidade, qual é o nível de seu desdobramento? Há indicadores de confiabilidade. Quais são e como são tratados? 
Há indicadores de dos tempos de reparo? e indicadores dos tempos de paralisação?

Há desdobramentos dos indicadores de confiabilidade e dos indicadores dos tempos de reparo? e dos tempos de paralisação e de resolução dos problemas relacionados a falhas?

1.4. Gestão das operações de manutenção: tomadas de decisão em função da disponibilidade

Como são agrupadas as atividades de campo (operações elementares) de manutenção?

Há políticas de atuação estabelecidas ? Há alguma abordagem de gestão da manutenção implantada, ou em implantação?

Há evidências (exemplos) de tomadas de decisão em função de indicadores de ou resultados de disponibilidade? Há evidências de tomadas de decisão em função de análises de tendência de indicadores de disponibilidade?

Manifestam-se tomadas de decisão usando indicadores de disponibilidade e confrontação com padrões de disponibilidade, caracterizando uma atitude pró-ativa dos responsáveis pela manutenção?

P2: A adequada definição das políticas e operações de manutenção requer considerar, de modo sistematizado, compromissos com o ambiente, determinações legais, normas técnicas,custos, segurança e processo de produção

\subsection{Estágio de sistematização do tratamento de compromissos}

Há evidências de compromissos que pressionam os gestores de manutenção (estando implícito que a manutenção visa atender à necessidade de equipamentos disponíveis para a produção)? Solicitar inicialmente ao entrevistado que enumere os tipos de pressão. Em seqüência, questionar sobre elas, procurando evidências de critérios explícitos (orçamentos, normas e procedimentos internos, arquivos e relações de instruções). Procurar abordar os seis compromissos em estudo.

Ambiente / Determinações legais / Normas técnicas / Custos / Segurança / Processos de produção. 
Investigar sobre exemplos de problemas que caracterizaram esses compromissos e que provocam, por meio de lições aprendidas, aprimoramentos de forma continuada.

\subsection{Definição de políticas e operações de manutenção em função de compromissos}

Como os requisitos desses compromissos interferiram na definição de práticas de manutenção?

As políticas são estabelecidas em função de pressões momentâneas? Elas estão claramente estruturadas?

Há um plano, portanto considerando ações futuras, de aprimoramento dessas políticas levando em conta os compromissos detectados e que deverão ser atendidos?

P3: As empresas consideram relevante, para a obtenção da disponibilidade, levar em conta, por ocasião de projetos de novos sistemas produtivos ou de projetos de renovação, ampliação ou substituição, o estudo perspectivo do ciclo de vida

3.1. Estudo perspectivo do ciclo de vida no estágio de projeto de novos sistemas produtivos

Como é definido o processo de projeto na empresa? Como é elaborada a especificação técnica do equipamento?

Por ocasião dessa especificação quais são os critérios e preocupações?

Caracterizar se há uma visão do ciclo de vida do equipamento produtivo.

Há critérios definidos para o projeto? Normas e instruções que contemplem o projeto ao longo do seu ciclo de vida?

Qual é o nível de análise por ocasião do projeto? Investimento imediato, custos ao longo do ciclo de vida, desempenho de produção?

Há especificação de padrões de disponibilidade por ocasião do projeto?

3.2. Consideração da disponibilidade por ocasião de renovação, ampliação ou substituição

Caracterizar a preocupação com o ciclo de vida de equipamentos que já estão implantados, ou em regime de produção. 
Há previsão de renovação, ampliação ou substituição e, para isso a empresa dispõe de registros efetivos de comportamentos de projetos implantados?

Com são tratados os projetos já implantados e em produção: são atualizados de modo sistemático? (sistemática de "as built").

Há confronto dos desempenhos operacionais obtidos (por ex.: disponibilidade) com padrões definidos por ocasião do projeto? 


\section{Anexo B: Sumário de Dados Coletados nas Entrevistas}

Nota: Este Sumário traduz o esforço de ajuste das informações fornecidas nas empresas aos "pacotes" de variáveis e proposições da pesquisa. Essa ordenação da informação se mostrou necessária, em face das respostas dos entrevistados e das informações complementares nem sempre terem sido fornecidas dentro de uma correspondência sincronizada com a ordem das variáveis para efeito da verificação das proposições. Nessa ordenação procurou-se manter o teor da informação e, no geral, não representar uma interpretação do pesquisador.

\section{EMPRESA TPT1}

Nota: Os dados coletados na entrevista na empresa TPT1 foram complementados por evidências extraídas de relatórios fornecidos pela Organização. Quando cabível, o Relatório fonte do dado é identificado com um código que o representa: Relatório da Diretoria de Operação1996 (RO 1996), Informativo da Gerência de Manutenção 1997 (RM 1997) e Relatório Operacional 1999 (RO 1999).

P1: O desdobramento do indicador global de disponibilidade em indicadores parciais, obtidos através de um sistema integrado de informações (manutenção, produção e suprimentos) facilita a gestão das operações de manutenção

TPT1 P1 1.1. Sistema integrado de informação (manutenção, produção, e suprimentos)

- Os Sistemas de Informação são individualizados. Relatórios de cada Sistema são analisados em conjunto para tomadas de decisão. Não há um sistema que integre diretamente as informações da Operação, da Manutenção e de Suprimentos.

TPT1 P1 1.2. Averiguação de indicadores de disponibilidade pela organização

- A Manutenção possui Sistema da Qualidade, atendendo a requisitos da ISO 9000. A manutenção está definindo indicadores em conjunto com a Operação. Entre eles estão sendo definidos indicadores de disponibilidade para todos os 
equipamentos e sistemas. Padrões estão sendo revisados para que haja um método uniformizando os cálculos para todas as linhas.

- A oferta do material rodante é medida pelo índice de disponibilidade e o objetivo é assegurar um atendimento de $100 \%$ nos horários de pico, manhã e tarde dos dias úteis (RO 1996, p.31).

- Nos horários de pico, o índice de disponibilidade do material rodante representa a oferta de trens para a operação nos períodos de maior demanda, e é expresso por (RO 1996, p.31):

$\mathrm{D}=$ (número de trens disponíveis / número máximo requerido de trens) x $100 \%$.

- A oferta geral é medida pelo índice de disponibilidade, através da seguinte expressão, onde o valor obtido representa, em percentual, a quantidade de trens considerada em condições para operação (RO 1996, p.31):

$\mathrm{D}=[(\mathrm{T}-\mathrm{TI}) / \mathrm{T}] 100 \%$, onde

$\mathrm{T}=$ quantidade de trens da frota $\mathrm{x}$ número de dias no período $\mathrm{x} 24$ horas do dia $\mathrm{TI}=$ tempo consumido em manutenção preventiva + corretiva + outros, no período

- A disponibilidade de escadas rolantes é dada por um índice que representa, em porcentagem, as horas em que o conjunto de escadas esteve integralmente disponível para a operação comercial, durante 19 horas. É calculada pela seguinte expressão (RO 1996, p.36):

$\mathrm{D}=[(\mathrm{T}-\mathrm{T} 1) / \mathrm{T}] 100 \%$

$\mathrm{T}$ = quantidade de equipamentos x no. de dias no período x 19 horas / dia (operação comercial)

$\mathrm{T} 1$ = tempo consumido em manutenção preventiva, mais corretiva, mais inspeções no período

\section{TPT1 P1 1.3. Desdobramento do indicador de disponibilidade}

- A operação da empresa tem todas as suas atividades gerenciadas em seus vários aspectos. É acompanhada a evolução de um grande número de indicadores de desempenho, dos mais específicos de um pequeno setor aos mais gerais, de compromisso comum a todos (RO 1996, p.20). 
- Quanto à disponibilidade estão sendo definidos dois níveis: Itens de Controle, que correspondem aos indicadores finais, estabelecidos em consenso com a Operação, e Itens de Verificação, que correspondem a desdobramentos dos primeiros, e sobre os quais a Manutenção deve atuar, sendo muitas vezes associados a equipamentos componentes de um sistema.

- Desempenho técnico da frota é medido pelo MKBF (Mean Kilometers Between Failures). Refere-se à distância média, expressa em quilômetros, que um trem percorre sem que ocorra uma falha, enquanto está em operação comercial. É calculado pela seguinte expressão (RO 1996, p.32):

$\mathrm{MKBF}=\mathrm{km}$ da frota / número de falhas

- Como meta, espera-se atingir o MKBF padrão de $1.200 \mathrm{~km}$ e, em conseqüência, atingir uma disponibilidade média mensal de 90\% (RO 1996, p.32).

- Para avaliar o desempenho dos sistemas e equipamentos de alimentação elétrica, o MTBF (Mean Time Between Failures) é um dos indicadores mais utilizados e representativos, pois retrata o tempo médio de funcionamento no período analisado e o número de equipamentos instalados. É obtido através da expressão (RO 1996, p.33):

$\mathrm{MTBF}=(\mathrm{NE} \times \mathrm{ND} \times \mathrm{NH}) / \mathrm{NF}$, onde

$\mathrm{NE}=\mathrm{N}^{\mathrm{o}}$ de equipamentos instalados

$\mathrm{ND}=\mathrm{N}^{\mathrm{o}}$ de dias do período analisado

$\mathrm{NH}=\mathrm{N}^{0}$ de horas de funcionamento por dia

$\mathrm{NF}=\mathrm{N}^{\mathrm{o}}$ de falhas ocorridas no período

- Em subestações auxiliares observou-se uma tendência de estabilização dos índices de MTBF, também favorecida pela introdução de recursos e atividades como inspeção termográfica e análises de óleos isolantes no processo de manutenção (RO 1996, p.34).

- nível de desempenho das escadas rolantes, medido pelo MTBF, é calculado pela seguinte expressão:

$\mathrm{MTBF}=\mathrm{T} / \mathrm{NF}$, onde 
$\mathrm{T}=$ quantidade de equipamentos x no. de dias no período x 19 horas de operação comercial / dia

$\mathrm{NF}=$ quantidade de falhas no período.

- desempenho dos bloqueios (catracas) é medido pela relação Passageiros / Falhas de Bloqueios, que é a relação entre a quantidade de entrada de passageiros nos bloqueios e o total de falhas no período comercial. É representado pela expressão (RO 1996, p.39):

$\mathrm{P} / \mathrm{F}=$ (número de entradas de passageiros) / FC, onde

$\mathrm{FC}=$ Total de falhas

- Um dos indicadores utilizados na avaliação do desempenho técnico da via permanente é a quantidade de viagens realizadas por falha em máquinas de chave (RO 1999, p.61).

- Quanto ao tempo de reparo é analisada sua tendência. A melhor marca atingida em um determinado ano, passa a ser benchmark para o ano seguinte. As atuações de campo têm segmentos de tempo devidamente registrados e avaliados: recebimento da informação da ocorrência, início de atendimento, chegada ao local da falha, tempo de reparo (restabelecimento operacional), e término do serviço. Esses tempos são informados pelos técnicos de manutenção ao CIM (Centro de Informação da Manutenção). Há assim, controle de tempos de atuação.

- No caso da Linha 5, verificou-se elevado tempo de locomoção da equipe, quando comparado com indicadores de outras Linhas. Como as equipes movem-se fora do sistema o trânsito pesado em horário de pico influi no tempo decorrido, podendo provocar alteração do local da base da equipe.

- O processo de manutenção corretiva tem como indicador do seu desempenho o Tempo Médio de Liberação - TML. Esse índice é destinado a medir o tempo médio de liberação de trens em manutenção corretiva, em um determinado período. Correspondente aos "tempos cessantes" de operação de um equipamento. O TML é representado pela expressão (RO 1996, p.32): 
$\mathrm{TML}=\mathrm{TL} / \mathrm{TO}$, onde:

$\mathrm{TL}=$ somatório dos tempos transcorridos entre a entrega e a devolução dos equipamentos

$\mathrm{TO}=$ total de ocorrência no mesmo período

- A meta a ser alcançada para o TML é de 2 h30min, para a frota. Para isso, estão em curso implementações que visam introduzir recursos para possibilitar o diagnóstico de falhas, facilitando sua identificação e, conseqüentemente, diminuindo o tempo de liberação (RO 1996, p.32).

- Obteve-se um nível médio de atendimento de requisições de material da ordem de $97,5 \%$ (RO 1996, p.40).

\section{TPT1 P1 1.4. Gestão das operações de manutenção: tomadas de decisão em} função da disponibilidade

- A empresa possui o SIP - Sistema Integrado de Programação, adaptação da técnica Kanban às características dos serviços prestados pelas oficinas de manutenção, tendo como objetivo a auto-programação, por meio de um painel, que aponta a prioridade de execução de serviços (RO 1996, p.56).

- O estabelecimento dos processos de trabalho confere à Manutenção um caráter estruturado e, portanto, administrável: torna-se possível o planejamento, o dimensionamento de recursos, a aferição de resultados e a tomada de decisões para aperfeiçoamento de sua produção.

- O gerenciamento da manutenção exige que a disponibilidade operacional dos equipamentos e instalações do sistema metroviário seja constantemente assegurada, de acordo com padrões pré-estabelecidos.

- No caso do material rodante, não há tempo de deslocamento. A análise de benchmark do tempo de reparo pode provocar desdobramento do indicador, apontando para causas associadas ao equipamento que exige upgrade, substituição, adaptação, treinamento da equipe, e dispositivos e ferramental especiais. Pode também apontar necessidade de mudança do processo de manutenção: após desmontar tudo, nos primeiros sete meses a mortalidade 
infantil era alta. Foram introduzidos erros humanos, como, por exemplo, lavar uma mangueira com solvente agressivo. Caracteriza-se que em certos componentes é melhor não mexer, é melhor praticar a política da corretiva.

- Há um tratamento para se caracterizar e controlar módulos do trem. Investiu-se em controle de números de série. Por meio de software soma-se a quilometragem percorrida pelo módulo. Atua-se sobre os módulos e em conseqüência o trem não fica praticamente paralisado. Isso implica em retirar equipamentos garantindo a operacionalidade do trem. Assim, se diminui a necessidade de compra de mais trens.

- Para o material rodante, em função da demanda requerida, os processos de manutenção preventiva e corretiva são desenvolvidos tendo por objetivo assegurar uma disponibilidade média mensal de 90\% (RO 1996, p31).

- Visando manter a confiabilidade dos sistemas e equipamentos instalados, alguns em operação há mais de duas décadas, efetuou-se uma série de substituições e revisões gerais, devido à obsolescência, desgaste natural de componentes e dificuldades para o processo de manutenção (RO 1996, p.5).

- A aplicação da análise de vibração no sistema de ventilação possibilitou a elevação do MTBF de 15.000 para 20.000 horas (RO 1999, p.79).

- Foi possível diagnosticar a presença de defeito em componente, antes dele gerar danos maiores ao equipamento. Nas escadas rolantes, por exemplo, a possibilidade de identificar desgaste em um simples rolamento, através da Análise de Vibrações, gerou uma economia total de $\mathrm{R} \$ 600.000,00$ e evitou a utilização imediata de $26.880 \mathrm{Hh}$, em corretiva programada .

- Em complementação às ações de manutenção, foram concluídos vários estudos que visam obter: melhoria de desempenho, aumento de confiabilidade e de disponibilidade, redução de custos e manutenção da segurança dos sistemas, empregados e usuários (RO 1996, p.6).

P2: A adequada definição das políticas e operações de manutenção requer considerar, de modo sistematizado, compromissos com o ambiente, determinações legais, normas técnicas, custos, segurança e processo de produção. 


\section{TPT1 P2 2.1. Estágio de sistematização do tratamento de compromissos}

\section{TPT1 P2 2.2. Definição de políticas e operaçães de manutenção em função de compromissos}

\section{Ambiente:}

- Para limpeza, soprava-se o trem. Gerava poeira na oficina. Ar comprimido, limalha de ferro, efeitos colaterais. Criou-se uma área fechada, confinada, aspiradores, filtros e pessoal protegido. Para o projeto do próximo trem definiu-se não ter equipamentos que fiquem contaminados. Aletas vão direcionar o ar ambiente. Ar de refrigeração é forçado e acumula sujeira. Geram-se falhas. Exige preventiva para retirar falhas. A nova especificação exige que ar de refrigeração não passe internamente ao componente. Vai aumentar o intervalo de preventiva.

- Procurando dar melhor orientação ao usuário na utilização do sistema e contar com sua colaboração, foram realizadas campanhas conclamando sua cooperação (RO 1996, p.5).

- Foram realizadas campanhas de conservação e limpeza, visando a contribuição do usuário na manutenção do nível de limpeza do sistema operacional (RO 1996, p.5)

- Uma das características do serviço da empresa, que a diferencia de outros modos de transporte é, na opinião do usuário, a limpeza, que lhe confere uma imagem de civilidade e bem estar (RO 1996, p.24).

- Foi realizada a substituição de dez aparelhos de apoio dos pilares do elevado Tatuapé, em função de danos causados por incêndio em favela situada sob o viaduto (RO 1996, p45).

- A empresa desenvolveu esforços para, em primeira instância, conviver com restrições impostas pelo ambiente e, em seqüência, interagir com ele, provocando respostas que satisfizessem às suas necessidades.

- Como o usuário aumentou seu nível de exigência, a manutenção adotou diretrizes que redundaram na implementação e revisão de diversas atividades e processos relacionados a: desempenho dos equipamentos e sistemas, estratégias 
diferenciadas de manutenção preditiva e "manutenção progressiva", aplicação de normas da série NBR 19000 à manutenção.

- A gestão operacional do sistema produtivo da empresa baseia-se na verificação sistemática de uma série de indicadores de desempenho. A análise da evolução dos índices, conjugada com a avaliação dos usuários, orienta a tomada de decisões (RO 1999, p.40).

Determinações legais:

- Ruído / Barreira acústica / motores de tração / bancadas de testes / simulação de funcionamento de motor gerava ruído afetando pessoal na redondeza. Solução: confinamento em sala acústica. Outro exemplo, lei municipal exigindo engenheiro credenciado como responsável pela manutenção de escada rolante. Lei municipal determina inspeção mensal de elevadores e escadas rolantes, com plano de manutenção.

- Foi efetuada a substituição de transformadores a ascarel por transformadores a seco (RO 1996, p.6). A substituição, além de atender à legislação nacional e internacional, que restringe a utilização do ascarel, também tem por objetivo proporcionar aos usuários e aos próprios empregados do a condições operacionais e de segurança adequadas (RO 1996, p.43).

\section{Normas Técnicas:}

- Citadas ABNT, ISO e AAR definindo a manutenção. Sem tratamento sistematizado.

\section{Custos:}

- Determinam a manutenção. A empresa sempre investiu na manutenção. Estão estudando a adoção de RCM: para se fazer a manutenção onde se requer maiores cuidados. Estão retirando da operação algumas atividades. Na verdade é um TPM inverso. Ex.: as manobras do sistema elétrico com duplicidade de manobristas, os de manutenção e os de operação. Já que a manutenção efetua manobras, que o faça sempre. Reduz custos”. 
- Implantado projeto piloto de iluminação eficiente visando a redução do consumo de energia elétrica, sem perda de qualidade (RO 1996, p.5).

- Foi adquirida uma unidade de caminhão-oficina, contendo, em seu interior, diversos equipamentos específicos para uso da equipe de manutenção de alta tensão em subestações elétricas. Esse recurso permite que pequenos reparos em equipamentos das subestações, antes realizados nas oficinas, sejam efetuados no próprio local. Isso dará uma maior flexibilidade à equipe e resultará em ganhos de produtividade (RO 1996, p45).

- A Manutenção apresenta composição detalhada dos seus gastos, e indicadores de eficiência associados, como por exemplo "o custo de manutenção acumulado no ano por km de via mantida" (RM 1997, p.9).

- A continuidade da utilização da manutenção preditiva através da análise de vibração nos equipamentos de ventilação proporcionou uma economia de $\mathrm{R} \$$ 500.000 (RO 1999, p79).

\section{Segurança:}

- A segurança operacional é fundamental. Preocupa-se com a análise de liberação de equipamentos de sinalização. No caso de se envolver segurança, a empresa exige duas análises.Toda falha deve provocar condição segura. Ex.: frenagem. No túnel e na via a manutenção atua sempre com duas pessoas. Os Planos de Segurança estão dentro do orçamento. Há alterações de manutenção, em função de falhas COPESE ( que requerem análise de uma Comissão Permanente de Segurança), dividida em três sistemas, material rodante, sinalização e via permanente.

- Serviços especiais de manutenção foram efetuados com a preocupação em manter a segurança dos sistemas, equipamentos, instalações, estruturas, túneis e elevados (RO 1996, p.6).

- Pesquisas com o usuário assinalam que a segurança operacional é um dos aspectos diferenciais do serviço da empresa (RO 1996, p.8). 


\section{Processo de Operação:}

- Estratégias que envolvam a interrupção da operação, da prestação de serviços, devem ser definidas. As estratégias visam evitar indecisões, atendimento rápido, sem conflitos. Ponto forte: procedimentos de interfaces entre operação e manutenção. Quem faz o quê. Limites de atuação são definidos.

- Para atender aos requisitos do programa horário imposto pela demanda de transporte, são desenvolvidos processos de manutenção preventiva e corretiva (RO 1996, p.30).

- O processo de Manutenção Preventiva do material rodante consiste de três diferentes níveis de intervenção: Nível 1, executado no horário entre os picos de demanda a cada $11.250 \mathrm{~km}$, consistindo de inspeções e trocas de componentes; Nível 2, também entre picos de demanda, a cada $23.000 \mathrm{~km}$, consistindo de inspeções e trocas de equipamentos; e Nível 3, a cada 1.300 .000 km, com revisão geral em oficinas, provocando a indisponibilização de um trem (RO 1996, p.30).

- As manutenções preventivas dos equipamentos de via permanente são realizadas no horário noturno (01h00 às 04 h30) para não haver interferência no horário da operação comercial (RO 1999, p.59).

- Para proporcionar uma maior disponibilidade de trens nos horários de picos, foi extinta a manutenção preventiva denominada nível 3, sendo suas atividades previstas incorporadas às de nível 2 , otimizando-se dessa forma os processos de manutenção (RO 1999, p.75).

P3: As empresas consideram relevante, para a obtenção da disponibilidade, levar em conta, por ocasião de projetos de novos sistemas produtivos ou de projetos de renovação, ampliação ou substituição, o estudo perspectivo do ciclo de vida

TPT1 P3 3.1. Estudo perspectivo do ciclo de vida no estágio de projeto de novos sistemas produtivos

- A empresa define na especificação técnica, a qualidade esperada, norteando a confiabilidade e o tempo de reparo. Cerca tempo de reparo, manutenibilidade, facilidades de acesso. 


\section{TPT1 P3 3.2. Consideração da disponibilidade por ocasião de projeto de renovação, ampliação ou substituição}

- Toma-se por base uma análise de custo benefício, considerando problema de desempenho, o custo hoje, o custo da troca, qual é a otimização depois do equipamento trocado. Hoje se questiona trocar o sistema de propulsão da linha mais antiga, passando de c.c. para c.a. Mas, há motores c.c. em condições de rodar mais trinta anos, há vida pela frente ainda. Estudos são feitos para análise da viabilidade da troca considerando não só custos, mas também desempenho.Valores de disponibilidade para o material rodante mostraram a necessidade de melhoria e, por este motivo, tem sido alvo de uma série de modificações, que visam aumentar o desempenho técnico do equipamento e fazer com que este atinja os índices desejados de disponibilidade para atendimento dos picos de demanda (RO 1996, p.31).

- Foram substituídas, por final de vida útil, 15.000 placas de apoio dos trilhos, objetivando a manutenção da segurança de tráfego (RO 1996, p.44).

- Foi efetuada a revisão e atualização de cerca de 2.500 falhas originais de documentação, devido a modificações e implantação de melhorias realizadas (RO 1996, p.45).

- Após mais de 25 anos de operação, diversos sistemas já apresentam sinais de obsolescência. Porém, estudos são desenvolvidos com o intuito de prolongar a vida útil até a efetiva substituição (RO 1999, p.11).

- Apesar do intenso uso que o material rodante vem sofrendo ao longo dos anos, alguns com 25 anos de serviço, e da obsolescência em vários de seus sistemas, estudos mostram que sua estrutura está em excelentes condições, apontando a possibilidade de modernização e reutilização da frota. Nessas condições , foi elaborado estudo de renovação de toda a frota, considerando-se o parque industrial metro-ferroviário nacional, que atende à expectativas de desenvolvimento tecnológico mostrando-se economicamente vantajoso (RO 1999, p.79). 
- A implementação nas caixas de lógica dos carros, de novas funções que permitam diagnosticar falhas em propulsão dos trens da frota, durante a operação comercial, facilitará as ações corretivas das equipes de manutenção e reduzirá o tempo médio de liberação (RO 1996, p.42).

\section{EMPRESA TPT2}

Nota: Os dados coletados nas duas entrevistas na empresa TPT2 foram complementados por evidências extraídas de relatório fornecido pela Organização. Quando cabível, o Relatório fonte do dado é identificado com um código que o representa: Relatório Anual da Diretoria de Operação e Manutenção 2001 (RM 2001). Algumas evidências extraídas do Relatório se mostraram comuns às duas entrevistas.

\section{CASO TPT2A}

Nota: Essa entrevista foi feita dentro de um enfoque mais voltado para o equipamento móvel, ou seja, o material rodante.

P1: O desdobramento do indicador global de disponibilidade em indicadores parciais, obtidos através de um sistema integrado de informações (manutenção, produção e suprimentos) facilita a gestão das operações de manutenção

TPT2A P1 1.1. Sistema integrado de informação (manutenção, produção, $e$ suprimentos)

- Os dados relativos às ocorrências são coletados mensalmente, através da Intranet, e provém do banco de dados do Sistema de Controle de Operação e Manutenção - SICOM, alimentado continuamente pelos três Centros de Controle Operacionais (RM 2001, p.8).

- Os dados relativos ao Desempenho de Sistemas são oriundos, na sua grande maioria, do SRCF - Sistema de Registro e Controle de Falhas, alimentado 
continuamente pelo CIMs - Centros de Informação da Manutenção. Estes são consolidados e fornecidos pela Engenharia de Manutenção, após conferência com as áreas, mais especificamente os "abrigos", no que diz respeito a Material Rodante (RM 2001, p.8).

- Está implantado e disponibilizado na intranet o Diário Operacional e o Módulo de Ocorrências do SICOM - Sistema de Controle de Operação e Manutenção, em substituição a um outro sistema, o CADFFER, que foi desativado (RM 2001 p.10).

- A empresa está implantando o BSC (Balanced Score Card) e um software de gerenciamento corporativo, que está na internet, informando para toda a empresa dados de disponibilidade e confiabilidade. Entretanto, este software não integra software de manutenção. A empresa procura nacionalizar conceitos de manutenção para que sejam implantados no seu âmbito de trabalho.

- Há um PCP que administra os dados coletados e a emissão de relatórios. O BSC é corporativo e não existe um sistema de manutenção integrado com o sistema de materiais. As informações ainda não estão integradas. Assim, na dependência do ciclo de manutenção é indicada a lista de itens a serem trocados. Os materiais aplicados são contabilizados por meio de apuração da quantidade de revisões efetuadas. (Assim, no entender do pesquisador, há uma estimativa, e não uma contabilidade efetiva). Para a manutenção do MRO há aproximadamente $2.000 \mathrm{a}$ 3.000 itens de estoque. A área de materiais faz seu próprio orçamento, em separado do de manutenção.

\section{TPT2A P1 1.2. Averiguação de indicadores de disponibilidade pela organização}

- O melhor índice de atendimento no horário de pico foi apresentado na Linha C, com $40 \%$ dos headways programados cumpridos, apesar da disponibilidade de trens situar-se por volta de 90\% naquela linha (RM 2001, p.35).

- Há gráficos que apontam a evolução da disponibilidade média de trens nos horários de pico nos dia úteis, em \% (RM 2001, p.40). 
- Apresentam-se indicadores de Disponibilidade Patrimonial (frota incluindo os trens imobilizados) e Disponibilidade Operacional (frota incluindo trens em operação ou em manutenção leve) (RM 2001, p.60).

- Há informação da evolução de disponibilidade do material rodante por frota (RM 2001, p.66).

- Diariamente é levantada a situação de disponibilidade dos trens. Medem a disponibilidade da frota patrimonial (operacional / total da frota do patrimônio) e a disponibilidade operacional (disponível para a operação / frota operacional). A disponibilidade da frota é publicada diariamente na intranet. Padrões de disponibilidade têm sido estabelecidos em contratos de terceirização, mas internamente não há o mesmo rigor.

\section{TPT2A P1 1.3. Desdobramento do indicador de disponibilidade}

- Aponta o desenvolvimento de esforços de toda a estrutura na definição de indicadores de gestão empresarial que buscam monitorar a eficiência, a efetividade, a confiabilidade e a disponibilidade dos recursos de infra-estrutura, buscando sempre a melhoria contínua dos serviços prestados, com a evolução das práticas operacionais que consideram a segurança e a qualidade.

- Mede-se MKBF (Quilometragem média entre falhas).

- A empresa adota como parâmetro de controle da confiabilidade a quilometragem percorrida pelo trem, e não o tempo. Assim, mede a confiabilidade por meio do MKBF.

- No caso do material rodante a confiabilidade diz respeito à performance e é avaliada pelo MKBF. O MKBF é desdobrado em níveis, associados a tipos de falhas, e em subsistemas.

- O tempo de reparo não é tratado com métodos de uma engenharia de produção. No passado foram efetuadas cronometragens e entrevistas para compor a duração das atividades. A duração do serviço é determinada pela pressão para liberar o equipamento para a operação. O pessoal e o material não são suficientes para atender às necessidades. 


\section{TPT2A P1 1.4. Gestão das operações de manutenção: tomadas de decisão em} função da disponibilidade

- Há indicação de distribuição de falhas por sistema componente do material rodante (RM 2001, p.71).

- Os anos anteriores foram de melhoria dos processos produtivos de manutenção.

- Contrataram-se terceiros para manutenção de parte da frota e no início do contrato houve queda do MKBF, recuperado depois (RM 2001, p.63).

- Desenvolvimento de dispositivo para execução de serviços de manutenção sem danificar rolamentos (RM 2001, p.63).

- Os serviços foram planejados pela manutenção em conjunto com a área operacional, usando também como parâmetro o sistema de falhas operacionais (RM 2001, p.82).

- Está em andamento um PQMR - Plano Qüinqüenal de Modernização e Recuperação da Frota (RM 2001, p.61).

- Considera-se relevante para a manutenção obedecer a conceitos, que pelos exemplos apresentados caracterizam uma forma sistemática de trabalho. O material rodante é um equipamento complexo, possuindo a empresa equipamentos de gerações tecnológicas diversas. Desde 1979 a empresa estabeleceu políticas de manutenção preventiva e de manutenção corretiva. Ao incorporar outra empresa, recebeu equipamentos antigos, com manuais antigos e metodologias antigas, que foram atualizados, criando um ciclo de MP próprio, ou “nosso". O nível mínimo do profissional contratado hoje, é o curso do SENAI..

- Há um grande desafio: onde efetuar a inspeção do trem.. A revisão obedece a procedimentos de MP. As informações acima são conduzidas do escritório até o trem, por meio da Ordem de Serviço (OS), relatando sinteticamente o que deve ser feito. O retorno da informação é por meio da própria OS. Na prática a OS leva a "receita de bolo" da MP, mas a oficina aproveita a oportunidade para uma inspeção adicional, verificando se há algum problema, ocorrendo eventual atuação corretiva. Ainda, na OS da MP pode constar indicação para remover algumas falhas, que são classificadas em níveis (como banco riscado, janela com vidro trincado, etc.). 
- Não há manutenção preditiva institucionalizada. Abordagens "são modismos". Houve as épocas do TQC, da Reengenharia, que fracassaram por falta de recursos financeiros. "O BSC também vai ser um modismo".

- Não há padrões claramente estabelecidos. Em função da disponibilidade alteramse roteiros de manutenção para minimizar a ocorrência de falhas.

P2: A adequada definição das políticas e operações de manutenção requer considerar, de modo sistematizado, compromissos com o ambiente, determinações legais, normas técnicas,custos, segurança e processo de produção

TPT2A P2 2.1. Estágio de sistematização do tratamento de compromissos

TPT2A P2 2.2. Definição de políticas e operaçães de manutenção em função de compromissos

Ambiente:

- É importante um clima de trabalho adequado. O empregado tem que ter liderança, sem supervisão a qualidade cai. Quanto ao ambiente operacional, há a pressão de se disponibilizar a frota em vésperas de feriados, como é o caso do carnaval. $\mathrm{O}$ vandalismo encarece a manutenção, e atrasa programas de revisão.

- As preocupações com o ambiente resultaram no estabelecimento de um Sistema de Gestão da Qualidade Ambiental.

- Vandalismo é um problema (RM 2001, p.51)

- Indisponibilidade do material rodante é "manchete"

Determinações legais:

- Não foi lembrado nenhum exemplo referente ao trem. Foi citado o caso do reservatório de ar comprimido da própria oficina de manutenção e dos efluentes, em face da legislação ambiental.

Normas Técnicas:

- Seguem recomendações da ABNT, da AAR. 
Custos:

- De qualquer modo todos os itens acabam sendo priorizados no orçamento. A fonte de recursos é fundamental.

Segurança:

- A Segurança é fundamental. Hoje a "empresa está mais preocupada com a segurança, do que com a confiabilidade, em face da falta de recursos financeiros": a confiabilidade pode ser baixa, mas a segurança é essencial.

- Com foco foco prioritário no usuário, implantou-se o COPESE - Conselho Permanente de Segurança Operacional, dedicado ao estudo, pesquisa, desenvolvimento de soluções estruturadas nas práticas prevencionistas de segurança de tráfego, voltado para aperfeiçoar os processos produtivos de operação e manutenção integrada, permitindo assim, estruturar a evolução na segurança da circulação dos trens.

\section{Processo de operação:}

- A Operação quer trens confiáveis, limpos e seguros.

- Há registros de acidente ferroviário, incêndio, abalroamento (RM 2001, p47)

- Ocorre desrespeito por parte do maquinista a regulamentos (RM 2001, p49)

- Todos os serviços executados alimentam um banco de dados. A MP exige tempo e há padrões para cada tipo de revisão. Para atender aos requisitos de disponibilidade nas horas de pico de transporte, procura-se executar as inspeções nos vales de demanda, ou entre as horas de rush.

P3: As empresas consideram relevante, para a obtenção da disponibilidade, levar em conta, por ocasião de projetos de novos sistemas produtivos ou de projetos de renovação, ampliação ou substituição, o estudo perspectivo do ciclo de vida

TPT2A P3 3.1. Estudo perspectivo do ciclo de vida no estágio de projeto de novos sistemas produtivos 
- O projeto nasce por meio de Especificações Técnicas da empresa. A especificação do equipamento é atualizada, incorporando especificações técnicas, que são encaminhadas para os fabricantes. Há critérios de atendimento de demanda, conforto do passageiro, aceleração, frenagem, etc. Já há contratos de fornecimento que estabelecem o MKBF. Preocupa-se com a manutenção e com potencial falta de sobressalente, em face da rápida obsolescência tecnológica.

TPT2A P3 3.2. Consideração da disponibilidade por ocasião de projeto de renovação, ampliação ou substituição

- A Manutenção carece de instrumental para esse tratamento mais detalhado. As frotas de várias gerações, recebidas nas incorporações que formaram a empresa, representam dificuldade para esse tratamento.

\section{CASO TPT2B}

Nota: Essa entrevista foi feita dentro de um enfoque mais voltado para os equipamentos fixos, ou seja, aqueles que estão instalados ao longo da linha do sistema operacional.

P1: O desdobramento do indicador global de disponibilidade em indicadores parciais, obtidos através de um sistema integrado de informações (manutenção, produção e suprimentos) facilita a gestão das operações de manutenção

TPT2B P1 1.1. Sistema integrado de informação (manutenção, produção, e suprimentos)

- Os dados relativos às ocorrências são coletados mensalmente, através da Intranet, e provém do banco de dados do Sistema de Controle de Operação e Manutenção - SICOM, alimentado continuamente pelos três CCOs (RM 2001, p.8). 
- Os dados relativos ao Desempenho de Sistemas são oriundos, na sua grande maioria, do SRCF - Sistema de Registro e Controle de Falhas, alimentado continuamente pelo CIMs - Centros de Informação da Manutenção (RM 2001, p.8).

- Está implantado e disponibilizado na intranet o Diário Operacional e o Módulo de Ocorrências do SICOM - Sistema de Controle de Operação e Manutenção, em substituição a um outro sistema, o CADFFER, que foi desativado (2001 p.10).

- Ainda, sobre Informação: há o SICOM, onde são registradas todas as ocorrências, o que permite uma série de estatísticas, para todos os sistemas. Há um sistema de falhas, que registra ocorrências e atuações. È um banco de dados; gera indicadores como MKBF para o material rodante e MTBF, para os sistemas. O SICOM é uma interface entre a operação e a manutenção. Há um Centro de Informações da Manutenção (CIM), que registra a atuação da manutenção no campo. A operação tem seu sistema de ocorrências operacionais que é o SICOM.

- O sistema de materiais não está integrado eletronicamente ao da manutenção. Pretendiam implantar o SAP para integrar, mas não foi possível. Optaram por um sistema simplificado, o Apolo, mas não conseguiram a integração ainda. Têm que migrar informações, provocando re-trabalho. Hoje há uma redução na capacidade de compra. Não conseguem executar a MP: muitas vezes chega o material e não há condições de realizar a MP, pois falta mão-de-obra. Nem sempre conseguem o “casamento". Como não conseguem contratar a mão-de-obra, por causa de falta de recursos financeiros, há dificuldade para execução da MP.

\section{TPT2B P1 1.2. Averiguação de indicadores de disponibilidade pela organização}

- Aplicação de indicador de disponibilidade: é medida e informada todos os dias. A disponibilidade da rede aérea é praticamente $100 \%$, só cai em caso de acidente. A disponibilidade é uma medida global para a administração por meio do BSC. Não há um padrão de disponibilidade, mas um código de compromisso com o usuário,que é fixado nas estações. 


\section{TPT2B P1 1.3. Desdobramento do indicador de disponibilidade}

- Há esforço de toda a estrutura na definição de indicadores de gestão empresarial que buscam monitorar a eficiência, a efetividade, a confiabilidade e a disponibilidade dos recursos de infra-estrutura, buscando sempre a melhoria contínua dos serviços prestados, com a evolução das práticas operacionais que consideram a segurança e a qualidade.

- Há indicação do MTBF, e de suas média anuais, consideradas por sistema (RM 2001, p.72).

- É importante a visão do usuário. Indicadores que afetam o usuário são relevantes. A implantação do BSC requer indicadores, entre os quais os de disponibilidade.e os de confiabilidade. Há metas associadas.

- Planejamento Estratégico: Há MP. Não conseguem cumprir plenamente o programa de MP, devido à falta de recursos. A segurança (ex.: sistema de freio) é essencial. Esse foco na segurança prejudica a confiabilidade. Há um programa multidisciplinar de confiabilidade, formado por 19 grupos, procurando identificar falhas que são relevantes. As principais falhas são identificadas por meio de curvas de Pareto e cortes das principais causas. São nomeados líderes de grupos de sistemas. Há portanto uma “Gestão da Confiabilidade”. Muita coisa pode ser obtida por meio de ajustes de procedimentos e de motivação. Os indicadores são medidos de forma global, o que representa um risco.

- Gestão de Rotinas: há indicadores parciais, sendo que a área de suprimentos tem os seus. Está se firmando uma cultura, para que cada área tenha seu indicador.

- Gestão dos Grandes Contratos Terceirizados: os indicadores são diferentes. São por confiabilidade. Entretanto, há uma limitação de responsabilidade do contratado, já que parte dela permanece com a contratante. Não há ainda uma forma de contratação que transfira totalmente a responsabilidade para $o$ contratado: foi contratada só a manutenção. Falhas de projeto não podem ser transferidas para terceiros contratados.

- Há contratação da manutenção da via permanente por meio de indicadores. Um deles é "a quantidade de quilometragem de restrição de velocidade da via". 
- O indicador de disponibilidade não é único, é medido para série de equipamentos. Confiabilidade e disponibilidade, MKBF e MTBF, por sistemas. Há tempos de reparos (tempo médio de reparos, tempo de atendimento, tempos de liberação, tempos de deslocamento), que são medidos no SICOM. Isso para sistemas, já que há deslocamentos de mais de $10 \mathrm{~km}$. A empresa está espalhada geograficamente. Os tempos de deslocamento são significativos, o que é significativo para a disponibilidade dos sistemas. No caso do material rodante, a situação é diferente: normalmente ele vem até à oficina.

TPT2B P1 1.4. Gestão das operações de manutenção: tomadas de decisão em função da disponibilidade

- Há indicação de ocorrências por tipo de falha para os sistemas fixos (sinalização, energia rede aérea) (RM 2001, p.77).

- Os anos anteriores foram de melhoria dos processos produtivos de manutenção (RM 2001).

- Têm uma estrutura 24h/dia para as tradicionais MP e MC. Não existe uma manutenção preditiva institucionalizada para os sistemas fixos: há parte dessa manutenção, como análise de óleo, em locomotiva, acompanhamento do desgaste de rodas, termografia, no sistema elétrico, e ultra-som (que estão relacionadas com o material rodante).

- Permanentemente identificam falhas. A política de manutenção é função da gestão da confiabilidade.

P2: A adequada definição das políticas e operações de manutenção requer considerar, de modo sistematizado, compromissos com o ambiente, determinações legais, normas técnicas,custos, segurança e processo de produção

TPT2B P2 2.1. Estágio de sistematização do tratamento de compromissos

TPT2B P2 2.2. Definição de políticas e operações de manutenção em função de compromissos 


\section{Ambiente:}

- $270 \mathrm{~km}$ de linhas, agentes externos, vandalismo, roubo de cabos (que mesmo após decidir-se enterrá-los são roubados) e de componentes de cobre. Até a rede aérea é roubada, após a provocação de curtos circuitos. No trem, roubam janelas de alumínio (para minimizar o problema foram travadas). Intempérie e inundações representam outro problema do ambiente. Há equipes de sobreaviso, que são chamadas para dar atendimento, mediante escalas, nos diversos escalões.

- A preocupação com o ambiente resultou no estabelecimento de um Sistema de Gestão da Qualidade Ambiental (RM 2001).

- Ocorrem interdições de trechos devido a vandalismo (RM 2001, p.11).

- Cita-se a "reabertura de estação, fechada por depredação" (RM 2001. p.12).

- Há registro de furto de fios (RM 2001, p.44).

- Falta de energia por parte da concessionária.

- Invasão de faixa e inundação na via permanente (RM 2001, p.50).

- Perturbações decorrentes de fatores fora do controle da operação incluem : descarga atmosférica, falta da energia da concessionária, atropelamento de animal, invasão de faixa, inundação da via permanente (RM 2001, p.54).

\section{Determinações legais:}

- operadores de empilhadeira têm que sofre reciclagem e treinamento. Há a responsabilidade civil dos engenheiros. de manutenção.

\section{Normas Técnicas:}

- ABNT, AAR, ISSO, americanas, européias,. Cada sistema tem sua manutenção associada a diversas normas técnicas.

\section{Custos:}

- Sistema complicado. Sistema empresarial nem sempre identifica os custos particulares da manutenção. Não conseguem ter o custo de manutenção de determinado trem. 
Segurança:

- "Sacrifica-se a confiabilidade, mas não a segurança", que é considerada prioritária. Pode afetar a disponibilidade.

- O COPESE - Conselho Permanente de Segurança Operacional pesquisa soluções estruturadas de segurança de tráfego. É voltado para aperfeiçoar os processos produtivos de operação e manutenção integrada, permitindo assim, estruturar a evolução na segurança da circulação dos trens. (RM 2001).

Processo de Produção (Operação):

- O usuário danificava o sistema de portas. Provocou modificações no sistema para minimizar o problema. Depende da linha: linhas C e E estão com bom nível de aceitação.

- Definição de Políticas de Manutenção: a própria filosofia do BSC é de balanceamento. Está contemplado dentro do BSC.

- Há registros de acidente ferroviário, incêndio, abalroamento (RM 2001, p.47)

- Acidentes incluem tombamento, choque, colisão, abalroamento de veículo rodoviário, descarrilamento (RM 2001, p.55)

- Transposição AMV, com chave ao contrário,(RM 2001, p.57)

- Colisão com trem de carga (2001, p.59)

P3: As empresas consideram relevante, para a obtenção da disponibilidade, levar em conta, por ocasião de projetos de novos sistemas produtivos ou de projetos de renovação, ampliação ou substituição, o estudo perspectivo do ciclo de vida

TPT2B P3 3.1. Estudo perspectivo do ciclo de vida no estágio de projeto de novos sistemas produtivos

- Aquisição: entra a Engenharia de Projeto e a Engenharia de Manutenção, mais a área operacional. Os critérios dependem do projeto, partindo tudo do plano operacional e de simulações de demanda. Há um Plano Mestre até 2020.

- Ciclo de Vida: não há essa preocupação. "Não é empresa privada". As decisões dependem muito das exigências das fontes de financiamento, com suas regras e 
direcionamentos. A preocupação imediata é com a aquisição do sistema. Não há preocupação institucionalizada com o ciclo de vida. Para os equipamentos mais recentes, e com a terceirização, começa a transparecer essa preocupação. $\mathrm{Na}$ verdade, há equipamentos recebidos sem a estrutura para manter. Começa a haver especificação de disponibilidade, com parte da garantia do fornecedor, associada a uma operação assistida.

TPT2B P3 3.2. Consideração da disponibilidade por ocasião de projeto de renovação, ampliação ou substituição

- Implantação da alimentação elétrica em alta tensão $(6,6 \mathrm{kV})$ dos centros de distribuição de energia elétrica de tração, dando maior confiabilidade ao sistema de alimentação da sinalização (RM 2001, p.8).

- Substituição de isoladores de secção antigos por isoladores novos, a fim de eliminar o constante desarme (RM 2001, p.77).

- A documentação é atualizada., é uma exigência operacional. Há uma estrutura formal para controlar a documentação. No projeto são apresentadas as características e avaliação final é do conjunto, pois sempre há conflitos.

\section{EMPRESA IPA1}

P1: O desdobramento do indicador global de disponibilidade em indicadores parciais, obtidos através de um sistema integrado de informações (manutenção, produção e suprimentos) facilita a gestão das operaç̃̃es de manutenção

IPA1 P1 1.1. Sistema integrado de informação (manutenção, produção, e suprimentos)

- A manutenção tem uma base de dados fundamentada no uso de planilhas Excel, dirigido ao atendimento do sistema contábil financeiro, não se ajustando ao sistema industrial. O sistema de manutenção está em transição para se compatibilizar com um sistema mais abrangente, o "sistema empresarial". Esse 
sistema é "home made". Integra informações de manutenção, produção e suprimentos.

- Para a gestão da manutenção as informações relevantes são aquelas de natureza "financeira", destacando o gestor aquelas relacionadas com os tempos de parada de máquinas e com as manutenções preventivas e corretivas.

- As informações são coletadas por meio de Ordens de Serviços (OSs) e registradas no sistema. Também são emitidas Requisições de Materiais (RMs). As informações são setorizadas por linhas de produção.

- A Gerência de Manutenção considera que as principais características do Sistema de Informação são: objetividade, facilidade de acesso à informação e facilidade de interpretação.

- As informações são processadas diariamente, não havendo acesso real time.

- A OS apresentada é a convencional, contemplando campos para registros do serviço solicitado, do serviço executado e dos materiais aplicados. O fato de a OS contemplar o campo para materiais aplicados, confirma uma falta de integração sistêmica com suprimentos, já que foi citada a existência de RM, que poderia encaminhar a integração da informação.

\section{IPA1 P1 1.2. Averiguação de indicadores de disponibilidade pela organização}

- A obtenção de indicadores faz parte da especificação do Plano da Qualidade, atendendo à ISSO 9000. O indicador fundamental é o tempo de manutenção: perseguem sua redução, procurando investir em métodos. A preocupação fundamental é com os custos decorrentes dos tempos de parada.

- A fonte de obtenção dos tempos de parada de máquina é obtida dos registros de produção.

- A disponibilidade é vinculada às etapas produtivas. 


\section{IPA1 P1 1.3. Desdobramento do indicador de disponibilidade}

- A quantidade de falhas não é medida (não foi usado o termo confiabilidade). "Não há qualidade de informação necessária". Há alguma deficiência no uso da informação pois afirma-se que tem histórico de máquina.

- Não há emissão sistemática de relatórios. "Estamos em processo evolutivo".

- Não há padrões estabelecidos. Não têm ainda "estudos estatísticos".

- Medem o tempo de reparo associado aos tempos de produção. Seu desdobramento é pela origem: mecânica, elétrica, pneumática, etc. e não desmembrando o tempo de reparo. Não nenhum indicador de espera de material, por exemplo. (è interessante que dando tanta atenção ao tempo de reparo ele não seja desmembrado em alguns outros indicadores!)

- Há uma "enchedora" que foi comprada em função de diminuir tempos de reparo, gastos com peças e custos. (Embora seja manifestada mais uma vez a preocupação com custos, transparece aqui uma preocupação implícita com a manutenibilidade, termo que não foi citado em qualquer instante da entrevista!).

IPA1 P1 1.4. Gestão das operaçães de manutenção: tomadas de decisão em função da disponibilidade

- Para a gerência há manutenção preventiva (todo acompanhamento é feito por check-lists e por setor), manutenção corretiva (atuação em nível de quebra) e manutenção preditiva (reforma programada). (A interpretação de preditiva parece não corresponder ao conceito da literatura!). Confirmou que não adotam a preditiva integralmente.

- Não estão implantando nenhuma abordagem de gestão, como TPM e RCM (aliás estranhou o termo TPM!). Assim, transparece que a abordagem é a da empresa.

P2: A adequada definição das políticas e operações de manutenção requer considerar, de modo sistematizado, compromissos com o ambiente, determinações legais, normas técnicas,custos, segurança e processo de produção 
IPA1 P2 2.1. Estágio de sistematização do tratamento de compromissos

\section{IPA1 P2 2.2. Definição de políticas e operaçães de manutenção em função de compromissos}

Ambiente:

- Quanto ao ambiente de produção, o grande desafio relaciona-se com eventuais reincidências de problemas. Isso, para a gerência, significa que a manutenção não consegue ser eficaz. (é interessante este aspecto que se relaciona com o ambiente de convivência entre a manutenção e a produção!).

- A influência ambiental de ácido acético é fator preponderante no ambiente da fábrica. Os equipamentos e tubulações requerem construção em aço inox 316L e cuidado ambiental. Quanto à CETESB, o principal cuidado é com a presença de ácido acético na ETE (Estação de Tratamento de Efluentes).

Determinações legais:

- Quanto a determinações legais cita o exemplo das caldeiras, que são inspecionadas a cada seis meses, e cita o cuidado especial com as máquinas de ink-jet, que datam os prazos de validade dos produtos embalados. A multa por eventual erro é de valor bastante relevante (é milionária).

Normas técnicas:

- Quanto a Normas Técnicas, cita a ANSI, para tubulação e normas de especificação técnica de pressões e temperaturas, por ocasião de compras e reformas de equipamentos.

\section{Custos:}

- A primeira pressão, ou compromisso, é com custos. A peça orçamentária para investimentos e despesas é "Bíblia".

- Voltando aos custos: sua contenção provoca a redução de MP, aumentando em conseqüência a MC, acelera a depreciação do equipamento, e depois requer gasto 
dobrado para recuperar o equipamento. Conhecer e enfrentar esse “desbalanceamento financeiro" representa o maior desafio.

Segurança:

- Quanto à segurança do pessoal de manutenção há a determinação de usos de EPIs: cuidados especiais devem ser observados na manutenção de reatores, já que a presença de vapores de ácido acético pode levar o mantenedor ao desmaio.

Processo de Produção:

- Há cuidados com drenos e comprimentos de tubulações de linhas de transferência, que podem provocar "acedificação" excessiva na tubulação.

- Resíduos de solda representam um desafio para que não cheguem ao consumidor.

- Quanto ao processo de produção a manutenção deve ser a mais limpa possível para que não ocorra contaminação dos produtos a serem comercializados.

- A água de poços artesianos exige cuidados de tratamento, para a caldeira para processos.

Não há nenhum plano escrito explicitando intenções para os compromissos citados. Por isso consideram importante implantar um sistema de informação da manutenção(?).

P3: As empresas consideram relevante, para a obtenção da disponibilidade, levar em conta, por ocasião de projetos de novos sistemas produtivos ou de projetos de renovação, ampliação ou substituição, o estudo perspectivo do ciclo de vida

IPA1 P3 3.1. Estudo perspectivo do ciclo de vida no estágio de projeto de novos sistemas produtivos

- Desenvolvem o projeto basicamente analisando a necessidade. A maior incidência é para atender a novos produtos, em decorrência de análises de custos (custos fixos e custos variáveis) para obter seu payback, análise técnica e, principalmente, análise de custo/benefício. 
- Nem sempre compram o melhor equipamento, mas procura-se a melhor relação de custo benefício. Consideram uma visão geral da vida do equipamento, sua depreciação e inclusive a garantia por parte do fabricante.

- Para a "enchedora" citada anteriormente consideraram um horizonte de vida de dez anos, com uma depreciação contábil de cinco anos.

- Normalmente a especificação adotada é a do fabricante.

IPA1 P3 3.2. Consideração da disponibilidade por ocasião de projeto de renovação, ampliação ou substituição

- Por ocasião do projeto não há especificação de indicadores de disponibilidade, por enquanto, para o fornecimento da máquina.

- Devido à conjuntura do país, hoje, não há qualquer previsão de investimento para ampliação da fábrica.

- A vida da máquina é acompanhada por registros históricos internos de comportamento ou junto a outro cliente do mesmo fornecedor.

- Todos os desenhos, manuais e esquemas das principais máquinas são os do fornecedor. Não fazem atualizações, isto é, não há “as-built”.

\section{EMPRESA IPA2}

P1: O desdobramento do indicador global de disponibilidade em indicadores parciais, obtidos através de um sistema integrado de informaçães (manutenção, produção e suprimentos) facilita a gestão das operações de manutenção

IPA2 P1 1.1. Sistema integrado de informação (manutenção, produção, $e$ suprimentos)

- Cada unidade tem seu modo de trabalho. A produção anota motivos de parada e serviços realizados. Há apenas uma unidade com informatização da manutenção, usando um sistema denominado SEMAPI. As emergências dessa unidade, mais nova, são ativadas pelo rádio. Pretende-se passar a informatização para todas as 
quatro unidades. A manutenção tem um quadro fixo de pessoal, o ano inteiro. $\mathrm{O}$ SEMAPI não integra produção e suprimentos: necessita incorporar módulos. Há um sistema orçado, que integraria a produção. Entretanto consideram que esse módulo é complexo.

- Relatórios são obtidos na produção. No final do turno há relatórios com ocorrências. A manutenção tem registro paralelo, mas prevalece a produção.Há relatórios diários e mensais, de cada fábrica, que são encaminhados à diretoria.

\section{IPA2 P1 1.2. Averiguação de indicadores de disponibilidade pela organização}

- Há indicadores básicos: horas paradas / horas trabalhadas (\%), por linha de produção. São linhas contínuas: qualquer problema para a linha. No caso do panetone a produção ocorre no último quatro meses do ano, 24 horas/dia, inclusive sábado e domingo. Assim, a manutenção preventiva é feita antecipadamente para que não ocorra interrupção da produção.

- Não há padrões estabelecidos. Adota-se a experiência. ë um referencial, mais que um padrão.

\section{IPA2 P1 1.3. Desdobramento do indicador de disponibilidade}

- Só mede a disponibilidade. Tempo de reparo só é medido na unidade do Sul de Minas. Não há metodologia para reduzir o tempo de reparo. Só se o problema se repete.

IPA2 P1 1.4. Gestão das operações de manutenção: tomadas de decisão em função da disponibilidade

- Na fábrica de panetone e colomba, que é sazonal, adota-se a preventiva antecipando a safra. Na fábrica de biscoitos adota-se preventiva com pequenos reparos; para aos domingos e faz-se pequenos ajustes e corretiva. Na unidade do Sul de Minas, de amanteigados e salgados, usa-se a preditiva ( com análise de 
óleo). Só na unidade do sul de MInas usa-se a disponibilidade para se definir políticas de manutenção.

- Não há ISO 9000. Adotam o sistema HACCP, que corresponde a uma análise de pontos críticos de produção.

P2: A adequada definição das políticas e operações de manutenção requer considerar, de modo sistematizado, compromissos com o ambiente, determinações legais, normas técnicas,custos, segurança e processo de produção

\section{IPA2 P2 2.1. Estágio de sistematização do tratamento de compromissos}

IPA2 P2 2.2. Definição de políticas e operações de manutenção em função de compromissos

Ambiente:

- "no alto verão, com muito calor, aumenta a quebra de equipamentos. Não há tecnologia própria para o Brasil. São marcantes no verão os problemas de natureza mecânica e eletrônica. Estão investindo em ar condicionado e ventilação forçada para os painéis".

Determinações legais:

- "a NR-10 faz parte da manutenção elétrica e segurança".

Normas Técnicas:

- "não há citação" "Lembra-se da ABNT".

\section{Custos:}

- "há um ano o investimento era em qualidade. Hoje é custos. Há orçamento de manutenção, que não é rigoroso. Há verbas de investimento para atacar segurança". 
Segurança:

- “caso do elevador de tacho, onde se faz o bolo. o sistema de proteção desativado representa problema. Pessoal desativa o sistema de segurança e esquece desativado. Há relatórios de empresa terceirizada sobre a segurança de elevadores de carga".

Processo de produção:

- “treinamento, limpeza, boné, ferramentas limpas, panos de limpeza, álcool onde colocaram as mãos, não contaminar o produto. Solda na fábrica exige segurança".

- "Datadoras é responsabilidade da produção. São máquinas bastante confiáveis".

P3: As empresas consideram relevante, para a obtenção da disponibilidade, levar em conta, por ocasião de projetos de novos sistemas produtivos ou de projetos de renovação, ampliação ou substituição, o estudo perspectivo do ciclo de vida

IPA2 P3 3.1. Estudo perspectivo do ciclo de vida no estágio de projeto de novos sistemas produtivos

- Estudo de mercado define o produto. Engenharia faz levantamento e passa informação para o Marketing, que verifica se o estudo compensa o investimento. A preocupação fundamental é com o retorno do investimento em um ano. É difícil obter aprovação, quando o prazo de retorno do investimento é maior do que um ano.

IPA2 P3 3.2. Consideração da disponibilidade por ocasião de projeto de renovação, ampliação ou substituição

- Os estudos são direcionados para qualidade sem padrões de disponibilidade. 99\% das máquinas são importadas. Está se iniciando a nacionalização de máquinas de embalagem. Há constante renovação. Mas, hoje o mercado está se estabilizando por baixo. Desenhos são arquivados por linha de produção. Não há " $a s$ built". 
Anexo C - Compilação de Exemplos de Compromissos apontados nas Entrevistas

\begin{tabular}{|c|c|c|c|c|c|}
\hline & TPT 1 & TPT 2A & TPT 2B & IPA 1 & IPA 2 \\
\hline AMBIENTE & \begin{tabular}{|lrr|} 
ALTERAÇÃO & DE \\
PROJETO DO & TREM, \\
PARA & EVITAR \\
ACÚMULO DE & POEIRA \\
E & DIMINUIR \\
PREVENTIVAS & DE \\
LIMPEZAS & \\
CAMPANHAS & JUNTO \\
AO USUÁRIO & PARA \\
ASSEGURAR O NÍVEL & DE LIMPEZA & DO \\
DE & \\
SISTEMA & INCENDIO EM FAVELA \\
\multicolumn{3}{l}{ SOB VIADUTO }
\end{tabular} & $\begin{array}{llr}\text { AMBIENTE } & \text { DE } \\
\text { TRABALHO } & \\
\text { COMPATIBILIZADO } \\
\text { COM LIDERANÇA E } \\
\text { SUPERVISÃO } & \\
\text { - } & \text { PRESSÃO } & \text { DO } \\
& \text { USUÁRIO } & \text { EM } \\
& \text { VÉSPERAS } & \text { DE } \\
& \text { FERIRADO } & \\
\text { - } & \text { VANDALISMO } & \\
\text { - SISTEMA } & \text { DE } \\
& \text { GESTÃO } & \text { DA } \\
& \text { QUALIDADE } & \\
& \text { AMBIENTAL } & \\
\text { IMAGEM: } & \\
\text { DISPONIBILIDADE } \\
\text { E DO TREM É } \\
\text { MANCHETE }\end{array}$ & 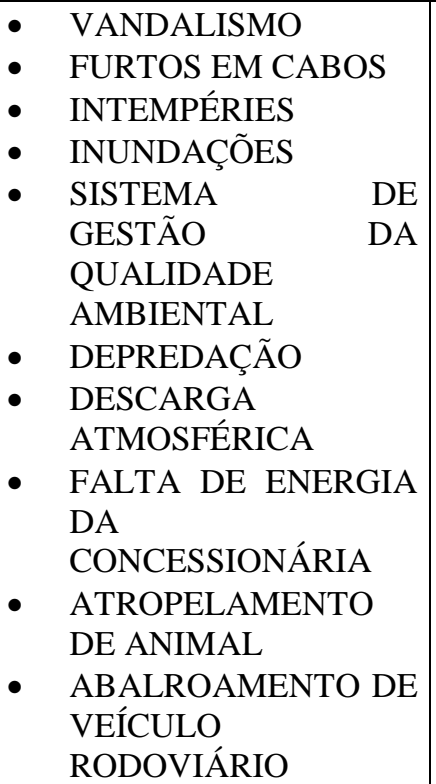 & $\begin{array}{ll}\text { AMBIENTE } & \text { DE } \\
\text { PRODUÇÃO: } & \\
\text { REINCIDÊNCIA DE } \\
\text { PROBLEMAS } \\
\text { GERA IMAGEM DE } \\
\text { MANUTENÇÃO } \\
\text { INEFICAZ } & \\
\text { CUIDADO COM } & \text { COLUENTES } \\
\text { ÉCIDOS } & \\
\text { ÁCIDOS }\end{array}$ & $\begin{array}{ll}- & \text { CALOR EXCESSIVO } \\
\text { NO } & \text { VERÃO } \\
\text { AUMENTA } & \text { A } \\
\text { QUEBRA } & \text { DE } \\
\text { EQUIPAMENTOS } & \end{array}$ \\
\hline $\begin{array}{l}\text { DETERMINAÇÕES } \\
\text { LEGAIS }\end{array}$ & 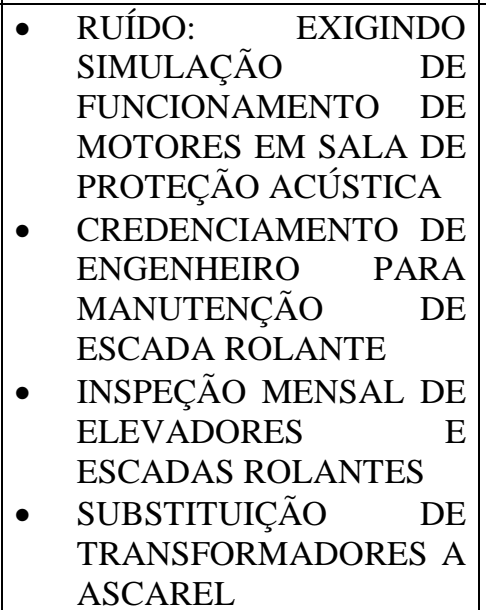 & $\begin{array}{lll}\text { - } & \text { EFLUENTES } & \text { EM } \\
\text { FACE } & \text { DA } \\
\text { LEGISLAÇÃO } & \\
\text { AMBIENTAL } & \end{array}$ & $\begin{array}{lrr}\text { OPERADORES } & \text { DE } \\
\text { EMPILHADEIRA } & \\
\text { DEVEM } & \text { TER } \\
\text { TREINAMENTO } & \text { DE } \\
\text { RECICLAGEM } & \\
\text { - } & \text { RESPONSABILIDADE } \\
\text { CIVIL } & \text { DOS } \\
\text { ENGENHEIROS } & \text { DE } \\
\text { MANUTENÇÃO } & \end{array}$ & \begin{tabular}{ll} 
- & \multicolumn{2}{l}{ MANUTENÇÃO DE } \\
CALDEIRAS QUE \\
SÃO \\
INSPECIONADAS A \\
CADA SEIS MESES \\
- & CUIDADOS COM \\
MÁQUINAS & \\
INK.JET, & \\
DATADORAS & DE \\
PRAZOS & DE \\
VALIDADE &
\end{tabular} & $\begin{array}{ll}\text { - } & \text { NR - 10 FAZ PARTE } \\
\text { DA MANUTENÇÃO } \\
\text { ELÉTRICA } \\
\text { SEGURANÇA }\end{array}$ \\
\hline
\end{tabular}




\begin{tabular}{|c|c|c|c|c|c|c|c|}
\hline NORMAS TÉCNICAS & & - ABNT, ISO e AAR & - $\quad$ ABNT, AAR & & - $\quad$ ABNT, AAR, ISO & \begin{tabular}{ll|}
- & ANSI \\
& TUBULAÇÕES) \\
\end{tabular} & $\begin{array}{ll} & \mathrm{ABNT} \\
\end{array}$ \\
\hline CUSTOS & & 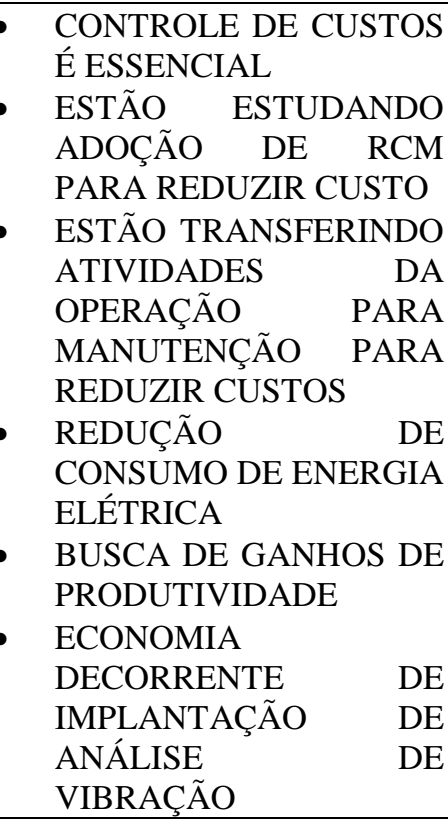 & $\begin{array}{ll}- & \text { QUALQUER } \\
& \text { ATIVIDADE } \\
& \text { PRIORIZADA } \\
& \text { FUNÇÃO } \\
& \text { ORÇAMENTO }\end{array}$ & $\begin{array}{r}\text { É } \\
\text { EM } \\
\text { DO }\end{array}$ & 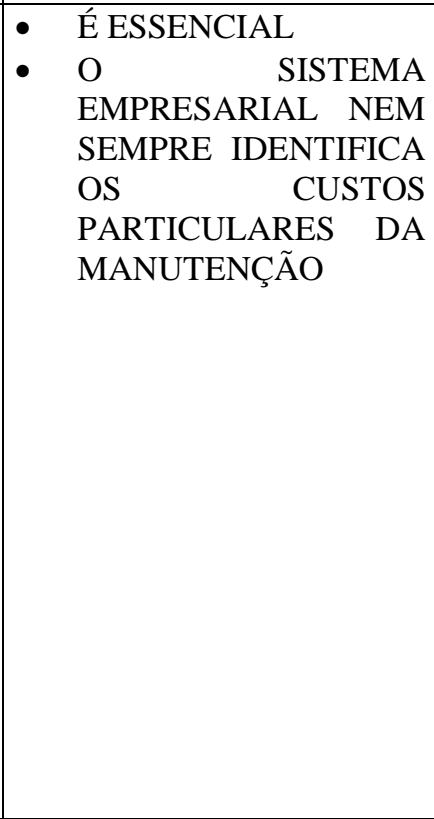 & $\begin{array}{llr}- & \text { O COMPROMISSO } \\
\text { É COM CUSTOS } \\
\text { - O ORÇAMENTO } \\
\text { DEVE r SER } \\
\text { SEGUIDO r } \\
\text { RIGOROSAMENTE }\end{array}$ & 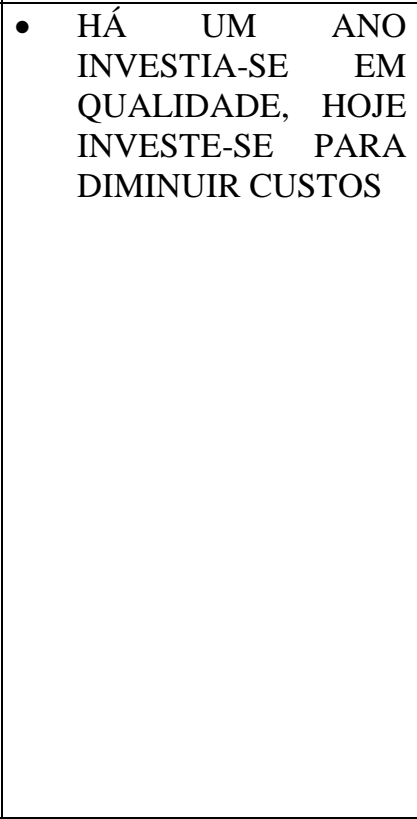 \\
\hline
\end{tabular}




\begin{tabular}{|c|c|c|c|c|c|}
\hline SEGURANÇA & \begin{tabular}{llr} 
& QUANDO A FALHA \\
\multicolumn{3}{l}{ ENVOLVE SEGURANÇA } \\
OPERACIONAL r A \\
EMPRESA EXIGE DUAS \\
ANÁLISES \\
- \\
TODA FALHA DEVE \\
PROVOCAR CONDIÇÃO \\
SEGURA \\
A SEGURANÇA \\
OPERACIONAL É UM \\
DOS DIFERENCIAIS DO \\
SERVIÇO DA EMPRESA \\
HÁ COMISSÃO \\
PERMANENTE \\
SEGURANÇA DE \\
\end{tabular} & $\begin{array}{lll}\text { - } & \text { SACRIFICA-SE } & \text { A } \\
\text { CONFIABILIDADE } & \\
\text { MAS NÃO } & \text { A } \\
\text { SEGURANÇA } & \\
- & \text { HÁ UM CONSELHO } \\
\text { PERMANENTE } & \text { DE } \\
\text { SEGURANÇA } & \\
\text { OPERACIONAL } & \end{array}$ & $\begin{array}{lrr}\text { - } & \text { SEGURANÇA } & \text { É } \\
\text { PRIORITÁRIA } & \\
\text { EMBORA } & \text { POSSA } \\
\text { AFETAR } & \text { A } \\
\text { DISPONIBILIDADE } & \\
\text { - } & \text { IMPLANTOU-SE } & \text { UM } \\
\text { CONSELHO } & \\
\text { PERMANENTE } & \text { DE } \\
\text { SEGURANÇA } & \\
\text { OPERACIONAL } & \end{array}$ & $\begin{array}{ll}- & \text { CUIDADO NO USO } \\
\text { DE EPI } & \\
\text { CUIDADOS } \\
\text { ESPECIAIS NO USO } \\
\text { DE REATORES, } \\
\text { DEVIDO } \\
\text { PRESENÇA } \quad \text { DE } \\
\text { VAPORES ÁCIDOS }\end{array}$ & $\begin{array}{llr}\text { - } & \text { CUIDADO } & \text { COM } \\
\text { ELEVADORES } & \text { DE } \\
\text { CARGA } & \end{array}$ \\
\hline $\begin{array}{l}\text { PROCESSO } \\
\text { PRODUÇÃO }\end{array}$ & $\begin{array}{ll}\text { - } & \text { ESTRATÉGIAS } \\
\text { ENVOLVAM QUE } \\
\text { INTERRUPÇÃO DA } \\
\text { OPERAÇÃO DEVEM } \\
\text { SER DEFINIDAS } \\
\text { - } \\
\text { PROCESSOS DE MP E } \\
\text { MC SÃO } \\
\text { COMPATIBILIZADOS } \\
\text { COM A DEMANDA } \\
\text { OTIMIZAR O PROCESSO } \\
\text { DE MANUTENÇÃO } \\
\text { VISANDO } \\
\text { PROPORCIONAR } \\
\text { MAIOR } \\
\text { DISPONIBILIDADE }\end{array}$ & 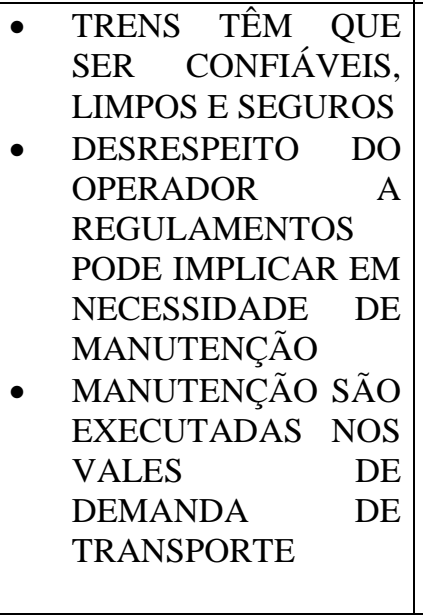 & \begin{tabular}{llr} 
O & USUÁRIO \\
& DANIFICA & O \\
& SISTEMA & \\
- & TRANSPOSIÇÃO & DE \\
& APARELHOS & DE \\
& MUDANÇA DE VIA \\
- & \multicolumn{2}{l}{ DESCARRILAMENTO }
\end{tabular} & $\begin{array}{llr}\text { - } & \text { CUIDADOS } & \text { COM } \\
\text { DRENOS } & \text { E } \\
\text { COMPRIMENTOS } \\
\text { DE TUBULAÇÃO } \\
\text { - } & \text { RESÍDUOS } \quad \text { DE } \\
\text { SOLDA r NÃO } & \text { PODEM CHEGAR } \\
& \text { AO CONSUMIDOR } \\
\text { - } & \text { MANUTENÇÃO } \\
& \text { DEVE ZELAR POR } \\
& \text { LIMPEZA } \\
\text { TRATAMENTO DE } \\
\text { ÁGUA, DE POÇOS } \\
\text { ARTESIANOS } \\
\text { (UTILIDADE) }\end{array}$ & $\begin{array}{ll}\bullet \quad \text { TREINAMENTO, } \\
\text { LIMPEZA, CUIDADO } \\
\text { COM SOLDA }\end{array}$ \\
\hline
\end{tabular}




\section{Anexo D - Enquadramento dos Casos no Quadro Referencial de Avaliação das Variáveis}

\begin{tabular}{|c|c|c|c|c|c|}
\hline VARIÁVEIS CASO & TPT1 & ТРТ2A & ТРT2B & IPA1 & IPA2 \\
\hline \multicolumn{6}{|c|}{$\begin{array}{l}\text { P1: O DESDOBRAMENTO DO INDICADOR DE DISPONIBILIDADE EM INDICADORES PARCIAIS, OBTIDOS ATRAVÉS DE UM SISTEMA INTEGRADO DE } \\
\text { INFORMAÇÃO (MANUTENÇÃO, PRODUÇÃO E SUPRIMENTOS), FACILITA A GESTÃO DAS OPERAÇÕES DE MANUTENÇÃO }\end{array}$} \\
\hline $\begin{array}{l}\text { 1.1. SISTEMA } \\
\text { INTEGRADO DE } \\
\text { INFORMAÇÃO } \\
\text { (MANUTENÇÃO, } \\
\text { PRODUÇÃOE } \\
\text { SUPRIMENTOS) }\end{array}$ & 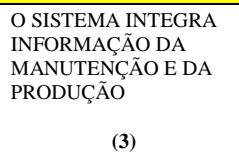 & $\begin{array}{l}\text { O SISTEMA INTEGRA } \\
\text { INFORMACC̃̃O DA } \\
\text { MANUTENÇÃO E DA } \\
\text { PRODUÇÃO } \\
\qquad \text { (3) }\end{array}$ & 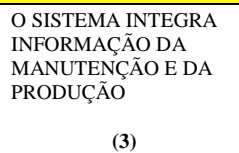 & $\begin{array}{l}\text { HÁ SISTEMA NÃO } \\
\text { INTEGRADO } \\
\text { ATENDENDO À } \\
\text { MANUTENÇÃO } \\
\text { (2) }\end{array}$ & $\begin{array}{l}\text { HÁ SISTEMA NÃO } \\
\text { INTEGRADO } \\
\text { ATENDENDO À } \\
\text { MANUTENÇÃO } \\
\text { (2) }\end{array}$ \\
\hline $\begin{array}{l}\text { 1.2. AVERIGUAÇÃO } \\
\text { DE INDICADORES } \\
\text { DE } \\
\text { DISPONIBILIDADE } \\
\text { PELA } \\
\text { ORGANIZAÇÃO }\end{array}$ & $\begin{array}{l}\text { HÁ CONFRONTOS DE } \\
\text { INDICADORES DE } \\
\text { DISPONIBILIDADE } \\
\text { COM PADRÕES } \\
\text { ATUALIZADOS }\end{array}$ & 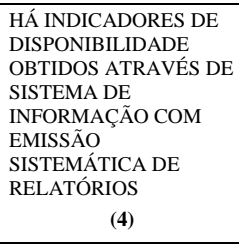 & 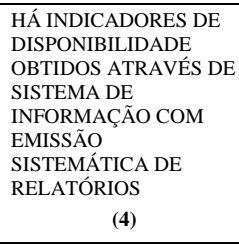 & $\begin{array}{l}\text { HÁ INDICADORES DE } \\
\text { DISPONIBILIDADE, } \\
\text { OBTIDOS A PARTIR DE } \\
\text { DADOS DE PRODUÇÃO }\end{array}$ & $\begin{array}{l}\text { HÁ INDICADORES DE } \\
\text { DISPONIBILIDADE, } \\
\text { OBTIDOS A PARTIR DE } \\
\text { DADOS DE PRODUÇÃO }\end{array}$ \\
\hline $\begin{array}{l}1.3 . \\
\text { DESDOBRAMENTO } \\
\text { DO INDICADOR DE } \\
\text { DISPONIBILIDADE }\end{array}$ & 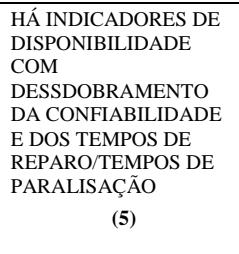 & $\begin{array}{l}\text { HÁ INDICADORES DE } \\
\text { DISPONIBILIDADE E } \\
\text { DE CONFIABILIDADE }\end{array}$ & $\begin{array}{l}\text { HÁ INDICADORES DE } \\
\text { DISPONIBILIDADE, DE } \\
\text { CONFIABILIDADE E } \\
\text { DOS TEMPOS DE } \\
\text { REPARO/TEMPOS DE } \\
\text { PARALISAÇÃO } \\
\\
\text { (4) }\end{array}$ & $\begin{array}{l}\text { HÁ INDICADORES DE } \\
\text { DISPONIBILIDADE }\end{array}$ & $\begin{array}{l}\text { HÁ INDICADORES DE } \\
\text { DISPONIBILIDADE }\end{array}$ \\
\hline $\begin{array}{l}\text { 1.4. GEST ÃO DAS } \\
\text { OPERAÇÕES DE } \\
\text { MANUTENÇÃO: } \\
\text { TOMADAS DE } \\
\text { DECISÃO EM } \\
\text { FUNÇÃO DA } \\
\text { DISPONIBILIDADE }\end{array}$ & $\begin{array}{l}\text { HÁ TOMADAS DE } \\
\text { DECISÃO USANDO } \\
\text { INDICADORES DE } \\
\text { DISPONIBILIDADE E } \\
\text { ANÁLISES DE } \\
\text { TENDÊNCIA E } \\
\text { CONFRONTAÇÃO COM } \\
\text { PADRÕES PRÉ- } \\
\text { ESTABELECIDOS } \\
\text { (ATITUDE PRÓ-ATIVA) } \\
(\mathbf{5})\end{array}$ & $\begin{array}{l}\text { HÁ TOMADAS DE } \\
\text { DECISÃO EM FUNÇÃO } \\
\text { DE INDICADORES DE } \\
\text { DISPONIBILIDADE } \\
\text { (ATITUDE REATIVA) }\end{array}$ & $\begin{array}{l}\text { HÁ TOMADAS DE } \\
\text { DECISÃO EM FUNÇÃO } \\
\text { DE INDICADORES DE } \\
\text { DISPONIBILIDADE } \\
\text { (ATITUDE REATIVA) }\end{array}$ & $\begin{array}{l}\text { HÁ TOMADAS DE } \\
\text { DECISÃO EM FUNÇÃO } \\
\text { DE INDICADORES DE } \\
\text { DISPONIBILIDADE } \\
\text { (ATITUDE REATIVA) }\end{array}$ & $\begin{array}{l}\text { HÁ ALGUMAS } \\
\text { POLÍTICAS E } \\
\text { PRÁTICAS } \\
\text { ESTABELECIDAS, } \\
\text { TOMADAS DE } \\
\text { DECISÃO EM FUNÇÃO } \\
\text { DE PRESSÕES } \\
\text { PONTUAIS } \\
\\
\text { (2) }\end{array}$ \\
\hline
\end{tabular}

P2: A ADEQUADA DEFINIÇÃO DAS POLÍTICAS E OPERAÇÕES DE MANUTENÇãO REQUER CONSIDERAR, DE MODO SISTEMATIZADO, COMPROMISSOS COM O AMBIENTE, DETERMINAÇÕES LEGAIS, NORMAS TÉCNICAS, CUSTOS, SEGURANÇA E PROCESSO DE PRODUÇÃO. 2.1. ESTÁGIO DE SISTEMATIZAÇÃO DO TRATAMENTO DE COMPROMISSOS

\begin{tabular}{|c|c|c|c|c|c|}
\hline AMBIENTE & $\begin{array}{l}\text { HÁ CRITÉRIOS } \\
\text { EXPLIÍCITOS QUE } \\
\text { CONSIDERAM OS } \\
\text { COMPROMISSOS } \\
\text { (3) }\end{array}$ & \begin{tabular}{|c|} 
HÁ CRITÉRIOS \\
EXPLÍCITOS QUE \\
CONSIDERAM OS \\
COMPROMISSOS \\
$\mathbf{( 3 )}$
\end{tabular} & $\begin{array}{l}\text { HÁ CRITÉRIOS } \\
\text { EXPLIÍCITOS QUE } \\
\text { CONSIDERAM OS } \\
\text { COMPROMISSOS } \\
\text { (3) }\end{array}$ & $\begin{array}{l}\text { HÁ CRITÉRIOS QUE } \\
\text { CONSIDERAM } \\
\text { PARCIALMENTE OS } \\
\text { COMPROMISSOS } \\
\text { (2) }\end{array}$ & \begin{tabular}{l} 
HÁ CRITÉRIOS QUE \\
CONSIDERAM \\
PARCIALMENTE OS \\
COMPROMISSOS \\
\multicolumn{1}{|c|}{$(\mathbf{2})$}
\end{tabular} \\
\hline $\begin{array}{l}\text { DETERMINAÇÕES } \\
\text { LEGAIS }\end{array}$ & \begin{tabular}{l} 
HÁ CRITÉRIOS \\
EXPLÍCITOS QUE \\
CONSIDERAM \\
PARCIALMENTE OS \\
COMPROMISSOS \\
\multicolumn{1}{c}{$(\mathbf{2})$}
\end{tabular} & \begin{tabular}{|l|} 
HÁ CRITÉRIOS \\
EXPLÍCITOS QUE \\
CONSIDERAM \\
PARCIALMENTE OS \\
COMPROMISSOS \\
\multicolumn{1}{|c|}{$(\mathbf{)})$} \\
\end{tabular} & \begin{tabular}{l} 
HÁ CRITÉRIOS \\
EXPLÍCITOS QUE \\
CONSIDERAM \\
PARCIALMENTE OS \\
COMPROMISSOS \\
\multicolumn{1}{c}{$(\mathbf{2})$}
\end{tabular} & \begin{tabular}{l} 
HÁ CRITÉRIOS \\
EXPLÍCITOS QUE \\
CONSIDERAM \\
PARCIALMENTE OS \\
COMPROMISSOS \\
\multicolumn{1}{c}{$(\mathbf{2})$}
\end{tabular} & \begin{tabular}{l} 
HÁ CRITÉRIOS \\
EXPLÍCITOS QUE \\
CONSIDERAM \\
PARCIALMENTE OS \\
COMPROMISSOS \\
\multicolumn{1}{c}{$(\mathbf{2})$}
\end{tabular} \\
\hline NORMAS TÉCNICAS & $\begin{array}{l}\text { HÁ CRITÉRIOS } \\
\text { EXPLIICITOS QUE } \\
\text { CONSIDERAM } \\
\text { PARCIALMENTE OS } \\
\text { COMPROMISSOS } \\
\qquad \begin{array}{c}\text { (2) } \\
\end{array}\end{array}$ & \begin{tabular}{|l|} 
HÁ CRITÉRIOS \\
EXPLÍCITOS QUE \\
CONSIDERAM \\
PARCIALMENTE OS \\
COMPROMISSOS \\
\multicolumn{1}{c}{$(\mathbf{2})$} \\
\end{tabular} & $\begin{array}{l}\text { HÁ CRITÉRIOS } \\
\text { EXPLÍCITOS QUE } \\
\text { CONSIDERAM } \\
\text { PARCIALMENTE OS } \\
\text { COMPROMISSOS } \\
\qquad \begin{array}{c}(\mathbf{2}) \\
\end{array}\end{array}$ & $\begin{array}{l}\text { HÁ CRITÉRIOS } \\
\text { EXPLÍCITOS QUE } \\
\text { CONSIDERAM } \\
\text { PARCIALMENTE OS } \\
\text { COMPROMISSOS } \\
\qquad \begin{array}{c}\text { (2) } \\
\end{array}\end{array}$ & \begin{tabular}{l} 
HÁ CRITÉRIOS \\
EXPLÍCITOS QUE \\
CONSIDERAM \\
PARCIALMENTE OS \\
COMPROMISSOS \\
\multicolumn{1}{c}{$(\mathbf{2})$} \\
\end{tabular} \\
\hline CUSTO & \begin{tabular}{l} 
HÁ APRIMORAMENTO \\
CONSTANTE ATRAVÉS \\
DE REGISTROS E \\
LIÇÕES APRENDIDAS \\
REFERENTES AOS \\
COMPROMISSOS \\
\multicolumn{1}{|}{$\mathbf{5})$} \\
\end{tabular} & 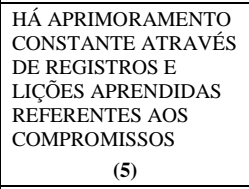 & \begin{tabular}{l} 
HÁ APRIMORAMENTO \\
CONSTANTE ATRAVÉS \\
DE REGISTROS E \\
LIÇÕES APRENDIDAS \\
REFERENTES AOS \\
COMPROMISSOS \\
\multicolumn{1}{c}{$\mathbf{( 5 )}$} \\
\end{tabular} & 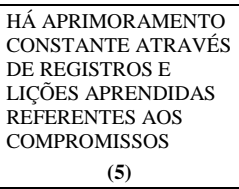 & \begin{tabular}{l} 
HÁ APRIMORAMENTO \\
CONSTANTE ATRAVÉS \\
DE REGISTROS E \\
LIÇÕES APRENDIDAS \\
REFERENTES AOS \\
COMPROMISSOS \\
\multicolumn{1}{c}{$\mathbf{5})$}
\end{tabular} \\
\hline SEGURANÇA & \begin{tabular}{l} 
HÁ APRIMORAMENTO \\
CONSTANTE ATRAVÉS \\
DE REGISTROS E \\
LIÇÕES APRENDIDAS \\
REFERENTES AOS \\
COMPROMISSOS \\
\multicolumn{1}{|}{$\mathbf{5})$} \\
\end{tabular} & \begin{tabular}{|l|} 
HÁ APRIMORAMENTO \\
CONSTANTE ATRAVÉS \\
DE REGISTROS E \\
LIÇÕES APRENDIDAS \\
REFERENTES AOS \\
COMPROMISSOS \\
\multicolumn{1}{|c|}{$\mathbf{5}$} \\
\end{tabular} & \begin{tabular}{l} 
HÁ APRIMORAMENTO \\
CONSTANTE ATRAVÉS \\
DE REGISTROS E \\
LIÇÕES APRENDIDAS \\
REFERENTES AOS \\
COMPROMISSOS \\
\multicolumn{1}{|}{$\mathbf{5})$} \\
\end{tabular} & $\begin{array}{l}\text { HÁ CRITÉRIOS } \\
\text { EXPLÍCITOS QUE } \\
\text { CONSIDERAM } \\
\text { PARCIALMENTE OS } \\
\text { COMPROMISSOS } \\
\qquad(2) \\
\end{array}$ & \begin{tabular}{l} 
HÁ CRITÉRIOS \\
EXPLÍCITOS QUE \\
CONSIDERAM \\
PARCIALMENTE OS \\
COMPROMISSOS \\
\multicolumn{1}{c}{$(\mathbf{2})$} \\
\end{tabular} \\
\hline $\begin{array}{l}\text { PROCESSO DE } \\
\text { PRODUÇÃO }\end{array}$ & $\begin{array}{c}\text { HÁ CRITÉRIOS } \\
\text { EXPLIICITOS QUE } \\
\text { CONSIDERAM OS } \\
\text { COMPROMISSOS } \\
\text { (3) }\end{array}$ & \begin{tabular}{|c} 
HÁ CRITÉRIOS \\
EXPLÍCITOS QUE \\
CONSIDERAM OS \\
COMPROMISSOS \\
(3)
\end{tabular} & $\begin{array}{l}\text { HÁ CRITÉRIOS } \\
\text { EXPLÍCITOS QUE } \\
\text { CONSIDERAM OS } \\
\text { COMPROMISSOS } \\
\text { (3) }\end{array}$ & \begin{tabular}{l} 
HÁ CRITÉRIOS \\
EXPLÍCITOS QUE \\
CONSIDERAM \\
PARCIALMENTE OS \\
COMPROMISSOS \\
\multicolumn{1}{c}{$(\mathbf{2})$}
\end{tabular} & \begin{tabular}{l} 
HÁ CRITÉRIOS \\
EXPLÍCITOS QUE \\
CONSIDERAM \\
PARCIALMENTE OS \\
COMPROMISSOS \\
\multicolumn{1}{c}{ (2) }
\end{tabular} \\
\hline
\end{tabular}




\begin{tabular}{|c|c|c|c|c|c|}
\hline VARIÁVEIS CASO & TPT1 & TPT2A & ТРТ2B & IPA1 & IPA2 \\
\hline \multicolumn{6}{|c|}{$\begin{array}{l}\text { P2: A ADEQUADA DEFINIÇÃO DAS POLÍTICAS E OPERAÇÕES DE MANUTENÇÃO REQUER CONSIDERAR, DE MODO SISTEMATIZADO, } \\
\text { COMPROMISSOS COM O AMBIENTE, DETERMINAÇÕES LEGAIS, NORMAS TÉCNICAS, CUSTOS, SEGURANÇA E PROCESSO DE PRODUÇÃO. }\end{array}$} \\
\hline \multicolumn{6}{|c|}{ 2.2. DEFINIÇÃO DE POLÍTICAS E OPERAÇÕES DE MANUTENÇÃO EM FUNÇÃO DE COMPROMISSOS } \\
\hline AMBIENTE & \begin{tabular}{l} 
HÁ POLÍTICAS E \\
OPERAÇÕES \\
CLARAMENTE \\
ESTRUTURADAS E \\
DEFINIDAS EM \\
FUNÇÃO DE \\
COMPROMISSOS \\
\multicolumn{1}{|c}{$(\mathbf{3})$} \\
\end{tabular} & \begin{tabular}{l} 
HÁ POLÍTICAS E \\
OPERAÇÕES \\
CLARAMENTE \\
ESTRUTURADAS E \\
DEFINIDAS EM \\
FUNÇÃO DE \\
COMPROMISSOS \\
\multicolumn{1}{|c}{$(\mathbf{3})$} \\
\end{tabular} & \begin{tabular}{|l} 
HÁ POLÍTICAS E \\
OPERAÇÕES \\
CLARAMENTE \\
ESTRUTURADAS E \\
DEFINIDAS EM \\
FUNÇÃO DE \\
COMPROMISSOS \\
\multicolumn{1}{c}{$(\mathbf{3})$} \\
\end{tabular} & 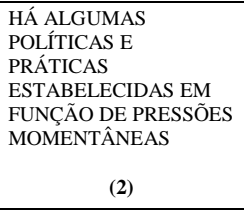 & $\begin{array}{l}\text { HÁ ALGUMAS } \\
\text { POLÍTICAS E } \\
\text { PRÁTICAS } \\
\text { ESTABELECIDAS EM } \\
\text { FUNÇÃO DE PRESSÕES } \\
\text { MOMENTÂNEAS } \\
\qquad(\mathbf{2}) \\
\end{array}$ \\
\hline $\begin{array}{l}\text { DETERMINAÇÕES } \\
\text { LEGAIS }\end{array}$ & $\begin{array}{l}\text { HÁ ALGUMAS } \\
\text { POLÍTICAS E } \\
\text { PRÁTICAS } \\
\text { ESTABELECIDAS EM } \\
\text { FUNÇÃO DE PRESSÕES } \\
\text { MOMENTÂNEAS } \\
\quad \text { (2) }\end{array}$ & $\begin{array}{l}\text { HÁ ALGUMAS } \\
\text { POLÍTICAS E } \\
\text { PRAATICAS } \\
\text { ESTABELECIDAS EM } \\
\text { FUNÇÃO DE PRESSÕES } \\
\text { MOMENTÂNEAS } \\
\quad \text { (2) }\end{array}$ & \begin{tabular}{|l|} 
HÁ ALGUMAS \\
POLÍTICAS E \\
PRÁTICAS \\
ESTABELECIDAS EM \\
FUNÇÃO DE PRESSÕES \\
MOMENTÂNEAS \\
$\quad$ (2)
\end{tabular} & $\begin{array}{l}\text { HÁ ALGUMAS } \\
\text { POLÍTICAS E } \\
\text { PRÁTICAS } \\
\text { ESTABELECIDAS EM } \\
\text { FUNÇÃO DE PRESSÕES } \\
\text { MOMENTÂNEAS } \\
\quad \text { (2) }\end{array}$ & $\begin{array}{l}\text { HÁ ALGUMAS } \\
\text { POLÍTICAS E } \\
\text { PRÁTICAS } \\
\text { ESTABELECIDAS EM } \\
\text { FUNÇÃO DE PRESSÕES } \\
\text { MOMENTÂNEAS } \\
\text { (2) }\end{array}$ \\
\hline NORMAS TÉCNICAS & $\begin{array}{l}\text { HÁ ALGUMAS } \\
\text { POLÍTICAS E } \\
\text { PRÁTICAS } \\
\text { ESTABELECIDAS EM } \\
\text { FUNÇÃO DE PRESSÕES } \\
\text { MOMENTÂNEAS } \\
\qquad \begin{array}{l}(\mathbf{2}) \\
\end{array}\end{array}$ & $\begin{array}{l}\text { HÁ ALGUMAS } \\
\text { POLÍTICAS E } \\
\text { PRÁTICAS } \\
\text { ESTABELECIDAS EM } \\
\text { FUNÇÃO DE PRESSÕES } \\
\text { MOMENTÂNEAS } \\
\qquad \begin{array}{l}(\mathbf{2}) \\
\end{array} \\
\end{array}$ & \begin{tabular}{l} 
HÁ ALGUMAS \\
POLÍTICAS E \\
PRÁTICAS \\
ESTABELECIDAS EM \\
FUNÇÃO DE PRESSÕES \\
MOMENTÂNEAS \\
\multicolumn{1}{c|}{$(\mathbf{2})$} \\
\end{tabular} & $\begin{array}{l}\text { HÁ ALGUMAS } \\
\text { POLÍTICAS E } \\
\text { PRÁTICAS } \\
\text { ESTABELECIDAS EM } \\
\text { FUNÇÃO DE PRESSÕES } \\
\text { MOMENTÂNEAS } \\
\qquad \begin{array}{l}(\mathbf{2}) \\
\end{array}\end{array}$ & \begin{tabular}{l} 
HÁ ALGUMAS \\
POLÍTICAS E \\
PRÁTICAS \\
ESTABELECIDAS EM \\
FUNÇÃO DE PRESSÕES \\
MOMENTÂNEAS \\
\multicolumn{1}{|c|}{$(\mathbf{2})$} \\
\end{tabular} \\
\hline CUSTO & 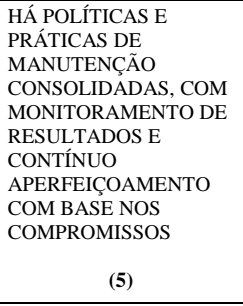 & $\begin{array}{l}\text { HÁ POLÍTICAS E } \\
\text { OPERAÇÕES } \\
\text { CLARAMENTE } \\
\text { ESTRUTURADAS E } \\
\text { DEFINIDAS EM } \\
\text { FUNÇÃO DE } \\
\text { COMPROMISSOS }\end{array}$ & \begin{tabular}{|l|} 
HÁ POLÍTICAS E \\
OPERAÇÕES \\
CLARAMENTE \\
ESTRUTURADAS E \\
DEFINIDAS EM \\
FUNÇÃO DE \\
COMPROMISSOS
\end{tabular} & $\begin{array}{l}\text { HÁ POLÍTICAS E } \\
\text { OPERAÇÕES } \\
\text { CLARAMENTE } \\
\text { ESTRUTURADAS E } \\
\text { DEFINIDAS EM } \\
\text { FUNÇÃO DE } \\
\text { COMPROMISSOS }\end{array}$ & $\begin{array}{l}\text { HÁ POLÍTICAS E } \\
\text { OPERAÇÕES } \\
\text { CLARAMENTE } \\
\text { ESTRUTURADAS E } \\
\text { DEFINIDAS EM } \\
\text { FUNÇÃO DE } \\
\text { COMPROMISSOS }\end{array}$ \\
\hline SEGURANÇA & $\begin{array}{l}\text { HÁ POLÍTICAS E } \\
\text { PRÁTICAS DE } \\
\text { MANUTENÇÃO } \\
\text { CONSOLIDADAS, COM } \\
\text { MONITORAMENTO DE } \\
\text { RESULTADOS E } \\
\text { CONTÍNUO } \\
\text { APERFEIÇOAMENTO } \\
\text { COM BASE NOS } \\
\text { COMPROMISSOS } \\
\qquad \\
(\mathbf{5}) \\
\end{array}$ & 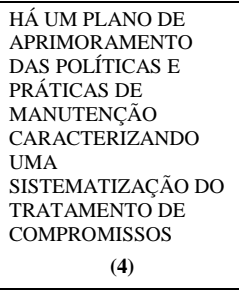 & 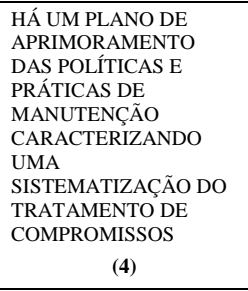 & $\begin{array}{l}\text { HÁ ALGUMAS } \\
\text { POLÍTICAS E } \\
\text { PRÁTICAS } \\
\text { ESTABELECIDAS EM } \\
\text { FUNÇÃO DE PRESSÕES } \\
\text { MOMENTÂNEAS }\end{array}$ & $\begin{array}{l}\text { HÁ ALGUMAS } \\
\text { POLÍTICAS E } \\
\text { PRAATICAS } \\
\text { ESTABELECIDAS EM } \\
\text { FUNÇÃO DE PRESSÕES } \\
\text { MOMENTÂNEAS }\end{array}$ \\
\hline $\begin{array}{l}\text { PROCESSO DE } \\
\text { PRODUÇÃO }\end{array}$ & \begin{tabular}{l} 
HÁ POLÍTICAS E \\
OPERAÇÕES \\
CLARAMENTE \\
ESTRUTURADAS E \\
DEFINIDAS EM \\
FUNÇÃO DE \\
COMPROMISSOS \\
\multicolumn{1}{c}{$(\mathbf{3})$}
\end{tabular} & \begin{tabular}{l} 
HÁ POLÍTICAS E \\
OPERAÇÕES \\
CLARAMENTE \\
ESTRUTURADAS E \\
DEFINIDAS EM \\
FUNÇÃO DE \\
COMPROMISSOS \\
\multicolumn{1}{c}{$(\mathbf{3})$} \\
\end{tabular} & \begin{tabular}{|l} 
HÁ POLÍTICAS E \\
OPERAÇÕES \\
CLARAMENTE \\
ESTRUTURADAS E \\
DEFINIDAS EM \\
FUNÇÃO DE \\
COMPROMISSOS \\
\multicolumn{1}{c}{$(\mathbf{3})$} \\
\end{tabular} & $\begin{array}{l}\text { HÁ ALGUMAS } \\
\text { POLIITICAS E } \\
\text { PRÁTICAS } \\
\text { ESTABELECIDAS EM } \\
\text { FUNÇÃO DE PRESSÕES } \\
\text { MOMENTÂNEAS } \\
\qquad \begin{array}{c}\text { (2) } \\
\end{array}\end{array}$ & $\begin{array}{l}\text { HÁ ALGUMAS } \\
\text { POLÍTICAS E } \\
\text { PRÁTICAS } \\
\text { ESTABELECIDAS EM } \\
\text { FUNÇÃO DE PRESSÕES } \\
\text { MOMENTÂNEAS } \\
\qquad(2) \\
\end{array}$ \\
\hline \multicolumn{6}{|c|}{$\begin{array}{l}\text { P3: AS EMPRESAS CONSIDERAM RELEVANTE, PARA A OBTENÇÃO DA DISPONIBILIDADE, LEVAR EM CONTA, POR OCASIÃO DE PROJETOS DE } \\
\text { NOVOS SISTEMAS PRODUTIVOS OU DE PROJETOS DE RENOVAÇÃO, AMPLIAÇÃO OU SUBSTITUIÇÃO, O ESTUDO PERSPECTIVO DO CICLO DE VIDA } \\
\text { DO EQUIPAMENTO }\end{array}$} \\
\hline $\begin{array}{l}\text { 3.1. ESTUDO } \\
\text { PERSPECTIVO DO } \\
\text { CICLO DE VIDA NO } \\
\text { ESTÁGIO DE } \\
\text { PROJETO DE NOVOS } \\
\text { SISTEMAS } \\
\text { 5PRODUTIVOS }\end{array}$ & \begin{tabular}{l} 
HÁ ANÁLISE DE \\
CUSTOS E DE \\
DESEMPENHO, \\
CONSIDERANDO DE \\
MODO INTEGRAL AS \\
ETAPAS DO CICLO DE \\
VIDA. HÁ \\
ESPECIFICAÇÃO \\
ANTECIPADA DE \\
PADRÕES DE \\
DISPONIBILIDADE, \\
CONFIABILIDADE E \\
MANUTENIBILIDADE, \\
POR OCASIÃO DO \\
PROJETO \\
\multicolumn{1}{|}{$(\mathbf{5})$} \\
\end{tabular} & \begin{tabular}{l} 
HÁ ANÁLISE DE \\
CUSTOS E DE \\
DESEMPENHO, \\
CONSIDERANDO DE \\
MODO INTEGRAL AS \\
ETAPAS DO CICLO DE \\
VIDA. HÁ \\
ESPECIFICAÇÃO \\
ANTECIPADA DE \\
PADRÕES DE \\
DISPONIBILIDADE, \\
CONFIABILIDADE E \\
MANUTENIBILIDADE, \\
POR OCASIÃO DO \\
PROJETO \\
\multicolumn{1}{|}{$(\mathbf{5})$} \\
\end{tabular} & \begin{tabular}{|l} 
HÁ ANÁLISE DE \\
CUSTOS E DE \\
DESEMPENHO, \\
CONSIDERANDO DE \\
MODO INTEGRAL AS \\
ETAPAS DO CICLO DE \\
VIDA. HÁ \\
ESPECIFICAÇÃO \\
ANTECIPADA DE \\
PADRÕES DE \\
DISPONIBILIDADE, \\
CONFIABILIDADE E \\
MANUTENIBILIDADE, \\
POR OCASIÃO DO \\
PROJETO \\
\multicolumn{1}{|c|}{$(\mathbf{5})$} \\
\end{tabular} & $\begin{array}{l}\text { HÁ PREOCUPAÇÃO } \\
\text { COM INVESTIMENTO, } \\
\text { CUSTOS, } \\
\text { OPERACIONAIS }\end{array}$ & $\begin{array}{l}\text { HÁ PREOCUPAÇÃO } \\
\text { COM INVESTIMENTO, } \\
\text { CUSTOS, } \\
\text { OPERACIONAIS }\end{array}$ \\
\hline $\begin{array}{l}\text { 3.2. CONSIDERAÇÃO } \\
\text { DA } \\
\text { DISPONIBILIDADE } \\
\text { POR OCASIÃO DE } \\
\text { PROJETO DE } \\
\text { RENOVAÇÃO, } \\
\text { AMPLIAÇÃO OU } \\
\text { SUBSTITUIÇÃO }\end{array}$ & $\begin{array}{l}\text { HÁ ATUALIZAÇÃO DE } \\
\text { PROJETOS. HÁ } \\
\text { CONFRONTO DE } \\
\text { DESEMPENHO } \\
\text { OPERACIONAL COM } \\
\text { PADRÕES DE PROJETO } \\
\qquad \mathbf{( 5 )}\end{array}$ & $\begin{array}{l}\text { CARACTERIZA-SE O } \\
\text { ESTÁGIO DO CICLO DE } \\
\text { VIDA E LEVA-SE EM } \\
\text { CONTA RESULTADOS } \\
\text { DE DISPONIBILIDADE } \\
\text { OBTIDOS } \\
\text { (3) }\end{array}$ & 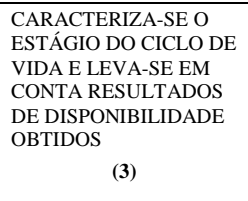 & $\begin{array}{l}\text { HÁ INDICADORES DE } \\
\text { DISPONIBILIDADE } \\
\text { MAS NÃO SÃO } \\
\text { UTILIZADOS }\end{array}$ & $\begin{array}{l}\text { HÁ INDICADORES DE } \\
\text { DISPONIBILIDADE } \\
\text { MAS NÃO SÃO } \\
\text { UTILIZADOS }\end{array}$ \\
\hline
\end{tabular}




\section{REFERÊNCIAS BIBLIOGRÁFICAS}

BALDIN, A. et al. Manual de mantenimiento de instalaciones industriales. Barcelona: Gustavo Gili, 1982.

BANDEIRA, A.B. Rede de indicadores de desempenho para gestão de uma usina hidroelétrica. 1997. 157p. Dissertação (Mestrado) - Escola Politécnica, Universidade de São Paulo. São Paulo, 1997.

BRYMAN, A. Research methods and organization studies. London: Routledge, 1995.

BURGESS, J. A. Design assurance for engineers and managers. New York: Marcel Dekker, 1984.

CAVALCANTE, C.A. Evento e análise organizacional: contribuição de um estudo sobre as atividades de manutenção. 1998. 121p. Tese (Doutorado) - Escola Politécnica, Universidade de São Paulo. São Paulo, 1998.

CONTADOR, J. C. Gestão de operações. São Paulo: Fundação Vanzolini / Edgard Blücher, 1997.

1994. Produtividade fabril. Gestão \& Produção, São Carlos, v.1, n.3, p.217-238,

CORDER, A. Maintenance management techniques. London: Mc Graw-Hill, 1976.

CORRÊA, H. L.; CAON, M. Gestão de serviços. São Paulo: Atlas, 2002.

DRAPINSKI, J. Manual de manutenção mecânica básica. São Paulo: McGrawHill, 1973.

FLEURY, A.; VARGAS, N. Organização do trabalho. São Paulo: Atlas, 1983.

FRANCISCHINI, P. G. Técnicas de avaliação da produtividade. São Paulo: SEBRAE-SP / Fundação Vanzolini, 1994. (Apostila).

Balanced scorecard: integrando estratégia e medidas de desempenho. Conectivo, São Paulo, n.50, p.8-9, 2002.

GARTNER, Describing the capability maturity model. Measure, p.1-3, 2001.

GRAY, C.; LARSON, E. Project management : the complete guide for every manager. New York: McGraw Hill, 2002.

HAMEL, G.; PRAHALAD, C.K. Competindo pelo futuro. Rio de Janeiro: Campus, 1997. 
HAMMER, M. A. A empresa voltada para o sucesso. HSM-MANAGEMENT, v.2, n.9, p.80-85, jul/ago. 1998.

HARDING, H. A. Administração da produção. São Paulo: Atlas, 1992.

HIPKIN, I.B.; DE COCK, C. TQM and BPR: lessons for maintenance management. Omega: The International Journal of Management Science, Oxford, v.28, n.3, p. 277-292, 2000.

HUSBAND, T.M. Maintenance management and terotechnology. Hants: (England), Saxon House, 1976.

JOHNSTON, R.; CLARK, G. Administração de operações de serviço. São Paulo, Atlas, 2002.

KARDEC, A.; NASCIF, J. Manutenção função estratégica. Rio de Janeiro: Qualitymark, 2001.

KARMAN, J. Manutenção hospitalar preditiva. São Paulo: Pini, 1994.

KELLY, A. ; HARRIS, M.J. Administração da manutenção industrial. Rio de Janeiro: IBP, 1980.

KERZNER, H. Project management: a systems aproach to planning, scheduling and controlling. New York: John Wiley, 2001.

KLETZ, T. A. O que houve de errado? Casos de desastres em indústrias químicas, petroquímicas e refinarias. São Paulo: Makron Books, 1993.

LAFRAIA, J.R.B. Manual de confiabilidade, mantenabilidade e disponibilidade. Rio de Janeiro: Qualitymark, 2001.

LAURINDO, F.J.B. Tecnologia da informação: eficácia nas organizações. São Paulo: Futura, 2002.

LIMA, J.G.S. Organização da manutenção em empresas de transporte.1992. 195p. Dissertação (Mestrado) - Escola Politécnica, Universidade de São Paulo. São Paulo, 1992.

MARTINS, R.A. Sistemas de Medição de Desempenho: um Modelo para Estruturação do Uso. 1999. 248p. Tese (Doutorado) - Escola Politécnica, Universidade de São Paulo. São Paulo, 1999.

MARTINS, P.G.; ALT, P.R.C. Administração de materiais e recursos patrimoniais. São Paulo: Saraiva, 2001.

MARX, R. Trabalho em grupos e autonomia como instrumentos de competição. São Paulo: Atlas, 1998. 
McLACHLIN, R. Management initiatives and just-in-time manufacturing. Journal of Operations Management, v.15, n.4, p.271-292, 1997.

MILASCH, M. Manutenção de transformadores em líquido isolante. São Paulo: Edgard Blücher, 1984.

MIYAKE, D. I. Programas de melhoria da produtividade e qualidade: um estudo comparativo dos modelos just-in-time, total quality control e total productive maintenance. 1993. 163p. Dissertação (Mestrado) - Escola Politécnica, Universidade de São Paulo. São Paulo, 1993.

MONCHY, F. A Função manutenção: formação para a gerência da manutenção industrial. São Paulo, Ebras/Durban, 1989.

MOREIRA, D. A. Administração da produção e operações. São Paulo, Pioneira, 1993.

MOUBRAY, J. Reliability-centered maintenance. Lutterworth: Aladon, 2003.

MUSCAT, A. R. N; FLEURY, A. C. C. Indicadores de qualidade e produtividade na indústria brasileira. Revista Indicadores de Qualidade e Produtividade, v.1, n.2, p.81-107, set. 1993.

NAKAJIMA, S. Introdução ao TPM. São Paulo: IM\&C, 1989.

NBR 5462: Confiabilidade e mantenabilidade. Rio de Janeiro: 1996.

NBR ISO 9001: 2000 Sistemas de gestão da qualidade: requisitos. Rio de Janeiro: 1996.

NBR ISO 14001: Sistemas de gestão ambiental: especificação e diretrizes para uso. Rio de Janeiro: 1996.

PATTON, Jr., J.D. Maintainability and maintenance management. North Carolina: Instrument Society of America, 1980.

PENNYPACKER, J. S.; GRANT, K. P. Project management maturity: an industry Benchmark. Project Management Journal, v.34, n.1, p.4-11, 2003.

PEREIRA, J. C. Análise de dados qualitativos. São Paulo: EDUSP / FAPESP, 2001.

PESSÔA, M.; SPÍNOLA, M.; DELLA VOLPE, R.L. Uma experiência prática na implantação do modelo CMM. In: SIMPÓSIO BRASILEIRO DE ENGENHARIA DE SOFTWARE, 11./ WORKSHOP QUALIDADE DE SOFTWARE, 4., Fortaleza, 1997. Anais. Fortaleza: Universidade Federal do Ceará, 1997. p.49-57. 
PETINON, J.; SHIMIZU, T. Implementando um protótipo de sistema flexível de informações. São Paulo: EPUSP, 2001. 12p. (Boletim Técnico da Escola Politécnica da USP. Departamento de Engenharia de Produção, BT/PRO/093)

PORTER, M. E. Vantagem competitiva. Rio de Janeiro: Campus, 1989.

ROSENTHAL, C.W.; VIGELAND, R. An update on a maturity benchmarking process for electronic design processes. Computers in Industry, v.30, p.5-11, 1996.

SEI - Software Engineering Institute. Capability maturity model integration: Version 1.1. Pittsburgh, Carnegie Mellon, 2002. (Online). Disponível em: http://www.sei.cmu.edu/publications. Acesso em: 16 abr 2003.

SHIMIZU, T. Decisão nas organizações. São Paulo: Atlas, 2001.

SILVA, M.T. Correntes do pensamento administrativo. In: CONTADOR, J.C. Gestão de operações. São Paulo: Fundação Vanzolini / Edgard Blücher, 1997, p.1530 .

A empresa moderna. In: CONTADOR, J.C. Gestão de operações. São Paulo: Fundação Vanzolini / Edgard Blücher, 1997. p.31-37.

SILVEIRA, G.; SLACK, M. Exploring the trade-off concept. International Journal of Operations \& Production Management, v.21, n.7, p.949-964, 2001.

SLACK, N. et al. Administração da produção. São Paulo: Atlas, 2002.

SMITH, D. J. Reliability and maintainability in perspective. New York: Halsted, 1985.

STONER, J.A.F. Administração. Rio de Janeiro: Prentice-Hall do Brasil, 1985.

TAKAHASHI, Y.; OSADA, T. Manutenção produtiva total. São Paulo: IMAM, 1993.

TOLEDO, N.N.; RABECHINI Jr., R.; MARQUES Jr., L.J. Grau de maturidade em gerenciamento de projetos. In: CONGRESSO IBERO-AMERICANO DE GERÊNCIA DE PROJETOS: crescimento e integração, 3., Caracas, 2002. Anais. Caracas, PMI, 2002.

TRIOLA, M.F. Introdução à Estatística. Rio de Janeiro: LTC, 1999.

VAZ, J. C. Gestão da manutenção. In: CONTADOR, J.C. Gestão de operações. São Paulo: Fundação Vanzolini / Edgard Blücher, 1997. p.397-408. 
VAZ, J.C.; MIYAKE, D.I. Gestão da produtividade em função do ciclo de vida do equipamento. In: V SIMPÓSIO DE ADMINISTRAÇÃO DA PRODUÇÃO, LOGÍSTICA E OPERAÇÕES INTERNACIONAIS, São Paulo, 2002. Anais. P.231241. São Paulo, FGV, 2002.

VAZ, J.C.; MIYAKE, D.I. Avaliação da função manutenção em organizações produtivas com base num instrumento derivado do CMM. In. XXIII ENCONTRO NACIONAL DE ENGENHARIA DE PRODUÇÃO, Ouro Preto, 2003. Artigo aprovado para apresentação em out 2003.

WILD, R. Production and operations management: principles and techniques. London: Holt, 1984.

XENOS, H.G. Gerenciando a manutenção produtiva. Belo Horizonte: EDG, 1998.

YIN, R.K. Estudo de caso: planejamento e métodos. Porto Alegre: Bookman, 2001.

ZARIFIAN, P. Valor, organização e competência na produção de serviços. In: SEMINÁRIO TEMÁTICO INTERDISCIPLINAR: os estudos do trabalho, nvas problemáticas, novas metodologias e novas áreas de pesquisa. São Paulo, 1999. Anais. São Paulo: USP/UNICAMP/CEBRAP/SENAC, 1999. 


\section{BIBLIOGRAFIA COMPLEMENTAR}

ANSOFF, H. I. Corporate strategy. New York: McGraw-Hill, 1965.

ARIZA, C.F. Introdução à Aplicação da manutenção preventiva. São Paulo: McGraw-Hill, 1978.

BOLLIET, T. Planification des travaux de construction et d'entretien: la methode matricielle. Paris: Eyrolles, 1975.

BOULENGER, A. Vers le zéro panne avec la maintenance conditionelle. Paris: AFNOR, 1988.

BRADLEY, S. P; HAUSMAN, J. A.; NOLAN, R. L.; Globalization technology and competition: the fusion of computers and telecommunication in the 1990s. Boston: Harvard Business School, 1993.

CHIAVENATO, I. Os novos paradigmas: como as mudanças estão mexendo com as empresas. São Paulo: Atlas, 1998.

CHURCHMAN, C. W. Introdução à toria dos Sistemas. 2.ed. Petrópolis: Vozes, 1972.

CLELAND, D. I.; KING, W. R. Análise de sistemas e administração de projetos. São Paulo: Pioneira, 1998.

COLLACOTT, R. A. Mechanical fault diagnosis and condition monitoring. London: Chapman and Hall, 1977.

CROSBY, P. B. Qualidade é investimento. Rio de Janeiro: José Olímpio, 1986.

CSILLAG, J. M. Análise de valor: metodologia do valor, gerenciamento do valor, redução de custos, racionalização administrativa. São Paulo: Atlas, 1986.

FARIA, J.G.A. Administração da manutenção sistema P.I.S. São Paulo: Edgard Blucher, 1994.

FEIGENBAUM, A. V. Total quality control. New York: McGraw-Hill, 1983.

FLAHERTY, M. T. Global operations management. New York: McGraw-Hill, 1996.

GRADON, F. Maintenance engineering organization \& management. London: Applied Science, 1973. 
HAMELIN, B. Entretien et maintenance. Paris: Eyrolles, 1973.

HEMKE, H. P. Engenharia de Manutenção de Aeronaves. São José dos Campos: CTA, 1958.

HIBI, S. How to measure maintenance performance. Tóquio: APO, 1980. HILDEBRAND, J.K. Maintenance turns to the computer. Boston: Cahners Book, 1972.

HURST, R. Servicios e mantenimiento de hoteles e residências. Madrid: Paraninfo, 1976.

IMAI, M. Kaizen. New York: Random House, 1984.

LEWIS, B.T.; TOW, L.M. Readings in maintenance management. Boston: Cahners Books, 1973.

LEWIS, B.T.; PEARSON, W.W. Manual de manutenção preventiva. Rio de Janeiro: DENISA, 1965.

LINZMAYER, E. Guia Básico para Administração da Manutenção Hoteleira. São Paulo: SENAC, 1994.

MALDONADO, C. El mantenimiento preventivo que es y para que. Madrid: Index, 1971.

MANN, Jr.,L. Maintenance management. Toronto: Lexington Books, 1978.

MAXIMIANO, A. C. A. Introdução à administração. São Paulo: Atlas, 1985.

MAYNARD, H. B. Manual de engenharia de produção. São Paulo: Edgar Blücher/EDUSP, 1970.

MIRSHAWKA, V. Manutenção preditiva: caminho para zero defeitos. São Paulo: Makron Books, 1991.

MONKS, J. G. Administração da produção. São Paulo: McGraw-Hill, 1987.

MOTTER, O. Manutenção industrial. São Paulo: Hemus, 1992.

NEWBROUGH, E.T. Effective maintenance management. New York: McGrawHill, 1967.

PATTON, Jr, J.D. Preventive maintenance. Englewood Cliffs: Prentice-Hall, 1983.

PERIER, M.A. EI Entretenimiento preventivo. Bilbao: DEUSTO, 1966. 
PERIER, M.A. Le service entretien méthodes actuelles de gestion. Paris: Entreprise Moderne, 1969.

PINTO, C.V. Introdução ao planeamento da manutenção em empresas industriais. Lisboa: Datinvest, 1986.

PIRSIG, R.M. ZEN e a arte da manutenção de motocicletas. Rio de Janeiro: Paz e Terra, 1984.

PRIEL, V. La maintenance techniques modernes de gestion. Paris: Entreprise Moderne, 1974, 1976.

SAYLES, L.R. The working leader. New York: The Free Press, 1993.

SACRISTÁN, F.R. Gestão de manutenção mecânica e elétrica na indústria e nas oficinas. Lisboa: CETOP, 1975.

SPITERI, J.V.P. Organización del mantenimiento preventivo. Madrid: Index, 1977.

WHITE, A. Melhoria contínua da qualidade : um guia prático para desenvolver um programa de qualidade eficaz. Rio de Janeiro: Record, 1998. 